\title{
Sugar Beet Leaves For Functional Ingredients
}

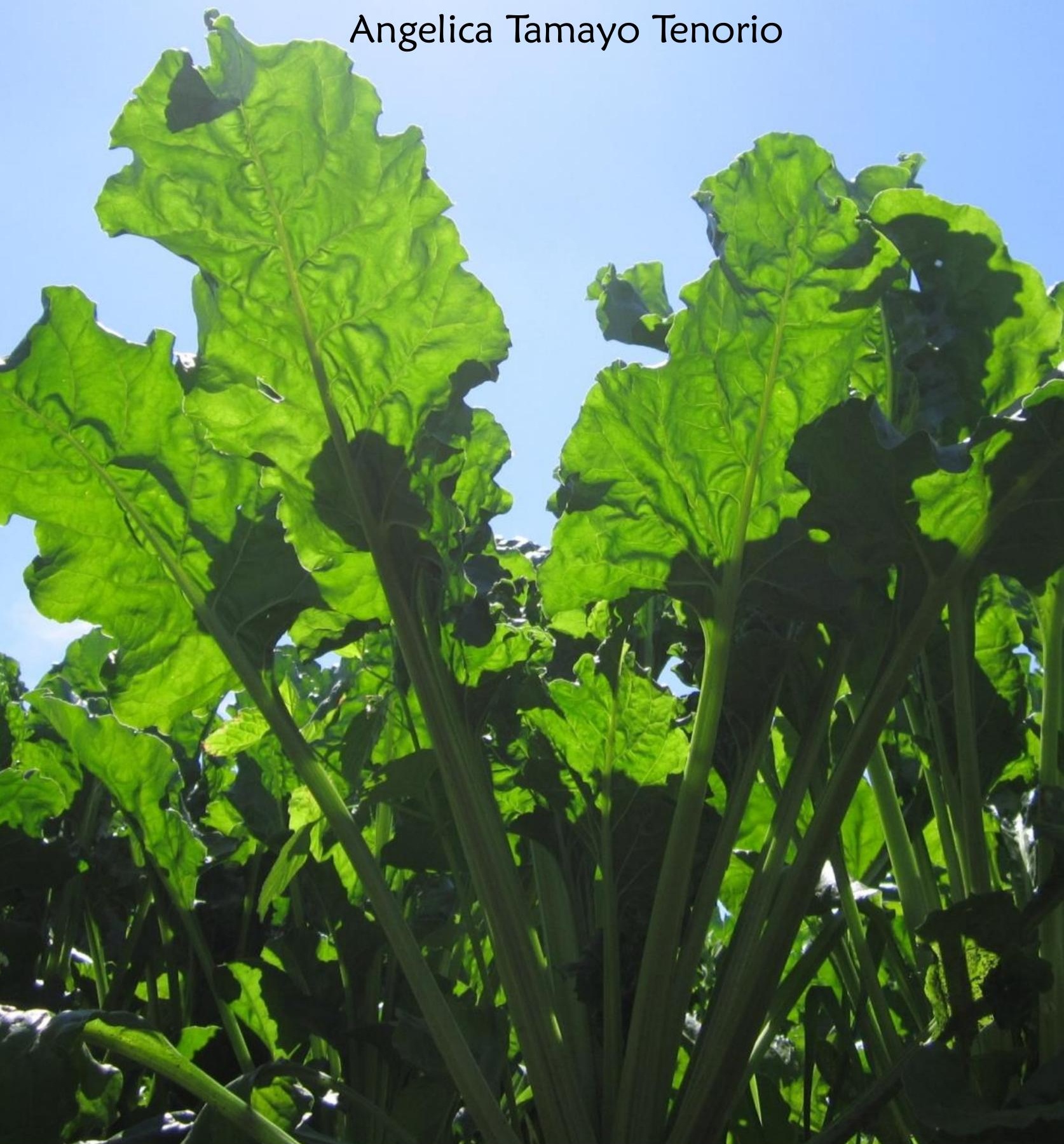



Sugar beet leaves for functional ingredients

Angelica Tamayo Tenorio 


\section{Thesis committee}

\section{Promotor}

Prof. Dr R.M. Boom

Professor of Food Process Engineering

Wageningen University \& Research

\section{Co-promotor}

Prof. Dr A.J. van der Goot

Personal chair at the Laboratory of Food Process Engineering

Wageningen University \& Research

\section{Other members}

Prof. Dr R.J. Bino, Wageningen University \& Research

Prof. Dr J.H. Bitter, Wageningen University \& Research

Dr P.J.Th. Bussmann, TNO, Zeist, The Netherlands

Dr C.M. Galanakis, Galanakis Laboratories, Chania, Greece

This research was conducted under the auspices of Graduate School VLAG (Advanced studies in Food Technology, Agrobiotechnology, Nutrition and Health Sciences). 


\title{
Sugar beet leaves for functional ingredients
}

\author{
Angelica Tamayo Tenorio
}

\section{Thesis}

submitted in fulfilment of the requirements for the degree of doctor

at Wageningen University

by the authority of the Rector Magnificus

Prof. Dr A.P.J. Mol,

in the presence of the

Thesis committee appointed by the Academic Board

to be defended in public

on Friday 12 May 2017

at 11 a.m. in the Aula. 
Angelica Tamayo Tenorio

Sugar beet leaves for functional ingredients, 190 pages

PhD thesis, Wageningen University, Wageningen, NL (2017)

With references, with summary in English

ISBN: 978-94-6343-137-8

DOI: $10.18174 / 409816$ 


\section{Contents}

$\begin{array}{lll}\text { Chapter } 1 & \text { Introduction } & 1\end{array}$

Chapter 2 Recovery of protein from green leaves: Overview of crucial 17 steps for utilisation

Chapter 3 Understanding leaf membrane protein extraction to develop a food-grade process

Chapter 4 Interfacial properties and emulsification performance of thylakoid membrane fragments

Chapter 5 Interfacial properties of green leaf cellulosic particles

Chapter 6 Processing concepts for the use of green leaves as raw materials for the food industry

Chapter 7 General discussion

Summary

Acknowledgments

About the author 

1

Introduction 
Plant leaves are recognised as a potential protein source for food applications based on their nutritional profile and their large availability in agricultural waste streams. For most industrialised crops, only specific parts of the plants (e.g. root, flowers, fruits) are harvested and processed, while the leaves are left unused. These discarded leaves account for many tonnes of biomass per year. Several attempts have been made to find high-value uses through biorefining, including protein extraction for human food and feed.

The available processes for leaf protein extraction until now focused on purification of a soluble and colourless protein fraction. This process discards a large portion of the leaf proteins, which remain unused. Besides proteins, leaves have a rich nutritional profile (e.g. dietary fibres, minerals and secondary metabolites) and consist of complex biological structures (e.g. chloroplastic membranes) that can be explored as novel fractions that ultimately broaden the use of leaves.

Compared to traditional crops used for protein isolates and concentrates, protein extraction from leaves leads to additional challenges. The high water content and enzymatic activity require an initial stabilisation process to prevent spoilage before processing. This susceptibility to spoilage is compounded by the seasonal availability of some leaves, demanding large processing capacity. In this context, the overall sustainability of the process needs to be assessed to find feasible processing routes for the leaves and optimum applications for the resulting leaf products.

\subsection{Greens leaves as a food source}

\subsubsection{Source of proteins}

The use of leaves as a protein source actually comprises a long history of research motivated by different situations: a) war time and the accompanying general food shortage (Morrison \& Pirie, 1961; N. Pirie, 1959; N. W. Pirie, 1966); b) localised inadequate supplies of food protein and unequal distribution of resources (J. C. Wang \& Kinsella, 1976); and c) population growth and/or change of life style and the subsequent increase in protein demand (Fiorentini \& Galoppini, 1983; Nagy et 
al., 1978). Several crops have been studied for leaf protein extraction, including alfalfa (A. Hernández et al., 1989; T. Hernández et al., 1997; Lamsal et al., 2003; Prevot-D’Alvise et al., 2004; J. C. Wang \& Kinsella, 1976), spinach (Barbeau \& Kinsella, 1988), tobacco (Fantozzi \& Sensidoni, 1983; Fu et al., 2010), cassava (Coldebella et al., 2013; Urribarrí et al., 2009), Moringa olifera leaves (Teixeira et al., 2014), soybean leaves (Betschart \& Kinsella, 1973), residues from tropical plants (Agbede, 2006), among many local crops in different countries.

One important leaf source around the globe is sugar beet plants (Beta vulgaris L.), which are within the ten-most-produced crops in several countries (e.g. Chile, Belgium, Germany, France, The Netherlands, Italy, Turkey, Russia) (FAOSTAT, 2014). The leaves constitute $20-34 \%$ of the plant. In the Netherlands, the annual production of roots is around $75 \mathrm{t} / \mathrm{ha}$ (Factfish.com, 2014), resulting in nearly 29 $\mathrm{t} /$ ha of leaves available every year. While the beets are used for sugar production, the leaves are mainly left on the fields. Sugar beet leaves $(\mathrm{SBL})$ are reported to contain an average of $22.8 \%$ crude protein on dry matter basis (Lammens et al., 2012; Merodio \& Sabater, 1988), meaning that about $400-600 \mathrm{~kg} / \mathrm{ha}$ of protein is present inside the leaves. This value is fairly comparable to the protein production of soy (450-600 kg/ha) and cereals ( $570 \mathrm{~kg} / \mathrm{ha})$ (van Krimpen et al., 2013). On wet basis, the protein content of leaves is rather low (3-5\%), but the abundance and free availability of leafy biomass (i.e. waste streams) have motivated research on their use as a protein source (Merodio \& Sabater, 1988).

Concerning the type of proteins, leaf proteins consist of both soluble and insoluble proteins. In the soluble fraction, the enzyme ribulose bisphosphate carboxylase oxygenase (rubisco) accounts for almost half of the soluble proteins. The insoluble proteins mainly consists of the membrane proteins in the chloroplastic membranes (i.e. thylakoid membranes), where they are associated with chlorophyll, carotenoids and lipids.

In plant cells, the majority of both soluble and insoluble proteins are located in the chloroplast (Figure 1. 1), where these proteins convert light energy into chemical energy through photosynthetic reactions. The insoluble membrane proteins 
produce energy through an electron transport chain, and this energy fuels the $\mathrm{CO}_{2}$ fixation catalysed by rubisco (MacAdam, 2009). Rubisco consists of eight large subunits $(53 \mathrm{kDa})$ and eight small subunits $(14 \mathrm{kDa})$ that assemble in a $550 \mathrm{kDa}$ complex (Barbeau \& Kinsella, 1988; Fiorentini \& Galoppini, 1983). In contrast, membrane proteins consist of more than 100 different proteins with broad subunits sizes (from $<5 \mathrm{kDa}$ to $>60 \mathrm{kDa}$ ) that form complex photosynthetic systems together with pigments and cofactors. A smaller fraction of leaf proteins is found in the cell wall (Figure 1. 1), either attached to the polysaccharides to aid the cell cytoskeleton or loosely bound to play catalytic or regulatory roles (Kqczkowski, 2003).

\subsubsection{Source of other valuable components}

Leaves have more to offer than proteins. A deeper look into the typical leaf composition points out a rich nutritional profile. Leaves are rich in minerals $(\mathrm{Ca}, \mathrm{Cu}$, $\mathrm{Fe}, \mathrm{Mg}, \mathrm{Mn}, \mathrm{P}, \mathrm{Zn}, \mathrm{Si})$, vitamins (A, B, C, D, E, K, U), phytochemical substances (carotene, chlorophyll, coumarins, isoflavones) and secondary metabolites (phytoestrogens like isoflavones and coumestrol). Some of these compounds are recognised as nutraceuticals with a beneficial effect on human's health (Gaweł, 2012).

Additionally, leaves contain abundant carbohydrates or fibres that form the cell walls (Figure 1.1) and confer rigidity to the leaf tissue. The cell wall consists of cellulose microfibrils set in a matrix of non-cellulosic polysaccharides, structural proteins and phenolic components (e.g. lignin) (Beck, 2005). Leaf fibres are actually more abundant than proteins and they are generally discarded after initial processing of the leaves. The common uses for the discarded fibres are animal feed, silage and biofuels. These rather low-value applications are chosen due to the high content of cellulose and hemicellulose, which have low digestibility (Bals et al., 2012). However, better uses have been described for similar cellulose-rich material, like orange peel (de Moraes Crizel et al., 2013; Wallecan et al., 2015) and cocoa fibres (Gould et al., 2013). Cellulose-rich materials have potential for the production of nanofibers or cellulose-rich particles with techno-functional properties 
as food ingredients (e.g. thickening, emulsifying). Moreover, the leaf fibres can be considered to be a source of dietary fibres, which have known health benefits for human health (Harris \& Smith, 2006).

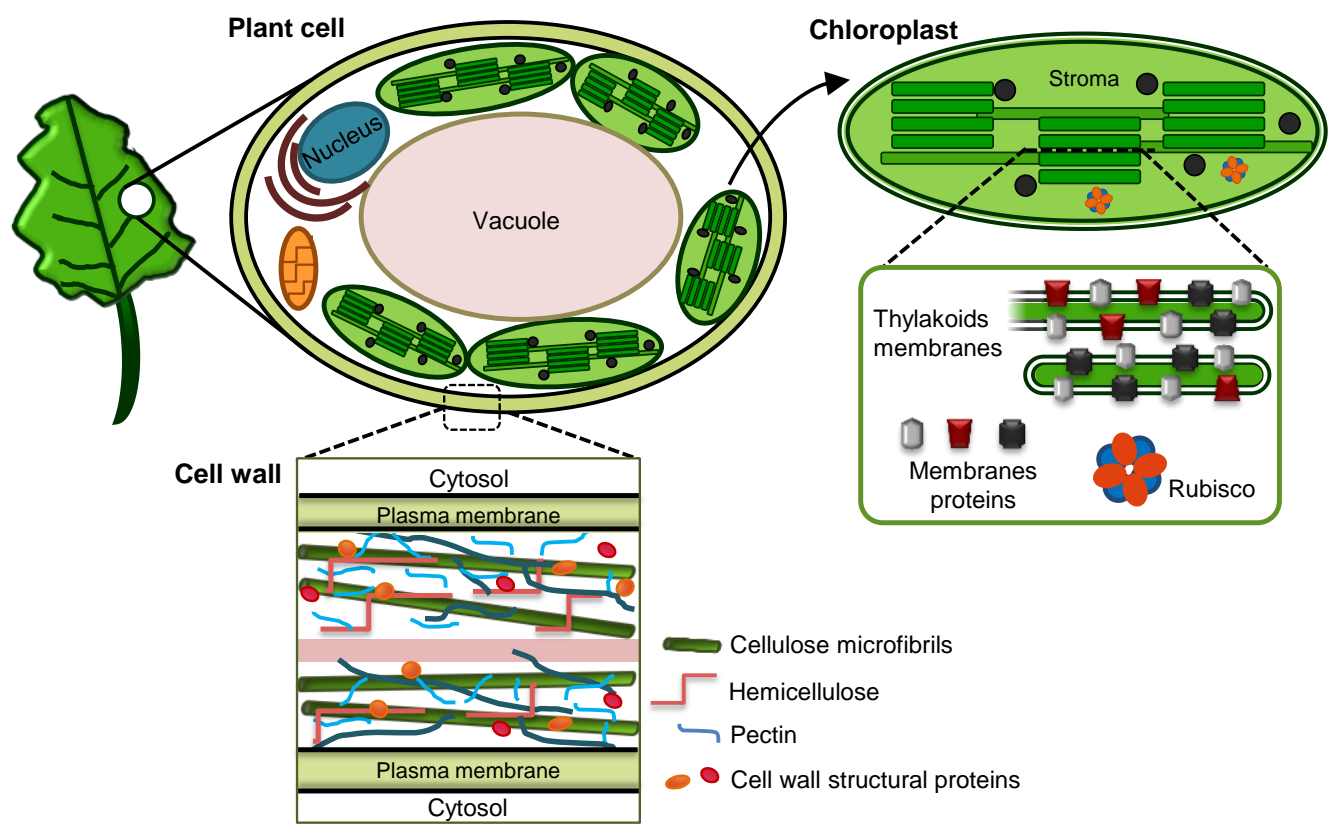

Figure 1. 1. Scheme of the plant cell and the structure of cell wall and chloroplasts. Close-up in the chloroplast to show the location of most of the leaf proteins: membrane proteins in the thylakoid membranes and rubisco in the chloroplast stroma. Close-up in the cell wall to show its structure and main components.

\subsubsection{Source of functional structures}

In addition to single ingredients or macromolecules, leaves have highly structured components that enable their efficient role in the plant and that can be explored as such for high-value applications. As an example, membrane proteins are part of sophisticated membrane structures called thylakoid membranes (Figure 1. 1), which consists of proteins and lipids in a well-defined arrangement. Consumption of thylakoid membranes has already been found to result in satiation and reduction of hunger, and these effects are attributed to both composition and structure of these membranes (Erlanson-Albertsson \& Albertsson, 2015). Thus, combining the 
leaf's composition and microstructures can result in even higher value applications for green leaves.

\subsection{Extraction processes with leaves}

\subsubsection{Extraction of leaf soluble proteins}

As mentioned earlier, leaf protein extraction has been studied for several decades and the typical process contains four main operations (Figure 1. 2): tissue disruption and filtration, protein fractionation, protein separation and concentration, and final protein purification. The mechanical disruption of the leaves opens the plant cells and releases the cellular contents. This step is normally done by pressing and filtration to collect the leaf juice and simultaneously separate the cell wall components. Typical equipment includes sugarcane rollers, extruders, hammer mills, screw presses, cheesecloth-filtration systems, belt presses, roller presses and V-presses. A sequence of devices results in nearly complete cell disruption, although at high energy inputs (Bals et al., 2012).

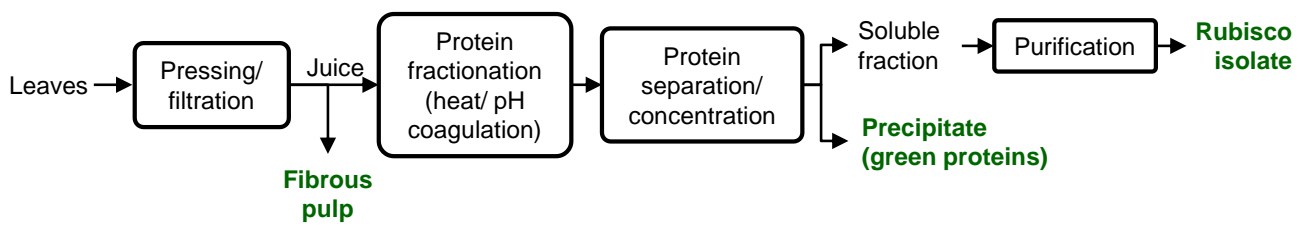

Figure 1. 2. Overview of a leaf protein extraction process.

Once the leaf juice is produced, the next step is to separate the soluble and insoluble protein fractions. Typical processes include coagulation by heat or $\mathrm{pH}$, based on different denaturation temperatures and isoelectric points of leaf proteins, respectively (Jwanny et al., 1993; Lamsal et al., 2003; Merodio et al., 1983). Then, the dissolved proteins can be separated and concentrated by salt precipitation, ultrafiltration (Fiorentini \& Galoppini, 1983), polyelectrolyte coagulation (Bray \& Humphries, 1979; Fiorentini \& Galoppini, 1983) or membraneless osmosis (Yu A Antonov, 2000a; Yu A Antonov \& Tolstoguzov, 1990). 
So far, only soluble proteins have been studied for food applications because of their white colour, nutritional quality and easy extractability (Bals et al., 2012; T. Hernández et al., 1997). Within the soluble proteins, rubisco protein is the main target for extraction given its abundance and specific molecular weight, which enables the use of chromatographic techniques for purification towards a rubisco protein isolate.

\subsubsection{Extraction of leaf membrane protein}

Leaf membrane proteins, also referred as green proteins (Chiesa \& Gnansounou, 2011), are discarded during rubisco isolation. Those green proteins contain the chlorophylls and pigments, which explains the green colour (Fiorentini \& Galoppini, 1983). Besides the green colour, leaf membrane proteins are not used for food so far due to their lower nutritional quality compared to soluble proteins in terms of amino acid profile and presence of antinutritional factors (e.g. phytates, saponins, tannins, protease inhibitors) (Bals et al., 2012; Chiesa \& Gnansounou, 2011; T. Hernández et al., 1997). However, the latter can be reduced by choosing the right plant source (e.g. varieties among one specie), adapting the processing conditions (Bals et al., 2012) or working with edible leaves.

Despite the disadvantages of membrane proteins for food applications, they often represent the majority of the proteins in leaves, and their extraction could contribute to increase the protein yield and improving total feasibility of leaf processing. The extraction of leaf membrane proteins demands specific processing steps that detach the proteins from the lipid membrane and remove cofactors, chlorophylls, and other pigments. Such processing steps are described in analytical methods of research disciplines like proteomics and photosynthesis biology that perform fractionation on analytical scales, aimed at understanding the biological function of these complex proteins. For these disciplines, the extraction conditions have no constraints as compared to food-grade processes, and therefore allows the extraction of membrane proteins that are rather difficult to extract. Therefore, protocols used in proteomics can provide understanding on the fundamental steps for membrane protein extraction. 


\subsubsection{Extraction of other components}

Leaves and leaf side-streams are suitable for the extraction of cell wall components using processing routes that have been developed for other waste streams with similar dietary fibre composition. Cell wall components have potential applications based on health benefits, and more interestingly, based on their abilities to bind water and stabilise emulsions (Harris \& Smith, 2006). Different products are obtained from cell walls depending on the extraction conditions. Harsh conditions (e.g. alkaline $\mathrm{pH}$ ) produce cellulose nanofibers and nanocrystals that can be used in nanocomposite edible sheets and fat replacers, respectively. The harsh conditions enable the hydrolysis of non-cellulosic compounds to yield pure cellulose particles. Milder conditions like grinding and aqueous treatment result in cellulose-rich particles that can form particle stabilised emulsions (pickering emulsions) or may increase the viscosity of a suspension (Harris \& Smith, 2006). The benefit of producing less pure particles is two-sided. First, the mild or less processing results in an overall chain that has a smaller footprint and thus contributes to sustainable use of the biomass. And second, the other components present in the particles may result in a better nutritional profile and might broaden the final application, as it occurs with protein traces found in polysaccharides used as emulsifiers and stabilisers (Wallecan et al., 2015).

\subsection{Leaf processing challenges}

\subsubsection{Leaf anatomy}

Understanding the anatomy of the leaves is key to develop leaf fractionation processes. The leaf's primary photosynthetic role yields an anatomy that is rich in active metabolic entities and lean in storage domains (Beck, 2005). This is contrary to storage plant tissues such as seeds, roots, or fruits in which the fraction of storage domains is much larger, both in quantity and size. Figure 1. 3 shows a rough comparison of the sizes of plant cell organelles or entities. Oil bodies $(0.5-$ $5 \mu \mathrm{m})$ and protein bodies $(<3 \mu \mathrm{m})$ are typically found in seeds, while starch granules $(10-100 \mu \mathrm{m})$ are accumulated in roots and grains. These three entities 
constitute storage domains and their size and robust structure facilitate separation. In contrast, the components in leaves are structured at a smaller scale of size. Most leaf proteins are inside the chloroplast $(3-5 \mu \mathrm{m})$ in sophisticated structures with lipids and pigments, forming the highly specialised thylakoid membranes. Inside these structures, the membrane proteins are interconnected with other membrane domains to carry out the multiple photosynthetic reactions.
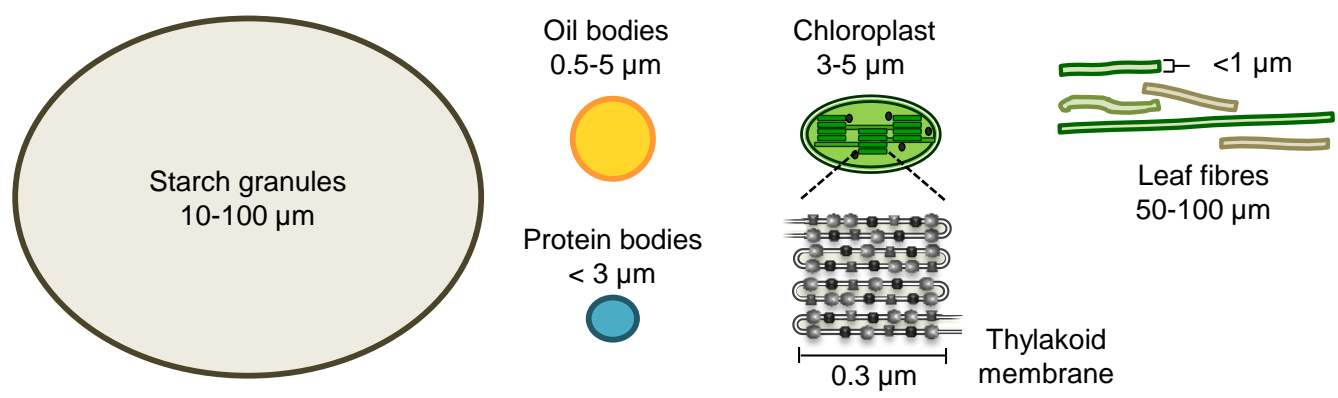

Figure 1. 3. Plant cell domains and their average size. Leaf fibres corresponds to fibre fragments present in the juice after leaf pressing.

The leaf fibres are then an exception to the small-size arrangement of the plant cell due to their rigidity, which renders large fragments $(50-100 \mu \mathrm{m})$ in the leaf juice (Figure 1. 3). This fraction is in principle removable by filtration or decanting. However, leaf fibres have a high water holding capacity and many of the cell contents (e.g. proteins) are retained within the fibre structure. Removing the fibres would also translate into protein losses.

\subsubsection{Low protein yield}

One of the motivations for the present study is the low protein yield reached with protein extraction processes developed for leaves in earlier studies. A leaf protein concentrate from alfalfa leaves was achieved with a protein yield of $\sim 6 \%$ and a protein content of $74 \%$ in the concentrate (Dijkstra et al., 2003). Similarly, an isolate from spinach leaves can have a protein content of 95\% (Martin et al., 2014), with an estimated protein yield of $4.5 \%$. This low protein yield is due to large protein losses along the process, amongst other in the form of a green insoluble curd that contains the leaf insoluble proteins. With this waste stream, about $50 \%$ of 
the total protein is discarded (Barbeau \& Kinsella, 1988) and further protein losses occur after subsequent purification steps. The net effect of a low protein yield from leaves is that the extraction processes has not been widely adopted, mainly because the economics are not competitive with those of other protein sources (Dale et al., 2009). Hence, methods that extract a larger fraction of proteins will improve process feasibility.

Moreover, the moisture content of leaves ranges between 85 and $90 \%$. Therefore, processing leaf plant material means handling large amounts of water. The high moisture content of leaf and leaf products implies large volumes of biomass to be transported and requires fast stabilisation to avoid spoilage. The process logistics to tackle these problems are challenged even more by the seasonal availability of some crops that demand high peak capacities for some unit operations. Specifically, sugar beet leaves are available during autumn, which is a wet and cold season. The options to avoid spoilage are stabilising treatments that aim at removing water (e.g. drying) or halting enzymatic reactions (e.g. freezing). The energy requirements for stabilisation methods might determine the sustainability of the process, which are particularly high for drying treatments. Therefore, the initial handling of leafy biomass is important to assess the overall sustainability of leaf processing.

\subsection{Aim and outline of this thesis}

The overall aim of this thesis is to obtain understanding on the use of green leaves as a food source by exploring currently neglected leaf fractions. The research can be divided into three objectives concerning the extraction of membrane proteins from leaves, the properties of other valuable leaf components (complexes and fibres), and the feasibility of leaves as a food crop. These topics are developed throughout the chapters.

Chapter 2 studies the extraction of leaf proteins from sugar beet leaves by a traditional heat coagulation method. The distribution of soluble and insoluble proteins is followed along the extraction process to discern the effect of the heating 
step on protein fractionation. At the same time, other leaf components are analysed along the process to identify interactions that can impair protein extraction and fractionation. Further processing of the insoluble protein fraction is proposed through multiple washing and the addition of surfactants. A final discussion focuses on the relation between protein content and protein yield in the resulting fractions. This relation is used as starting point to develop new approaches for leaf use.

To gain deeper understanding on the extraction of leaf insoluble proteins, Chapter 3 describes the application of proteomic analytical extraction protocols to analyse the fractionation behaviour of the proteins. First, a solvent extraction protocol is examined. The analysis of each extraction step comprises the effect on the extracted proteins and other leaf components (e.g. secondary metabolites), as well as the protein yield. Second, a milder proteomics protocol was considered (i.e. phase-partitioning with surfactant) to have a broader view of membrane protein extraction options. A detailed look into characteristics of leaf membranes proteins is used to explain the necessity for the extraction steps found in proteomic protocols. This knowledge is then translated into food-grade processing steps. The protein heterogeneity determines the processing conditions required, but also enables fractionation of leaf biomass with potential properties for food.

Chapter 4 analyses the properties of a class of valuable components from leaves (i.e. thylakoid membranes) and their emulsifying mechanism. Thylakoid membranes are regarded as protein/lipid complexes that are characterised by a sophisticated and dynamic structure. Both composition and structure make thylakoid membranes suitable as a biobased material for food and pharma applications such as target release encapsulates. Having in mind these applications, thylakoid membranes were extracted from sugar beet leaves through a sequence of buffer washing and filtration steps. The resulting extract was characterised in terms of composition and physical properties, and was used as emulsifier in oil-in-water emulsions. The interfacial properties and surface rheology analyses were used to discern the emulsifying mechanism of thylakoid membranes. Moreover, the thylakoid's composition and 3D structure were 
considered to understand the interfacial behaviour and emulsifying properties of these natural membranes.

To continue exploring valuable structures from leaves, Chapter 5 reports on the interfacial properties of cellulose-rich particles obtained from leaf pulp. The pulp obtained after leaf pressing is rich in dietary fibre and represents a large side stream during leaf processing. To determine potential applications for this pulp, aqueous purification was applied, followed by drying and milling. This mild processing aimed at sustainable process conditions while retaining natural leaf structures. The resulting powder was characterised for its composition and interfacial behaviour. Exploring the applications of this leaf side stream broadens the options for total leaf processing, contributing to resource use optimisation.

A sustainability assessment of leaf processing is discussed in Chapter 6, focusing on challenges that may appear at large scale. Sugar beet plants, as potential leaf sources, are seasonal crops and the beet root determines the optimum harvest time. The seasonal availability of leaves implies large amounts of biomass that need to be processed or stabilised within a short time. The time constrains are defined by the high moisture content of leaves (85-90\%) and their sensitivity to spoilage. Freezing whole leaves was considered as stabilisation step at different points of leaf processing, analysing two scenarios i.e. centralised and decentralised processing. The sustainability of such process and network configurations was assessed with energy consumption and exergy analysis. Exergy is a thermodynamic state variable that quantifies the potential work of a processing stream. Cumulative exergy losses were used as indicators to visualise the effect of freezing as stabilising treatment during leaf processing and the feasibility of a centralised or decentralised process. Moreover, the sustainability assessment was extended with reported information on soil quality and fertility associated to sugar beet leaves. 
Chapter 7, concludes this thesis with a general discussion of the main findings. First, the main results and conclusions are summarised, followed by the implications for processing options that aim at total leaf biorefinery. We will then conceptually design a biorefining strategy that would result in protein rich fractions that can be used for food. The chapter ends with an outlook for future research of leafy biomass and potential uses of the final products.

\section{References}

Agbede, J. O. (2006). Characterisation of the leaf meals, protein concentrates and residues from some tropical leguminous plants. Journal of the Science of Food and Agriculture, 86(9), 1292-1297.

Antonov, Y. A. (2000). Use of membraneless osmosis for concentration of proteins from molecular-dispersed and colloidal-dispersed solutions (review). Applied Biochemistry and Microbiology, 36(4), 325-337.

Antonov, Y. A., \& Tolstoguzov, V. (1990). Food protein from green plant leaves. Food/Nahrung, 34(2), 125-134.

Bals, B., Dale, B. E., Balan, V., Bergeron, C., Carrier, D. J., \& Ramaswamy, S. (2012). Recovery of leaf protein for animal feed and high-value uses Biorefinery CoProducts (pp. 179-197): John Wiley \& Sons, Ltd.

Barbeau, W. E., \& Kinsella, J. E. (1988). Ribulose biphosphate carboxylase/oxygenase (rubisco) from green leaves-potential as a food protein. Food Reviews International, 4(1), 93-127.

Beck, C. B. (2005). An Introduction to Plant Structure and Development: Cambridge University Press.

Betschart, A., \& Kinsella, J. E. (1973). Extractability and solubility of leaf protein. Journal of Agricultural and Food Chemistry, 21(1), 60-65.

Bray, W. J., \& Humphries, C. (1979). Preparation of white leaf protein concentrate using a polyanionic flocculant. Journal of the Science of Food and Agriculture, 30, 171-176.

Coldebella, P. F., Gomes, S. D., Evarini, J. A., Cereda, M. P., Coelho, S. R. M., \& Coldebella, A. (2013). Evaluation of protein extraction methods to obtain protein concentrates from Cassava leaf. Engenharia Agricola, 33(6), 1223-1233.

Dale, B. E., Allen, M. S., Laser, M., \& Lynd, L. R. (2009). Protein feeds coproduction in biomass conversion to fuels and chemicals. Biofuels, bioproducts and biorefining, 3(2), 219-230.

de Moraes Crizel, T., Jablonski, A., de Oliveira Rios, A., Rech, R., \& Flôres, S. H. (2013). Dietary fiber from orange byproducts as a potential fat replacer. LWT - Food Science and Technology, 53(1), 9-14. doi: 10.1016/j.lwt.2013.02.002 
Dijkstra, D. S., Linnemann, A. R., \& van Boekel, T. A. (2003). Towards sustainable production of protein-rich foods: appraisal of eight crops for Western Europe. PART II: Analysis of the technological aspects of the production chain. Critical Reviews in Food Science and Nutrition, 43(5), 481-506.

Erlanson-Albertsson, C., \& Albertsson, P. Å. (2015). The use of green leaf membranes to promote appetite control, suppress hedonic hunger and loose body weight. Plant Foods for Human Nutrition, 70(3), 281-290. doi: 10.1007/s11130-015-0491-8

Factfish.com. (2014). Netherlands: Sugar beet, production quantity (tons) Retrieved August 18, 2016, from http://www.factfish.com/statisticcountry/netherlands/sugar\%20beet,\%20production\%20quantity

Fantozzi, P., \& Sensidoni, A. (1983). Protein extraction from tobacco leaves: technological, nutritional and agronomical aspects. Plant Foods for Human Nutrition, 32(3-4), 351368. doi: 10.1007/bf01091194

FAOSTAT. (2014). Production/Crop: Sugar beet 1993 - 2013. Retrieved 5-02-2015, 2015, from http://faostat3.fao.org/browse/Q/QC/E

Fiorentini, R., \& Galoppini, C. (1983). The proteins from leaves. Qualitas Plantarum-Plant Foods For Human Nutrition, 32, 335-350.

Fu, H., Machado, P. A., Hahm, T. S., Kratochvil, R. J., Wei, C. I., \& Lo, Y. M. (2010). Recovery of nicotine-free proteins from tobacco leaves using phosphate buffer system under controlled conditions. Bioresource Technology, 101(6), 2034-2042. doi: 10.1016/j.biortech.2009.10.045

Gaweł, E. (2012). Chemical compositions of lucerne leaf extract (EFL) and its applications as a phytobiotic in human nutrition. Acta Scientiarum Polonorum Technologia Alimentaria, 11, 303-309.

Gould, J., Vieira, J., \& Wolf, B. (2013). Cocoa particles for food emulsion stabilisation. Food \& Function, 4(9), 1369-1375. doi: 10.1039/c3fo30181h

Harris, P. J., \& Smith, B. G. (2006). Plant cell walls and cell-wall polysaccharides: structures, properties and uses in food products. International Journal of Food Science \& Technology, 41(s2), 129-143.

Hernández, A., Martínez, C., \& Alzueta, C. (1989). Effects of alfalfa leaf juice and chloroplast-free juice $\mathrm{pH}$ values and freezing upon the recovery of white protein concentrate. Journal of Agricultural and Food Chemistry, 37(1), 28-31.

Hernández, T., Martínez, C., Hernández, A., \& Urbano, G. (1997). Protein quality of alfalfa protein concentrates obtained by freezing. Journal of Agricultural and Food Chemistry, 45(3), 797-802.

Jwanny, E. W., Montanari, L., \& Fantozzi, P. (1993). Protein production for human use from sugarbeet: byproducts. Bioresource Technology, 43, 67-70.

Kqczkowski, J. (2003). Structure, function and metabolism of plant cell wall. Acta Physiologiae Plantarum, 25(3), 287 - 305. 
Lammens, T. M., Franssen, M. C. R., Scott, E. L., \& Sanders, J. P. M. (2012). Availability of protein-derived amino acids as feedstock for the production of bio-based chemicals. Biomass \& Bioenergy, 44, 168-181. doi: 10.1016/j.biombioe.2012.04.021

Lamsal, B. P., Koegel, R. G., \& Boettcher, M. E. (2003). Separation of protein fractions in alfalfa juice: Effects of some pre-treatment methods. Transactions of the American Society of Agricultural Engineers, 46(3), 715-720.

MacAdam, J. W. (2009). Structure and function of plants (1st ed.): Wiley-Blackwell.

Martin, A. H., Nieuwland, M., \& De Jong, G. A. H. (2014). Characterization of heat-set gels from RuBisCO in comparison to those from other proteins. Journal of Agricultural and Food Chemistry, 62(44), 10783-10791. doi: 10.1021/jf502905g

Merodio, C., Martín, M., \& Sabater, B. (1983). Improved separation of green and soluble leaf proteins by $\mathrm{pH}$ shift. Journal of Agricultural and Food Chemistry, 31(5), 957-959.

Merodio, C., \& Sabater, B. (1988). Preparation and properties of a white protein fraction in high yield from sugar beet (Beta vulgaris $L$ ) leaves. Journal of the Science of Food and Agriculture, 44, 237-243.

Morrison, J., \& Pirie, N. (1961). The large-scale production of protein from leaf extracts. Journal of the Science of Food and Agriculture, 12(1), 1-5.

Nagy, S., Telek, L., Hall, N. T., \& Berry, R. E. (1978). Potential food uses for protein from tropical and subtropical plant leaves. Journal of Agricultural and Food Chemistry, 26(5).

Pirie, N. (1959). Leaf protein as human food. The Lancet, 274(7109), 961-962.

Pirie, N. W. (1966). Leaf protein as a human food. Science, 152(3730), 1701-1705. doi: $10.2307 / 1718350$

Prevot-D'Alvise, N., Lesueur-Lambert, C., Fertin-Bazus, A., Fertin, B., Dhulster, P., \& Guillochon, D. (2004). Continuous enzymatic solubilization of alfalfa proteins in an ultrafiltration reactor. Enzyme and Microbial Technology, 34(5), 380-391. doi: 10.1016/j.enzmictec.2003.05.001

Teixeira, E. M. B., Carvalho, M. R. B., Neves, V. A., Silva, M. A., \& Arantes-Pereira, L. (2014). Chemical characteristics and fractionation of proteins from Moringa oleifera Lam. leaves. Food Chemistry, 147, 51-54. doi: 10.1016/j.foodchem.2013.09.135

Urribarrí, L., Chacón, D., González, O., \& Ferrer, A. (2009). Protein extraction and enzymatic hydrolysis of ammonia-treated cassava leaves (Manihot esculenta Crantz). Applied biochemistry and biotechnology, 153(1-3), 94-102.

van Krimpen, M. M., Bikker, P., van der Meer, I. M., van der Peet-Schwering, C. M. C., \& Vereijken, J. M. (2013). Cultivation, processing and nutritional aspects for pigs and poultry of European protein sources as alternatives for imported soybean products. Wageningen, The Netherlands: Wageningen UR Livestock Research. 
Wallecan, J., McCrae, C., Debon, S. J. J., Dong, J., \& Mazoyer, J. (2015). Emulsifying and stabilizing properties of functionalized orange pulp fibers. Food Hydrocolloids, 47, 115-123. doi: 10.1016/j.foodhyd.2015.01.009

Wang, J. C., \& Kinsella, J. E. (1976). Functional properties of novel proteins: Alfalfa leaf protein. Journal of Food Science, 41, 286-292. 


\section{Recovery of protein from green leaves: Overview of crucial steps for utilisation}

\section{Highlights}

- We extracted proteins from sugar beet leaves by traditional heat coagulation method.

- Leaf proteins divide almost equally over the resulting fractions.

- Both soluble and insoluble proteins are found in the various leaf products.

- Proteins and cell debris seem to irreversibly associate upon heat precipitation.

- Functionality of protein-containing fractions could increase leaf utilisation.

This chapter has been published as:

Tamayo Tenorio, A., Gieteling, J., de Jong, G. A. H., Boom, R. M., \& van der Goot, A. J. Recovery of protein from green leaves: Overview of crucial steps for utilisation. Food Chemistry (2016), vol 203, pages 402-408. 


\section{Abstract}

Plant leaves are a major potential source of novel food proteins. Till now, leaf protein extraction methods mainly focus on the extraction of soluble proteins, like rubisco protein, leaving more than half of all protein unextracted. Here, we report on the total protein extraction from sugar beet leaves (Beta vulgaris L.) by a traditional thermal extraction method consisting of mechanical pressing, heating to $50^{\circ} \mathrm{C}$ and centrifugation. The resulting streams (i.e. supernatant, green-protein pellet and fibrous pulp) were characterised in terms of composition, physical structure and processing options. The protein distributed almost equally over the supernatant, pellet and pulp. This shows that thermal precipitation is an unselective process with respect to fractionation between soluble (rubisco) and insoluble (other) proteins. About $6 \%$ of the total protein could be extracted as pure rubisco ( $90 \%$ purity) from the supernatant. Surfactants commonly used for protein solubilisation could hardly re-dissolve the precipitated proteins in the pellet phase, which suggested that irreversible association was induced between the coprecipitated proteins and cell debris. Thus, the extraction of this protein will require prevention of their co-precipitation, and should take place in the original juice solution. 


\subsection{Introduction}

Leaf proteins could potentially form a major protein source for food application. Leaves from several crops have been considered depending on their protein content, regional availability, social needs and current uses (e.g. alfalfa, spinach, grass, cassava, moringa, tobacco). Other sources include leaves that are available as by-products from certain crops on large scale (e.g. cassava, barley, broccoli, sugar beet). Despite many decades of leaf protein study and the broad portfolio of suitable crops, the existing extraction processes have not reached industrial production for human food application yet. An important reason could be the focus on soluble proteins, thereby neglecting the great potential of the other proteins present in leaves. It is therefore important to further explore how te remaining proteins can utilised as well, which is the purpose of this study.

Traditional leaf protein extraction methods focus on soluble protein recovery in the form of leaf protein concentrate (LPC). Soluble LPC accounts for about half of the leaf proteins and it is the preferred protein fraction for human food applications due to its white colour and lack of off-flavour (Barbeau \& Kinsella, 1988). The enzyme ribulose-1,5-bisphosphate carboxylase/oxygenase (rubisco) accounts for most of the solubilised protein and it can be purified from the soluble leaf protein fraction. During LPC production, the final protein yield is typically 40 to $60 \%$ of the total leaf protein and it depends on the plant source and extraction process (Bals et al., 2012; Chiesa \& Gnansounou, 2011; Dijkstra et al., 2003).

Leaf protein extraction involves three major steps: tissue disruption by mechanical treatments, protein precipitation by one or more heat and/or $\mathrm{pH}$ treatments and protein concentration (Coldebella et al., 2013; Edwards et al., 1975; Jwanny et al., 1993; Merodio \& Sabater, 1988). For instance, rubisco purification from soluble leaf concentrate often combines different methods such as heat precipitation at 80 $82^{\circ} \mathrm{C}, \mathrm{pH}$ precipitation, flocculation and organic solvent precipitation (Barbeau \& Kinsella, 1983, 1988; Martin et al., 2014; Van de Velde et al., 2011). The combination of steps allows protein fractionation to some extent as well as removal of the undesired green colour. 
LPC and rubisco by-products contain the remaining leaf proteins. These by products are the leaf pulp (rich in fibres) and a green insoluble curd. In general, rubisco isolation methods are designed to precipitate undesired components to the green curd, which contains cell debris, broken chloroplast, pigments and particulates (Lamsal et al., 2003). The proteins in the curd are often referred as green-protein fraction. So far, main focus was on the nutritional value of this protein fraction for animal feed applications rather than exploring further processing options and protein recovery for high value applications such as food (Byers, 1971; Chiesa \& Gnansounou, 2011; Merodio et al., 1983).

The fact that rubisco and LPC side streams are still rich in proteins explains the low protein yield of the extraction processes. Leaf protein production for food is not yet economically feasible at large scale, though coupling to biofuel production in a larger biorefinery operation might positively influence the economic feasibility (Bals \& Dale, 2011; Bals et al., 2012; Chiesa \& Gnansounou, 2011). The use of rubisco side streams for high value applications such as food proteins has not been extensively reported. A study with tobacco leaves described the extraction of green-proteins using harsh conditions such as alkaline $\mathrm{pH}$, organic solvents and high temperatures, recovering half of the protein from the tobacco biomass (Teng \& Wang, 2011). A similar approach for protein recovery would not only improve the feasibility of rubisco production, but would also enhance the use of existing bioresources; although milder extraction conditions are necessary to preserve protein functionality and achieve a food grade application.

The aim of this study is to consider options for protein extraction from side streams of the rubisco production and to analyse the effects of the initial extraction steps on the overall protein yield and the downstream processes. Rubisco production processes have been extensively developed and optimised for several crops; therefore, it is a relevant starting point to explore the used of the valuable side streams. Sugar beet leaves were used for this study due to their large availability and the lack of extensive research on protein extraction from those leaves. The resulting fractions after thermal extraction were characterised in terms of 
composition, physical structure, functional properties and processing options. This information was used to evaluate the feasibility of two processing scenarios: further protein recovery from side streams after rubisco extraction and total protein recovery from leaves. The latter is focused on obtaining functional leaf fractions rather than single-protein isolation and considers the need for re-thinking the leaf biorefinery approach that has been followed for several decades.

\subsection{Materials and methods}

\subsubsection{Leaf material and protein extraction}

Sugar beet leaves (SBL) were harvested from a sugar beet production field in Wageningen, The Netherlands. The leaves had an average dry matter content of $12 \%(w t)$ and the average composition in dry basis was $14.8 \mathrm{wt} \%$ protein, $2.9 \mathrm{wt} \%$ fat, $30.3 \mathrm{wt} \%$ total dietary fibre and $20 \mathrm{wt} \%$ ash. The leaves were washed with cool tap water $\left(\sim 10^{\circ} \mathrm{C}\right.$; hardness 4.4 degrees German hardness, dGH) and dried with towel-paper before processing the leaves with a screw press, Angelia juicer II 7500 (Angel Juicers, Queensland, Australia). Pressing gives a layer of fibres around the screws inside the press barrel, acting as filtering bed. A green juice is expressed, while the fibrous pulp is extruded out at the end of the screws.

Leaf proteins were extracted from the juice by heat precipitation $\left(50^{\circ} \mathrm{C}, 30 \mathrm{~min}\right)$ as described by several authors for rubisco and LPC extraction protocols (Jwanny et al., 1993; Martin et al., 2014; Merodio et al., 1983; Rathore, 2010; Sheen, 1991; Telek, 1983). The heated juice was centrifuged at $15000 \mathrm{~g}$ for $30 \mathrm{~min}$ and carefully separated into supernatant and pellet.

\section{Consecutive washing}

The SBL green pellet remaining after centrifugation was washed three times with tap water for additional recovery of the soluble protein that remained in the interstitial fluid. The washing steps were done with a pellet-to-water weight ratio of 1:20 and centrifuged at 7,000 $\mathrm{g}$ for $30 \mathrm{~min}$. The resulting supernatant and pellet were analysed for composition and mass distribution. 


\section{Solubilisation with surfactants}

The pellet obtained after heat precipitation was freeze dried and stored before processing. The dried pellet was re-suspended in different surfactant solutions or water as control. The surfactants tested were Triton X-100 ( $p-(1,1,3,3-$ tetramethylbutyl)-phenyl ether, octyl phenol ethoxylate), Zwittergent 3-12 (nDodecyl-n,n-dimethyl-3-ammonio-1-propanesulfonate) and CHAPS ((3-[(3chol-amido propyl)-dimethyl-ammonio]-1-propanesulfonate); all from SigmaAldrich (St. Louis, MO, USA) at the same concentration (0.3 wt\%) and two pellet concentrations were compared $0.3 \mathrm{wt} \%$ and $5 \mathrm{wt} \%$. The final mix was centrifuged at $\sim 4800 \mathrm{~g}$ for $20 \mathrm{~min}$. The resulting supernatant and pellets were analysed for composition and mass distribution.

\subsubsection{Compositional analysis}

The dry matter content was determined by oven drying at $50^{\circ} \mathrm{C}$ for $48 \mathrm{~h}$ and the weight losses were recorded. Protein nitrogen was determined by Dumas analysis with a NA 2100 Nitrogen and Protein Analyser (ThermoQuest-CE Instruments, Rodeno, Italy). Methionine was used as standard during the analysis. Duplicate measurements were made for all samples. A conversion factor of 6.25 was used to convert nitrogen values to protein; this factor is commonly used in previous leaf protein studies (Fantozzi \& Sensidoni, 1983; T. Hernández et al., 1997; Sheen, 1991; Teixeira et al., 2014; Teng \& Wang, 2011; Zanin, 1998). The concentration of soluble protein was determined by BCA assay (Smith et al., 1985), using Pierce BCA Protein Assay Kit (Thermo Scientific, Rockford, US), in which BSA was used as standard. The lipid content was determined by Soxhlet extraction with petroleum ether, according to AACC method 30-25 (AACC, 1983b). The samples were dried and ground before the extractions. Total dietary fibre was determined according to AACC method 32-05.01 using Megazyme assay kit K-TDFR (Megazyme International, Bray, Ireland). The ash content was determined according to the AACC official method 08-01 (AACC, 1983a). 


\subsubsection{Microscopy}

Microscopic images of the SBL products were made with a Nikon Microphot FL microscope equipped with a Photometrics CCD camera (Photometrics ${ }^{\circledR}$, Tucson, USA). Samples were placed directly on a glass slide, covered with a normal cover glass and observed using normal light, polarised light, and fluorescence with a Nikon B-3A fluorescence filter to detect chlorophyll auto-fluorescence $\left(\lambda_{\mathrm{exc}}=\right.$ $\left.440 \mathrm{~nm} ; \lambda_{\mathrm{em}}=685 \mathrm{~nm}\right)$. Rhodamine $B$ was used for protein staining.

\subsubsection{SDS-page}

The protein characterisation of the samples was done by reducing SDS polyacrylamide gel electrophoresis, using a Bio-Rad Mini-Protean cell (Bio-Rad Laboratories Inc., Hercules, USA). The samples were diluted with sample buffer (62.5 nM Tris- $\mathrm{HCl}, \mathrm{pH} 6.8 ; 2 \% \mathrm{w} / \mathrm{v}$ SDS; $5 \% \mathrm{w} / \mathrm{v}$ 2-mercaptoethanol). The weight ratio of sample-to-buffer was 1:4 for pellet samples and 1:1 for supernatant and juice samples. Before electrophoresis, each sample was heated to $95^{\circ} \mathrm{C}$ for $5 \mathrm{~min}$ in a heating block and then centrifuged at $10,000 \mathrm{~g}$ for $10 \mathrm{~min}$. An amount of $20 \mu \mathrm{L}$ of each sample was loaded on a $12 \%$ Tris-HCI SDS-ready gel; and $10 \mu \mathrm{L}$ of PreStained Protein Standard (Bio-Rad Laboratories Inc, Hercules, USA) were loaded. The electrophoresis was carried out at $200 \mathrm{~V}$ for about $1 \mathrm{~h}$. Afterwards, the gel was stained with Bio-safe Coomassie Stain (Bio-Rad Laboratories Inc, Hercules, USA). The identification of the proteins in the samples was done by comparing their band pattern with results from previous studies.

\subsection{Results and discussion}

The dry matter composition of the SBL fractions and its distribution is presented in Figure 2. 1. The composition of the juice resembles that of the leaves except for the total dietary fibre, which was clearly the main component of the fibrous pulp. The supernatant carried most of the ash and rest of the dry matter from the juice. This latter fraction includes soluble carbohydrates, pigments and other soluble dry matter. 


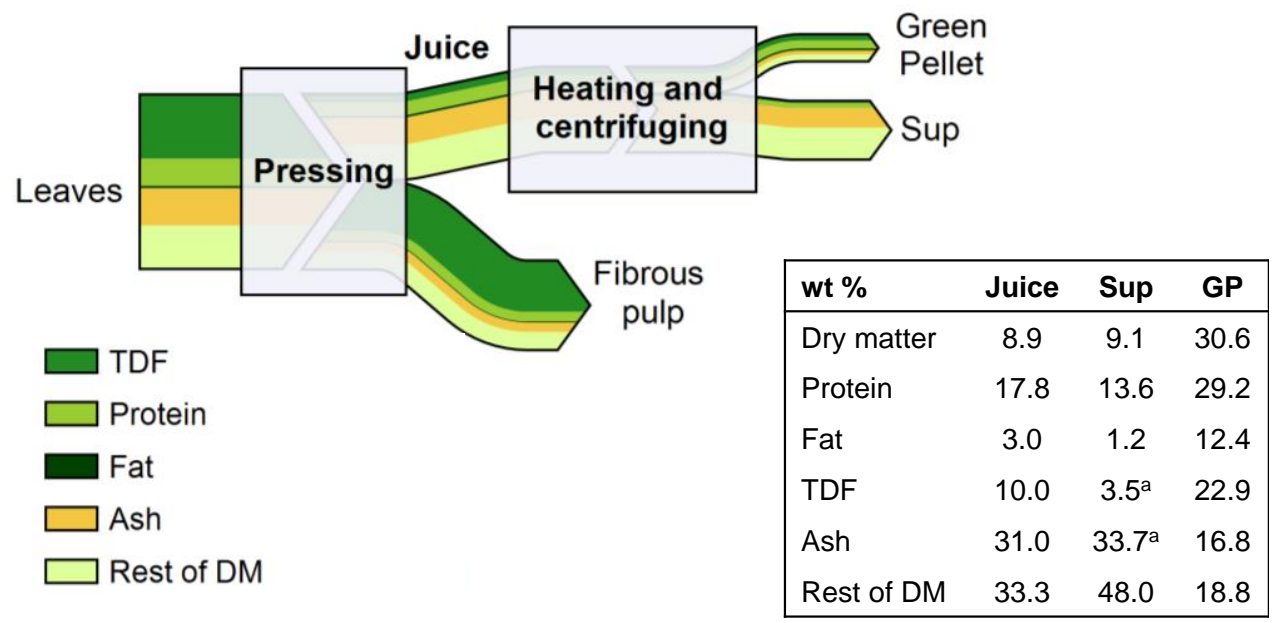

Figure 2. 1. Dry matter composition and distribution during protein extraction from SBL. Embedded table: composition of SBL fractions in dry basis, except the dry matter content. Sup $=$ supernatant. GP $=$ green pellet, TDF $=$ total dietary fibre, and DM $=$ dry matter. ${ }^{2}$ Values estimated from the mass balance.

Sugar beet leaves have a low lipid content $(3.4 \pm 1.0 \mathrm{wt} \%)$, which was mainly recovered from the green pellet fraction after leaf processing. This fraction contains cell debris and particulates that include chloroplastic structures. The latter are rich in lipids and consist mainly of pigments and lipid membranes (i.e. outer membrane and thylakoids) (Bolton \& Harwood, 1978). The low lipid content is a typical feature for leaves because of the physiological function of leaves in the plant: the leaves do not accumulate lipids but carbohydrates to support the plant structure and growth (Chapman et al., 2013).

The sugar beet leaves have a higher ash content (20 wt\%) compared to other crops used for LPC such as cassava leaves (4.6 - 6\%) (Awoyinka et al., 1995), alfalfa (9.6\%) (Edwards et al., 1975) and Moringa leaves (10.9\%) (Teixeira et al., 2014). The mineral composition of the SBL has been reported as part of a nutrient study of leaves at different ages and plant locations. The minerals monitored included $\mathrm{P}, \mathrm{K}, \mathrm{Ca}, \mathrm{Mg}, \mathrm{Na}, \mathrm{Zn}, \mathrm{Cu}, \mathrm{Fe}, \mathrm{Mn}, \mathrm{B}$, and Mo, showing different concentrations depending on leaf age, plant location and season (Fragoso et al., 1993). 


\subsubsection{Characterisation of SBL fractions}

\section{Leaf composition and protein distribution}

The SBL have an average water content of $88.5 \pm 1.6 \mathrm{wt} \%$. The protein content of the dry matter was $15.5 \pm 1.7 \mathrm{wt} \%$. A higher protein content ( $23 \mathrm{wt} \% \mathrm{db})$ has been reported for SBL (Lammens et al., 2012; Merodio \& Sabater, 1988), but this compositional difference can be explained by differences in leaf processing. Whole leaves (blade and stem) were used for the present study. When only blades were processed for protein extraction, the leaf protein content was increased to $21.6 \pm 1.6 \mathrm{wt} \% \mathrm{db}$, which is in agreement with the values reported earlier. The stem accounted for $49.8 \mathrm{wt} \%$ of the leaf and contains only $10.4 \pm 1.7 \mathrm{wt} \%$ protein (db).

Nevertheless, it was decided to use full leaves as separation of leaves into blades and stems might be difficult on (semi-) industrial scale. Due to the high water holding capacity and stiffness of the cellulose rich material, a large by-product stream is created of about $16.0 \mathrm{wt} \%$ of the leaves after SBL pressing. The rest of the leaves was transformed into a green juice. The proteins in the fibrous pulp accounted for $31 \%$ of the leaf proteins (Figure 2. $2 \mathrm{~A}$ ).

Extra washing of the fibrous pulp solubilised only $2.2 \%$ of extra leaf protein. Similar results were observed with cassava leaves. Additional processing of the fibrous residue did not increase the protein yield (Coldebella et al., 2013). The protein collected in the supernatant and pellet accounted for $68.9 \%$ of the leaf protein. To increase the protein concentration and purity, the supernatant can be further processed to isolate rubisco as described by Martin et al. for spinach leaves (2014).

For this study, the total protein content was determined from total nitrogen values, while the amount of solubilised protein was determined by a spectrophotometric method. The difference between these values was assumed to be the green (insoluble) protein content; a similar approach was used by Teixeira et al. with 
A

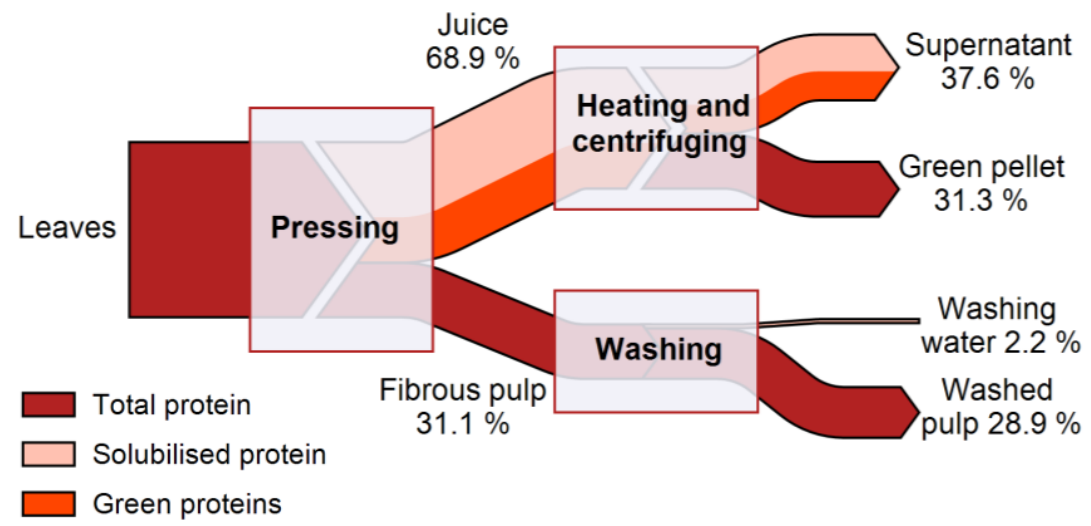

B

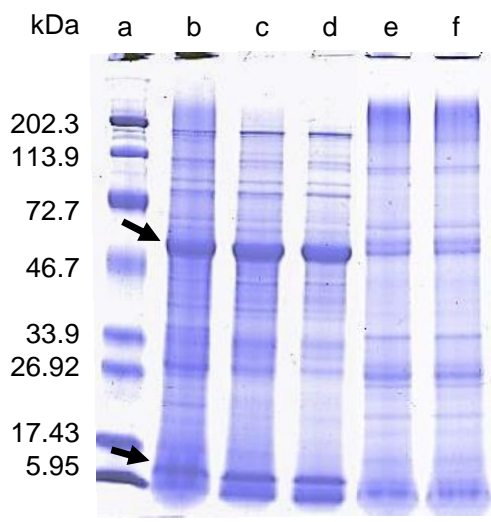

Figure 2. 2. (A) Protein distribution during protein extraction from SBL. A fraction of the green proteins remain suspended in the supernatant. (B) Coomassie blue-stained SDS-page of SBL fractions on a $12 \%$ polyacrylamide gel. a) molecular weight marker. b) SBL juice. Soluble protein fraction (supernatant): c) from fresh juice and d) from heat treated juice. Green proteins (pellet): e) from fresh juice and f) from heat treated juice. The arrows indicate the bands for rubisco subunits.

Kjeldahl and Lowry methods (2014). The pellet composition was estimated from a mass balance of the soluble and green proteins, obtaining $69.5 \mathrm{wt} \%$ and $30.5 \mathrm{wt} \%$, respectively. Consequently, both solubilised proteins and green proteins distribute more or less evenly among pellet and supernatant. These results were supported by an amino acid analysis of the SBL fractions (supplementary Figure. S1). The amino acid profile in the supernatant did not resemble that of rubisco, suggesting that other proteins remained suspended in this fraction. As described by previous studies, portions of both cytoplasmic (soluble) and chloroplastic (insoluble) proteins 
can be found in the green and white fractions (Chiesa \& Gnansounou, 2011) because the heat precipitation is not highly selective (Merodio et al., 1983). The centrifugation divided the proteins in two fractions almost equally: $45.4 \mathrm{wt} \%$ in the pellet and $54.6 \mathrm{wt} \%$ in the supernatant.

\section{Protein characterisation}

The proteins extracted in each fraction were characterised with SDS-page (Figure 2. $2 \mathrm{~B}$ ). Both supernatant and pellet contained rubisco subunits (53 kDa and $14 \mathrm{kDa}$ ), which were clearly more abundant in the supernatants as expected. The bands observed in the pellet samples were regarded as mostly membrane protein subunits given the molecular weight of the bands obtained. Plant membrane proteins are generally part of the chloroplastic membranes and include the photosynthetic systems. These photosystems are known for their high complexity, illustrated by the fact that they contain more than 100 different proteins (Friso et al., 2004 ), with subunit sizes ranging between $<5 \mathrm{kDa}$ to $>60 \mathrm{kDa}$. The protein complexes can contain up to 11 different subunits (e.g. Photosystem I) reaching a size of $540 \mathrm{kDa}$ with attached chlorophylls and pigments (Kügler et al., 1997).

There were no clear differences between the fresh and heat treated samples: all samples showed similar band patterns from the supernatants and from the pellets (Figure 2. 2 B: lanes $\mathrm{c}-\mathrm{d}$ and $\mathrm{e}-\mathrm{f}$, respectively). Membrane proteins are known to aggregate between 50 and $64^{\circ} \mathrm{C}$, while soluble proteins aggregate a higher temperature $\left(80-82^{\circ} \mathrm{C}\right)$ (Nagy et al., 1978). We therefore assumed that the heat treatment did not affect the type of precipitated proteins, but just increased the final protein yield (about $50 \%$ more protein was recovered from the heated juice).

\section{Microscopic observations}

The mechanical press converted $84 \mathrm{wt} \%$ of the wet weight of the starting leaves into a green juice (Figure 2. $3 \mathrm{~A}$ ) that is rich in cell contents and cell debris. A few intact cells were observed among the juice solids (Figure 2. $3 \mathrm{~B}-\mathrm{C}$ ). It is usual that a few intact cells remain after mechanical cell disruption; their percentage depends on the plant source, fibre (cellulose/lignin) content and the mechanical disruption technique. With low-fibre leaves the percentage of intact cells can be as high as 
$5-10 \%$ (Barbeau \& Kinsella, 1988), while adding a disk mill after pressing can reduce this percentage to $0 \%$ (Bals et al., 2012). Besides intact cells, large pieces of plant fibres and aggregates were observed. Chloroplasts were identified by fluorescence (Figure 2. $3 \mathrm{C}$ ), making use of the auto-fluorescence of the chlorophyll.
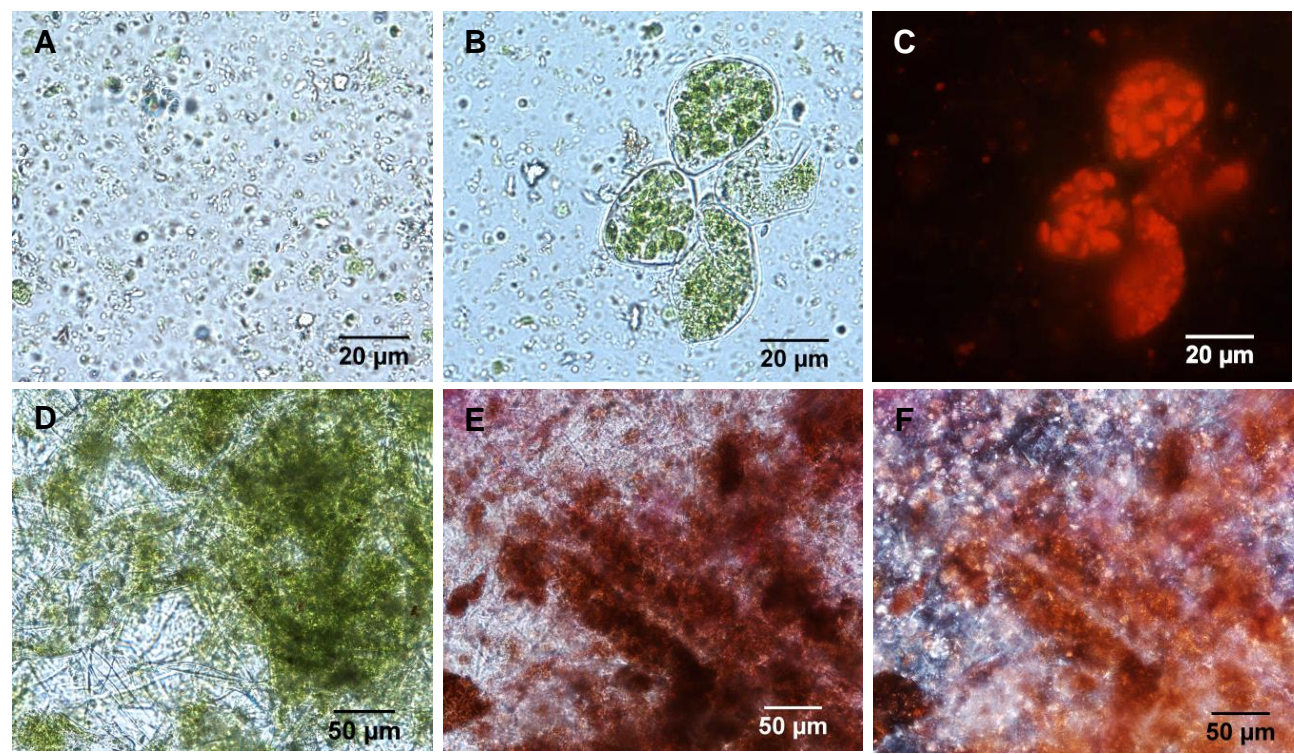

Figure 2. 3. Microscopy pictures of SBL juice: (A) bright field; (B) bright field focused on intact cell cluster and (C) cell cluster observed with fluorescence filter to detect chlorophyll autofluorescence (red). Microscopy pictures of SBL pellet: (D) bright field; (E) rhodamine B-staining for proteins (red); and (F) rhodamine B-staining and polarised light.

Similarly, the pellet containing the green proteins was observed with light microscopy. This SBL fraction was rich in long rod-like structures, probably being cellulosic material (Figure 2. 3D) and contained protein as shown by using rhodamine-B for protein staining (Figure 2. $3 \mathrm{E}$ ). The cellulose and other fibrous material found in this fraction may absorb the green juice during leaf pressing, hindering extraction of soluble proteins. The juicing step needs to be fast to prevent protein losses (Barbeau \& Kinsella, 1988) or the fibre-rich portions of the plant (e.g. stems, petioles) have to be left out of the process (Coldebella et al., 2013; Kammes et al., 2011). Finally, small crystal-like structures were observed using polarised light (Figure 2. 3 F), but these were not starch particles as 
evidenced by the fact that they were not responding to starch staining (using iodine, image not shown). They were therefore regarded as salts, given the small size, the crystal-like structure and the literature available on SBL crystals (Semenova \& Romanova, 2011). The crystals' composition mainly comprises oxalate salts such as magnesium, potassium and calcium oxalate. These salts are abundant in SBL and they can be insoluble as a result of ion and osmotic regulation of the plant cells (Franceschi \& Horner, 1980). From these observations and at this structural level, the pellet fraction had no clear separation of components that could lead to physical means of fractionation.

\subsubsection{Further processing of the green protein fraction}

To increase the protein purity, the supernatant can be further processed to isolate rubisco as described by Martin et al. for spinach leaves (2014). The spinach supernatant is processed by adjusting the $\mathrm{pH}$ to 8 , filtering the juice and adsorbing the proteins on chromatographic columns. The resulting fractions containing rubisco are desalted and stored after sterile filtration. Although $90 \%$ purity is reached by this method, the protein yield is very low, $0.1 \mathrm{~g}$ of rubisco per $100 \mathrm{~g}$ of leaves, which makes the procedure suitable for analytical purposes, but not feasible for biorefinery purposes.

\section{Consecutive washing.}

The green protein fraction was washed 3 times with distilled water and centrifuged till obtaining a final precipitate. With each washing step, the pellet material was diluted to a very low concentration. This dilution might change the density and viscosity of the material and the solids are re-dispersed rather than solubilised, implying the loss of some solids in every step.

The protein content increased from $31.3 \mathrm{wt} \%$ to $41.1 \mathrm{wt} \%$ after 3 washes (Figure 2 . 4 ) and in total $\sim 26 \%$ of the dry matter was removed. However, the main effect was observed after one wash, which removed $17.1 \%$ of the dry matter, whereas the subsequent washes removed $7.0 \%$ and $3.4 \%$, respectively. Within the solubilised fractions, $5 \mathrm{wt} \%$ of the total protein was extracted. These results suggest a slight 
but consistent protein purification at each step. The type of proteins being solubilised was checked through SDS-Page (image not shown). Only a few proteins were solubilised during the first washing step. The second and third solubilised fractions did not show any bands. The proteins found in the green pellet remained constant after the consecutive washes. It was estimated from the mass balance that about $70 \mathrm{wt} \%$ of the proteins in the green protein fraction was soluble protein. However, only $12 \mathrm{wt} \%$ was actually recovered after washing the pellet. This suggests that the previously soluble proteins became insoluble during processing, possibly due to interaction (complexation) with other insoluble material in the pellet.

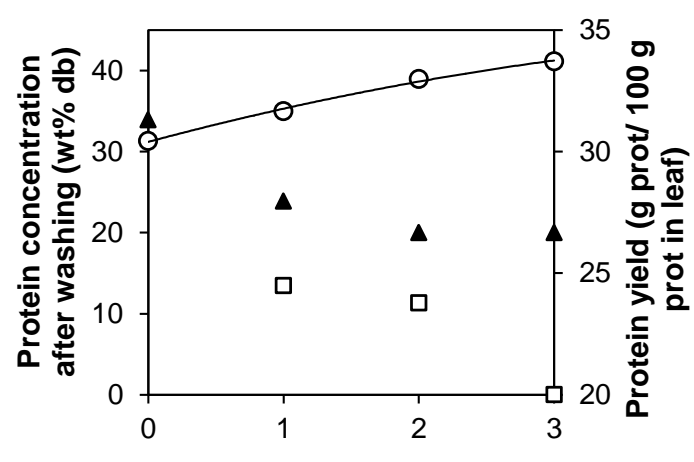

No. washing steps

Figure 2. 4. Protein concentration of the washed pellet $(\square)$ and washing liquid $(O)$, and total protein yield $(\Delta)$ after consecutive washes of the green pellet.

\section{Solubilisation with surfactants}

Since many of the green proteins are particular membrane proteins, it is to be expected that they cannot be solubilised as such. Thus they need to be solubilised with amphiphilic components. These can detach the proteins from the lipid membrane, from other proteins and from pigments, and suspend them into micellar structures. Triton X-100 (p-(1,1,3,3-tetramethylbutyl)-phenyl ether, octyl phenol ethoxylate), Zwittergent 3-12 (n-Dodecyl-n,n-dimethyl-3-ammonio-1-propane sulfonate) and CHAPS (3-[(3-cholamidopropyl)-dimethyl-ammonio]-1- propane sulfonate) were used to solubilise (part of) the green protein fraction. These surfactants were selected because of their successful earlier application on 
membrane protein extraction from leaf materials (Carpentier et al., 2005; KraghHansen et al., 1998). Zwittergent 3-12 was able to solubilise $49 \%$ of the protein present in the pellet when the protein to surfactant ratio was 1:1 (Figure 2. $5 \mathrm{~A}$ ). This was more than two-fold the value observed with just water, and also higher than with other surfactants. At higher protein to surfactant ratio, the highest protein solubilisation observed was $30 \%$ using Triton X-100 (Figure 2. $5 \mathrm{~B}$ ). The best solubilisation was observed when the surfactant was in excess compared to the protein in the mixture. This is also the case when proteins are solubilised by SDS for electrophoresis. For example, $1 \%$ SDS is used at a protein to surfactant ratio of $0.6: 1$.

A

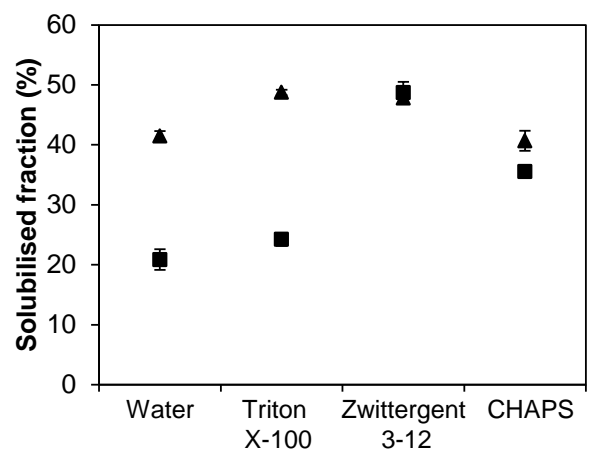

B

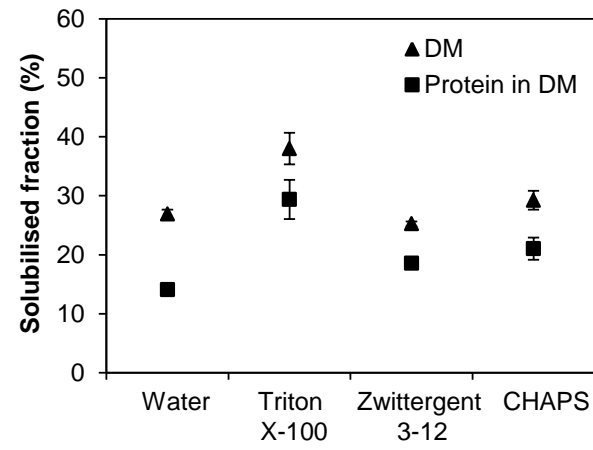

Figure 2. 5. Protein ( $\square)$ and dry matter yield $(\Delta)$ after protein solubilisation with surfactant solutions. Surfactant concentration was $0.3 \mathrm{wt} \%$ in all experiments. Green pellet concentrations were: (A) $1.0 \mathrm{wt} \%$; and (B) $5.1 \mathrm{wt} \%$. DM = dry matter. $n=3$

It is important to highlight that the surfactants were applied to a highly diluted suspension of pellets, and that not only protein but also other DM was solubilised. Therefore, some of the solids might be simply re-dispersed rather than solubilised. In all cases, the protein content was lower than in the starting material (which was about $30 \mathrm{wt} \%$ ), which points out that other solids (of variable composition) and soluble material (e.g. sugars) were preferentially dissolved or suspended, in spite of the presence of a surfactant.

It is difficult to determine to what extent the dry matter is associated to surfactant micelles. Lipids could form mixed micelles with the surfactants and contribute to 
protein solubilisation. Other solids may be dispersed by the weakening of the interaction between different particles, due to the presence of the surfactant. The resulting smaller particles can be more easily dispersed.

\subsubsection{Consequences for leaf biorefinery}

As for all purifications processes, any concentration step will compromise the final yield (Berghout et al., 2015). This can be depicted in Figure 2. 6. The concentrated rubisco fraction accounts for nearly $6 \%$ of the total proteins, about $50 \%$ ends up in the washing liquids. For a better understanding of leaf proteins and how to optimise their extraction, it helps to have a closer look to how they are arranged in the plant cell and what their physiological role is. About $80 \%$ of the leaf proteins are located inside the chloroplast (Fiorentini \& Galoppini, 1983), where a sophisticated membrane system (i.e. thylakoids) contains several membrane protein complexes. The surrounding fluid (i.e. stroma) contains rubisco and other soluble proteins. Most of these proteins are involved in the enzymatic reactions of the photosynthesis. The remaining $20 \%$ of the leaf proteins are found in the cytoplasm and small percentage is found within the nucleus (1 - 2\%) and mitochondria $(<5 \%)$ (Fiorentini \& Galoppini, 1983).

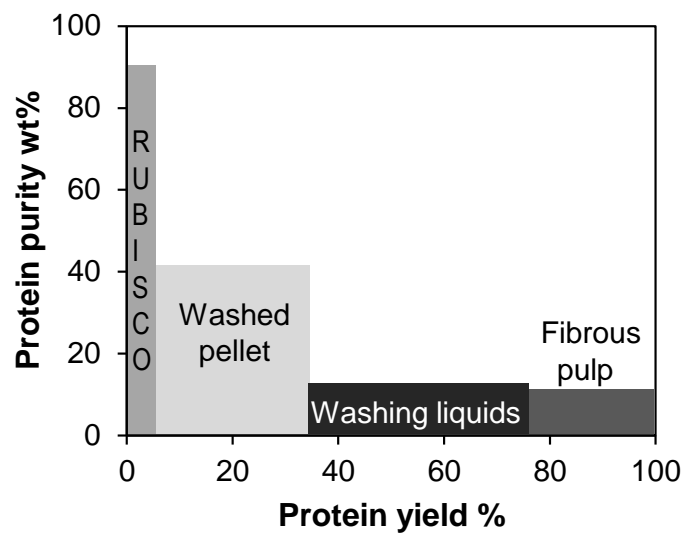

Figure 2. 6. Protein purity vs. protein yield of SBL products.

Optimising the process to reach high protein purity is limited to the soluble protein fraction. Protein coagulation either by heat treatment, $\mathrm{pH}$ shift, flocculation or 
membraneless osmosis mainly results in a discoloured protein solution that enables the production of a white protein powder from the soluble fraction ( $Y u$ A. Antonov, 2000b; Lamsal et al., 2003; Martin et al., 2014; Merodio et al., 1983; Telek, 1983). On the other hand, the green proteins remain in side streams mixed with chlorophylls, particulates and salts. The complexity of this green protein fraction implies further processing to remove the cellulosic material and the different pigments, and to further concentrate the proteins. The cellulosic materials can be avoided already by using low-fibre crops or removing fibre rich portions of the plant material (e.g. stems, petioles) (Bals et al., 2012); but the pigment removal and protein concentration steps have not been further developed for this protein fraction.

Compared to other plant segments such as seeds or roots, the leaves show a more or less homogeneous distribution of components on larger length scale, meaning that all parts have roughly the same composition. In contrast, in seeds starch is primarily localised in the endosperm, while oil and protein bodies are found in the embryo, and dietary fibre in the pericarp. Moreover, seed storage proteins are stored in abundance inside the protein bodies, lacking an enzymatic role in most cases, which makes them stable during processing (Tan-Wilson \& Wilson, 2012). Keeping these differences in mind, the approach for leaf protein extraction should be coupled to the intended use of the proteins extracted. Main attention should be on the question whether high purity is essential, or whether a fraction can have relevant properties as well (van der Goot et al., 2016).

The results in this paper show that a simple process leads to three product streams with a rich composition. That is why we suggest that biorefinery of leaves should aim for total protein use instead of pure-single proteins, because of the large variety of proteins and their location in the plant cell. We suspect that the feasibility of the extraction process is more influenced by protein yield rather than purity. A focus on total protein use can optimise the use of leaves as a food source and make use of the bioactive value of molecules that end up in the extracted proteins (e.g. carotene, zeaxanthin, chlorophyll, isoflavones). Additionally, the existing 
complexes (e.g. protein-lipid, protein-carbohydrate) might exhibit functional properties that need to be explored and characterised. For instance, the fibrous pulp can follow biorefinery processes that aim for feed or biofuels (T. Kim et al., 2013). It could even follow aqueous extraction to remove the remaining proteins and use the fibre-rich fraction as techno-functional ingredients for food. The existing complexes in the green proteins fraction, such as thylakoid membranes, could be refined from this neglected leaf protein fraction and increase its added value once a food application for the thylakoids is established.

\subsection{Conclusions}

Protein from plant leaves are traditionally extracted by mechanical pressing and thermal precipitation of fibre, chlorophyll and other components. Only part of the soluble proteins in the juice is then used for further refinement. For better use of the potential of SBL, also the other protein present in leafs should be made suitable for (food) applications.

We showed that both soluble and insoluble protein distribute almost evenly over the various fractions: juice, pulp, supernatant and final pellet. Re-dissolution of the precipitated proteins in the pellets is very difficult; even using surfactants that are commonly used for protein solubilisation do not result in re-dissolution of these proteins. Subsequent washing of the pellet yields an unrefined green protein fraction with 41.1 wt\% protein content, which account for $26.7 \%$ of the leaf protein. About $6 \%$ of the total protein could be extracted as pure rubisco ( $90 \%$ purity) from the supernatant. Most likely, harsh conditions may be required to obtain higher protein yields, which might impair the protein quality and compromise the economic feasibility.

We hypothesise that this is due to irreversible association between these proteins and the debris from the precipitation process. Thus, a future route towards utilisation of these proteins probably need to prevent their precipitation but should fractionate them while keeping them in solution. Also the functionality of protein- 
containing product streams should be explored as alternative to making pure protein fractions.

\section{Acknowledgments}

The authors thank Royal Cosun (The Netherlands) and the Technology Foundation STW (The Netherlands) for their project and financial support.

\section{Supplementary figure}

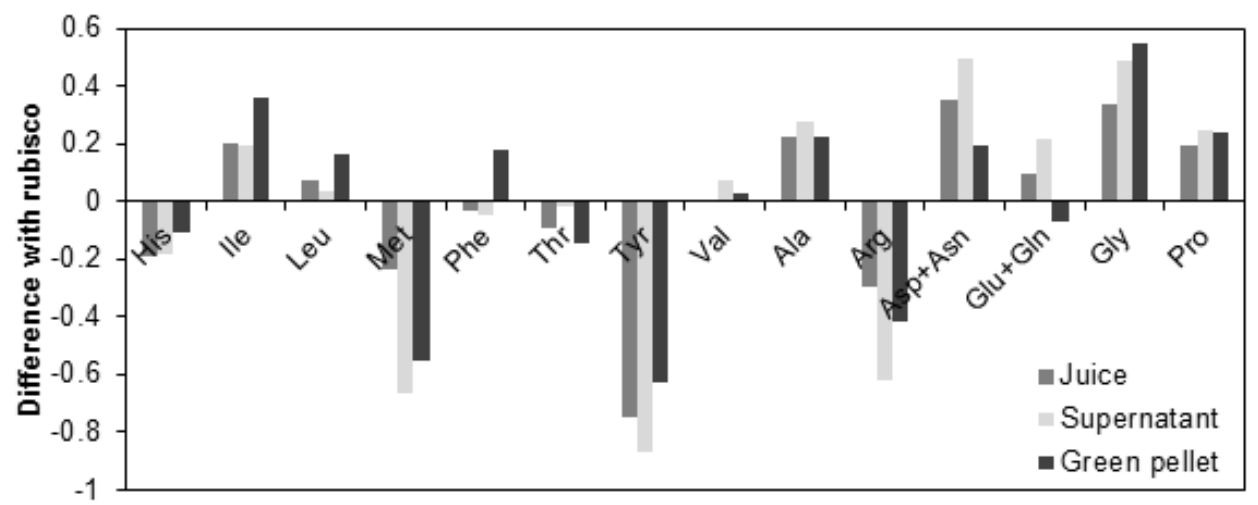

Figure S1. Amino acid (AA) profile of SBL fractions compared to that of rubisco. Cysteine, lysine, tryptophan and serine were not included in the calculations due to hydrolysis during sample preparation. Values for rubisco AA profile were obtained from the complete protein sequence (Dohm et al., 2014; H. Li et al., 2014). Amino acid composition determined via UPLC (Meussen et al., 2014) after sample hydrolysis in $6 \mathrm{~N} \mathrm{HCl}$ containing $1 \%(\mathrm{w} / \mathrm{v})$ phenol at $110^{\circ} \mathrm{C}$ for $24 \mathrm{~h}$. The amino acids were separated with an Acquity UPLC BEH C18 reversed phase column and the detection was done at wavelengths of $338 \mathrm{~nm}$ and $263 \mathrm{~nm}$, using Dionex RSLC (Dionex Corporation, Sunnyvale, CA, USA).

\section{References}

AACC. (1983a). Method 08-01: Ash - Basic Method. Approved Methods of Analysis, 10th ed. AACC International, St. Paul, MN, U.S.A.

AACC. (1983b). Method 30-25: Crude Fat in Wheat, Corn and Soy Flour, Feeds, and Mixed Feeds. Approved Methods of Analysis, 10th ed. AACC International, St. Paul, MN, U.S.A.

Antonov, Y. A. (2000). Use of membraneless osmosis for concentration of proteins from molecular-dispersed and colloidal-dispersed solutions (review). Applied Biochemistry and Microbiology, 36(4), 325-337. doi: 10.1007/bf02738039 
Awoyinka, A., Abegunde, V., \& Adewusi, S. R. (1995). Nutrient content of young cassava leaves and assessment of their acceptance as a green vegetable in Nigeria. Plant Foods for Human Nutrition, 47(1), 21-28.

Bals, B., \& Dale, B. E. (2011). Economic comparison of multiple techniques for recovering leaf protein in biomass processing. Biotechnology and bioengineering, 108(3), 530537.

Bals, B., Dale, B. E., Balan, V., Bergeron, C., Carrier, D. J., \& Ramaswamy, S. (2012). Recovery of leaf protein for animal feed and high-value uses Biorefinery CoProducts (pp. 179-197): John Wiley \& Sons, Ltd.

Barbeau, W. E., \& Kinsella, J. E. (1983). Factors affecting the binding of chlorogenic acid to fraction 1 leaf protein. Journal of Agricultural and Food Chemistry, 31(5), 993-998.

Barbeau, W. E., \& Kinsella, J. E. (1988). Ribulose biphosphate carboxylase/oxygenase (rubisco) from green leaves-potential as a food protein. Food Reviews International, 4(1), 93-127.

Berghout, J. A. M., Pelgrom, P. J. M., Schutyser, M. A. I., Boom, R. M., \& van der Goot, A. J. (2015). Sustainability assessment of oilseed fractionation processes: A case study on lupin seeds. Journal of Food Engineering, 150, 117-124. doi: 10.1016/j.jfoodeng.2014.11.005

Bolton, P., \& Harwood, J. (1978). Lipid metabolism in green leaves of developing monocotyledons. Planta: An International Journal of Plant Biology, 139(3), 267272. doi: $10.1007 /$ bf00388640

Byers, M. (1971). Amino acid composition and in vitro digestibility of some protein fractions from three species of leaves of various ages. Journal of the Science of Food and Agriculture, 22(5), 242-251. doi: 10.1002/jsfa.2740220508

Carpentier, S. C., Witters, E., Laukens, K., Deckers, P., Swennen, R., \& Panis, B. (2005). Preparation of protein extracts from recalcitrant plant tissues: An evaluation of different methods for two-dimensional gel electrophoresis analysis. Proteomics, 5(10), 2497-2507. doi: 10.1002/pmic.200401222

Chapman, K. D., Dyer, J. M., \& Mullen, R. T. (2013). Commentary: Why don't plant leaves get fat? Plant Science, 207(0), 128-134. doi: 10.1016/j.plantsci.2013.03.003

Chiesa, S., \& Gnansounou, E. (2011). Protein extraction from biomass in a bioethanol refinery--possible dietary applications: Use as animal feed and potential extension to human consumption. Bioresource Technology, 102(2), 427-436. doi: 10.1016/j.biortech.2010.07.125

Coldebella, P. F., Gomes, S. D., Evarini, J. A., Cereda, M. P., Coelho, S. R. M., \& Coldebella, A. (2013). Evaluation of protein extraction methods to obtain protein concentrates from Cassava leaf. Engenharia Agricola, 33(6), 1223-1233.

Dijkstra, D. S., Linnemann, A. R., \& van Boekel, T. A. (2003). Towards sustainable production of protein-rich foods: appraisal of eight crops for Western Europe. PART 
II: Analysis of the technological aspects of the production chain. Critical Reviews in Food Science and Nutrition, 43(5), 481-506.

Dohm, J. C., Minoche, A. E., Holtgräwe, D., Capella-Gutiérrez, S., Zakrzewski, F., Tafer, H., . . . Reinhardt, R. (2014). The genome of the recently domesticated crop plant sugar beet (Beta vulgaris). Nature, 505(7484), 546-549.

Edwards, R. H., Miller, R. E., Fremery, D. d., Knuckles, B. E., Bickoff, E. M., \& Kohler, G. O. (1975). Pilot Plant Production of an Edible White Fraction Leaf Protein Concentrate from Alfalfa. Journal of Agricultural and Food Chemistry, 23(4).

Fantozzi, P., \& Sensidoni, A. (1983). Protein extraction from tobacco leaves: technological, nutritional and agronomical aspects. Plant Foods for Human Nutrition, 32(3-4), 351368. doi: 10.1007/bf01091194

Fiorentini, R., \& Galoppini, C. (1983). The proteins from leaves. Qualitas Plantarum-Plant Foods For Human Nutrition, 32, 335-350.

Fragoso, M. A. C., Van Beusichem, M. L., Houwers, A., Branco, M. A. C., Serrão, M. G., Fernandes, M. L., . . . Pires, F. P. (1993). Foliar diagnosis of sugarbeet: Mineral composition of leaves of different physiological age during the season Optimization of Plant Nutrition (Vol. 53, pp. 137-146): Springer Netherlands.

Franceschi, V. R., \& Horner, H. T. (1980). Calcium oxalate crystals in plants. Botanical Review, 46(4), 361-427.

Friso, G., Giacomelli, L., Ytterberg, A. J., Peltier, J. B., Rudella, A., Sun, Q., \& Van Wijk, K. J. (2004). In-depth analysis of the thylakoid membrane proteome of Arabidopsis thaliana chloroplasts: new proteins, new functions, and a plastid proteome database. Plant Cell, 16(2), 478-499. doi: 10.1105/tpc.017814

Hernández, T., Martínez, C., Hernández, A., \& Urbano, G. (1997). Protein quality of alfalfa protein concentrates obtained by freezing. Journal of Agricultural and Food Chemistry, 45(3), 797-802.

Jwanny, E. W., Montanari, L., \& Fantozzi, P. (1993). Protein production for human use from sugarbeet: byproducts. Bioresource Technology, 43, 67-70.

Kammes, K. L., Bals, B. D., Dale, B. E., \& Allen, M. S. (2011). Grass leaf protein, a coproduct of cellulosic ethanol production, as a source of protein for livestock. Animal Feed Science and Technology, 164(1-2), 79-88. doi: 10.1016/j.anifeedsci.2010.12.006

Kim, T., Yoo, C., \& Lamsal, B. P. (2013). Front-end recovery of protein from lignocellulosic biomass and its effects on chemical pretreatment and enzymatic saccharification. Bioprocess and Biosystems Engineering, 36(6), 687-694. doi: 10.1007/s00449013-0892-8

Kragh-Hansen, U., le Maire, M., \& Møller, J. V. (1998). The mechanism of detergent solubilization of liposomes and protein-containing membranes. Biophysical Journal, 75(6), 2932-2946. doi: 10.1016/S0006-3495(98)77735-5 
Kügler, M., Jänsch, L., Kruft, V., Schmitz, U. K., \& Braun, H.-P. (1997). Analysis of the chloroplast protein complexes by blue-native polyacrylamide gel electrophoresis (BN-PAGE). Photosynthesis Research, 53, 35-44.

Lammens, T. M., Franssen, M. C. R., Scott, E. L., \& Sanders, J. P. M. (2012). Availability of protein-derived amino acids as feedstock for the production of bio-based chemicals. Biomass \& Bioenergy, 44, 168-181. doi: 10.1016/j.biombioe.2012.04.021

Lamsal, B. P., Koegel, R. G., \& Boettcher, M. E. (2003). Separation of protein fractions in alfalfa juice: Effects of some pre-treatment methods. Transactions of the American Society of Agricultural Engineers, 46(3), 715-720.

Li, H., Cao, H., Cai, Y.-F., Wang, J.-H., Qu, S.-P., \& Huang, X.-Q. (2014). The complete chloroplast genome sequence of sugar beet (Beta vulgaris ssp. vulgaris). Mitochondrial DNA, 25(3), 209-211. doi: doi:10.3109/19401736.2014.883611

Martin, A. H., Nieuwland, M., \& De Jong, G. A. H. (2014). Characterization of heat-set gels from RuBisCO in comparison to those from other proteins. Journal of Agricultural and Food Chemistry, 62(44), 10783-10791. doi: 10.1021/jf502905g

Merodio, C., Martín, M., \& Sabater, B. (1983). Improved separation of green and soluble leaf proteins by pH shift. Journal of Agricultural and Food Chemistry, 31(5), 957-959.

Merodio, C., \& Sabater, B. (1988). Preparation and properties of a white protein fraction in high yield from sugar beet (Beta vulgaris $L$ ) leaves. Journal of the Science of Food and Agriculture, 44, 237-243.

Meussen, B., van Zeeland, A. T., Bruins, M., \& Sanders, J. M. (2014). A fast and accurate UPLC method for analysis of proteinogenic amino acids. Food Analytical Methods, 7(5), 1047-1055. doi: 10.1007/s12161-013-9712-7

Nagy, S., Telek, L., Hall, N. T., \& Berry, R. E. (1978). Potential food uses for protein from tropical and subtropical plant leaves. Journal of Agricultural and Food Chemistry, 26(5).

Rathore, M. (2010). Leaf protein concentrate as food supplement from arid zone plants. Journal of Dietary Supplements, 7(2), 97-103. doi: 10.3109/19390211003766777

Semenova, G. A., \& Romanova, A. K. (2011). Crystals in sugar beet (Beta vulgaris L.) leaves. Cell and Tissue Biology, 5(1), 74-80. doi: 10.1134/s1990519x11010147

Sheen, S. J. (1991). Comparison of chemical and functional properties of soluble leaf proteins from four plant species. Journal of Agricultural and Food Chemistry, 39, 681-685.

Smith, P. K., Krohn, R. I., Hermanson, G. T., Mallia, A. K., Gartner, F. H., Provenzano, M. D., . . . Klenk, D. C. (1985). Measurement of protein using bicinchoninic acid. Analytical Biochemistry, 150(1), 76-85. doi: 10.1016/0003-2697(85)90442-7

Tan-Wilson, A. L., \& Wilson, K. A. (2012). Mobilization of seed protein reserves. Physiologia Plantarum, 145(1), 140-153. doi: 10.1111/j.1399-3054.2011.01535.x 
Teixeira, E. M. B., Carvalho, M. R. B., Neves, V. A., Silva, M. A., \& Arantes-Pereira, L. (2014). Chemical characteristics and fractionation of proteins from Moringa oleifera Lam. leaves. Food Chemistry, 147, 51-54. doi: 10.1016/j.foodchem.2013.09.135

Telek, L. (1983). Leaf protein extraction from tropical plants. Paper presented at the Plants: the Potential for Extracting Protein Medicines and Other Useful Chemicals, US Congress, Washington, DC.

Teng, Z., \& Wang, Q. (2011). Extraction, identification and characterisation of waterinsoluble proteins from tobacco biomass. Journal of the Science of Food and Agriculture, 92, 1368-1374.

Van de Velde, F., Alting, A., \& Pouvreau, L. (2011). Process for isolating a dechlorophyllized rubisco preparation from a plant material. Patent number: WO2011078671, 30.

van der Goot, A. J., Pelgrom, P. J. M., Berghout, J. A. M., Geerts, M. E. J., Jankowiak, L., Hardt, N. A., . . Boom, R. M. (2016). Concepts for further sustainable production of foods. Journal of Food Engineering, 168, 42-51. doi: 10.1016/j.jfoodeng.2015.07.010

Zanin, V. (1998). A new nutritional idea for man: lucerne leaf concentrate. Paris, France. 


\section{Understanding leaf membrane protein extraction to develop a food-grade process}

\section{Highlights}

- There is no process to extract leaf membrane proteins for food applications

- We used proteomic extraction protocols with leaves to inspire a food-grade process

- Processing steps provide conditions (e.g. solubility, polarity) to isolate proteins

- Leaf protein heterogeneity limits selectivity of the extraction

- Protein heterogeneity also enables fractions with potential properties for food

This chapter has been published as:

Tamayo Tenorio, A., Boom, R. M., \& van der Goot, A. J. Understanding leaf membrane protein extraction to develop a food-grade process. Food Chemistry (2017), vol 217, pages 234-243. 


\section{Abstract}

Leaf membrane proteins are an underutilised protein fraction for food applications. Proteins from leaves can contribute to a more complete use of resources and help to meet the increasing protein demand. Leaf protein extraction and purification is applied by other disciplines such as proteomics. Therefore, this study analysed proteomic extraction methods for membrane proteins as an inspiration for a foodgrade alternative process. Sugar beet leaves were extracted with two proteomic protocols: solvent extraction and Triton X-114 phase partitioning method. Extraction steps contributed to protein purity and/or to selective fractionation, enabling the purification of specific proteins. It was observed that membrane proteins distributed among different solvents, buffers and solutions used due to their physicochemical heterogeneity. This heterogeneity does not allow a total membrane protein extraction by a unique method or even combinations of processing steps, but it enables the creation of different fractions with different physicochemical properties useful for food applications. 


\subsection{Introduction}

Green leaves are considered as an underutilised protein source for food applications. A potential leaf source are leaves from sugar beet plants (Beta vulgaris L.), since the leaves can be regarded as edible (Lim, 2016) and constitute an abundant waste stream. Total protein extraction from sugar beet leaves would deliver $450-600 \mathrm{~kg} / \mathrm{ha}$, which is comparable to soy (450-600 kg/ha), and cereals ( $\sim 570 \mathrm{~kg} / \mathrm{ha})$ (van Krimpen et al., 2013). However, the use of leaf proteins, not only from sugar beet plants, is hindered by the lack of extraction processes that can reach high yields (Bals et al., 2012). So far, the development of protein extractions processes from leaves have focused on the soluble protein fraction, leaving the insoluble fraction in side streams (Angelica Tamayo Tenorio, Gieteling, et al., 2016). Therefore, a suitable extraction process for these neglected proteins is needed to increase the current protein yield, to deliver food quality proteins, and ultimately to optimise existing resources.

Leaf insoluble proteins mainly consist of membrane proteins and their lack of solubility in water hinders extraction and subsequent utilisation. These proteins are removed in the extraction processes available for food applications (Lamsal et al., 2007). By discarding the membrane proteins, not only the intense green colour of leaf proteins is removed, but also half of the proteins. To utilise the leaves better, processes for the extraction of the membrane proteins are required. Other disciplines such as proteomics, photosynthesis biology and plant membrane dynamics utilise different solubilisation strategies to analyse these proteins. Thus, the extraction methods developed for analytical purposes can provide insights and inspiration on how to extract membrane proteins.

Proteomic protocols are optimised to extract all types of membrane proteins, even in their native state because of their important roles in several cell functions. Isolation of membrane proteins means detaching the proteins from the lipid membrane and breaking the interactions (electrostatic, van der Waals, hydrogen bonds) with enzyme cofactors, chlorophylls, and other pigments. These interactions and the presence of interfering compounds, make leaf and stem 
material more challenging for protein extraction compared to tissue from other organisms such as yeast or mammals (W. Wang et al., 2008). Even if proteomic protocols are meant to achieve complete extraction, they cannot be directly translated to a preparative, industrial scale process, since they use extraction media that would not be allowed on larger scales. However, the protocols do generate understanding of the interactions that are at play, providing valuable insights for large-scale extraction using other media.

The objective of the study reported here is therefore to learn from proteomic protocols on possible extraction routes for leaf membrane proteins and evaluate food-grade equivalent options through understanding the role of each extraction step/reagent and the behaviour of the membrane proteins during extraction. Two proteomic extraction methods were explored with sugar beet leaves: a protocol designed especially for membrane protein purification, and a phase partitioning protocol using Triton X-114, designed for integral membrane protein isolation. The effect of each extraction step was analysed in terms of total protein distribution and chlorophyll removal. The knowledge gained through these proteomic methods was used to assess the possibilities for membrane protein extraction and to explore food-grade alternatives depending on the final application. Understanding these methods gave insights on the technical feasibility of a food-grade process aimed for large scale implementation.

\subsection{Materials and methods}

\subsubsection{Chemicals}

Ammonium acetate, phenol, TCA (trichloroacetic acid), SDS (Sodium dodecyl sulphate), Triton X-114 ((1,1,3,3-Tetramethylbutyl)phenyl-polyethylene glycol)), $\mathrm{HCl}$ (hydrogen chloride), Tris- $\mathrm{HCl}, 2$-mercaptoethanol and PBS components $\left(\mathrm{Na}_{2} \mathrm{HPO}_{4}\right.$, $\mathrm{KH}_{2} \mathrm{PO}_{4}, \mathrm{NaCl}, \mathrm{KCl}$ ) were purchased from Sigma-Aldrich Co. LLC. (St. Louis, USA). Pre-Stained Protein Standard and $12 \%$ Tris-HCl SDS-ready gel were purchased from Bio-Rad (Bio-Rad Laboratories Inc., Hercules, USA) Acetone and methanol were purchased from Actu All Chemicals b.v. (Oss, The Netherlands). 


\subsubsection{Plant material}

Sugar beet leaves (SBL) were collected from a sugar beet field ( $0.85 \mathrm{ha}$ ) near Wageningen, The Netherlands. The field belongs to Wageningen University. The leaves had an average dry matter content of $10.3 \pm 0.4 \mathrm{wt} \%$ and a protein content of $19.4 \pm 1.9$ wt $\%$ on dry basis. Before processing, the leaves were washed with cool tap water $\left(\sim 10^{\circ} \mathrm{C}\right.$; hardness 4.4 degrees German hardness, $\left.\mathrm{dGH}\right)$ and dried with paper-towel. SBL are regarded as edible leaves and as a potential crop for protein extraction.

\subsubsection{Proteomic extraction protocols}

Two proteomic protocols were considered in this study to observe the protein distribution under different conditions. Proteomic studies usually combine several methods, which complement each other and result in identification of more proteins (Friso et al., 2004; Kamal et al., 2013).

\section{Solvent extraction protocol}

A standard proteomic extraction protocol was used as described by Wang et al. (2006), while the sample size was increased up to $10 \mathrm{~g}$ to allow mass and protein balance calculations. SBL were pulverised with liquid nitrogen and mixed with $10 \%$ TCA/acetone in a powder to liquid ratio of 1:10, followed by centrifugation (step 1). After discarding the supernatant, $80 \%$ methanol with $0.1 \mathrm{M}$ ammonium acetate was added to the pellet in a 1:10 ratio, mixed and then centrifuged (step 2). The supernatant was again discarded, replaced with $80 \%$ acetone in a pellet to solvent ratio of 1:10, mixed and centrifuged (step 3). The supernatant was discarded and the pellet was air dried. Afterwards, $6 \mathrm{ml} / \mathrm{g}$ pellet of $1: 1$ phenol/SDS buffer was added, mixed and incubated for $5 \mathrm{~min}$ at room temperature to allow phase separation (step 4). After centrifugation, the phenol phase was transferred to a new centrifuge tube. The tube was filled with $80 \%$ methanol with $0.1 \mathrm{M}$ ammonium acetate in a 10:1 ratio with the phenol phase. The mixture was stored over night at $-20^{\circ} \mathrm{C}$ and then centrifuged (step 5). The white pellet was collected and washed consecutively with $100 \%$ methanol (step 5) and $80 \%$ acetone (step 6), followed by 
centrifugation each time. The final pellet was air dried. All mixing steps where done by vortexing at room temperature and the centrifugation steps were done at 16,000 $g$ at $4^{\circ} \mathrm{C}$ for $3 \mathrm{~min}$. From the mass and protein balance, the protein yield was calculated as grams of protein in the sample per grams of protein in the starting leaf material.

\section{Phase partitioning protocol}

The phase partitioning with Triton X-114 was done based on two methods: according to Brusca and Radolf (1994) and Okamoto (2001). SBL were also ground in liquid nitrogen. The leaf powder was mixed with a Titron X-114 solution (2\% final concentration) in PBS ( $\mathrm{pH} 7.4$ ) to a surfactant:protein ratio of 10 to 1 , using a rotor-stator IKA T25 (IKA-Werke GmbH \& Co. KG, Staufen, Germany) at $6,500 \mathrm{rpm}$ for $30 \mathrm{~s}$ and at $9,500 \mathrm{rpm}$ for $30 \mathrm{~s}$. The mixture was centrifuged $(13,000$ $\mathrm{g}, 4^{\circ} \mathrm{C}, 10 \mathrm{~min}$ ) to remove the cell debris. The supernatant was incubated at $37^{\circ} \mathrm{C}$ for $10 \mathrm{~min}$ and centrifuged at $13,000 \mathrm{~g}$ for $10 \mathrm{~min}$. The surfactant (bottom) phase was analysed for composition and protein characteristics. The aqueous (top) phase was transferred to a new tube and mixed again with Titron X-114 solution in a 1:1 weight ratio, incubated and centrifuged under the same conditions. Samples were taken at each extraction step to establish mass and protein balances and to calculate the protein yield as previously indicated. The resulting phases were analysed for their composition and protein characteristics (SDS-page). Before compositional analysis, the fractions were dried in a convective oven at $105^{\circ} \mathrm{C}$ for $24 \mathrm{~h}$.

\subsubsection{Food-grade extractions}

Fresh SBL were pressed through a twin screw press Angelia juicer II 7500 (Angel Juicers, Queensland, Australia). The juice was used for protein extraction, while the fibrous pulp was extruded out at the press and discarded.

\section{pH precipitation}

The initial juice's $\mathrm{pH}$ was 6.1 and it was lowered to $\mathrm{pH} 3.5$ and 4.5 with a $1 \mathrm{M} \mathrm{HCl}$ solution. The juice was incubated under continuous stirring for $1 \mathrm{~h}$ and centrifuged 
at $7,000 \mathrm{~g}$ for $10 \mathrm{~min}$ at room temperature. Both the pellet and supernatant were collected for compositional analysis. Samples were done in triplicate.

\section{Successive acetone washes}

SBL juice was heated to $50^{\circ} \mathrm{C}$ for $30 \mathrm{~min}$ and centrifuged at $15,000 \mathrm{~g}$ for $30 \mathrm{~min}$. The resulting green pellet was freeze-dried and stored until used. The dry pellet was washed with $80 \%$ acetone for 5 times, using a powder to solvent ratio of 1 to 20. At each washing step, the mixture was incubated at $-20^{\circ} \mathrm{C}$ for $1 \mathrm{~h}$, followed by centrifugation at $4,816 \mathrm{~g}$ for $20 \mathrm{~min}$, at $4^{\circ} \mathrm{C}$. The supernatants were analysed for chlorophyll content and the pellets for composition.

\subsubsection{Compositional analysis}

The dry matter content was determined by drying each fraction overnight at $105^{\circ} \mathrm{C}$. The protein content was determined by Dumas analysis with a NA 2100 Nitrogen and Protein Analyser (ThermoQuest-CE Instruments, Rodeno, Italy), using methionine as standard and 6.25 as conversion factor. Although this conversion factor is high for leaf material, it was used to allow comparison to previous studies. A value based on amino acid composition could be around 5.3. Each sample was measured in duplicates. The protein content of a number of samples was estimated from the mass balance due to insufficient amount of material for analysis; those samples are indicated with * in the results. The chlorophyll concentration was estimated by spectrophotometry as described by Porra et al. (1989), using acetone for extraction.

\subsubsection{SDS-page}

The protein in the resulting phases was characterised by reducing SDS polyacrylamide gel electrophoresis, using a Bio-Rad Mini-Protean cell (Bio-Rad Laboratories Inc., Hercules, USA). The proteins were first precipitated with 10 volumes of $80 \%$ acetone, incubated at $-20^{\circ} \mathrm{C}$ overnight and centrifuged at $4,816 \mathrm{~g}$ for $15 \mathrm{~min}$. The resulting pellets were re-suspended in SDS-sample buffer. Sample preparation and electrophoresis were carried out as described by Tamayo Tenorio et al. (2016). 


\subsection{Results and discussion}

\subsubsection{Solvent extraction protocol}

Several proteomic protocols are available for membrane protein extraction depending on the target protein, the type of tissue and the research question. SBL were extracted with a protocol typically used for a wide range of leaves and fruits (W. Wang et al., 2006). Mass balances for the dry matter and total protein were established to show their distribution during the extraction process. Figure 3. $1 \mathrm{~A}$ and $B$ depict the dry matter flow and protein flow, respectively. Each step enables higher purity in the final fraction but leads to protein losses as well. The protein yield in the final pellet was $8.3 \pm 1.4 \%$, calculated as grams of protein in the pellet per grams of protein in the leaf. This final fraction had a protein content of $79.6 \pm$ $1.7 \mathrm{wt} \%(\mathrm{db})$. On wet basis, about $200 \mathrm{mg}$ of membrane protein extract (pellet 6) was obtained from $100 \mathrm{~g}$ of leaves.

\section{Role of each step}

The membrane protein extract (pellet 6) is the result of multiple steps, each of them fulfilling a specific purification task. The first step of any plant protein extraction process is mechanical tissue disruption for cell wall opening and release of cellular content. The mechanical process is done at low temperatures (liquid $N_{2}$ ) to avoid proteolytic and enzymatic degradation reactions, which are caused by proteases released from different organelles after tissue disruption (W. Wang et al., 2008), as well as phenoloxidases and polyphenols (Carpentier et al., 2005).

Once the plant material is pulverised, the addition of $10 \%$ TCA/acetone precipitates the protein and starts the removal of substances that interfere with final protein analysis, such as phenolics, lipids and pigments (Jacobs et al., 2000; W. Wang et al., 2008). The low pH induced by $10 \%$ TCA ensures an environment free of any enzymatic activity, preventing proteolysis and oxidation. Both enzymatic processes can modify the molecular weight or isoelectric point of the proteins, which interfere later with isolation techniques and subsequent interpretation of the analytical results (Jacobs et al., 2000). Similarly, acetone dissolves interfering compounds 
A

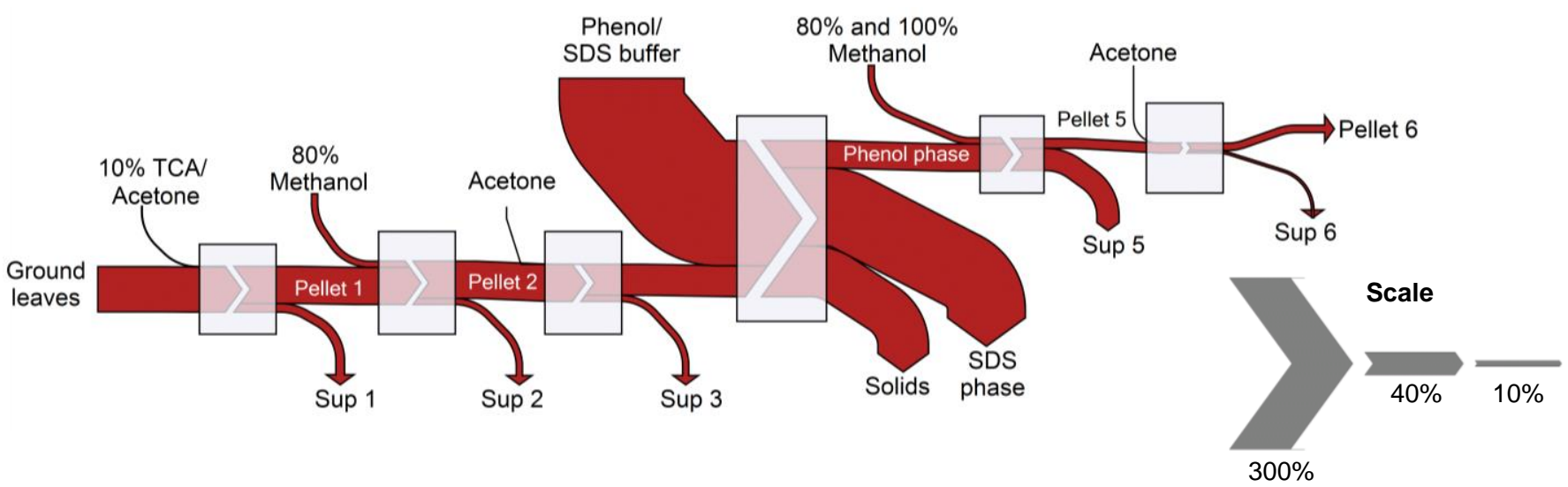

B

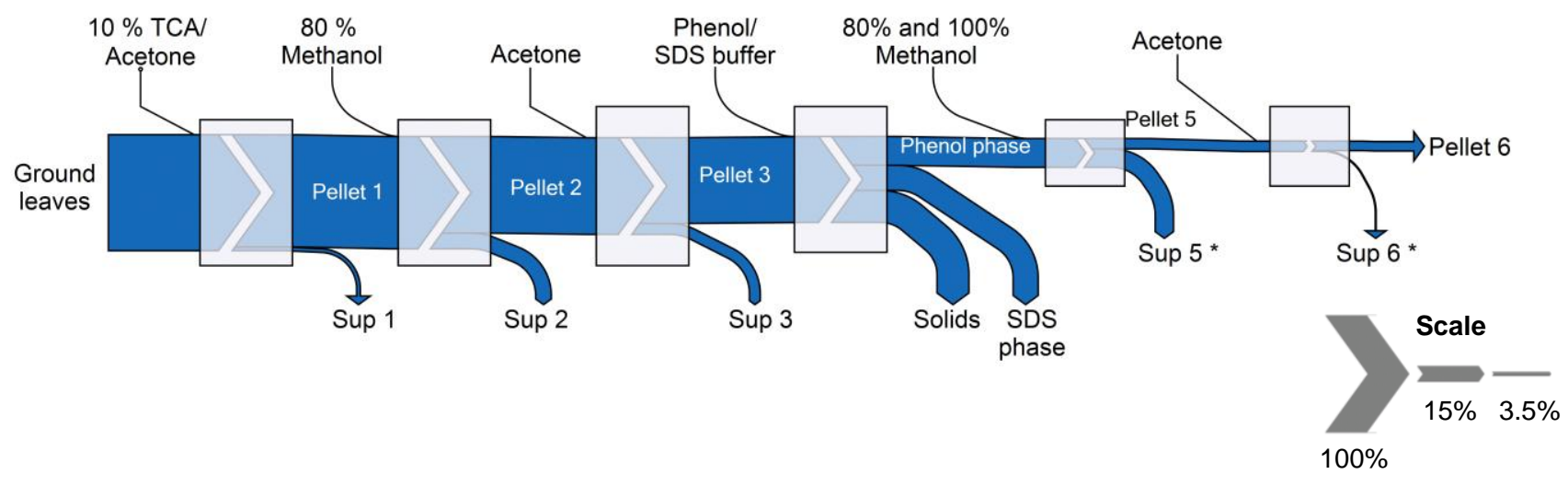

Figure 3. 1. Dry matter (A) and protein (B) distribution during proteomic extraction protocol from SBL. The details of each processing step are described in Materials and methods. Sup $=$ supernatant. $(*)$ denotes streams of which the composition was estimated by mass balances. The thickness of the arrows correlates with the size of the streams as depicted in the scale. 
such as polyphenols and pigments (W. Wang et al., 2006). The latter were analysed by chlorophyll content measurements and the results are described in the next section.

The precipitate obtained after the $10 \% \mathrm{TCA} /$ acetone treatment was consecutively washed with $80 \%$ methanol ( $0.1 \mathrm{M}$ ammonium acetate) and acetone. The methanol removes remaining TCA, while the ammonium acetate neutralises the TCA and prepares the material for the phenol/SDS solubilisation step (W. Wang et al., 2006). The acetone wash is a continuation of the removal of interfering compounds started by TCA/acetone.

The solvent-washed pellet was then mixed with a $1: 1$ phenol/SDS solution. After mixing and 5 min incubation, three layers were formed: a pellet phase (solid), an aqueous SDS phase (liquid) and a top organic phenol phase (liquid). Literature suggests that the pellet consists mainly of insoluble cell debris, while the SDS phase holds soluble proteins, carbohydrates, nucleic acids and salts, and the phenol phase holds cytosolic and membrane proteins, lipids and pigments (Carpentier et al., 2005). A pH of 8.0 was used to ionise phenolic compounds and therefore prevent their reactions with proteins, and to enable the partitioning of the nucleic acids towards the SDS phase. Besides being a solvent, phenol is a strongly dissociating agent that decreases molecular interactions within and between protein molecules and with other materials. Unfortunately, phenol is also highly toxic (Carpentier et al., 2005).

The phenol/SDS phase separation step enabled protein fractionation and accounted for the main protein fraction, when looking at total leaf proteins. After this step, only the phenol phase is further washed for final protein extraction, while the SDS (containing most of the soluble protein) and solid phases were not investigated further. These phases accounted for $\sim 49 \%$ of the leaf proteins, as depicted in Figure 3. 1 B. The continuation with the phenol phase implies that only a selective fraction of the leaf proteins was purified, namely insoluble proteins. We envisage that the soluble proteins that are now in the SDS phase will be recovered 
as well in a large-scale process, while the solid phase may be more difficult to extract further.

The phenol phase was then mixed with $80 \%$ methanol containing $0.1 \mathrm{M}$ ammonium acetate. About $36 \%$ of the proteins precipitated in this step, which represents $\sim 9 \%$ of the total proteins. Some of the proteins, pigments and phenolic compounds may remain in solution (W. Wang et al., 2003). The subsequent washing steps (100\% methanol, acetone) yielded a purified fraction (pellet 6) with $79.6 \pm 1.7 \mathrm{wt} \%$ protein (db). This final protein extract accounted for $8 \%$ of the initial leaf proteins.

Figure 3. 2 summarises the protein purification process as a function of total protein yield. As expected, the purification was achieved at the expense of yield and some steps had a stronger impact on the protein losses. The phenol/SDS phase separation presented not only the biggest losses (step 3 to 4), but also the lowest increase in purity. This step seemed detrimental for total protein extraction, but it was rather efficient for insoluble protein purification, knowing that the role of this step was protein fractionation. As a result, only the desired proteins (insoluble proteins) continue the purification process and a higher purity was achieved in the consecutive steps.

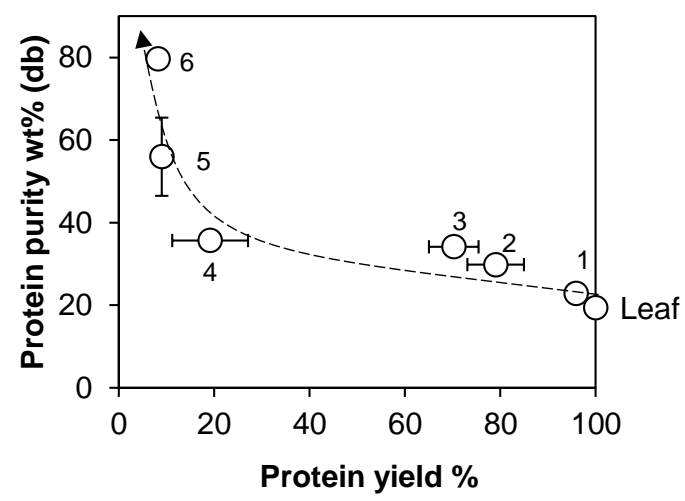

Figure 3. 2. Protein purity vs. protein yield in pellets obtained during solvent-based protein extraction from SBL. The number denote each of the steps described in the solvent extraction protocol. In step 4, much of the soluble proteins is separated, and thus the sudden loss in yield may not be present in a larger-scale process. 
All steps together enable the purification of specific proteins or group of proteins. Some steps contribute more to purity, some more to selective fractionation. The combination of different solvents provides a broad range of extraction conditions (e.g. polarity, solubility) that finally removes most of the interfering substances.

\section{Chlorophyll content during extraction}

The chlorophyll content was measured in the soluble fractions (i.e. supernatants) from each step (Figure 3. 3). Chlorophyll is representative for all the pigments present in leaf membrane proteins and is an indicator of the effectiveness of an extraction step to remove pigments. The highest chlorophyll concentration (31.8 $\mu \mathrm{g} / \mathrm{ml}$ ) was observed in step 1 (Figure 3. $3 \mathrm{~A}$ ), which accounted for about $92 \%$ of all the chlorophyll removed (Figure 3. $3 \mathrm{~B}$ ), although the remaining pellet still possessed some green colour. Steps 1,3 and 5 mostly removed the chlorophyll from the sample. The solvents used in these steps were acetone (steps 1 and 3) and methanol (step 5), which are both good solvents for chlorophyll. However, steps 2 and 6, which also involve methanol and acetone respectively, where not as effective to remove chlorophyll from the fractions.

A

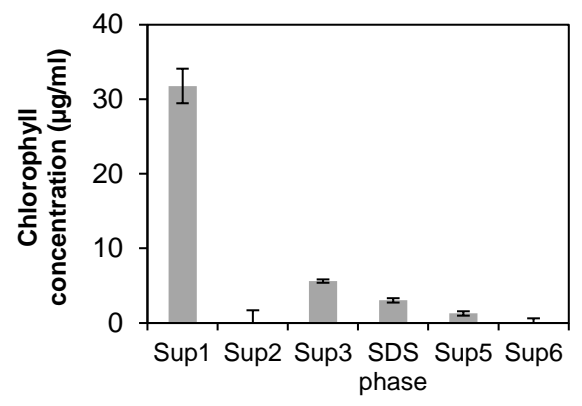

B

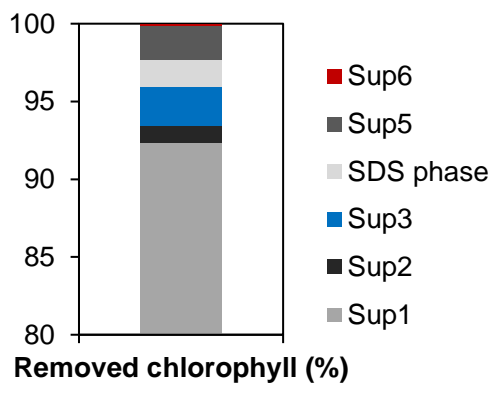

Figure 3. 3. Chlorophyll quantification on supernatants from each extraction step of the solvent extraction protocol. (A) Chlorophyll concentration. (B) Percentage of removed chlorophyll per step, assuming as $100 \%$ the sum of the chlorophyll measured in each step. Sup $=$ supernatant. $\mathbf{n}=\mathbf{3}$.

\subsubsection{Phase partitioning protocol}

Phase separation using surfactants is a milder option to isolate membrane proteins compared to the proteomic protocol described above. The protein separation here 
is based on hydrophobicity/hydrophilicity differences and is achieved by using surfactants that have a low critical solution temperature (LCST) and phase separate above this critical solution temperature, such as polyethylene glycolbased detergents (e.g. Triton) (Arnold \& Linke, 2008). As a result, the surfactant solution separates into aqueous and surfactant-enriched phases (Brusca \& Radolf, 1994). Detergents with a low cloud point are preferred, because their application does not lead to protein denaturation. From the Triton family, Triton X-114 has been widely used for membrane protein fractionation due to its cloud point at $22^{\circ} \mathrm{C}$.

\section{Protein fractionation}

Figure 3. 4 presents the mass and protein flows of the phase partitioning using Triton X-114 with SBL. The process involved two phase partitioning, both achieved by Triton $\mathrm{X}-114$ clouding at $37^{\circ} \mathrm{C}$. The dry matter flow depicted in Figure 3. $4 \mathrm{~A}$ distinguishes between the dry matter introduced by the buffer and the dry matter coming from the leaf material. The addition of the Triton X-114 solution allowed solubilisation of the leaf proteins while the system is being diluted. For these calculations, the phase partitioning protocol was done without the leaf material to follow how the surfactant distributed among the different phases, so it only represents an indication of the mass flows.

A second mass balance was made after subtracting the buffer contribution in order to have a clearer view of the distribution of protein within the leaf dry matter (Figure 3. $4 \mathrm{~B}$ ). The surfactant was able to solubilise not only proteins, but also other leaf components. Most of the leaf dry matter was recovered in the first surfactant phase as well as most of the protein. It is expected that the proteins in this fractions are mainly integral membrane proteins (i.e. hydrophobic proteins) (Brusca \& Radolf, 1994; Okamoto et al., 2001) that originate from the solubilisation from the lipid membrane by the surfactant. However, many other components remained in the first surfactant phase, given the fact that the dry matter recovered in this fraction was larger than the mass of all leaf membrane proteins together. Leaf membrane proteins are part of the insoluble protein fractions that constitutes about $50 \%$ of the proteins (Fiorentini \& Galoppini, 1983). Consequently, soluble proteins also 


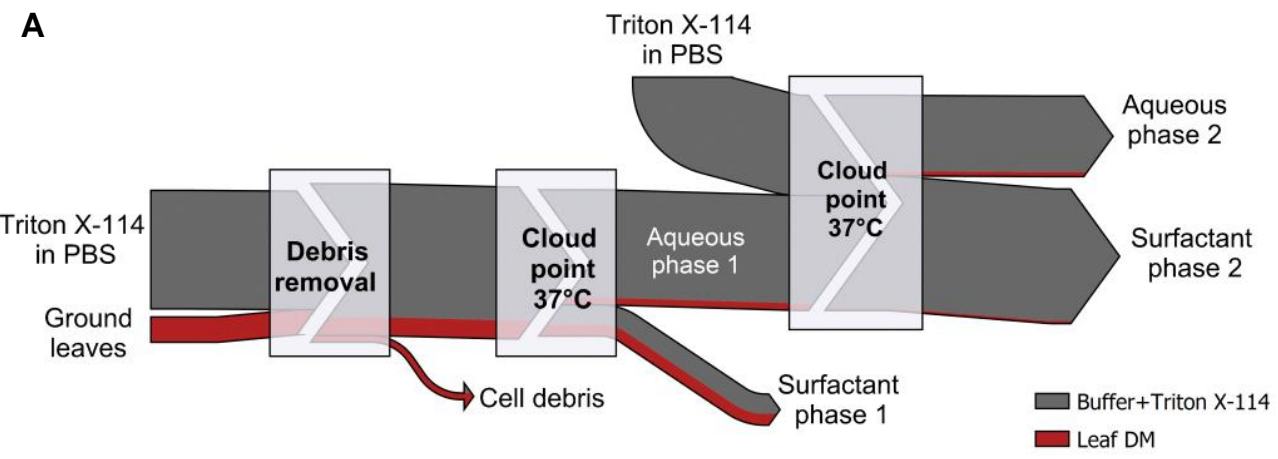

B

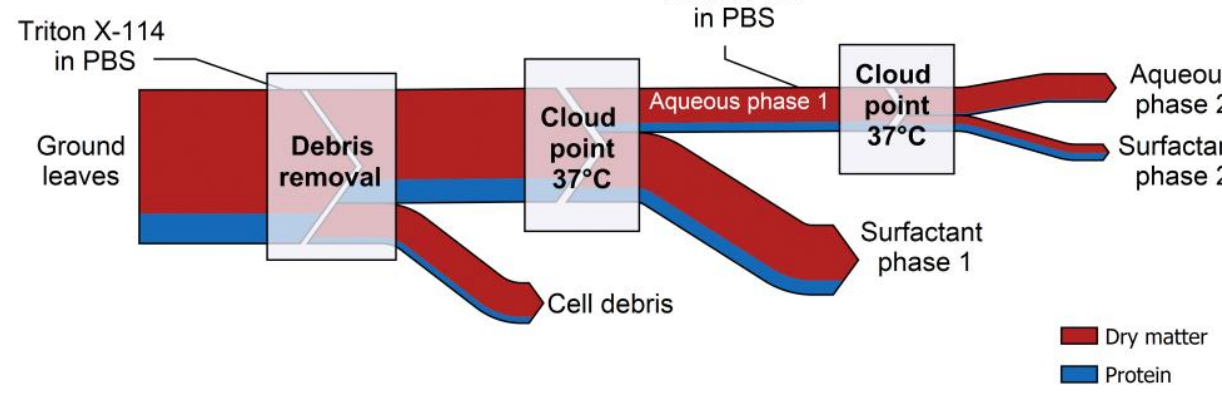

Triton X-114 in PBS

C
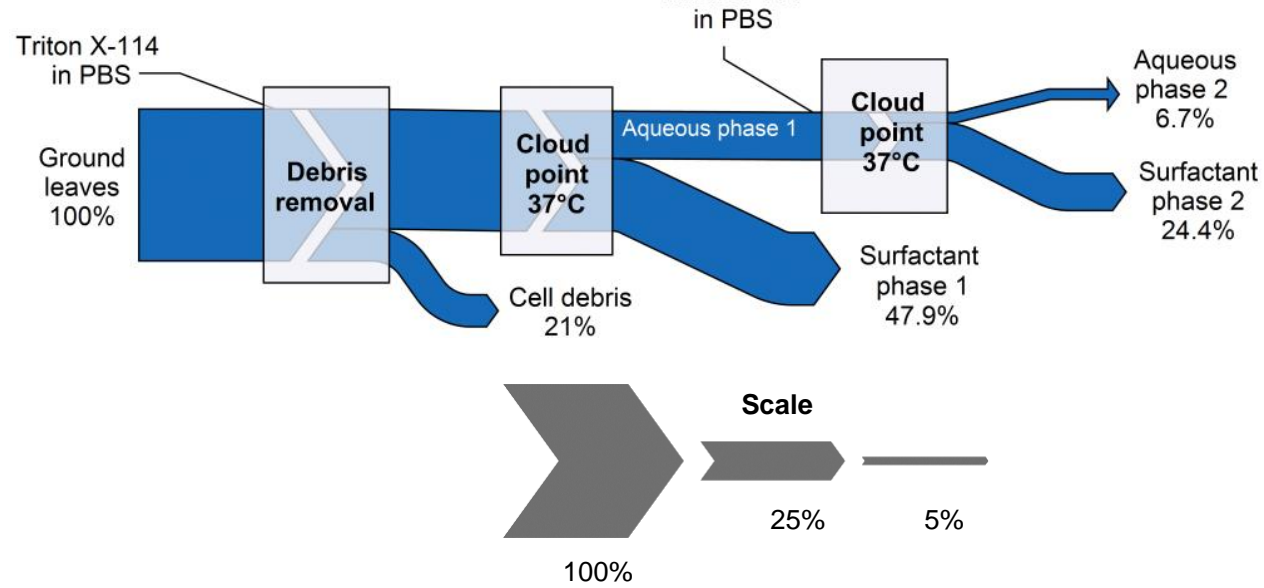

Figure 3. 4. Overall mass and protein flows during Triton X-114 phase partitioning with SBL. (A) Dry matter distribution, distinguishing between leaf and buffer. (B) Protein and dry matter distribution after subtracting the contribution of the buffer from the total mass. (C) Protein distribution, indicating the protein yield in each stream. The thickness of the arrows correlates with the size of the streams as depicted in the scale. 
partitioned to the first surfactant phase. This is an interesting finding that may enable us to isolate both soluble and insoluble proteins in the same fraction.

Most of the surfactant from the second wash was found in a phase that is relatively depleted of other components (Surfactant phase 2). Of course in a larger process one could easily recycle this stream, to minimise the losses of surfactant. In addition, diafiltration of surfactant from aqueous phase 2 and surfactant phase 1 could regain most of the remaining surfactant for the process.

Figure 3. $4 \mathrm{C}$ presents the protein flow along the process. The fact that most of the proteins were found in the first surfactant phase is due to the protein solubilisation achieved with surfactants and the amphiphilic nature of proteins. The effective separation of hydrophobic and hydrophilic proteins depends on their initial solubilisation in the solvents used and the surfactant to protein ratio. Once the different proteins are in solution, the phase separation creates two environments: hydrophilic (aqueous phase) and hydrophobic (surfactant-rich phase). These phases allow the partitioning of the proteins to their best solvent, as well as the partitioning of other compounds present in the sample. The results may well show that the proteins originally solubilise in micelles, which are then disrupted during clouding. While individual soluble proteins might in principle solubilise into the aqueous phase, their encapsulation by the surfactants may have exposed the more hydrophobic groups towards the surfactant, which then forces the proteins into the organic surfactant phase, even though some individual proteins remain in the aqueous phase. This is true for Triton $X$ detergents, which selectively bind to amphiphilic proteins; and in the case of Triton X-114, having a single hydrophobic group is enough for a protein to partition into the detergent phase (Brusca \& Radolf, 1994). The surfactant to protein ratio was not optimised here. The assumed ratio of $10: 1$ is typically used when extracting whole cells or tissues (Brusca \& Radolf, 1994). Higher or lower values are reported depending on the type of membrane being processed (González de la Vara \& Alfaro, 2009), the membrane proteins desired (Brusca \& Radolf, 1994) and the final analytical purpose (e.g. native proteins with biological activity)(Linke et al., 2009). Additional considerations 
to determine the amount of detergent needed are the protein/lipid ratio of the membrane and the detergent used (Arnold \& Linke, 2008). We expect that the development of a separation process on the basis of LCST behaviour would have a different optimum in ratios and concentrations, keeping the latter as low as possible.

After the second phase partitioning, the top aqueous phase had a protein content of $\sim 2 \mathrm{wt} \%(\mathrm{db})$, which accounts for $6.7 \%$ of the leaf proteins. The proteins in this phase are probably the soluble proteins and peripheral membrane proteins (i.e. hydrophilic proteins) (Okamoto et al., 2001), and might be isolated using ultrafiltration or heating and centrifugation. The second surfactant phase contained the proteins that did not partition to either the hydrophobic or the hydrophilic fractions. About $24 \%$ of the leaf proteins were recovered in this fraction. Due to their amphiphilic nature, membrane proteins may change their conformation, or may cluster upon extraction from the membrane and expose both hydrophilic and hydrophobic domains (T. C. Thomas \& McNamee, 1990). This results in partitioning into both aqueous and surfactant phases after extraction. The protein conformation changes are a response to the variations in the physical or chemical environment during extraction caused by solvent $\mathrm{pH}$ and hydrophobicity, ionic strength, temperature and interactions with other cell components (Hedin et al., 2011; Rose et al., 2004). These conformational changes can result in denaturation of the extracted proteins and impair the biological function. However detrimental for some applications, the denatured proteins can still exhibit techno-functional properties for food and retain their nutritional value. This is for instance accepted for industrially produced soy protein isolate in which the protein is completely denatured.

The order of conformational changes is also important. In small protein aggregates, hydrophilic groups are exposed when fractionated with water, whereas hydrophobic groups are exposed when extracted with a surfactant. Therefore, using successive extraction steps with different surfactant buffers can tune the 
conformational changes of the membranes and solubilise different proteins (Arnold \& Linke, 2008).

\section{Chlorophyll content and protein characterisation}

We interpreted the chlorophyll quantification as an indication of the membrane proteins in each phase, because the surfactant is not able to remove the chlorophyll from the extracted membrane proteins and no solvent washing was carried out. Chlorophyll concentration has been used before to indicate the concentration of chloroplastic membranes (i.e. thylakoids) (Emek et al., 2010), which are the most abundant leaf membrane structures and account for most of the leaf membrane proteins (Friso et al., 2004). The chlorophyll quantification and the SDS-page results (Figure 3.5) showed that almost all membrane bound proteins ended up in the first surfactant phase. This fraction (lane $c$ in Figure 3. 5 B) had by far the highest chlorophyll content $(33.2 \mu \mathrm{g} / \mathrm{ml})$, and a different band pattern compared to the aqueous phases (lanes $b$ and $d$ ), which had clear bands corresponding to both rubisco (ribulose-1,5-bisphosphate carboxylase/oxygenase) subunits (53 and $14 \mathrm{kDa}$ ). The amount of membrane proteins in the aqueous phase 1 can be neglected, as seen by the chlorophyll content $(0.4 \mu \mathrm{g} / \mathrm{ml})$ in this fraction. After the second phase partitioning step, the remaining membrane proteins were recovered in the second surfactant phase. The insert in Figure 3. $5 \mathrm{~A}$ gives an overview of the two phase partitioning steps and a clear observation of the chlorophyll in each of the phases.

The phase partitioning results suggest that the protocol fractionates leaf proteins under mild conditions. The membrane proteins partitioned to the surfactant phases, while soluble proteins distributed over the aqueous phases. Moreover, other leaf components (e.g. lipids, carbohydrates) also distributed over all fractions and they were also solubilised by the surfactant. For analytical purposes, the mass flow in Figure 3. 4 B was based on calculations that corrected for the contribution of the surfactant solution. For an industrial scale process, the surfactants should be removed from the different fractions to enable protein analysis. It is fortunate that most surfactant ends up in a stream that is relatively dilute in other components 
(surfactant phase 2), and one could easily recycle this stream. The other streams could for example be diafiltrated to recollect and recycle the surfactants. Several removal techniques are available depending on the surfactant type and the final protein analysis (Arnold \& Linke, 2008).

A

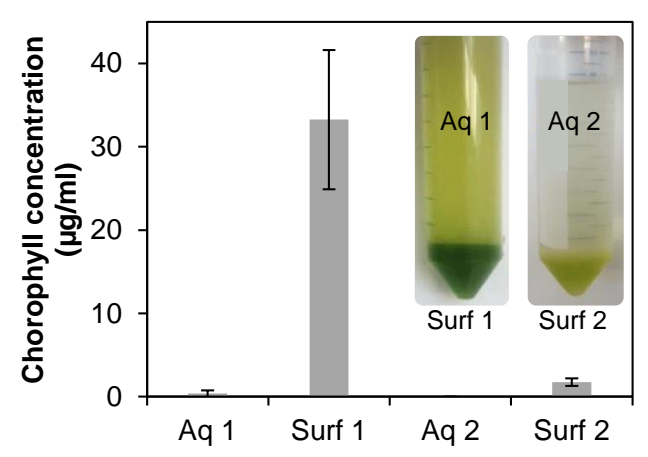

B

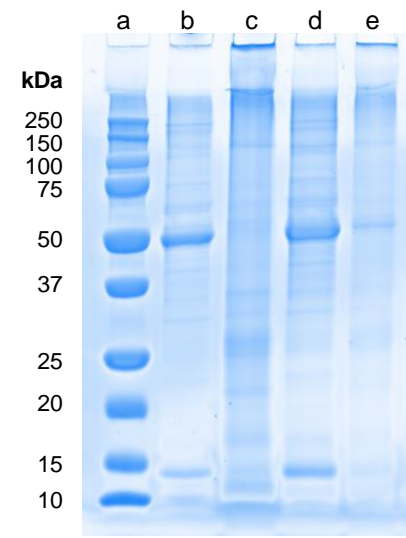

Figure 3. 5. Analysis of the resulting phases after two phase partitioning of SBL with Trion X-114. (A) Chlorophyll concentration of aqueous $(\mathrm{Aq})$ and surfactant (Surf) phases. $n=3$. (Insert) Pictures of the solutions after the two phase partitioning steps. (B) Coomassie blue-stained SDS-Page on a $12 \%$ polyacrylamide gel: a) Molecular weight marker; b) Aqueous phase 1; c) Surfactant phase 1; d) Aqueous phase 2; c) Surfactant phase 2.

\subsubsection{Plant proteins complexity}

The conditions required for plant protein extraction and isolation are defined by the nature of the desired protein. For instance, part of the nature of leaf membrane proteins is determined by the type of interactions between the lipid membrane and other proteins, and with components such as cofactors, chlorophylls and other pigments. Given these interactions, membrane proteins can be classified as peripheral or integral membrane proteins, and processing conditions aim for a specific type of proteins. In the case of peripheral membrane proteins, the proteins are attached to phospholipids and to other membrane proteins by weak electrostatic or van der Waals interactions, hydrogen bonds (Ephritikhine et al., 2004; Hedin et al., 2011; Ohlendieck, 2004); or even covalent anchors (Hedin et al., 2011). In most cases, the peripheral proteins are easily removed by $\mathrm{pH}$ shifts, changes in ionic strength or by using metal chelators (Lin \& Guidotti, 2009; 
Ohlendieck, 2004). Whereas integral membrane proteins are an intrinsic part of the membrane and they anchored by hydrophobic stretches of amino acids, hydrogen bonds or amphiphilic groups covalently linked to the polypeptide chains (Brusca \& Radolf, 1994). This group of membrane proteins can be extracted with detergents (Lin \& Guidotti, 2009; Ohlendieck, 2004), and some of them with organic solvents or alkaline treatments (Ephritikhine et al., 2004). Surprisingly, some proteins exist as both soluble and integral membrane isoforms, thus exhibiting different solubility and interactions within the same sample (Burn, 1988).

Membrane protein are quite heterogeneous in terms of charge, hydrophobicity, post-translational modification and complexation (Ohlendieck, 2004). Soluble protein fractions are generally dominated by a few abundant polypeptide species, such as the soluble rubisco in plant tissues (Rose et al., 2004; W. Wang et al., 2008), while membrane proteins are quite diverse (Lin \& Guidotti, 2009), leading to non-selective behaviour when regarded as single pool of proteins.

A final factor that hinders plant protein extraction is the presence of interfering compounds that may change the proteins during separation, or may interfere with the separation itself. These compounds include proteases and oxidative enzymes, phenolic compounds, carbohydrates, lipids, pigments, and a broad range of secondary metabolites (Carpentier et al., 2005; Rose et al., 2004). In some cases, the extraction process brings the interfering compounds in contact with the proteins, when organelles such as vacuoles release their contents. In other cases, like with chloroplastic membranes, the proteins are already bound to cofactors and pigments, which then interfere with their extraction (Choquet \& Vallon, 2000).

As a result of this great heterogeneity, membrane proteins distribute among different solvents, buffers and solutions, while the soluble rubisco can be isolated more easily. Therefore, it is more difficult to separate the membrane proteins from other components. 


\subsubsection{Food-grade options}

The experiments described above confirm the diversity in the behaviour of membrane proteins. While this requires a complex protocol for analytical purposes, it is not a problem when designing an isolation process that should isolate the membrane proteins as a total fraction, with or without soluble proteins. In proteomics, membrane proteins are extracted by methods that involve many variations of physical treatments, solvents and buffers, and each setting of extraction conditions isolates specific proteins. Translating this knowledge into a food-grade option implies a change of perspective, because some of the harsh conditions are difficult to reach using food-grade reagents, aqueous extraction and mild processing only. Fortunately, the resolution between the proteins is also not needed for most food applications.

The fundamental steps in the protocols used above involve: (1) tissue disruption, (2) enzymatic inhibition, (3) removal of interfering compounds, and (4) protein fractionation and purification. For food ingredient production, different challenges can be identified, i.e. final yield, desired properties of the isolated proteins (e.g. purity, techno-functionality, bioavailability and nutritional value), and the advantages compared to similar isolated proteins (e.g. yield per ha, sustainability and economic feasibility). Therefore, the fundamental steps defined for proteomic protocols were analysed from a food point of view, together with the results from food-grade extraction experiments.

(1) The tissue disruption is easily done by mechanical treatment of the leaf material and plays the same important role as for proteomic extraction of releasing cellular content. The food-grade extraction made in this study used a twin screw press that disrupts the leaf tissue and simultaneously filters the leaf juice. Part of the fibrous pulp builds a filtering bed around the screws and the rest is extruded out at the end of the screws. This type of screw press is the most effective for pulping leafy crops; although a combination of pressing and disk milling can yield higher cell disruption, but such combination is more energy intensive. Mechanical pressing is usually followed by filtration to 
remove fibrous leaf pulp and produce a clear leaf juice that is further processed (Bals et al., 2012).

(2) The enzymatic inhibition achieved by TCA and the low temperature conditions are also needed for food proteins to preserve protein functionality. For instance, protein bioavailability and nutritional value could be reduced after the complexation of proteins and polyphenols or after oxidative reactions (Chiesa \& Gnansounou, 2011). TCA inhibits enzyme activity by lowering the $\mathrm{pH}$. This inactivation can also be achieved with $\mathrm{HCl}$ or $\mathrm{H}_{2} \mathrm{SO}_{4}$, which are commonly used in food applications (Dijkstra et al., 2003). A decrease in $\mathrm{pH}$ precipitates the proteins, which can then be further processed. Figure 3. $6 \mathrm{~A}$ presents the protein content and protein yield of precipitates from SBL juice after $\mathrm{pH}$ shift with $\mathrm{HCl}$. The highest protein yield was achieved at $\mathrm{pH} 3.5$, having a protein content of about $34 \mathrm{wt} \%(\mathrm{db})$. Higher $\mathrm{pH}$ (4.5) resulted in lower protein yield, mainly due to the isoelectric point of leaf proteins that is around 4.5 (Lamsal et al., 2007), but it ranges between 3.4 and 5.5 (Emek et al., 2010). Similar results were observed with alfalfa leaves. Most proteins precipitate at $\mathrm{pH} 3.5$ 4.0 , together with a large amount of non-protein material, which explains the low protein purity of such a protein precipitate (Bals, 2012).

A

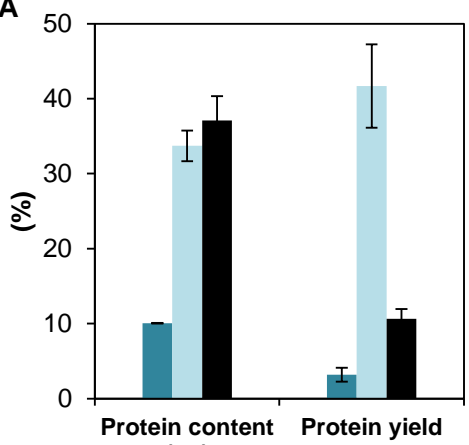

(db)
B

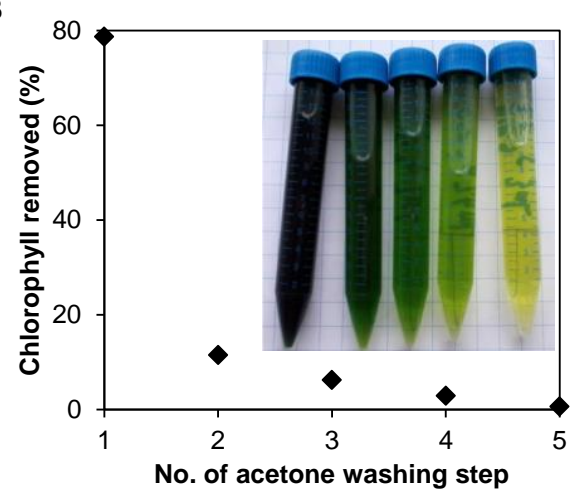

Figure 3. 6. ( A) Protein content and yield in pellet after $\mathrm{pH}$ precipitation. The protein content is expressed as wt\% in dry basis; the protein yield is calculated as grams of protein in the sample per grams of protein in the starting leaf material. The control sample had a $\mathrm{pH}$ of $6.1 \pm 0.1$. The $\mathrm{pH}$ was adjusted with $1 \mathrm{M} \mathrm{HCl}$. $n=3$. (B) Percentage of chlorophyll removed after subsequent $80 \%$ acetone washes. 
In addition to $\mathrm{HCl}$ or $\mathrm{H}_{2} \mathrm{SO}_{4}$ to lower the $\mathrm{pH}$ and recover leaf proteins, sodium metabisulphite can be added to prevent enzymatic oxidation and to retain the nutritional value of the extracted proteins. The latter is achieved by decreasing the oxidation of the sulphur-containing amino acids cysteine and methionine, which are commonly low in leafy crops. This has been reported for fresh alfalfa leaves, which was treated with $200 \mathrm{mg} / \mathrm{kg}$ of sodium metabisulphite before processing (Fiorentini \& Galoppini, 1983).

(3) The third challenge for proteomic protocols is the removal of interfering compounds. For food applications, those compounds affect potential technofunctionality, nutritional value and digestibility (Dijkstra et al., 2003) and they must be removed or neutralised. Polyphenols associate with the protein, rendering it brown or black, and may seriously hinder any application of the proteins. Solvent mixtures have been reported to remove phenolic compounds: methanol/water mixture with tobacco leaves (Teng \& Wang, 2011) and water/2-propanol and alcohol/water with alfalfa leaves (Dijkstra et al., 2003). Ethanol/water mixtures can successfully extract polyphenols from wet plant material like okara. This soy waste stream is another polyphenol-rich plant material with a moisture content comparable to leaves and the use of ethanol/water mixtures improves the extraction process (Lena Jankowiak, Trifunovic, et al., 2014).

Other interfering compounds that should be removed from leaf extracts are the pigments, especially chlorophylls that are responsible for the green colour. The intense green colour and grassy off-flavour of leaf extracts limit the range of food products in which leaf protein extract can be applied. The pigment removal can be achieved by solvent washing in a similar way as done in the solvent extraction protocol for proteomics. For this purpose, $80 \%$ acetone was chosen to wash green protein precipitate obtained from SBL. Acetone is classified as a food-grade solvent together with ethanol and methanol, although acetone use is limited to country/area regulations and its acceptance is decreasing. After 5 subsequent washes with acetone, most of the chlorophyll was removed from dried SBL green pellet (Figure 3. 6B), 
producing a whitish precipitate that retained its initial protein content $(\sim 27$ wt $\%, d b)$. Similarly, chlorophyll has been removed from dried alfalfa juice by extraction with $95 \%$ ethanol, producing a chlorophyll free protein concentrate ( 42 wt\% protein) (Bals et al., 2012).

Some of the interfering compounds have actually important biofunctional value once they have been extracted, like the antioxidant activity of polyphenols and pigments found in leaf extracts (Chiesa \& Gnansounou, 2011; Shahidi \& Ambigaipalan, 2015). Therefore, their removal during protein extractions should be considered as a simultaneous extraction, possibly giving valuable by-products.

An interesting alternative to enzyme inhibition (2) and removal of interfering compounds (3) is the use of supercritical $\mathrm{CO}_{2}$. Under specific conditions, $\mathrm{scCO}_{2}$ can work as an acidic solvent to induce protein precipitation and can solubilise low molecular weight compounds (<250) such as polyphenols or compounds with weakly polar groups such as lipids, cholesterol, aldehydes, ethers, esters and ketones (Raventós et al., 2002). When the $\mathrm{CO}_{2}$ is in contact with the water of the extracted material, it forms and dissociates carbonic acid that lowers the $\mathrm{pH}$ of the aqueous phase to approximately 3 (Toews et al., 1995). This $\mathrm{pH}$-value can lead to leaf protein precipitation while pigments and polyphenols are solubilised in the scfluid. The $\mathrm{pH}$ reached during extraction is also important for the stability and functionality of the pigments and polyphenols extracted, e.g. antioxidant activity (Junior Maróstica et al., 2010). $\mathrm{ScCO}_{2}$ extraction has been used for the extraction of carotenoids and chlorophylls from leaf protein concentrate (FAVATI et al., 1988) and olive husk (Gracia et al., 2011), among other materials. The extracted molecules are used as food-grade colorants and antioxidants. After scCO2 extraction, the remaining solid material could be further processed for protein extraction.

(4) Protein fractionation and purification is mainly achieved by surfactants and different solvents (e.g. phenol/SDS, Triton X-114 and phosphate buffer). As mentioned earlier, the isolation of membrane proteins for food applications 
can yield a final fraction with or without soluble proteins, allowing more flexibility on the fractionation step. We envisage that the fractionation may also be done with food-grade surfactants with similar clouding properties as reported here with Triton X-114. Triton X-100 and other polyoxyethylene derivatives like Tween 80 (polysorbate 80 ) are considered food-grade and could be used for protein extraction. Triton X-100 has a higher cloud point temperature $\left(65^{\circ} \mathrm{C}\right)$, which can be lowered by increasing the ionic strength of the solution (Arnold \& Linke, 2008). Tween 80 is frequently used for membrane protein solubilisation and it can be added up to $1-10 \mathrm{wt} \%$ in food (European-Commission, 2011); although its cloud point occurs at high temperature $\left(93^{\circ} \mathrm{C}\right.$ ) (Arnold \& Linke, 2008) requiring a different removal method. Nevertheless, the fractionation with surfactants is not selective for protein material and other leaf components are co-solubilised by the surfactant and distributed among the resulting fractions. Several purification steps are then needed to achieve protein enrichment.

A final point to discuss from a food ingredient production perspective is the protein yield, which can define the feasibility of a process or crop use. With the extraction processes available, the final protein yield achieved with leaves is much lower than for other plant sources that are already used at industrial scale. Values between $6 \%$ final protein yield have been reported for alfalfa leaves, with a protein content of $74 \%$ (Dijkstra et al., 2003). Our own yields reported in this paper start at around $8 \%$, but it is possible to get much higher yields, albeit at the cost of the purity (see figure 2).

Even though the yield depends on the extraction method, these values are not close to those of common plant sources like soy (50-60\% yield, $83 \%$ purity) (van der Goot et al., 2016), triticale (53-59\% yield, $83 \%$ purity) or lupine (60\% yield, 90\%) (Dijkstra et al., 2003). Therefore, food processes with leaves would benefit from total leaf fractionation, rather than protein fractionation (i.e. soluble and insoluble proteins). Such leaf fractionation process could deliver protein-rich fractions with a higher protein yield and contribute to resource optimisation. To assess the potential applications of such fractions, functional properties need to be 
explored as it has been done with novel fractions from other leaves, such as thylakoids from spinach (Emek et al., 2010).

\subsection{Conclusions}

Protein isolation protocols from the proteomics field were used to understand the solubilisation and fractionation behaviour of membrane proteins from sugar beet leaves. Four fundamental steps could be discerned: (1) Mechanical disruption of the cell matrix without activating proteolytic or oxidative enzymes. (2) Acidification to permanently inhibit enzymatic activity and to precipitate proteins. (3) Protein purification to remove interfering components, such as pigments and polyphenols and other components such as carbohydrates. (4) Protein fractionation to reach the wanted group of proteins.

In contrast to the isolation of only the soluble rubisco, membrane proteins have great diversity, and therefore generally end up in different fractions, making their isolation from other components difficult. The membrane protein heterogeneity does not allow a total membrane protein extraction by a unique method or even combinations of processing steps. However, their large heterogeneity also points to the possibility of creating different fractions with different physicochemical properties, by changing process conditions or selecting different fractions from the same process. Moreover, other leaf components distribute among the resulting fractions together with the desired proteins. These other compounds lower protein enrichment and demand extra purification steps while compromising the final yield.

\section{Acknowledgments}

The authors thank Charl Lu and Kris Kuppen for their contribution to the literature review and practical work; Twan America and Ingrid van der Meer from Plant Research International at Wageningen University (The Netherlands) for their contribution to the discussions, and the Technology Foundation STW (The Netherlands) and Royal Cosun (The Netherlands) for their financial and project support. 


\section{References}

Arnold, T., \& Linke, D. (2008). The use of detergents to purify membrane proteins. Current Protocols in Protein Science, Chapter 4, Unit 4 8 $1-4 \quad 8$ 30. doi: 10.1002/0471140864.ps0408s53

Bals, B., Dale, B. E., Balan, V., Bergeron, C., Carrier, D. J., \& Ramaswamy, S. (2012). Recovery of leaf protein for animal feed and high-value uses Biorefinery CoProducts (pp. 179-197): John Wiley \& Sons, Ltd.

Brusca, J. S., \& Radolf, J. D. (1994). [17] Isolation of integral membrane proteins by phase partitioning with triton X-114. Methods in Enzymology, 228, 182-193.

Burn, P. (1988). Talking point Amphitropic proteins: a new class of membrane proteins. Trends in Biochemical Sciences, 13(3), 79-83. doi: 10.1016/0968-0004(88)90043-6

Carpentier, S. C., Witters, E., Laukens, K., Deckers, P., Swennen, R., \& Panis, B. (2005). Preparation of protein extracts from recalcitrant plant tissues: An evaluation of different methods for two-dimensional gel electrophoresis analysis. PROTEOMICS, 5(10), 2497-2507. doi: 10.1002/pmic.200401222

Chiesa, S., \& Gnansounou, E. (2011). Protein extraction from biomass in a bioethanol refinery--possible dietary applications: Use as animal feed and potential extension to human consumption. Bioresource Technology, 102(2), 427-436. doi: 10.1016/j.biortech.2010.07.125

Choquet, Y., \& Vallon, O. (2000). Synthesis, assembly and degradation of thylakoid membrane proteins. [Biochimie]. Biochemie, 82(6-7), 615-634. doi: 10.1016/s03009084(00)00609-x c2 - 10946111

Dijkstra, D. S., Linnemann, A. R., \& van Boekel, T. A. (2003). Towards sustainable production of protein-rich foods: appraisal of eight crops for Western Europe. PART II: Analysis of the technological aspects of the production chain. Critical Reviews in Food Science and Nutrition, 43(5), 481-506.

Emek, S. C., Szilagyi, A., Akerlund, H. E., Albertsson, P. A., Kohnke, R., Holm, A., \& Erlanson-Albertsson, C. (2010). A large scale method for preparation of plant thylakoids for use in body weight regulation. Preparative Biochemistry \& Biotechnology, 40(1), 13-27. doi: 10.1080/10826060903413057

Ephritikhine, G., Ferro, M., \& Rolland, N. (2004). Plant membrane proteomics. Plant Physiology and Biochemistry, 42(12), 943-962. doi: 10.1016/j.plaphy.2004.11.004

European-Commission. (2011). Commission Regulation (EU) No 1129/2011. Official Journal of the European Union.

FAVATI, F., KING, J. W., FRIEDRICH, J. P., \& ESKINS, K. (1988). Supercritical CO2 extraction of carotene and lutein from leaf protein concentrates. Journal of Food Science, 53(5), 1532-1536.

Fiorentini, R., \& Galoppini, C. (1983). The proteins from leaves. Qualitas Plantarum-Plant Foods For Human Nutrition, 32, 335-350. 
Friso, G., Giacomelli, L., Ytterberg, A. J., Peltier, J. B., Rudella, A., Sun, Q., \& Van Wijk, K. J. (2004). In-Depth Analysis of the Thylakoid Membrane Proteome of Arabidopsis thaliana Chloroplasts: New Proteins, New Functions, and a Plastid Proteome Database. Plant Cell, 16(2), 478-499. doi: 10.1105/tpc.017814

González de la Vara, L. E., \& Alfaro, B. L. (2009). Separation of membrane proteins according to their hydropathy by serial phase partitioning with Triton X-114. Analytical Biochemistry, 387(2), 280-286. doi: 10.1016/j.ab.2009.01.035

Gracia, I., Rodríguez, J. F., de Lucas, A., Fernandez-Ronco, M. P., \& García, M. T. (2011). Optimization of supercritical CO 2 process for the concentration of tocopherol, carotenoids and chlorophylls from residual olive husk. The Journal of Supercritical Fluids, 59, $72-77$.

Hedin, L. E., Illergard, K., \& Elofsson, A. (2011). An introduction to membrane proteins. Journal of proteome research, 10(8), 3324-3331. doi: 10.1021/pr200145a

Jacobs, D. I., van der Heijden, R., \& Verpoorte, R. (2000). Proteomics in plant biotechnology and secondary metabolism research. Phytochemical Analysis, 11(5), 277-287. doi: 10.1002/1099-1565(200009/10)11:5<277::aid-pca535>3.0.co;2-s

Jankowiak, L., Trifunovic, O., Boom, R. M., \& van der Goot, A. J. (2014). The potential of crude okara for isoflavone production. Journal of Food Engineering, 124, 166-172. doi: 10.1016/j.jfoodeng.2013.10.011

Junior Maróstica, M. R., Leite, A. V., \& Dragano, N. R. V. (2010). Supercritical fluid extraction and stabilization of phenolic compounds from natural sources - review (supercritical extraction and stabilization of phenolic compounds). Open Chemical Engineering Journal, 4(1), 51-60.

Kamal, A. H. M., Cho, K., Choi, J.-S., Bae, K.-H., Komatsu, S., Uozumi, N., \& Woo, S. H. (2013). The wheat chloroplastic proteome. Journal of Proteomics, 93, 326-342. doi: 10.1016/j.jprot.2013.03.009

Lamsal, B. P., Koegel, R. G., \& Gunasekaran, S. (2007). Some physicochemical and functional properties of alfalfa soluble leaf proteins. LWT - Food Science and Technology, 4O(9), 1520-1526. doi: 10.1016/j.Iwt.2006.11.010

Lim, T. K. (2016). Edible medicinal and non medicinal plants. Volume 10, Modified stems, roots, bulbs. Dordrecht: Springer.

Lin, S. H., \& Guidotti, G. (2009). Purification of membrane proteins. Methods in Enzymology, 463, 619-629. doi: 10.1016/s0076-6879(09)63035-4

Linke, D., Richard, R. B., \& Murray, P. D. (2009). Chapter 34 Detergents: An Overview Methods in Enzymology (Vol. Volume 463, pp. 603-617): Academic Press.

Ohlendieck, K. (2004). Extraction of Membrane Proteins. In P. Cutler (Ed.), Protein Purification Protocols (pp. 283-293). Totowa, NJ: Humana Press.

Okamoto, T., Schwab, R. B., Scherer, P. E., \& Lisanti, M. P. (2001). Analysis of the Association of Proteins with Membranes Current Protocols in Cell Biology: John Wiley \& Sons, Inc. 
Porra, R., Thompson, W., \& Kriedemann, P. (1989). Determination of accurate extinction coefficients and simultaneous equations for assaying chlorophylls $a$ and $b$ extracted with four different solvents: verification of the concentration of chlorophyll standards by atomic absorption spectroscopy. Biochimica et Biophysica Acta (BBA)-Bioenergetics, 975(3), 384-394.

Raventós, M., Duarte, S., \& Alarcón, R. (2002). Application and possibilities of supercritical $\mathrm{CO} 2$ extraction in food processing industry: An overview. Food Science and Technology International, 8(5), 269-284. doi: 10.1177/1082013202008005451

Rose, J. K. C., Bashir, S., Giovannoni, J. J., Jahn, M. M., \& Saravanan, R. S. (2004). Tackling the plant proteome: practical approaches, hurdles and experimental tools. The Plant Journal, 39(5), 715-733. doi: 10.1111/j.1365-313X.2004.02182.x

Shahidi, F., \& Ambigaipalan, P. (2015). Phenolics and polyphenolics in foods, beverages and spices: Antioxidant activity and health effects - A review. Journal of Functional Foods, 18, 820-897. doi: 10.1016/j.jf.2015.06.018

Tamayo Tenorio, A., Gieteling, J., de Jong, G. A. H., Boom, R. M., \& van der Goot, A. J. (2016). Recovery of protein from green leaves: Overview of crucial steps for utilisation. Food Chemistry, 203, 402-408. doi: 10.1016/j.foodchem.2016.02.092

Teng, Z., \& Wang, Q. (2011). Extraction, identification and characterisation of waterinsoluble proteins from tobacco biomass. Journal of the Science of Food and Agriculture, 92, 1368-1374.

Thomas, T. C., \& McNamee, M. G. (1990). Purification of membrane proteins. Methods in Enzymology, 182, 499-520.

Toews, K. L., Shroll, R. M., Wai, C. M., \& Smart, N. G. (1995). pH-Defining Equilibrium between Water and Supercritical CO2. Influence on SFE of Organics and Metal Chelates. Analytical Chemistry, 67(22), 4040-4043.

van der Goot, A. J., Pelgrom, P. J. M., Berghout, J. A. M., Geerts, M. E. J., Jankowiak, L., Hardt, N. A., . . Boom, R. M. (2016). Concepts for further sustainable production of foods. Journal of Food Engineering, 168, 42-51. doi: 10.1016/j.jfoodeng.2015.07.010

van Krimpen, M. M., Bikker, P., van der Meer, I. M., van der Peet-Schwering, C. M. C., \& Vereijken, J. M. (2013). Cultivation, processing and nutritional aspects for pigs and poultry of European protein sources as alternatives for imported soybean products. Wageningen, The Netherlands: Wageningen UR Livestock Research.

Wang, W., Scali, M., Vignani, R., Spadafora, A., Sensi, E., Mazzuca, S., \& Cresti, M. (2003). Protein extraction for two-dimensional electrophoresis from olive leaf, a plant tissue containing high levels of interfering compounds. Electrophoresis, 24(14), 23692375. doi: $10.1002 /$ elps.200305500

Wang, W., Tai, F., \& Chen, S. (2008). Optimizing protein extraction from plant tissues for enhanced proteomics analysis. Journal of separation science, 31(11), 2032-2039. doi: $10.1002 / j s s c .200800087$ 
Wang, W., Vignani, R., Scali, M., \& Cresti, M. (2006). A universal and rapid protocol for protein extraction from recalcitrant plant tissues for proteomic analysis. Electrophoresis-An International Journal, 27(13), 2782-2786. 


\section{4 \\ Interfacial properties and emulsification performance of thylakoid membrane fragments}

\section{Highlight}

Composition and structure of thylakoid fragments determine interfacial behaviour and emulsifying capacity, characterised by elastic interfacial network and droplet aggregation

This chapter has been published as:

Tamayo Tenorio, A., de Jong, E. W. M., Nikiforidis, C. V., Boom, R. M., \& van der Goot, A. J. Interfacial properties and emulsification performance of thylakoid membrane fragments. Soft Matter (2017), vol 13, pages 608-618. 


\section{Abstract}

Thylakoids membranes are sophisticated, dynamic structures found in plant leaves, composed of protein complexes in a dynamic lipid matrix. The interfacial absorption dynamics and viscoelasticity of thylakoid membranes fragments were measured to assess the properties of the interfacial layer and to elucidate an emulsifying mechanism that includes the role of thylakoid's composition and 3D structure. Thylakoid membranes were extracted from sugar beet leaves by a series of buffer washing, filtration and centrifugation. The extract containing the intact thylakoid membranes was suspended in water through high-pressure homogenisation, which disrupted the structure into membrane fragments. Thylakoid fragments showed surface and interfacial behaviour similar to soft particles or pickering stabilisers with slow adsorption kinetics. After adsorption, an elastic and stable thin film was formed, indicating formation of new interactions between adjacent thylakoid fragments. In an emulsion, thylakoid fragments stabilised oil droplets against coalescence, despite droplet aggregation occurring already during emulsification. Droplet aggregation occurred by steric and electrostatic bridging, which in turn forms a 3D network where the oil droplets are immobilised, preventing further droplet coalescence or aggregation. It was concluded that both composition and structure of thylakoid fragments determine their emulsifying properties, conferring potential for encapsulation systems, where the search for natural materials is gaining more attention. 


\subsection{Introduction}

Plant leaves are rich in thylakoids; membrane structures that are responsible for the photosynthetic reactions. These membranes structures are one of the most abundant biological membranes in nature and are the most complex regarding composition, structure and function (Ruban \& Johnson, 2015). Thylakoid membranes structures comprise protein complexes in a dynamic lipid matrix, which enable the efficient conversion of light energy into chemical energy.

Thylakoids are located in the chloroplasts of green leaves in the form of stacks (granal thylakoids) that are interconnected by non-stacked lamellae (stromal thylakoids) (Rottet et al., 2015). These two domains are organised in a complex 3D network that is facilitated by the special composition of thylakoid membranes (Nevo et al., 2009). Thylakoids consist of $60-65 \mathrm{wt} \%$ proteins and $35-40 \mathrm{wt} \%$ lipids (Kirchhoff et al., 2002; Sprague, 1987; Staehelin \& van der Staay, 1996). The thylakoid proteins are protein complexes that are unevenly distributed within the membrane; their highly specialised functions explain their complex composition and 3D arrangement. Unlike most eukaryotic membranes, thylakoid lipids are poor in phospholipids $(\sim 5-12 \mathrm{wt} \%)$, but composed of galactolipids like monogalactosyldiacylglycerol (MGDG; 50\%), digalactosyldiacylglycerol (DGDG; $\sim 30 \%$ ), and sulfoquinovosyldiacylglycerol (SQDG; 5-12\%) (Loll et al., 2007). Both proteins and lipids in the thylakoid membranes adopt an intricate but dynamic structure (Ruban \& Johnson, 2015), showing transitions between conformations (e.g. bilayer to hexagonal phases) to enable enzyme activity (Loll et al., 2007) or to respond to stress conditions (Sprague, 1987).

Their sophisticated and dynamic structure motivates the study of thylakoids as a biobased material for valuable applications, as a response to the current need for resource optimisation and demand for natural ingredients. The use of more intact parts present in biomass is a promising route to reach those goals. Thylakoids are known to stabilise oil droplets (emulsifiers) and exhibit satiation effect upon consumption (Erlanson-Albertsson \& Albertsson, 2015; Marilyn Rayner et al., 2011), which has been attributed to slow digestion rate of the thylakoids and the 
subsequent release of satiety hormones, together with lipolysis inhibition (Erlanson-Albertsson \& Albertsson, 2015). Both the emulsifying ability and slow digestibility make thylakoids an excellent candidate as stabilisers of oil capsules for targeted release of healthy compounds. A further understanding of their functional properties may lead to advanced applications in foods, cosmetics and pharmaceuticals.

Little is known about the emulsifying mechanism and interfacial properties of thylakoid membranes (Östbring et al., 2015; Marilyn Rayner et al., 2011) and no literature reports on how these aspects are linked to their composition and $3 \mathrm{D}$ structure. It can be easily hypothesised that both proteins and lipids play an important role in droplet stabilisation. The interfacial properties of the protein/lipid complexes can be analysed based on adsorption dynamics and dilatational rheology analysis. The adsorption dynamics provide a deeper understanding of the kinetics of molecules towards an interface, while compression/expansion measurements define the interfacial viscoelasticity of the adsorbed layer through the dilatational modulus.

In this study, we extracted thylakoid membranes from sugar beet leaves based on protocols developed for photosynthesis analysis, rendering a rather pure thylakoid isolate. The characterisation of the isolated thylakoids focused on their technological functionality as emulsifiers. Their interfacial absorption and viscoelasticity were measured to assess the properties of the interfacial film. These fundamental measurements were further used to build a hypothesis on the emulsification mechanism with thylakoids as emulsifying structures. The discussion describes the possible relations of the interfacial behaviour with the thylakoid's composition and native 3D arrangements. Moreover, extraction of thylakoids from side streams like sugar beet leaves, constitutes a high value application for leafy biomass that takes advantage of functional structures present in nature (Angelica Tamayo Tenorio, Gieteling, et al., 2016). 


\subsection{Experimental section}

\subsubsection{Materials}

Agarose, EDTA (Ethylenediaminetetraacetic acid), glutaral-dehyde, hydrochloric acid, Hepes ((4-(2-hydroxyethyl)-1-piperazineethanesulfonic acid), osmium oxide $\left(\mathrm{OsO}_{4}\right)$, potassium ferricyanide, sodium cacodylate, sodium chloride $(\mathrm{NaCl})$, sodium hydroxide $(\mathrm{NaOH})$, Spurr resin and tricine were obtained from Sigma Aldrich (St. Louis, MO, USA). Magnesium chloride $\left(\mathrm{MgCl}_{2}\right)$, potassium hydroxide $(\mathrm{KOH})$ and D-sorbitol were obtained from Merck (Darmstadt, Germany). Sunflower oil was obtained from a local supermarket and used without further purification, except for interfacial tension measurements where the oil was stripped by means of alumina (MP Alumina N-Super I, MP Biomedicals, Germany) as described by Berton et al (2011). Milli-Q water was used in all the experiments.

\subsubsection{Thylakoids extraction}

Sugar beet leaves from mature plants were harvested prior to thylakoid extraction from a sugar beet production field in Wageningen, The Netherlands. Only leaf blades were used for extraction. The thylakoid extraction protocol was based on that of Casazza et al. (2001) and Joly \& Carpentier (2011) and is depicted in Figure 4. 1. The fresh leaves were blended in a kitchen blender Waring 8011EG (Waring, Torrington, USA), three times for $6 \mathrm{~s}$ with buffer 1 ( $0.4 \mathrm{M}$ sorbitol, $5 \mathrm{mM} \mathrm{MgCl}_{2}$, $20 \mathrm{mM}$ tricine/ $\mathrm{KOH}$ at $\mathrm{pH} 7.8,5 \mathrm{mM}$ EDTA), in a leaf-to-buffer weight ratio of 1:5. The homogenate was passed through four layers of cheese cloth and the retentate was discarded. After centrifugation $\left(10,000 \mathrm{~g}, 30 \mathrm{~min}, 4^{\circ} \mathrm{C}\right)$, the top layer of the pellet was recovered and re-suspended in buffer $2\left(0.3 \mathrm{M}\right.$ sorbitol, $5 \mathrm{mM} \mathrm{MgCl}_{2}$, $20 \mathrm{mM}$ tricine/ $\mathrm{KOH}$ at $\mathrm{pH} 7.8,2.5 \mathrm{mM}$ EDTA). After a second centrifugation $\left(10,000 \mathrm{~g}, 30 \mathrm{~min}, 4^{\circ} \mathrm{C}\right)$, the top part of the pellet was recovered and re-suspended in buffer 3 (3.5 mM EDTA, $20 \mathrm{mM}$ Hepes/KOH pH 7.5). After a final centrifugation at the same conditions, the top part of the pellet was collected and stored at $-18^{\circ} \mathrm{C}$. This pellet fraction is referred to as "thylakoid extract". 


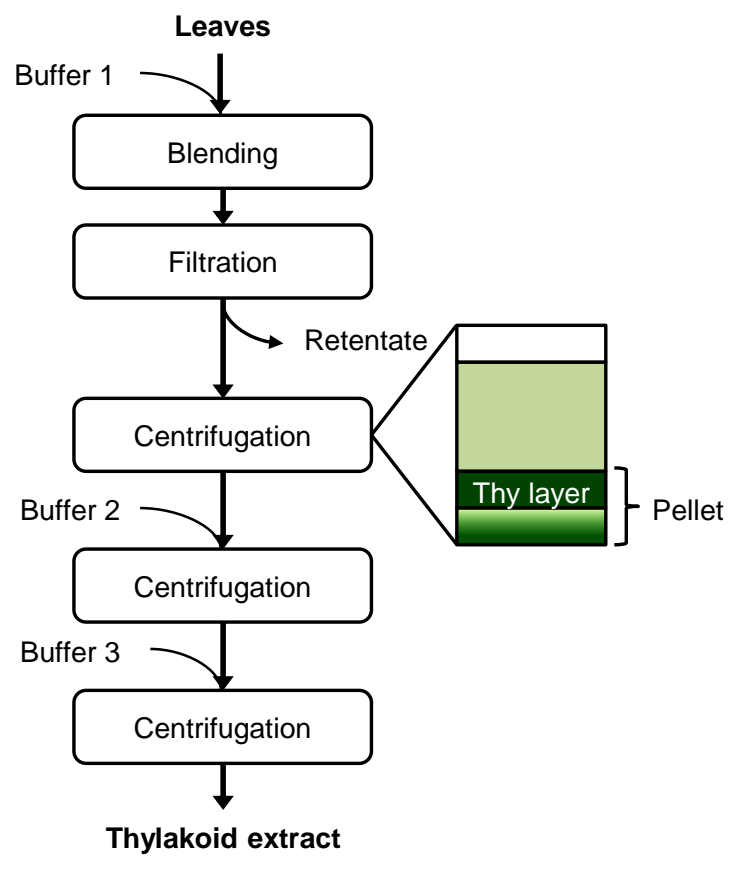

Figure 4. 1. Extraction protocol of thylakoid membranes from leaves. At each centrifugation step, only the thylakoid-containing layer was recovered to continue the protocol. Thy = thylakoids.

\subsubsection{Extract composition}

The moisture content was determined gravimetrically with samples that were dried in an oven at $50^{\circ} \mathrm{C}$ for $48 \mathrm{~h}$. The nitrogen content of dry samples was measured in duplicate by Dumas analysis (NA 2100 Nitrogen and Protein Analyser, ThermoQuest-CE Instruments, Rodeno, Italy). Nitrogen values were converted to protein values using a conversion factor of 6.25 with methionine as standard. Total dietary fibre was determined with a Megazyme assay kit (Megazyme International, Bray, Ireland) according to AACC method 32-05.01 (AACC, 1983c). Ash and fat content were determined with AACC method 08-01 and method 30-25, respectively (AACC, 1983a, 1983b).

\subsubsection{Zeta potential measurements}

The $\zeta$-potential was measured in triplicate as a function of $\mathrm{pH}$ by a Zetasizer (Malvern Instruments, Worcestershire, United Kingdom) with an autotitrator 
(Malvern Instruments, Worcestershire, United Kingdom) at pH between 2.0-10.0. A thylakoid dispersion $(0.013 \% \mathrm{w} / \mathrm{v})$ was prepared by homogenisation. The samples were diluted $\sim 1000$ times in Milli-Q water before analysis.

\subsubsection{Surface tension}

Homogenised thylakoid dispersions $(0.01,0.06,0.13$ and $0.25 \% \mathrm{w} / \mathrm{v})$ were analysed in triplicate with a Wilhelmy plate (Wägezelle Kraftaufnehmer Q11, HBM, Darmstadt, Germany). The concentrations refer to the amount of solids. The surface tension measurements were done over $4 \mathrm{~h}$ of immersing the plate in the solution; this time interval was appropriate to reach a final steady value $\left( \pm 0.5 \mathrm{mN} \cdot \mathrm{m}^{-1}\right)$ at $25^{\circ} \mathrm{C}$.

\subsubsection{Interfacial tension}

The interfacial tension of a thylakoid dispersion $(0.001 \% \mathrm{w} / \mathrm{v})$ was measured for $24 \mathrm{~h}$ in an automated drop tensiometer (Tracker, Teclis-instruments, Tassin, France). A pendant oil drop was formed at the tip of a stainless steel capillary (3 $\mathrm{mm}$ diameter), immersed in the thylakoid dispersion. Measurements were made at room temperature and stripped sunflower oil was used. The interfacial tension data measured over time were analysed by fitting to the following equation:

$$
\gamma(t)=\gamma_{\infty}+\gamma_{1} e^{-\frac{t}{t_{1}}}+\gamma_{2} e^{-\frac{t}{t_{2}}}
$$

where $\gamma_{\infty}$ represents the surface tension at equilibrium and the exponential terms correspond to the two relaxation modes known for proteins and other macromolecules. The first exponential decay describes the adsorption stage, while the second exponential decay describes the rearrangements of molecules at the interface. Non-linear numerical fitting of Eq 4.1 to the experimental data was done with the curve fitting tool box of MATLAB software (MathWorks, USA). 


\subsubsection{Dilatational viscoelasticity}

After reaching the interfacial tension equilibrium, dilatational viscoelasticity measurements were done by interfacial compression and expansion using an amplitude of $5 \%(\mathrm{v} / \mathrm{v})$ of the initial drop volume and oscillation frequencies of 0.001 , $0.005,0.01,0.02,0.05,0.1$ and $0.2 \mathrm{~s}^{-1}$. These measurements provide information on the dynamic properties of the adsorbed surface layer. Once the interface is disturbed, the adsorbed molecules can relieve stress depending on the adsorption or desorption from the bulk solution, resulting in relaxation processes and gradual re-equilibration of the system. The interfacial dilatational modulus $\left(E_{d}\right)$ gives a measure of the resistance to surface disturbances and is defined as:

$$
\mathrm{E}_{d}=\mathrm{E}_{d}^{\prime}+\mathrm{E}_{d}^{\prime \prime}
$$

Eq 4. 2

The real part $\left(\mathrm{E}_{d}^{\prime}\right)$ is called the storage modulus and represents the elastic energy stored in the interface (i.e. dilatational elasticity). The imaginary part $\left(\mathrm{E}_{d}^{\prime \prime}\right)$ is called the loss modulus and accounts for the energy dissipation in the relaxation process (i.e. dilatational viscosity).

\subsubsection{Emulsion preparation}

Oil-in-water emulsions were prepared by mixing aqueous thylakoid solutions at appropriate concentrations with sunflower oil, using a rotor stator (IKA-Werke GmbH \& Co. KG, Staufen, Germany) at 13,500 rpm for $2 \mathrm{~min}$, and subsequently homogenised (Delta Instruments, Drachten, The Netherlands) at 150 bar for 4 min. The sunflower oil concentration was always adjusted to $10 \% \mathrm{w} / \mathrm{w}$, while the thylakoid concentration was varied $(0.03,0.05,0.08,0.10 \% \mathrm{w} / \mathrm{v})$. All concentrations refer to the whole emulsion and not just to the aqueous phase. Emulsions were prepared and analysed in triplicate. The emulsions were stored at $4^{\circ} \mathrm{C}$ for stability analyses.

\subsubsection{Emulsion droplet size analysis}

The droplet size distributions of thylakoid emulsions was analysed by laser light diffraction with a Mastersizer 2000 (Malvern Instruments, Malvern, UK). High 
dilution conditions were used to characterised emulsion by dispersing the samples in distilled water. The refractive index ratio used to calculate the oil droplet size distribution was 1.4. Average droplet sizes were characterised in terms of the volume mean diameter:

$$
\mathrm{d}_{43}=\sum_{i} n_{i} \cdot d_{i}^{4} / \sum_{i} n_{i} \cdot d_{i}^{3}
$$

where $n_{i}$ is the number of droplets of diameter $d_{i}$. All measurements were made at ambient temperature on three separately prepared samples.

\subsubsection{Microscopy}

A leaf cross section, thylakoid extract and thylakoid emulsions were analysed with transmission electron microscopy (TEM). Small leaf pieces $(1.0 \times 1,5 \mathrm{~mm})$ were cut from the mid part of the leaf and fixed for $3 \mathrm{~h}$ at room temperature in $3 \%(\mathrm{v} / \mathrm{v})$ glutaraldehyde in $0.1 \mathrm{M}$ sodium cacodylate buffer $(\mathrm{pH} 7.2)$. Thylakoid extract and emulsion were mixed with $3 \%$ liquid low melting point agarose in a 1:1 ratio. The mix was immediately centrifuged at $5220 \mathrm{~g}, 3 \mathrm{~min}$. The mixture was allowed to solidify at $0^{\circ} \mathrm{C}$ and small pieces were cut and fixed for $1.5 \mathrm{~h}$ in the same fixative as the leaf pieces. After primary fixation, all samples were washed three times with buffer, successively treated with $1 \% \mathrm{w} / \mathrm{v}$ OsO 4 and $1 \% \mathrm{w} / \mathrm{v}$ potassium ferricyanide in the same buffer for $2 \mathrm{~h}$ at room temperature, rinsed in water and dehydrated in a graded ethanol series. The samples were infiltrated with modified Spurr resin mixture (Serva) and cut in ultra-thin $(70 \mathrm{~nm})$ sections with an ultra-microtome (Leica mirosystems, Vienna, Austria). The thin sections were analysed with a transmission electron microscope (JEOL, MA, USA). Micrographs were made with a digital camera (Olympus, Veleta).

Thylakoid emulsions were also observed with a light microscope (Axiovert-Zeiss, Gottingen, Germany) fitted with a digital camera (Axio Cam MRc 5, Gottingen, Germany). The samples were observed with and without polarised light. 


\subsection{Results and discussion}

\subsubsection{Characterisation of the thylakoid extract}

The thylakoid membrane extraction involved a series of washing and filtration steps. The used buffers and centrifugation steps enabled the separation of intact chloroplasts from the rest of cell components and subsequently, allowed the recovery of thylakoid membranes from the obtained chloroplasts.

\section{Composition and appearance}

The thylakoid extract had an average dry matter content (DM) of $12.6 \mathrm{wt} \%$. The composition of this DM is given in Table 4. 1. The protein-to-lipid ratio was 75:25, being in line with the thylakoid composition found in literature for other crops (Kirchhoff et al., 2002; Staehelin \& van der Staay, 1996). This protein-to-lipid ratio is common in energy converting membranes (Loll et al., 2007).

Table 4. 1. Composition of thylakoid extract on dry basis. The dry matter content was $12.6 \mathrm{wt} \%$. Values are expressed in dry basis. $n=3$

\begin{tabular}{lc}
\hline Composition & wt\% \pm sd \\
\hline Protein & $50.5 \pm 6.5$ \\
Dietary fibre & $14.2 \pm 3.2$ \\
Lipids & $17.1 \pm 2.3$ \\
Ash & $4.6 \pm 1.9$ \\
\hline
\end{tabular}

To visualise the thylakoids in their native form and after extraction, a leaf cross section and the thylakoid extract were analysed with the aid of TEM. Thylakoid structures were identified inside the chloroplast of the fresh leaf (Figure 4. $2 \mathrm{~A}$, arrows) as well as in the thylakoid extract (Figure 4. 2 B). The thylakoid extract and the fresh leaf contained additional cell structures such as plastoglubules. The latter are thylakoid microdomains responsible for storage and synthesis of lipids (Rottet et al., 2015) and they are identified as dark spherical structures next to the membrane structures.

The extract was a very dense material (semisolid) rich in stacked thylakoid membranes (grana). The stacked thylakoids are 3D structures as depicted in 
Figure 4. 2 C, and the interconnected supramolecular structures observed with TEM are actually a transversal view of the cylindrical structure. The cylindrical grana stacks are made of membranous discs piled one on top of the other, surrounded by unstacked membranes that are helically bound around the grana (Pribil et al., 2014). A cartoon of the transversal view of the grana is shown in Figure 4. $2 \mathrm{D}$, showing the crowded distribution of protein complexes throughout the lipid bilayer.
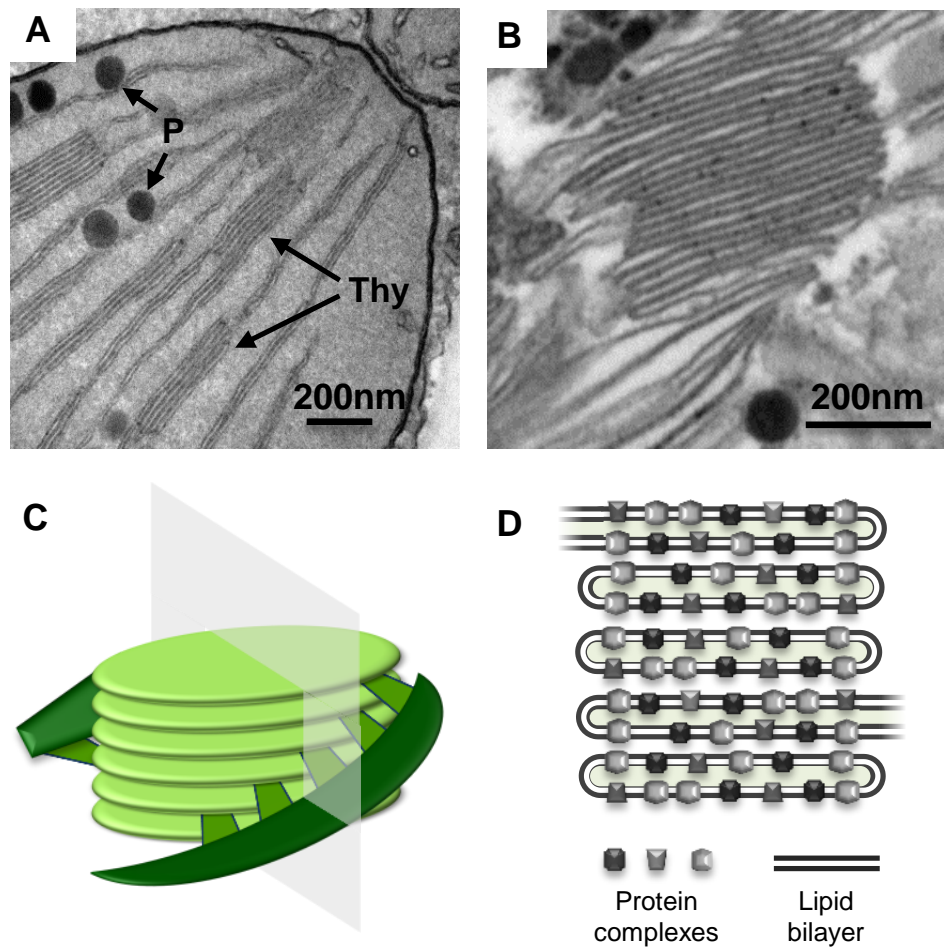

Figure 4. 2. TEM micrographs. (A) Leaf cross section focused on a chloroplast portion, thylakoid membranes (Thy) and plastoglobules (P) are identified with the arrows. (B) Thylakoid extract from sugar beet leaves, focused on a grana structure. (C) 3D schematic model of thylakoid grana structure, adapted from Ruban \& Johnson (2015). The plane denotes a transversal cut, which is normally observed with TEM micrographs. (D) A cartoon of the transversal view of the thylakoid grana.

The protein complexes in adjacent membranes are bridged through electrostatic interactions mediated by $\mathrm{Mg}^{2+}$ ions. Thylakoids are negatively charged due to protein phosphorylation and $\mathrm{Mg}^{2+}$ ions can balance the electrostatic repulsion by 
forming bridges between membranes, leading to membrane stacking (Finazzi et al., 2015; Fristedt et al., 2010). The membrane lipids (i.e. DGDG) also play a role in stacking by screening the negative charges and through hydrogen bonding between polar heads of adjacent membranes (Demé et al., 2014). Thus thylakoid membranes have the capacity to stack (or aggregate).

\section{$\zeta$-potential measurements}

The negative charge of the thylakoid membranes was observed with the $\zeta$-potential measurements. A suspension of thylakoids was measured as a function of $\mathrm{pH}$ to observe the effect of the environmental $\mathrm{pH}$ on the charge of this complex structure. The measurements showed an isoelectric point (IEP) at pH $4.7 \pm 0.2$ (Figure 4. 3), which is the same value reported in previous studies for thylakoids from spinach leaves (Åkerlund et al., 1979). The charge is mainly a contribution of the protein moieties rather than the lipid moieties for three main reasons: i). the abundance of proteins compared to lipids; ii) the lack of charge of the majority of lipids (i.e. MGDG, DGDG); and iii) the constant negative charge of the few polar lipids (i.e. $P G, S Q D G)$ at all $\mathrm{pH}$ ranges. Other charged molecules present in the thylakoids include pigments and minerals that have less pronounced effect on the $\zeta$-potential probably due to their even distribution on the thylakoids surface or to their location inside the core of the protein complexes.

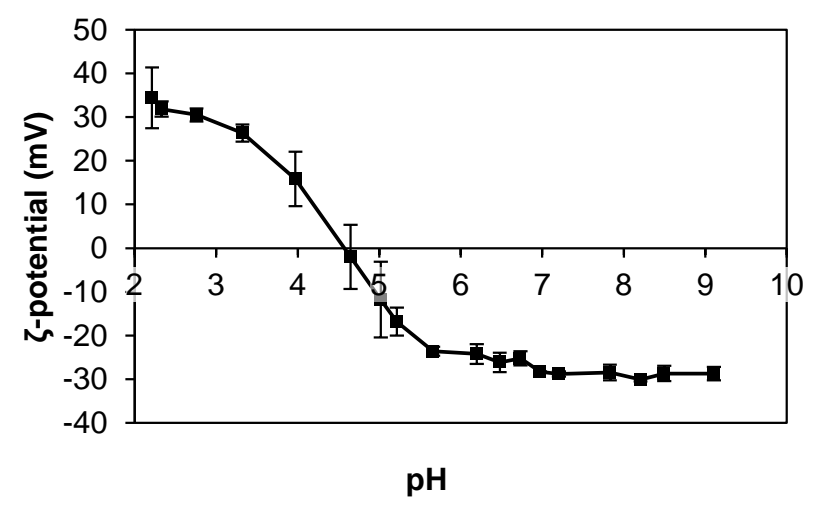

Figure 4. 3. $\zeta$-potential of thylakoid extract upon $\mathrm{pH}$ change. Thylakoid membranes were extracted from sugar beet leaves. $n=3$ 
In this study, the thylakoid extract was suspended in water by high-pressure homogenisation before any analysis. The thylakoid extract, rich in intact membrane structures (Figure 4. 2 B), was initially not soluble in water and appeared as large clusters $(\sim 100 \mu \mathrm{m})$ under the optical microscope (Figure 4. $4 \mathrm{~A})$. After homogenisation, these clusters were broken into smaller fragments $(<5 \mu \mathrm{m})$ (Figure 4. 4B), resulting in a light-green, almost transparent suspension. The mechanical treatment is expected to supply enough energy to the system to break the membrane structures at the weaker domains and even alter the ultrastructure (staked, non-stacked conformation). According to the size distribution analysis of the homogenised thylakoid dispersion (Figure 4. 4b B, the resulting thylakoid fragments include membrane domains and protein clusters surrounded by lipids (Figure 4. 4 C).

A

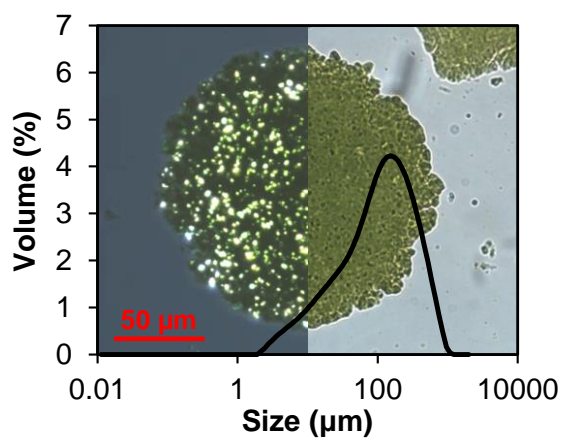

B

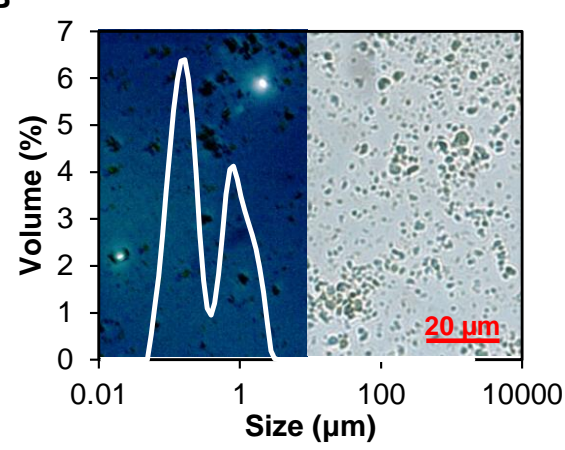

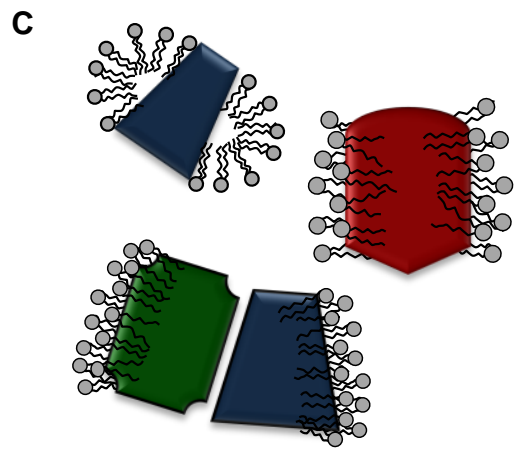

Figure 4. 4. Comparison of thylakoid extract before (A) and after (B) homogenisation. The background of the graphs are light microscope images with (left) and without (right) light polarisation. (C) Proposed structures of the thylakoid membrane fragments: membrane domains and protein clusters surrounded by lipids. 
The structure of the membrane fragments is probably dominated by the hydrophobic interactions between the lipid's hydrophobic tail and hydrophobic protein domains or by lipid/lipid and protein/lipid ionic interactions and hydrogen bonding, similar to the interactions occurring in the native thylakoid membranes (Loll et al., 2007; Siegenthaler \& Trémolières, 1998). These strong interactions prevent the release of lipids from the proteins upon membrane disruption and yield protein/lipid complexes. Nevertheless, lipids that were indeed detached can still bind to membrane proteins, which offer a complementary amphipathic surface. These types of interactions are described for protein-surfactant mixtures and are thermodynamically more favourable than micelles (Jones, 1992). Thus, complexes between proteins and lipids are expected to account for the majority of the thylakoid fragments obtained through homogenisation. The proteins in these fragments can include large protein clusters, since the densely packed protein complexes in thylakoid membranes can arrange in super and megacomplexes mediated by pigments and small proteins (Dekker \& Boekema, 2005).

In addition to the particle size, the micrographs facilitated the identification of the liquid-crystalline structure of the membrane lipids, which were observed as bright spots under polarised light (Figure 4. 4 A,B). Following mechanical rupture, crystalline structures were still observed, although at smaller sizes. Lipid crystal structures in thylakoid membranes include lamellar bilayers, together with hexagonal and cubic phases. The bilayer is a planar structure whereas the hexagonal phase consists of cylindrical inverted micelles packed on an hexagonal lattice (W. P. Williams, 1998). The cubic phase is a fatty acyl chains pointing toward the outside of tubules and the polar head groups toward the centre (Jouhet, 2013; Selstam, 1998). The type and amount of membrane lipids and protein complexes determine the crystal conformation adopted by the lipids (Selstam, 1998; W. P. Williams, 1998). These crystal structures are expected to be formed by the lipids surrounding the protein complexes upon thylakoid homogenisation, given the crystals observed in the homogenised material. 


\section{Surface tension}

The proteins forming the thylakoid membranes, and now the thylakoid fragments, are membrane spanning proteins. These proteins are rich in hydrophobic domains that can facilitate the adsorption at air-water and oil-water interfaces and contribute to a significant reduction of the interfacial tension. To characterise the interfacial properties of thylakoid membranes, their behaviour at the air-water interface was measured with a Wilhelmy plate during a $4 \mathrm{~h}$ period (Figure $4.5 \mathrm{~A}$ ). The higher the thylakoid concentration, the lower the final value, ranging from 43.3 to $31.5 \mathrm{mN} \mathrm{m}^{-1}$ at 0.01 and $0.25 \% \mathrm{w} / \mathrm{v}$, respectively (Figure 4. 5 B). At higher thylakoid concentration $(>0.25 \% \mathrm{w} / \mathrm{v})$, thylakoid fragments started to precipitate, probably due to aggregation.

A

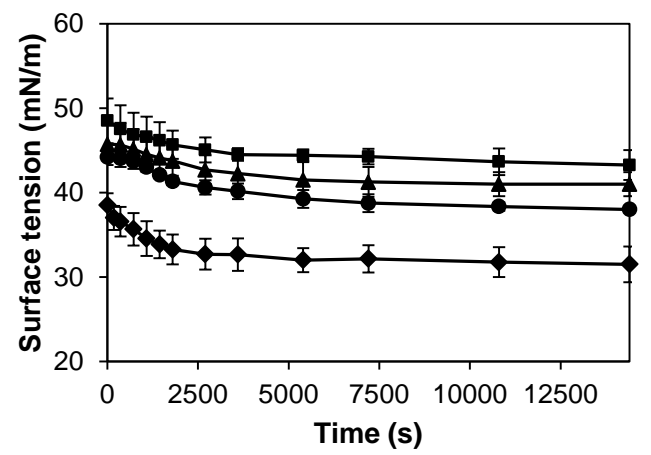

B

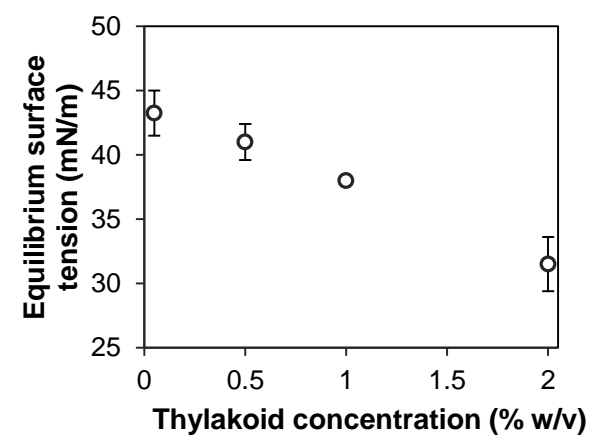

Figure 4. 5. (A) Surface tension of the air-water interface of thylakoid dispersions at different concentrations: $(\square) 0.01 \% \mathrm{w} / \mathrm{v},(\Delta) 0.06 \% \mathrm{w} / \mathrm{v},(\bullet) 0.13 \% \mathrm{w} / \mathrm{v}$, and $(\bullet) 0.25 \% \mathrm{w} / \mathrm{v}$, all in dry basis. (B) Final surface tension as a function of concentration of the thylakoid fragments. $n=3$

All tested concentrations $(0.01,0.06,0.13$ and $0.25 \% \mathrm{w} / \mathrm{v})$ showed a similar pattern of rapid initial decline which then slows down, reaching a semi-equilibrium at the end of the measurement. This is expected when larger entities, such as the thylakoid fragments, adsorb to an interface. Due to the mechanical homogenisation of the thylakoids, the proteins are part of small membrane fragments consisting of both proteins and lipids. These lipids can surround the proteins and cover the hydrophobic domains (Jouhet, 2013), producing stable thylakoid fragments that behave like soft particles at the air-water interface. As soft particles, the thylakoid fragments lower the surface tension due to capillary forces rather than 
conformational changes at the interface. In particle-stabilised interfaces, lateral attractive capillary forces occur due to deformation of the fluid interface around the particles. Such interactions contribute to the mechanical stability of the interfacial layer (Berton-Carabin \& Schroën, 2015).

\section{Dynamic interfacial tension}

The interfacial activity of thylakoid membranes at the oil-water interface was measured to assess their adsorption kinetics (Figure 4. 6). Measurements were done for $24 \mathrm{~h}$ with a pendant drop analysis at a thylakoid concentration of $0.001 \%$ $\mathrm{w} / \mathrm{v}$. When looking at the logarithmic time scale used in Figure 4. $6 \mathrm{~A}$, three phases of surface adsorption can be identified. These phases have been observed in most cases where proteins have been used as stabilisers (Beverung et al., 1999) and an analogy can be identified for the thylakoid fragments. In the first phase (I), the thylakoid fragments have not reached the interface yet and the interfacial tension remains constant. The second phase (II) describes the adsorption of thylakoid fragments to the interface, characterised by the main decrease in interfacial tension. Finally, during the third phase (III) interactions between the adsorbed fragments lower the interfacial tension to an equilibrium value. The measurements done on the air-water surface fit phase II and therefore show similar kinetics. This suggests that the same type of adsorptive process takes place there as well.

Similar adsorption kinetics have been observed for globular proteins (i.e. lipases, glutamate dehydrogenase) (Beverung et al., 1999), $\beta$-casein (Dan et al., 2014; Wüstneck et al., 2012) and for oleosins (Nikiforidis et al., 2013). In all cases, the equilibrium interfacial tension is reached after $\sim 20 \mathrm{~h}$, except for oleosins $(\sim 7 \mathrm{~h})$. Long times for adsorption are common for complex proteins (He et al., 2008), but also for soft particles that are surface active (Boker et al., 2007; Z. Li et al., 2015). As indicated earlier, the thylakoid fragments as expected to consist of membrane proteins covered by lipids, which can provide a stable conformation to the protein/lipid complexes and render a soft particle that adsorbs to the interface. 
A

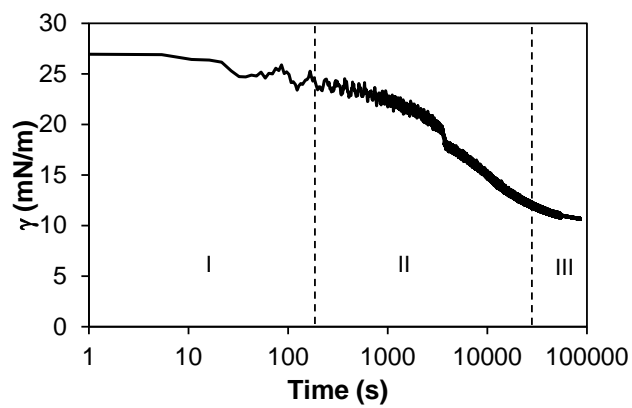

B

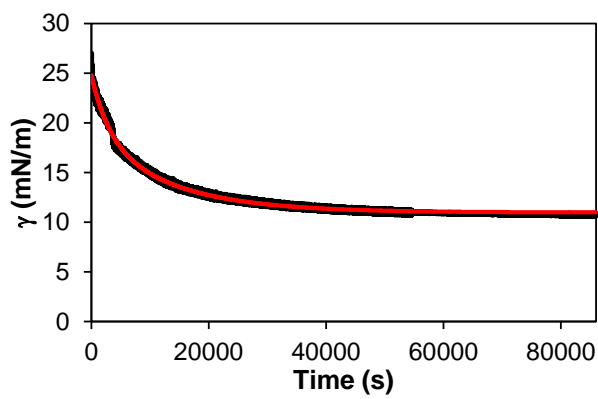

Figure 4. 6. Dynamic surface tension $(\gamma)$ measurements of $0.001 \% \mathrm{w} / \mathrm{v}$ thylakoid solution as a function of time. (A) Time expressed using a time logarithmic scale. I, II and III indicate the three phases of diffusion, adsorption and finally rearrangement and equilibrium, as defined for single proteins. And (B) time in linear scale. In red: theoretical curve using Eq 4. 1.

During the pendant drop analysis, the protein hydrophobic groups are partly covered by the surrounding lipids and partly exposed to the oil-water interface. Once at the interface, new non-covalent bonds are formed, and possibly new bridges and interactions. This process is often irreversible and results in closelypacked, cross-linked, gel-like structures at the interface (Mitropoulos et al., 2014). During adsorption of the thylakoid fragments, the membrane lipids play an important role. As single amphiphiles, lipids can displace proteins from the interface because they are effective surface-active substances and lower the interfacial tension more than proteins do (He et al., 2008; Walstra, 2003). This displacement will depend on the concentration of both lipids and proteins. A lipidcontrolled adsorption occurs much faster than with proteins and should result in a quick lowering of the interfacial tension. However, no decrease of interfacial tension was observed during the first seconds of analysis with the thylakoid fragments (Figure 4.6 A), suggesting that the thylakoids lipids are somehow not available to freely adsorb to the oil-water interface. This observation supports the idea that thylakoid fragments behave as intact particles and most of lipids remain complexed within this system.

To further analyse the interfacial behaviour of the thylakoid fragments, the interfacial tension was plotted against a linear time scale (Figure 4. 6 B). Similar to the surface tension measurements, the interfacial tension decreased before 
reaching a plateau value. The thylakoids lowered the interfacial tension to $\sim 10 \mathrm{mN}$ $\mathrm{m}^{-1}$, similar to values obtained by large proteins like ovalbumin (Seta et al., 2012), $\beta$-lactoglobulin, $\beta$-casein and human serum albumin (Lu et al., 2003).

Finally, the experimental data in Figure 4. $6 \mathrm{~B}$ was fitted well by Eq 4.1 as depicted by the red line. The relaxation times $t_{1}$ and $t_{2}$ were equal to $13,250 \mathrm{~s}$ and $3,058 \mathrm{~s}$, respectively, with a coefficient of determination $\left(r^{2}\right)$ of 0.9916 . These parameters describe the interfacial tension decay with time and they give an indication of the contributions of adsorption and rearrangement to the dynamic surface tension. In this case, $t_{1}$ was four times larger than $t_{2}$, suggesting a relatively slow adsorption compared to fast arrangements of fragments at the interface. Certainly, the large sizes of the thylakoid fragments determined a slow diffusion and adsorption, typical of large molecules or soft particles, resembling pickering emulsifiers.

\section{Surface elasticity and viscosity}

Dilatational rheology measurements were made after $24 \mathrm{~h}$ adsorption time of the thylakoid fragments at the oil-water interface to study the interfacial structure and interactions between adsorbed molecules. Figure 4. $7 \mathrm{~A}$ presents plots of the interfacial dilatational elastic $\left(\mathrm{E}_{d}^{\prime}\right)$ and viscous $\left(\mathrm{E}_{d}^{\prime \prime}\right)$ moduli versus angular frequency. The values of the moduli were dependent upon the applied frequency, meaning that the adsorbed thylakoid layer at the oil-water interface had viscoelastic properties (A. Williams \& Prins, 1996). The $\mathrm{E}_{d}^{\prime \prime}$ was negligible compared to $\mathrm{E}_{d}^{\prime}$, indicating that the adsorbed layer exhibited pure elastic behaviour.

Before oscillations started, the elastic modulus was $\sim 10 \mathrm{mN} \cdot \mathrm{m}^{-1}$ and increased with the drop deformation rate up to $23.3 \mathrm{mN} \cdot \mathrm{m}^{-1}$. Above a frequency of $0.02 \mathrm{~s}^{-1}$, the elastic modulus reached a plateau at $\sim 23 \mathrm{mN} \cdot \mathrm{m}^{-1}$. This behaviour suggests that the adsorbed layer formed a mechanically stable structure. 
A

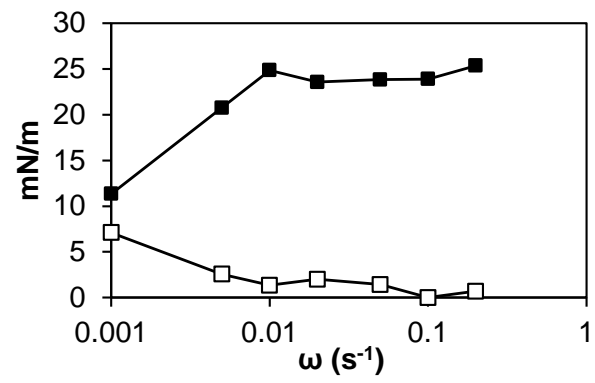

B

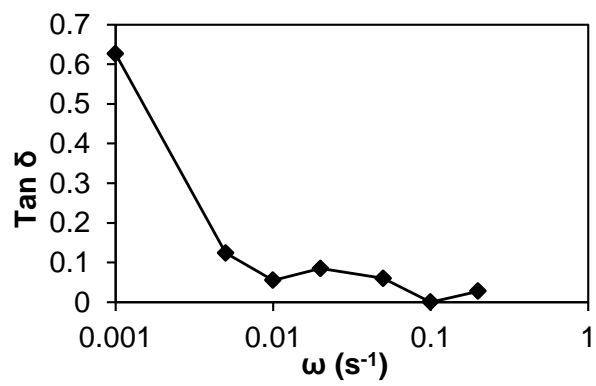

Figure 4. 7. (A) Interfacial dilatational elastic $E_{d}^{\prime}(\square)$ and viscous $E_{d}^{\prime \prime}(\square)$ moduli, and (B) loss tangent as a function of oscillation frequency with a $0.03 \% \mathrm{w} / \mathrm{v}$ thylakoid solution $\left(T=25^{\circ} \mathrm{C}\right.$, amplitude $=5 \%$ of the initial drop volume).

The dynamic viscoelastic behaviour can be analysed more intuitively with the loss tangent $(\tan \delta)$, which is equal to $\mathrm{E}_{d}^{\prime \prime} / \mathrm{E}_{d}^{\prime}$. When $\tan \delta>1, \mathrm{E}_{d}^{\prime \prime}$ is dominant and the interface mainly exhibits viscous properties. In contrast, when tan $\delta<1$, the interface mainly exhibits elastic properties. In our system, the tan $\delta$ was below 1 at all frequencies and from $0.01 \mathrm{~s}^{-1}$, with low frequency dependence (Figure 4. $7 \mathrm{~B}$ ). Thus, the surface elasticity had a greater contribution to the dilatational modulus than the surface viscosity. Between the thylakoid fragments, the protein/protein, protein/lipid and lipid/lipid interactions will take place at the interface and result in an elastic interfacial film or 2D network, which can show viscoelastic response to mechanical disturbances (Dickinson, 2012, 2013).

\subsubsection{Thylakoid stabilised emulsions}

The interfacial properties of thylakoid membranes can be related to their emulsifying activity, as it has been done for proteins (A. Williams \& Prins, 1996) and hydrocolloids (Dickinson, 2009). Therefore, oil-in-water emulsions were prepared with homogenised thylakoid extract at different concentrations. Two phases were observed at all concentrations due to size dispersity of the oil droplets and/or aggregates of droplets (Figure 4. 8). The droplet size indeed showed a bimodal distribution (Figure 4. 9); however, the majority of the droplets had small size at all concentrations, as observed in the micrographs (backgrounds in Figure 4. 9). The large oil droplets are due to slow diffusion of the thylakoids fragments, 
which cannot efficiently stabilise all the newly created interface during emulsion formation. This behaviour suggests similarities between thylakoid fragments and soft particles or pickering emulsifiers. Furthermore, droplet aggregates were observed at increasing thylakoid concentrations. The aggregates resulted in peaks at large particle size $(\sim 100 \mu \mathrm{m})$ (Figure 4. $9 \mathrm{~B})$ and in a larger top phase in the emulsions (Figure 4. 8).

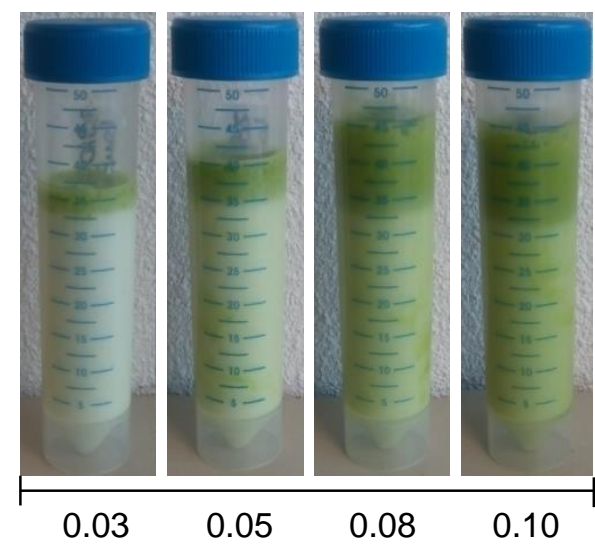

Thylakoid concentration (\% w/w, db)

Figure 4. 8. Visual appearance of oil-in-water emulsions stabilised by thylakoid extract at different concentrations. Pictures were taken right after emulsions preparation.

A

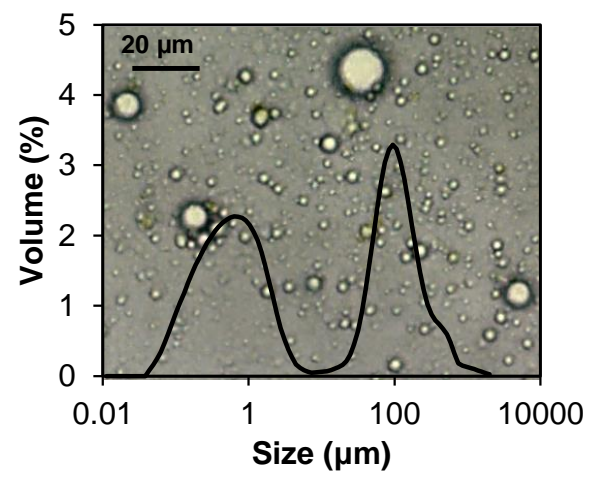

B

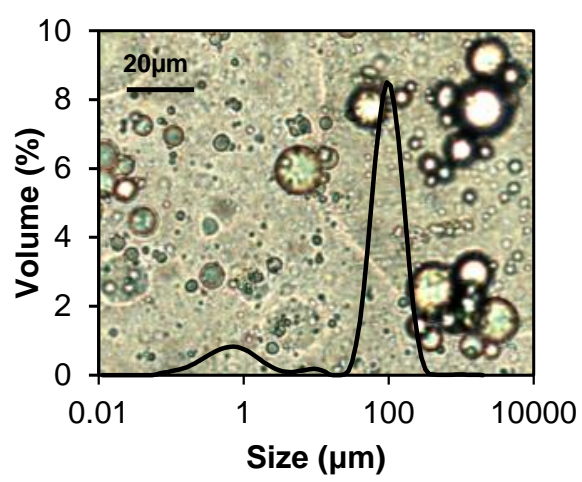

Figure 4. 9. Optical micrographs combined with their respective oil droplet-size distributions obtained by laser light diffraction of thylakoid-stabilised $0 / w$ emulsions after dilution of 1:100. (A) $0.05 \% \mathrm{w} / \mathrm{v}$ and (B) $0.1 \% \mathrm{w} / \mathrm{v}$ thylakoids. 
To further characterise the colloidal stability of the emulsions, the $\zeta$-potential was measured as a function of $\mathrm{pH}$ (Figure 4. 10). The IEP was found at $\mathrm{pH} 5.1$, higher

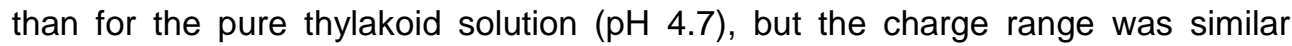
$( \pm 30 \mathrm{mV})$. The change of the IEP suggests re-arrangement of the proteins and lipids in the thylakoid fragments. Upon homogenisation, the resulting protein/lipid complexes had a different distribution of charges around protein complexes that induced an IEP shift.

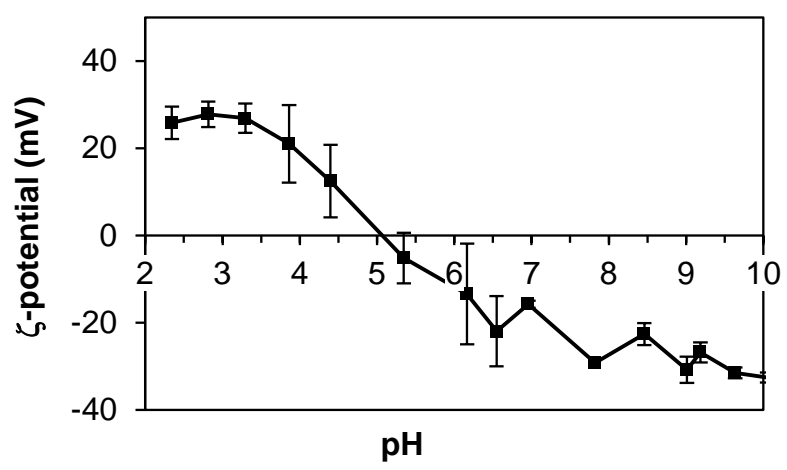

Figure 4. 10. $\zeta$-potential of thylakoid stabilised emulsion upon $\mathrm{pH}$ change. $0.05 \% \mathrm{w} / \mathrm{v}$ thylakoid solution. $\mathrm{n}=3$

At the emulsion conditions ( $\mathrm{pH}$ 6.8), the oil droplets covered with thylakoids are expected to repel each other due to the negative charge that is exposed at this $\mathrm{pH}$. However, having droplet aggregates at this $\mathrm{pH}$ suggests that the attractive forces are stronger than the electrostatic repulsion and aggregation occurs, probably in a similar manner as thylakoid membranes stack on top of each other in the native structure. In the emulsion system, the exposed negative charges on the thylakoid fragments, together with the available multivalent cations, can balance the electrostatic repulsion and facilitate the inter droplet interactions. Additionally, emulsions prepared at different $\mathrm{pH}$ conditions ( $\mathrm{pH} 3.0,4.7$, and 7.0) showed similar properties and stability (data not shown) as the emulsions at $\mathrm{pH}$ 6.8. This observation confirmed that electrostatic interactions played no major role on the stabilisation mechanism. Instead, stabilising forces on the interface and bulk phase might be ruled by hydrophobic and van der Waals' interactions, which can contribute to stability of the interfacial layer as well as bridging of droplets. 
Moreover, the attractive interactions between droplets might be enhanced by small thylakoid fragments that can induce depletion flocculation and contribute to phase separation of the emulsions.

Despite the droplet aggregation, the thylakoid emulsions were stable against coalescence over time. The average diameter $d_{43}$ did not increase over 7 days of storage (Figure 4. 11) and no free oil was observed on the emulsion's surface. The aggregation of droplets occurred already during emulsion preparation and the droplet clusters remained stable. This immediate aggregation might be caused by insufficient thylakoid fragments to saturate the droplet surface. In that case, the insufficient adsorbed molecules are shared between droplets and steric bridging occurs. Such bridging flocculation during emulsification has been described for single proteins (i.e. lactoglobulin) and an increase on protein concentration reduced droplet aggregation ( $\mathrm{H}$. J. Kim et al., 2004). Nevertheless, the increase of thylakoid concentration resulted in even more aggregation. Most likely, multiple layers of thylakoids were formed at the interface due to the excess of material and the electrostatic bridging between droplets was probably promoted. Since the thylakoids have a natural tendency to stack, one may expect that this also happens on an interface. A stack of thylakoids can then easily form a bridge towards neighbouring droplets, resulting in aggregation.

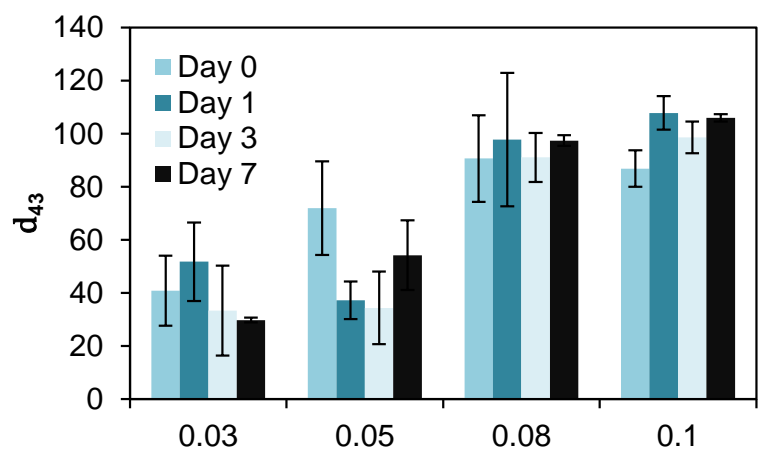

Thylakoids concentration $(\% \mathrm{w} / \mathrm{v})$

Figure 4. 11. Average droplet size diameter $d_{43}$ of emulsions stabilised by thylakoid solutions at different concentrations and after 7 days of storage at $4^{\circ} \mathrm{C} . \mathrm{n}=3$ 
After droplet aggregation, the adsorbed thylakoid fragments might form lateral interactions as part of the structural consolidation of the adsorbed layer. These interactions result in a 2D network around the oil droplets that ultimately stabilises the emulsion against coalescence over time.

A thylakoid stabilised emulsion was analysed with the aid of TEM (Figure 4. 12) to visualise the emulsion droplets and the thylakoid structures after emulsification. The size polydispersity of oil droplets and droplet aggregates are depicted in Figure 4. $12 \mathrm{~A}$ and $\mathrm{B}$, respectively. Aggregates contained small droplets with local flattening of the surface (see arrows) due to the elasticity of the adsorbed thylakoid layer, which deforms upon attraction. The local flattening may indicate a very strong bridging; strong enough to deform the droplets and hence enlarge their surface area. The elastic properties of the adsorbed layer were described during the dilatational rheology analysis of the thylakoids, suggesting the formation of a 2D network with viscoelastic response. The resulting surface flattening upon droplet aggregation can enhance the attractive forces between droplets (Walstra, 2003). However, no coalescence was observed after droplet aggregation, confirming the mechanical stability of the adsorbed layer.
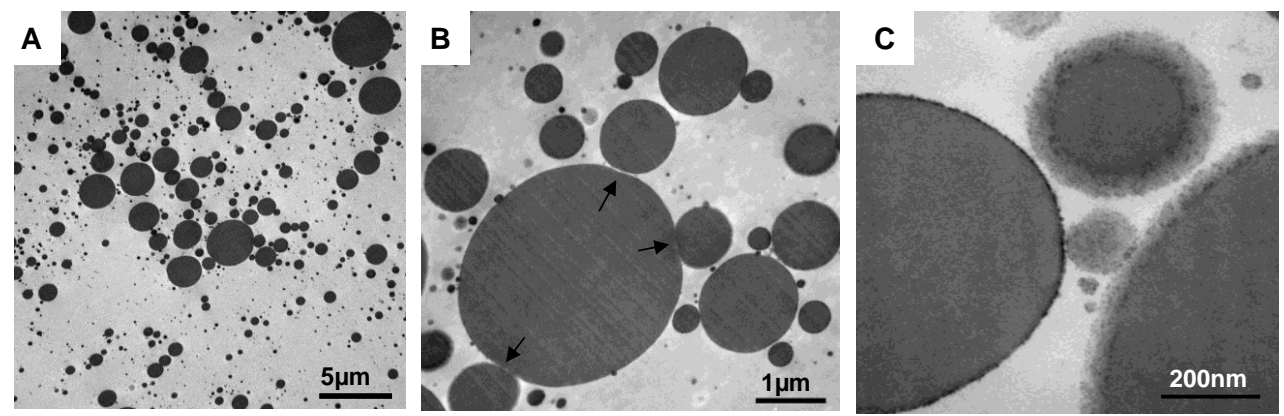

Figure 4. 12. TEM micrographs of thylakoid stabilised emulsion at different magnification levels. (A) size polydispersity of oil droplets. (B) Zoom-in on a cluster of droplets; the arrows point at local flattening of the droplets, probably due to surface deformation upon droplet aggregation. (C) Zoom-in on a droplet edge.

Moreover, no intact thylakoid structures were observed when using higher magnification level (Figure 4.12 Cc), which was the same magnification level used to visualise the thylakoid extract in Figure 4. 2 B. Interestingly, no thylakoid vesicles 
stuck out of the droplets as previously described by Rayner, et al. (2011) when thylakoid-stabilised emulsions where tested. The different thylakoid isolation method and emulsion preparation might account for this major difference. In particular, the homogenisation step was done at higher pressure in our case (150 bar compared to 100 bar), and this high pressure can lead to more breakage of the thylakoid ultrastructure. Instead of having intact thylakoid domains reaching the oil-water interface, small thylakoid fragments adsorbed at the interface and formed a thin covering layer. This covering layer can be the cause for the smeared edges of the oil droplets in the close-up image (Figure 4.12 C). The smeared layer had a thickness of $30-50 \mathrm{~nm}$, suggesting the adsorption of multiple layers since the thickness of lamellar thylakoids is $\sim 10 \mathrm{~nm}$. Those observations confirm the tendency of the thylakoids to stack. The presence of multiple adsorbed layers promotes bridging between droplets either by steric or electrostatic bridging, which was confirmed by the immediate aggregation of droplets during emulsification even at higher thylakoid concentrations.

Additionally, the black dots or small droplets $(10-80 \mathrm{~nm})$ observed in the emulsions had comparable sizes to the plastoglobules identified in the thylakoid extract and in the homogenised material. These thylakoid microdomains have a diameter ranging between $30-100 \mathrm{~nm}$ and are assumed to remain in suspension after emulsion preparation due to their stable conformation and due to interface crowding by thylakoid fragments.

\section{Emulsifying mechanism}

Figure 4. 13 depicts a proposed mechanism of thylakoid fragment adsorption at the oil-water interface. The lipids in the thylakoid fragments cover the hydrophobic patches of the protein complexes and thereby provide a stable conformation to the membrane proteins. The strong interactions between the lipids and proteins result in fragments that behave more like soft particles at the interface, impeding the individual adsorption of either the proteins of the lipids. During emulsification, bridging flocculation of thylakoid-covered droplets occurs through electrostatic interactions similar to those in thylakoid stacking and hydrophobic interactions. 
Over time, the adsorbed thylakoid fragments form new interactions that result in an elastic and stable 3D network. This 3D network ensures long time stability against coalescence, since the oil droplets are immobilised within a gel-like film with elastic properties (Dickinson, 2013).
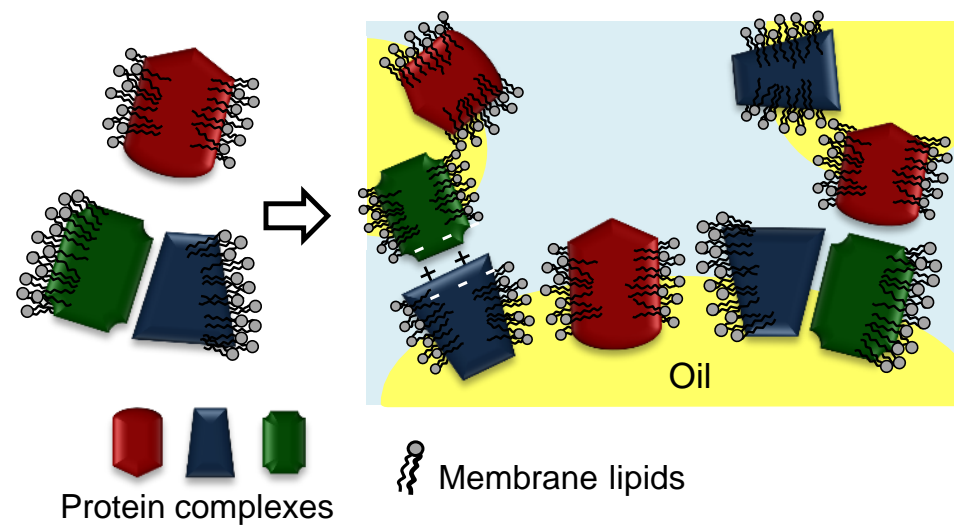

\$? Membrane lipids

Figure 4. 13. Proposed emulsifying mechanism of thylakoid membrane fragments.

\subsection{Conclusions}

In this work we have studied the interfacial behaviour of thylakoid membranes to discern the adsorption mechanism and the ability to stabilise oil-water interfaces. Thylakoid membranes are unique biological membranes with a high protein/lipid ratio, a special lipid composition and specific protein/lipid interactions. The thylakoid proteins and their intrinsic lipids form stable thylakoid fragments that behave like soft particles during adsorption and interface stabilisation. In emulsions, the adsorbed thylakoid fragments form an elastic network around oil droplets and render an emulsion stable against coalescence, despite aggregation of droplets by bridging. The droplet aggregation is proposed to be promoted by the natural tendency towards stacking of the native thylakoid membranes. Both composition and structure of thylakoid fragments determine their emulsifying properties and make the interfacial behaviour more complex compared to artificial protein/lipid mixtures. The emulsion stability obtained with thylakoid fragments can be further explored in specialised applications of encapsulation systems, where the search for natural materials is gaining more attention. 


\section{Acknowledgements}

The authors thank Jun Qiu for his contribution to the data fitting in MATLAB, and the Technology Foundation STW (The Netherlands) and Royal Cosun (The Netherlands) for their financial and project support.

\section{References}

AACC. (1983a). Method 08-01: Ash - Basic Method. Approved Methods of Analysis, 10th ed. AACC International, St. Paul, MN, U.S.A.

AACC. (1983b). Method 30-25: Crude Fat in Wheat, Corn and Soy Flour, Feeds, and Mixed Feeds. Approved Methods of Analysis, 10th ed. AACC International, St. Paul, MN, U.S.A.

AACC. (1983c). Method 32-05: Total Dietary Fiber. Approved Methods of Analysis, 10th ed. AACC International, St. Paul, MN, U.S.A.

Åkerlund, H.-E., Andersson, B., Persson, A., \& Albertsson, P.-Å. (1979). Isoelectric points of spinach thylakoid membrane surfaces as determined by cross partition. Biochimica et Biophysica Acta (BBA)-Biomembranes, 552(2), 238-246.

Berton-Carabin, C. C., \& Schroën, K. (2015). Pickering emulsions for food applications: Background, trends, and challenges. Annual Review of Food Science and Technology, 6, 263-297. doi: 10.1146/annurev-food-081114-110822

Berton, C., Genot, C., \& Ropers, M. H. (2011). Quantification of unadsorbed protein and surfactant emulsifiers in oil-in-water emulsions. Journal of Colloid and Interface Science, 354(2), 739-748. doi: 10.1016/j.jcis.2010.11.055

Beverung, C., Radke, C., \& Blanch, H. (1999). Protein adsorption at the oil/water interface: characterization of adsorption kinetics by dynamic interfacial tension measurements. Biophysical chemistry, 81(1), 59-80.

Boker, A., He, J., Emrick, T., \& Russell, T. P. (2007). Self-assembly of nanoparticles at interfaces. Soft Matter, 3(10), 1231-1248. doi: 10.1039/b706609k

Casazza, A. P., Tarantino, D., \& Soave, C. (2001). Preparation and functional characterization of thylakoids from Arabidopsis thaliana. Photosynthesis Research, 68(2), 175-180.

Dan, A., Wüstneck, R., Krägel, J., Aksenenko, E. V., Fainerman, V. B., \& Miller, R. (2014). Interfacial adsorption and rheological behavior of $\beta$-casein at the water/hexane interface at different pH. Food Hydrocolloids, 34, 193-201. doi: 10.1016/j.foodhyd.2012.10.015

Dekker, J. P., \& Boekema, E. J. (2005). Supramolecular organization of thylakoid membrane proteins in green plants. Biochimica et Biophysica Acta (BBA) - Bioenergetics, 1706(1-2), 12-39. doi: 10.1016/j.bbabio.2004.09.009 
Demé, B., Cataye, C., Block, M. A., Maréchal, E., \& Jouhet, J. (2014). Contribution of galactoglycerolipids to the 3-dimensional architecture of thylakoids. FASEB Journal, 28(8), 3373-3383. doi: 10.1096/fj.13-247395

Dickinson, E. (2009). Hydrocolloids as emulsifiers and emulsion stabilizers. Food Hydrocolloids, 23(6), 1473-1482. doi: 10.1016/j.foodhyd.2008.08.005

Dickinson, E. (2012). Use of nanoparticles and microparticles in the formation and stabilization of food emulsions. Trends in Food Science \& Technology, 24(1), 4-12. doi: 10.1016/j.tifs.2011.09.006

Dickinson, E. (2013). Stabilising emulsion-based colloidal structures with mixed food ingredients. Journal of the Science of Food and Agriculture, 93(4), 710-721. doi: $10.1002 /$ jsfa.6013

Erlanson-Albertsson, C., \& Albertsson, P. Å. (2015). The use of green leaf membranes to promote appetite control, suppress hedonic hunger and loose body weight. Plant Foods for Human Nutrition, 70(3), 281-290. doi: 10.1007/s11130-015-0491-8

Finazzi, G., Petroutsos, D., Tomizioli, M., Flori, S., Sautron, E., Villanova, V., . . SeigneurinBerny, D. (2015). Ions channels/transporters and chloroplast regulation. Cell Calcium, 58(1). doi: 10.1016/j.ceca.2014.10.002

Fristedt, R., Granath, P., \& Vener, A. V. (2010). A protein phosphorylation threshold for functional stacking of plant photosynthetic membranes. PLOS ONE, 5(6). doi: 10.1371/journal.pone.0010963

He, Q., Zhang, Y., Lu, G., Miller, R., Möhwald, H., \& Li, J. (2008). Dynamic adsorption and characterization of phospholipid and mixed phospholipid/protein layers at liquid/liquid interfaces. Advances in Colloid and Interface Science, 140(2), 67-76. doi: 10.1016/j.cis.2007.12.004

Joly, D., \& Carpentier, R. (2011). Rapid isolation of intact chloroplasts from spinach leaves Photosynthesis Research Protocols (pp. 321-325): Springer.

Jones, M. N. (1992). Surfactant interactions with biomembranes and proteins. Chemical Society Reviews, 21(2), 127-136. doi: 10.1039/cs9922100127

Jouhet, J. (2013). Importance of the hexagonal lipid phase in biological membrane organization. Frontiers in plant science, 4, 494.

Kim, H. J., Decker, E. A., \& McClements, D. J. (2004). Influence of free protein on flocculation stability of $\beta$-lactoglobulin stabilized oil-in-water emulsions at neutral $\mathrm{pH}$ and ambient temperature. Langmuir, 20(24), 10394-10398. doi: 10.1021/la048122i

Kirchhoff, H., Mukherjee, U., \& Galla, H. J. (2002). Molecular architecture of the thylakoid membrane: lipid diffusion space for plastoquinone. Biochemistry, 41, 4872-4882.

Li, Z., Harbottle, D., Pensini, E., Ngai, T., Richtering, W., \& Xu, Z. (2015). Fundamental study of emulsions stabilized by soft and rigid particles. Langmuir, 31(23), 62826288. doi: 10.1021/acs.langmuir.5b00039 
Loll, B., Kern, J., Saenger, W., Zouni, A., \& Biesiadka, J. (2007). Lipids in photosystem II: Interactions with protein and cofactors. Biochimica et Biophysica Acta Bioenergetics, 1767(6), 509-519. doi: 10.1016/j.bbabio.2006.12.009

Lu, G., Chen, H., \& Li, J. (2003). Forming process of folded drop surface covered by human serum albumin, $\beta$-lactoglobulin and $\beta$-casein, respectively, at the chloroform/water interface. Colloids and Surfaces A: Physicochemical and Engineering Aspects, 215(1-3), 25-32. doi: 10.1016/S0927-7757(02)00416-8

Mitropoulos, V., Mütze, A., \& Fischer, P. (2014). Mechanical properties of protein adsorption layers at the air/water and oil/water interface: A comparison in light of the thermodynamical stability of proteins. Advances in Colloid and Interface Science, 206, 195-206.

Nevo, R., Chuartzman, S. G., Tsabari, O., Reich, Z., Charuvi, D., \& Shimoni, E. (2009). Architecture of thylakoid membrane networks Lipids in photosynthesis (pp. 295328): Springer.

Nikiforidis, C. V., Ampatzidis, C., Lalou, S., Scholten, E., Karapantsios, T. D., \& Kiosseoglou, V. (2013). Purified oleosins at air-water interfaces. Soft Matter, 9(4), 1354-1363.

Östbring, K., Rayner, M., Albertsson, P. A., \& Erlanson-Albertsson, C. (2015). Heat-induced aggregation of thylakoid membranes affect their interfacial properties. Food and Function, 6(4), 1310-1318. doi: 10.1039/c4fo01074d

Pribil, M., Labs, M., \& Leister, D. (2014). Structure and dynamics of thylakoids in land plants. Journal of Experimental Botany, 65(8), 1955-1972. doi: 10.1093/jxb/eru090

Rayner, M., Ljusberg, H., Emek, S. C., Sellman, E., Erlanson-Albertsson, C., \& Albertsson, P.-A. (2011). Chloroplast thylakoid membrane-stabilised emulsions. Journal of the Science of Food and Agriculture, 91(2), 315-321. doi: 10.1002/jsfa.4187

Rottet, S., Besagni, C., \& Kessler, F. (2015). The role of plastoglobules in thylakoid lipid remodeling during plant development. Biochimica et Biophysica Acta (BBA) Bioenergetics, 1847(9), 889-899. doi: 10.1016/j.bbabio.2015.02.002

Ruban, A. V., \& Johnson, M. P. (2015). Visualizing the dynamic structure of the plant photosynthetic membrane. Nature Plants, 1. doi: 10.1038/nplants.2015.161

Selstam, E. (1998). Development of thylakoid membranes with respect to lipids. In S. PaulAndré \& M. Norio (Eds.), Lipids in Photosynthesis: Structure, Function and Genetics (pp. 209-224). Dordrecht: Springer Netherlands.

Seta, L., Baldino, N., Gabriele, D., Lupi, F. R., \& de Cindio, B. (2012). The effect of surfactant type on the rheology of ovalbumin layers at the air/water and oil/water interfaces. Food Hydrocolloids, 29(2), 247-257. doi: 10.1016/j.foodhyd.2012.03.012

Siegenthaler, P.-A., \& Trémolières, A. (1998). Role of acyl lipids in the function of photosynthetic membranes in higher plants. In S. Paul-André \& M. Norio (Eds.), Lipids in Photosynthesis: Structure, Function and Genetics (pp. 145-173). Dordrecht: Springer Netherlands. 
Sprague, S. G. (1987). Structural and functional consequences of galactolipids on thylakoid membrane organization. Journal of Bioenergetics and Biomembranes, 19(6), 691703. doi: $10.1007 /$ bf00762303

Staehelin, L. A., \& van der Staay, G. W. (1996). Structure, composition, functional organization and dynamic properties of thylakoid membranes Oxygenic photosynthesis: The light reactions (pp. 11-30): Springer.

Tamayo Tenorio, A., Gieteling, J., de Jong, G. A. H., Boom, R. M., \& van der Goot, A. J. (2016). Recovery of protein from green leaves: Overview of crucial steps for utilisation. Food Chemistry, 203, 402-408. doi: 10.1016/j.foodchem.2016.02.092

Walstra, P. (2003). Chapter 10: Surface phenomena Physical Chemistry of Foods. USA: Marcel Dekker Inc.

Williams, A., \& Prins, A. (1996). Comparison of the dilational behaviour of adsorbed milk proteins at the air-water and oil-water interfaces. Colloids and Surfaces $A$ : Physicochemical and Engineering Aspects, 114, 267-275.

Williams, W. P. (1998). The physical properties of thylakoid membrane lipids and their relation to photosynthesis. In S. Paul-André \& M. Norio (Eds.), Lipids in Photosynthesis: Structure, Function and Genetics (pp. 103-118). Dordrecht: Springer Netherlands.

Wüstneck, R., Fainerman, V. B., Aksenenko, E. V., Kotsmar, C., Pradines, V., Krägel, J., \& Miller, R. (2012). Surface dilatational behavior of $\beta$-casein at the solution/air interface at different $\mathrm{pH}$ values. Colloids and Surfaces $A$ : Physicochemical and Engineering Aspects, 404, 17-24. doi: 10.1016/j.colsurfa.2012.03.050 


\section{Interfacial properties of green leaf cellulosic particles}

\section{Highlight}

- Leaf cellulosic particles behave like soft particles at the oil-water interface

- Attractive particle-particle interactions form an elastic interfacial network

- Particle fines stabilise the interface as Pickering emulsifiers

- Large particles aggregate and form an stable cream that immobilises oil droplets

- Leaf pulp constitute an abundant bio-based source of functional ingredients

This chapter has been submitted as:

A. Tamayo Tenorio, J. Gieteling, C.V. Nikiforidis, R.M. Boom, and A. J. van der Goot. Interfacial properties of green leaf cellulosic particles.. 


\section{Abstract}

Cellulosic pulp from sugar beet leaves was fractionated and assessed on its interfacial properties. After pressing leaves to express the juice, the press cake was washed at alkaline $\mathrm{pH}(\mathrm{pH}$ 9) to remove residual protein, dried, milled and air classified. The obtained cellulosic particles mainly consisted of insoluble dietary fibre $(77.8 \mathrm{wt} \%)$ with traces of proteins $(6.3 \mathrm{wt} \%)$ and exhibited considerable interfacial activity. The particle adsorption kinetics were characteristic of soft particles or Pickering emulsifiers, and the surface elasticity suggested the formation of an elastic network, probably mediated by capillary forces between the particles. Stable oil-in-water emulsions were produced using cellulosic particles, and despite phase separation, the emulsions were stable against coalescence. The results suggested that mostly particle fines $(0.04-1.0 \mu \mathrm{m})$ were responsible for the interfacial stabilisation, given the small oil droplets obtained $(2-5 \mu \mathrm{m})$; whereas larger particles $(>10 \mu \mathrm{m})$ created a network in the continuous phase, which was responsible for the emulsion phase separation. It was concluded that the cellulosic particles had a soft nature and suitable shape to produce stable Pickering emulsions, which can be used as food-grade particles for food and pharma applications. 


\subsection{Introduction}

The use of solid particles as emulsion stabilizers is highly promising in many applications (e.g. food, pharma, cosmetics) because of their outstanding stabilization against coalescence compared to low molecular weight emulsifiers (Tcholakova et al., 2008). The stabilising mechanism of solid particles in Pickering emulsions is due to the accumulation of particles at the oil-water interface as a densely packed layer, which is determined by the particle properties and emulsification conditions (Binks, 2002; Tzoumaki et al., 2011; Wu \& Ma, 2016). The particles are irreversibly adsorbed at the interface, and the mechanical properties of the adsorbed layer contribute to the long-term stability of emulsions (Dickinson, 2012). The particles may be synthetic or obtained from different types of biobased feedstocks (Rayner et al., 2014), which can be extended to leaves and leaf byproducts.

Leaves and leaf by-products are available on massive scale from industrialized crops. Using leaves that are now discarded, may at least partly provide a sustainable alternative to producing more food from existing resources (Dijkstra et al., 2003). For this, leaves are processed to extract valuable components such as proteins. The extraction involves a pressing/grinding step that separates the intracellular fluids from the leaf fibrous pulp. So far, most scientific interest is focussed on further juice purification, thereby neglecting the fact that the pulp represents nearly $25 \mathrm{wt} \%$ of the starting biomass (Tamayo Tenorio, Gieteling, et al., 2016), and giving added value to this large side stream would contribute to a more complete use of the green leaves.

The leaf fibrous pulp is rich in dietary fibres like cellulose, hemicellulose and lignin, with the amounts present varying between crops (Siqueira et al., 2010). Dietary, fibre rich materials have multiple uses, including clouding of beverages, thickening and gelling, and also low calorie bulking (Galanakis, 2012). Moreover, fibre rich biomass is a potential source of Pickering emulsion stabilisers. Such materials have been produced from other agro-industrial waste like orange peel (Wallecan et 
al., 2015), mango peel (Serna-Cock et al., 2016), celery and spinach (Göksel Saraç \& Dogan, 2016) and cocoa fibres (Gould et al., 2013).

The type of particles produced is related to the cell wall structure and to the processing conditions that disrupt the cell wall. In general, plant cell walls are networks of interconnected biopolymers such as polysaccharides (cellulose, hemicelluloses, pectin), glycoproteins (i.e. extensins), and lignin (Beck, 2005). With harsh processing conditions (i.e. high pressure, high temperature, chemical hydrolysis), pure crystalline cellulose can be obtained, which has been used in particle stabilised emulsions (Pickering) and composites (Siqueira et al., 2010). With milder mechanical processing, the resulting particles are rich in cellulose but still contain other cell wall components, like polysaccharide complexes (Harris \& Smith, 2006), which can provide additional Pickering stabilization (Wallecan et al., 2015).

In this study, cellulosic particles were extracted from sugar beet leaves (SBL), using mild aqueous extraction. Our objective was to characterise these particles and to study their interfacial behaviour. Composition and size characterisation were followed by interfacial tension and interfacial rheology analysis, and the particles were finally added to oil-water emulsions as stabilisers. We concluded that fibrous leaf pulp is a potential source of cellulosic particles that can be used as Pickering emulsifiers in food applications.

\subsection{Materials and Methods}

\subsubsection{Purification of leaf fibres}

Sugar beet leaves from mature plants were harvested from a sugar beet production field in Wageningen, The Netherlands. The leaves were pressed with a screw press (Angelia juicer II 7500 from Angel Juicers, Queensland, Australia) to separate the leaf juice from the fibrous pulp. The pulp was then processed until a fine powder as depicted in Figure 5. 1. The fibrous pulp was washed 5 times for 1 hour with alkaline deionised water $(\mathrm{pH} 9.0)$ in a pulp-to-water weight ratio of 1:5. 
The material was dialysed against MilliQ water with a cellulose membrane (MW cut-off of $14 \mathrm{kDa}$ ) (Sigma-Aldrich, St. Louis, MO, USA). The dialysed pulp was filtered through four layers of cheese cloth, followed by freeze drying. The dried pulp was milled with a rotor mill (Pulverisette 14, Fritsch, Germany) using a sievesize of $0.08 \mathrm{~mm}$. The resulting powder was separated by air-jet sieving (Alpine200 LS-N, Hosokawa-Alpine, Augsburg, Germany), collecting four fractions $\leq 20,20$ $50,50-100$ and $\geq 100 \mu \mathrm{m}$. The fraction between $20-50 \mu \mathrm{m}$ was used for further experiments.

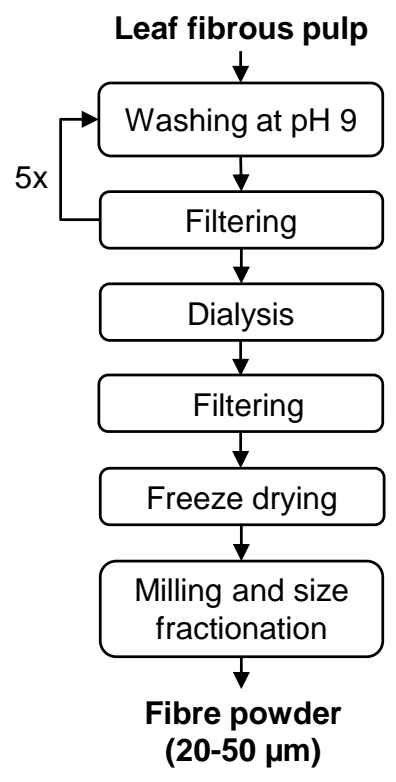

Figure 5. 1. Diagram of purification of fibre particles from sugar beet leaves.

\subsubsection{Compositional analysis}

The moisture content was determined with an infrared moisture analyser MA35 (Sartorius weighing technology $\mathrm{GmbH}$, Göttingen, Germany) at $105^{\circ} \mathrm{C}$. The nitrogen content of the dry samples was measured in duplicate by Dumas analysis (NA 2100 Nitrogen and Protein Analyser, ThermoQuest-CE Instruments, Rodeno, Italy). A conversion factor of 6.25 was used to convert nitrogen values to protein and to enable comparison with previous leaf protein studies, although lower 
conversion factors $(\sim 4.7)$ have been recently defined for SBL proteins (Kiskini et al., 2016). Total dietary fibre was determined with a Megazyme assay kit (Megazyme International, Bray, Ireland) according to AACC method 32-05.01 (AACC, 1983c). The ash and fat content were determined with official AACC method 08-01 and method 30-25, respectively (AACC, 1983a, 1983b).

\subsubsection{Zeta potential measurements}

The $\zeta$-potential was measured in triplicate as a function of $\mathrm{pH}$ with a Zetasizer (Malvern Instruments, Worcestershire, UK) coupled with an autotitrator (Malvern Instruments, Worcestershire, UK) at $\mathrm{pH}$ between 1.0-10.0. A cellulose particle dispersion $(0.5 \% \mathrm{w} / \mathrm{v})$ was prepared by vortexing and was analysed after $1 \mathrm{~h}$ of rest at $20^{\circ} \mathrm{C}$. Samples were diluted $\sim 1000$ times in Milli-Q water before the analysis.

\subsubsection{Interfacial tension and dilatational viscoelasticity}

The interfacial tension of a cellulose particle dispersion $(0.001 \% \mathrm{w} / \mathrm{v})$ was measured for $8 \mathrm{~h}$ in an automated drop tensiometer (Tracker, Teclis-instruments, Tassin, France), using a stainless steel capillary ( $3 \mathrm{~mm}$ diameter) to form a pendant sunflower oil drop in a particle dispersion at room temperature. The low particle concentration used was necessary to avoid precipitation during the measurement, which could affect the reproducibility of the results. Measurements were made with stripped sunflower oil prepared with alumina (Alumina N, Super I, MP Biomedicals, Germany) as described by Berton et al. (2011).

The interfacial tension data were analysed by fitting to the following equation:

$$
\gamma(t)=\gamma_{\infty}+\gamma_{1} e^{-\frac{t}{t_{1}}}+\gamma_{2} e^{-\frac{t}{t_{2}}}
$$

where $\gamma_{\infty}$ denotes the surface tension at equilibrium while the exponential terms represent two relaxation modes known for proteins and other macromolecules. The first exponential decay term may describe the adsorption, while the second exponential decay may be related to rearrangement of the components at the 
interface. Non-linear numerical fitting of Eq 5.1 to the experimental data was done with the curve fitting tool box in MATLAB (MathWorks, USA).

After reaching the equilibrium interfacial tension, compression and expansion measurements were done to determine the dilatational viscoelasticity, using an amplitude of $5 \%(\mathrm{v} / \mathrm{v})$ of the initial drop volume and frequencies of $0.001,0.005$, $0.01,0.02,0.05,0.1$ and $0.2 \mathrm{~s}^{-1}$. These measurements were used to estimate the interfacial dilatational modulus $\left(E_{d}\right)$, which is a measure of the resistance to surface disturbances and can be defined as $E_{d}=E_{d}^{\prime}+E_{d}^{\prime \prime}$. The storage modulus $\left(\mathrm{E}_{d}^{\prime}\right)$ represents the elastic energy stored in the interface (i.e. dilatational elasticity), while the loss modulus $\left(\mathrm{E}_{d}^{\prime \prime}\right)$ accounts for the energy dissipation in the relaxation process (i.e. dilatational viscosity).

\subsubsection{Emulsion preparation}

Oil-in-water emulsions were prepared by mixing aqueous cellulose particle suspensions at the appropriate concentrations with sunflower oil, using a rotorstator system (IKA-Werke GmbH \& Co. KG, Staufen, Germany) at 10,000 rpm for $2 \mathrm{~min}$, and subsequently homogenized (Delta Instruments, Drachten, The Netherlands) at 150 bar for $10 \mathrm{~min}$. The cellulose particle concentration was varied $(0.01,0.1,0.5,1.0 \% \mathrm{w} / \mathrm{v})$, while the oil concentration was always adjusted to $10 \mathrm{v} / \mathrm{v} \%$. All the concentrations refer to the whole emulsion and not just to the aqueous phase. Emulsions were stored at $20^{\circ} \mathrm{C}$ for stability analysis. Average droplet sizes were characterized in terms of the surface mean diameter $\mathrm{d}_{32}=$ $\sum_{i} n_{i} \cdot d_{i}^{3} / \sum_{i} n_{i} \cdot d_{i}^{2}$, with $n_{i}$ the number of droplets having a diameter $d_{i}$.

\subsubsection{Particle and droplet size analysis}

The particle size of the leaf fibre particles and the droplet size distributions of the emulsions were analysed by laser light diffraction (LD) with a Mastersizer 2000 (Malvern Instruments, Malvern, UK). High dilution was ensured by dispersing the samples in distilled water. The refractive index ratio used to calculate the oil droplet size distribution was 1.5. The fibre particles were suspended in water through high pressure homogenisation before the measurement. Additionally, the leaf fibre 
particle suspension was filtered ( $2.7 \mu \mathrm{m}$ cut off) and measured with a dynamic light scattering (DLS) spectrophotometer (Zetasizer, Malvern Instruments, Worcestershire, UK). This technique enables the detection of finer particles compared to the Mastersizer. All measurements were made at ambient temperature on three separately prepared samples.

\subsubsection{Surface coverage}

The surface coverage $(C)$ was determined by the ratio of the theoretical interfacial area that the particles can cover $\left(S_{p}\right)$ and the total interfacial area displayed by the oil droplets $\left(\mathrm{S}_{\mathrm{d}}\right)$ :

$$
\begin{gathered}
\mathrm{C}=\frac{\mathrm{S}_{p}}{\mathrm{~S}_{d}} \\
\mathrm{~S}_{p}=\frac{\mathrm{m}_{p}}{\mathrm{D}_{p} \rho_{p}} \\
\mathrm{~S}_{d}=\frac{6 \mathrm{~V}_{d}}{\mathrm{~d}_{32}}
\end{gathered}
$$

where $m_{p}, D_{p}$ and $\rho_{p}$ are the mass, average diameter and density of the cellulosic particles, respectively; $V_{d}$ is the volume of oil in the emulsion and $d_{32}$ is the average diameter of the oil droplets. The average diameter from the Zetasizer analysis was used as $D_{p}$. The density of the cellulosic particles was approximated to that of cellulose $(1.5 \mathrm{~g} / \mathrm{ml})$.

\subsubsection{Microscopy}

Scanning electron microscopy (SEM) was used to visualise the purified leaf fibre particles. The images were obtained with a Phenom G2 Pure (Phenom-world BV, Eindhoven, the Netherlands). Emulsions were observed with a light microscope (Axiovert-Zeiss, Gottingen, Germany) fitted with a digital camera (Axio Cam MRc 5, Gottingen, Germany), and with confocal laser scanning microscope (CLSM). The samples were visualised with an LSM 510 microscope (Zeiss, Germany). 


\subsection{Results and discussion}

\subsubsection{Characterisation of leaf fibre particles}

\section{Composition and particle size}

Fresh sugar beet leaves (SBL) were mechanically pressed to release their soluble intracellular fluid into a leaf juice while the cell wall material was retained as insoluble pulp or leaf fibres. A simplified scheme of a plant cell wall is depicted in Figure 5. $2 \mathrm{~A}$, identifying the major components and structural arrangements. The plant cell wall constitutes an ordered network of cellulose microfibrils coated with hemicellulosic polysaccharides, a gel-like matrix made of pectic polymers, and a network consisting of structural proteins that hold the polymers in place (Held et al., 2015).

A

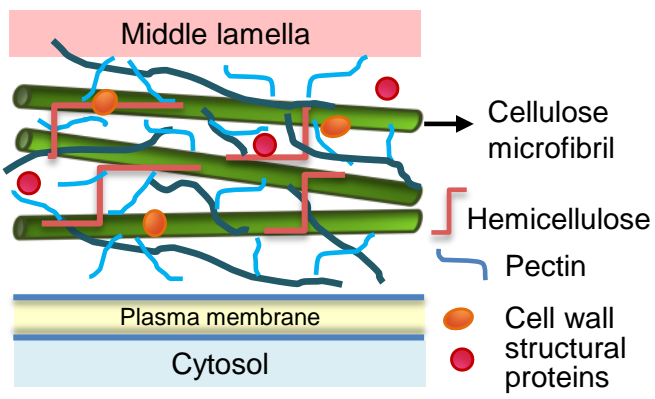

B

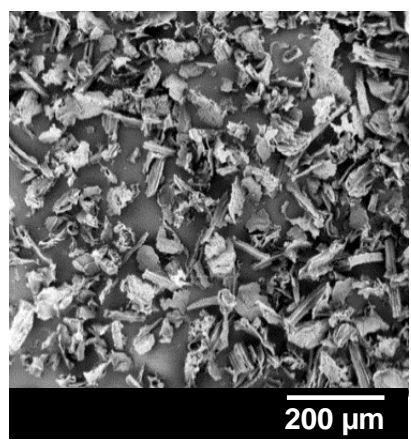

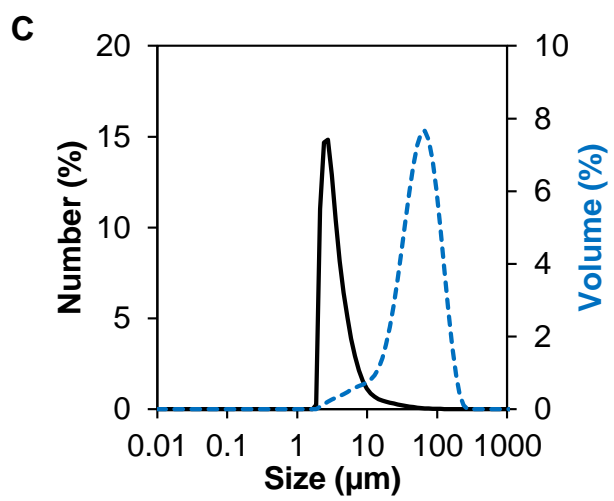

Figure 5. 2. (A) Simplified scheme of the primary cell wall structure, adapted from (Labavitch et al., 2015). Purified leaf fibres particles: (B) Scanning electron microscopy (SEM) image, and (C) particle size distribution of the $20-50 \mu \mathrm{m}$ fraction after suspension in water through high pressure homogenisation (measurement done with Mastersizer): (-) number based and (---) volume based data. 
The leaf pulp was used as raw material to obtain cellulose-rich particles, by washing at mild alkaline conditions ( $\mathrm{pH} 9.0$ ), drying, milling and air classification. The alkaline washing was applied to solubilize and remove components such as proteins (Walstra, 2003), while retaining most polysaccharide complexes. After washing, the cellulosic material was dried and milled to produce a fine powder with a particle sizes below $200 \mu \mathrm{m}$. Air classification was used to separate the particles between $20-50 \mu \mathrm{m}$, which were used for further analyses. This specific fraction was obtained in high yield ( $45 \mathrm{wt} \%$ of starting leaf pulp) and its size was below the negative mouthfeel threshold (Engelen \& Van Der Bilt, 2008). The particles in this fraction had a dietary fibre content of $77.8 \mathrm{wt} \%$ (Table 5. 1). About $82 \%$ of the fibres was insoluble, mainly consisting of cellulose and hemicellulose as described in previous studies with SBL (Singh et al., 1996). The remaining $18 \%$ of the dietary fibre corresponded to soluble dietary fibre, of which pectin is a major constituent (Harris \& Smith, 2006).

Table 5. 1. Composition of purified fibre particles from sugar beet leaves. Values expressed in dry basis. $n=3$

\begin{tabular}{lc}
\hline & wt\% $\mathbf{s d}$ \\
\hline Dietary fibre & $77.8 \pm 3.7$ \\
$\quad$ Insoluble & $64.1 \pm 2.3$ \\
$\quad$ Soluble & $13.7 \pm 1.4$ \\
Protein & $6.3 \pm 0.2$ \\
Ash & $5.2 \pm 2.5$ \\
Fat & $1.0 \pm 0.0$ \\
\hline
\end{tabular}

Besides polysaccharides, some protein (6.3 wt\%) was present in the cellulosic particles. The mild alkaline washing could remove unbound or soluble proteins, but at least some cell wall proteins were probably retained due to their strong interactions with the fibres. It is known that structural cell wall proteins bind the cell wall polysaccharides together through covalent bonds and ionic links (Eskin \& Hoehn, 2013; Held et al., 2015; Showalter, 1993).

Following the compositional analysis, the particles were visualized with scanning electron microscopy (SEM). The particles were irregular in size and shape (Figure 
5. 2B), but generally had a sheet geometry: one small dimension, and two much larger ones. After dispersion in water $(\mathrm{pH} 7)$ and high pressure homogenisation, the particle size ranged between 2-10 $\mu \mathrm{m}$ (Figure 5. 2 C), with some particles around $100 \mu \mathrm{m}$ (volume-based plot, Figure 5. 2 C). This analysis was done with a Mastersizer, which is based on laser light diffraction and has a particle size threshold between $1 \mu \mathrm{m}-1 \mathrm{~mm}$. To detect finer sizes, the particle suspension was also analysed with a Zetasizer, which is based on dynamic light scattering and can detect particle sizes between $0.5 \mathrm{~nm}-10 \mu \mathrm{m}$. This analysis showed particle fines ranging between $0.04-1.0 \mu \mathrm{m}$ (Figure $5.3 \mathrm{~A}$ ), clearly smaller than the size of particles observed with SEM in the dry state $(20-50 \mu \mathrm{m})$. The particles may break through homogenization into smaller sheet-like particles after swelling and softening in water.

A

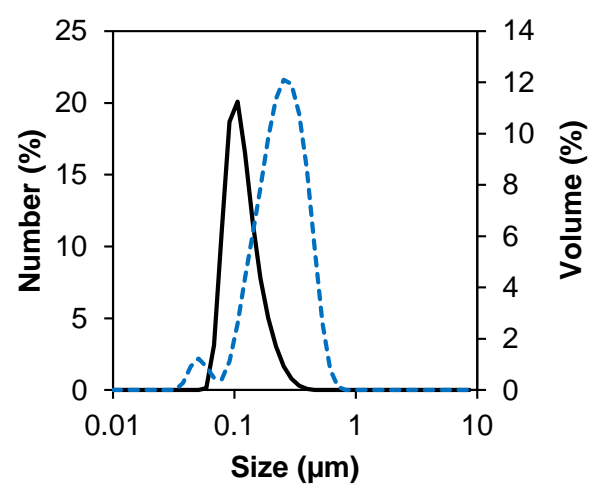

B

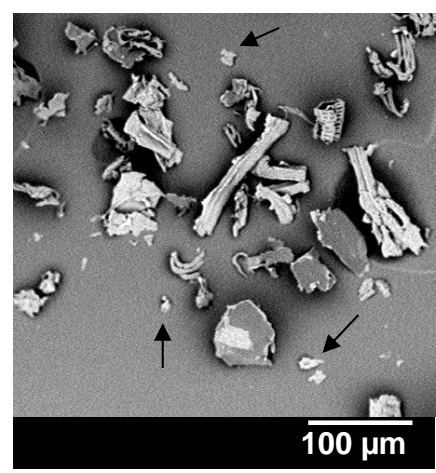

Figure 5. 3. (A) Particle size distribution of the 20 - $50 \mu \mathrm{m}$ particle fraction after suspension in water through high pressure homogenisation (measurement done with Zetasizer): (-) number based and (---) volume based data. (B) SEM image of leaf fibres particles after high pressure homogenisation (arrows point at particle fines).

High pressure homogenisation has been used earlier to functionalise fibres from orange peel, creating smaller particle sizes (Wallecan et al., 2015). Nevertheless, some particles remain intact after homogenisation as observed in Figure 5. $2 \mathrm{C}$ and in a SEM image of a sample that has been homogenised (Figure 5. $3 \mathrm{~B}$ ); this micrograph displays both particle fines and large/intact fragments. 


\section{S-potential analysis}

To further characterise the material regarding its purity and available chemical groups, the $\zeta$-potential of the cellulose particles was measured as a function of $\mathrm{pH}$ (Figure 5. $4 \mathrm{~A}$ ). The particles showed a zero charge point at $\mathrm{pH} 1.8$ while the negative charge reaches a plateau above $\mathrm{pH}$ 5.0. Similar $\zeta$-potential behaviour was reported for gum arabic, showing negative values (from -7 to ca. $-30 \mathrm{mV}$ ) at all $\mathrm{pH}$ and levelling off above $\mathrm{pH} \sim 4.0$ (Klein et al., 2010). Additional washing at $\mathrm{pH} 9.0$ and freeze drying (for extensive cell disruption) produced a purer cellulosic material, which exhibited no charge regardless of the pH (Figure 5. 4 B). Similar results have been reported with oat fibres, which showed a negligible potential after the removal of all soluble compounds (Chronakis et al., 2004). When the cellulosic particles were not exhaustively washed, the "impurities" (e.g. proteins, pectin) were retained and were responsible for the observed charge (Wallecan et al., 2015).

A

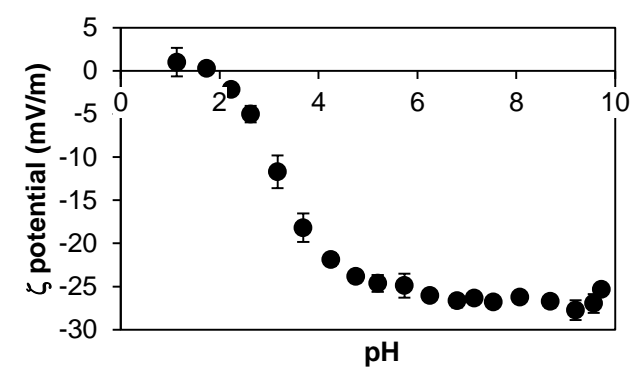

B

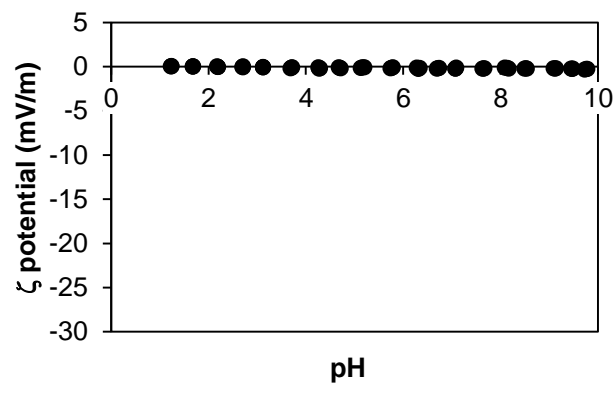

Figure 5. 4. $\zeta$ potential of SBL fibres after aqueous alkaline purification. (A) Cellulosic particles with " impurities", and (B) pure cellulosic particles.

\section{Dynamic interfacial tension}

The physical properties (i.e. size, amorphous shape, surface roughness) of the smaller cellulosic particles were expected to provide interfacial activity, since solid particles with some deformability and a rough surface are known to have surface activity (Deshmukh et al., 2014; Li et al., 2015; Madivala et al., 2009). Therefore, the adsorption dynamics of the cellulosic particles were measured at the oil-water interface with a drop tensiometer. As presented in Figure 5. 5, the cellulosic particles lowered the interfacial tension to an equilibrium value of $23 \mathrm{mN} \cdot \mathrm{m}^{-1}$. This 
decrease was rather small compared to the equilibrium value obtained with highly surface active molecules like lipids and proteins, but similar to that obtained with solid particles (Du et al., 2010). Due to their size, solid particles have a higher adsorption energy barrier, which is compensated by a very high desorption energy, explaining the stability of particle-stabilised emulsions (Tcholakova et al., 2008). Once at the interface, the cellulosic particles can lower the interfacial tension due to laterally attractive capillary forces between the adsorbed particles. These attractive interactions arise from distortions of the fluid interface that surrounds the particles, inducing changes on the surface tension (Binks, 2002). The attractive capillary forces are stronger for soft particles compared with rigid particles due to the large and heterogeneous wetting radius, which is caused by the deformable nature of the particles (Deshmukh et al., 2014; Van Hooghten et al., 2013). In the case of cellulosic particles, their irregular shaped and density might provide certain deformability, resulting in a soft type of particle. Additionally, particle-particle interactions may occur based on the particle's composition. Besides lowering the interfacial tension, the interfacial capillary forces and interactions between particles provide mechanical stability to the interfacial film formed after adsorption (BertonCarabin \& Schroën, 2015).

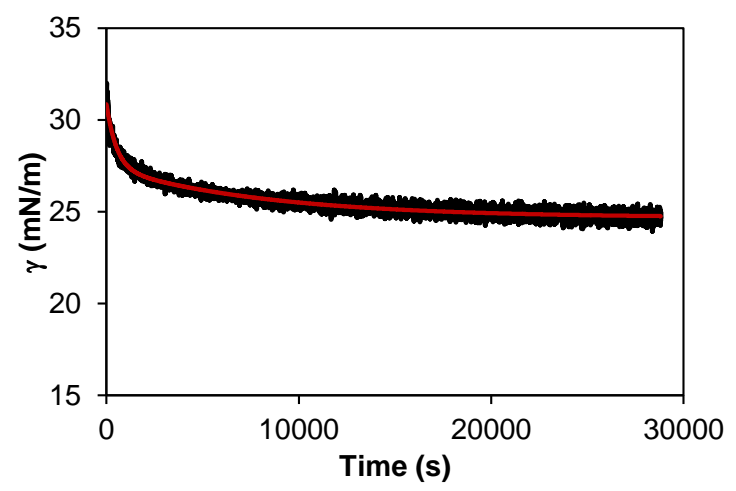

Figure 5. 5. Dynamic interfacial tension $(\gamma)$ measurements at the oil-water interface as a function of time (surface age) of a $0.001 \% \mathrm{w} / \mathrm{v}$ cellulosic particles dispersion. Cellulosic particles were dispersed in water through high-pressure homogenisation. In red: theoretical curve using Eq 5. 1.

To gain further knowledge on the adsorption mechanism, the experimental data in Figure 5.5 was fitted by Eq 5.1 as depicted by the red line. The relaxation times $t_{1}$ 
and $t_{2}$ were $8337.0 \mathrm{~s}(2.3 \mathrm{~h})$ and $513.4 \mathrm{~s}(8.6 \mathrm{~min})$, respectively, with a coefficient of determination $\left(r^{2}\right)$ of 0.9356 . These parameters give an indication of the mechanism during the interfacial tension decay. In this case, $t_{1}$ was significantly larger than $t_{2}$, suggesting that adsorption of the particles was the rate limiting step in the dynamic interfacial tension compared with rearrangement of the particles. This means that the cellulosic particles showed slow diffusion and adsorption, which is typical for solid particles (Pickering stabilizers). Similar adsorption kinetics were reported for nanoparticles (Boker et al., 2007; Liu \& Tang, 2016) and fragments from chloroplastic membranes (Tamayo Tenorio, de Jong, et al., 2016). While the diffusion of particles between $0.1-10 \mu \mathrm{m}$ is slow, the subsequent adsorption of particles may still be appreciable when the particles have some deformability (Li et al., 2015) and surface roughness (Van Hooghten et al., 2013). In the case of these irregular-shaped leaf cellulosic particles, their sheet-like geometry and composition indeed suggests deformability.

\section{Surface elasticity and viscosity}

Following the adsorption of the fibre particles at the oil-water interface, the interactions between the adsorbed molecules were investigated through dilatational oscillations. Figure 5. 6 presents a plot of the interfacial dilatational elasticity $\left(\mathrm{E}_{d}^{\prime}\right)$ as a function of the angular frequency. The viscous modulus $\left(\mathrm{E}_{d}^{\prime \prime}\right)$ was close to zero at all frequencies and negligible compared to $\mathrm{E}_{d}^{\prime}$. After $0.05 \mathrm{~s}^{-1}$, $\left(\mathrm{E}_{d}^{\prime}\right)$ reached a constant value around $14 \mathrm{mN} \cdot \mathrm{m}^{-1}$, similar to values reported for silica particles $\left(\sim 12 \mathrm{mN} \cdot \mathrm{m}^{-1}\right)$ at the frequency range discussed (Liggieri et al., 2011). The constant values of the elastic modulus after $0.05 \mathrm{~s}^{-1}$ suggests interaction between the particles on the interface, resulting in the creation of a network on the surface, rendering an interface that mostly exhibits elastic behaviour. Such behaviour is common for particle-stabilised emulsions where attractive interactions between particles provide some elasticity to the adsorbed layer (Tcholakova et al., 2008). The extent of the attractive interactions depends on particle properties such as their roughness and shape (Katepalli et al., 2017). Nonspherical particles can induce strong attractive capillary interactions and yield viscoelastic interfaces (Madivala et al., 2009). Additionally, hydrophobic and other 
types of physical interactions between the neighbouring adsorbed particles can contribute to the formation of the strong elastic network.

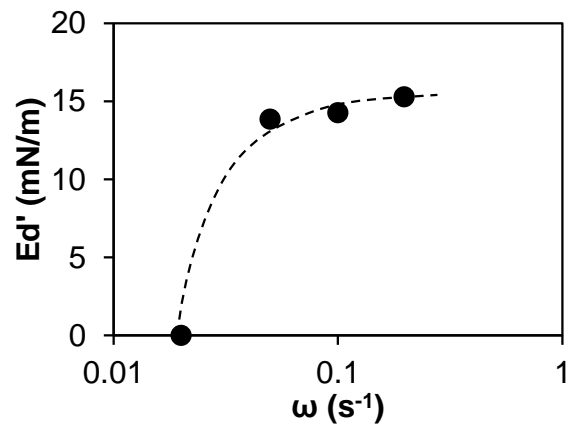

Figure 5. 6. Interfacial dilatational elastic modulus $\mathrm{E}_{d}^{\prime}$ as a function of oscillation frequency with a $0.001 \% \mathrm{w} / \mathrm{v}$ cellulosic particle solution $\left(\mathrm{T}=25^{\circ} \mathrm{C}\right.$, amplitude $=5 \%$ of the initial drop volume). The curve is meant to guide the eye.

\subsection{Emulsions stabilised with leaf cellulose particles}

The interfacial behaviour of the leaf cellulose particles was further studied by making oil-in-water emulsions. The mechanical treatment (homogenisation) provides enough energy to produce small oil droplets, while the cellulosic particles are transported to the interface by convection instead of diffusion. The oil-in-water emulsions that were obtained using the cellulosic particles showed a bimodal droplet size distribution (Figure 5. $7 \mathrm{~A}$ ); however, the majority of the droplets had small size as observed in the micrograph (figure background) and the number based plot. Therefore, the smaller peak was attributed to the oil droplets while the larger one to a minor fraction of large cellulosic particles, which had sizes around $100 \mu \mathrm{m}$ (Figure $5.7 \mathrm{C}$ ).

Two emulsion phases (top and bottom) were observed at all fibre particle concentrations, except at $0.01 \% \mathrm{w} / \mathrm{v}$ (Figure $5.7 \mathrm{~B}$ ). The top emulsion phase was likely formed by aggregates of large cellulosic particles, while the bottom phase contained only individual oil droplets $(<10 \mu \mathrm{m})$. The volume of the bottom phase was reduced at increasing concentrations of cellulosic particles, probably due to the increased number of large cellulosic particles in the continuous phase that 
promoted a network formation around the oil droplets (Binks, 2002; Wallecan et al., 2015).

A

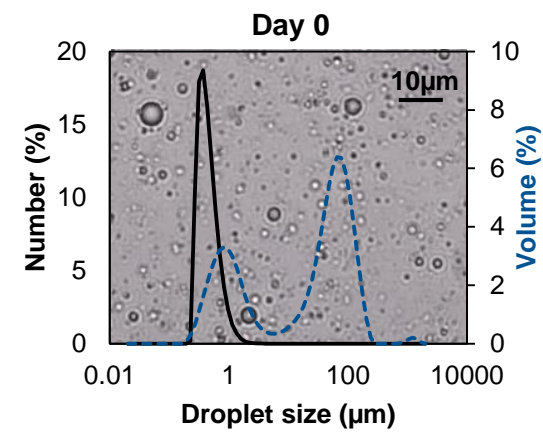

C

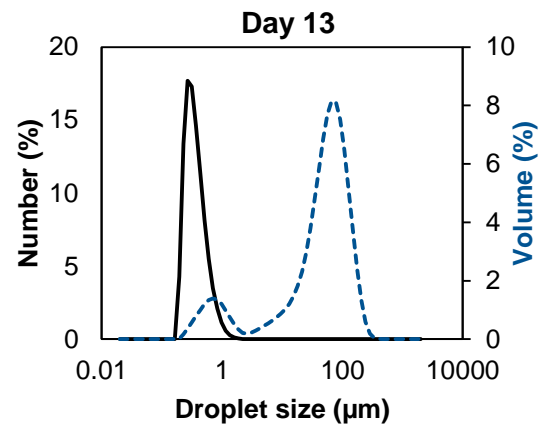

B

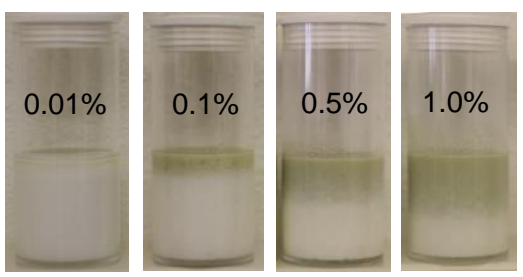

D

$0.5 \% \mathrm{w} / \mathrm{v}$

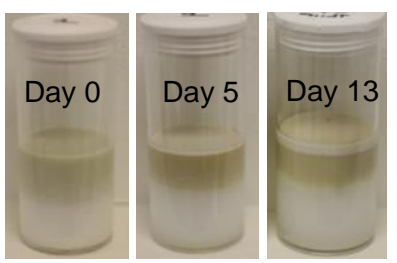

Figure 5. 7. Oil-in-water emulsions stabilised by cellulosic particles. Droplet-size distributions at $0.5 \% \mathrm{w} / \mathrm{v}$ particle concentration: $(\mathrm{A})$ at day 0 , the background of the graphs is a light microscope image, (C) at day 13 (storage at $20^{\circ} \mathrm{C}$ ); (-) number based and (--) volume based data. (B) Visual appearance at different particle concentrations (\% w/v). (D) Visual appearance of the $0.5 \% \mathrm{w} / \mathrm{v}$ emulsion over time.

Emulsions containing the cellulosic particles were stable over time against coalescence above a concentration of $0.1 \% \mathrm{w} / \mathrm{v}$ (Figure $5.7 \mathrm{C}$ and $\mathrm{D}$ ). At the current $\mathrm{pH}$ (6.5) the particles had a surface charge of $-25 \mathrm{mV}$ (Figure 5. $4 \mathrm{~A}$ ) and repel each other. As expected, no strong interactions occurred between the particles on neighbouring interfaces and no droplet aggregates were observed. At the lowest particle concentration $(0.01 \% \mathrm{w} / \mathrm{v})$, extensive coalescence and oil separation was observed after 1 day of storage. This concentration was therefore probably insufficient to completely cover the emulsion interface. This was confirmed with the surface coverage estimations (Table 5. 2), showing excess of 
particles in emulsions only when the particle concentration was above $0.1 \% \mathrm{w} / \mathrm{v}$. Moreover, above this concentration, the excess of particles can affect the viscosity of the emulsion and enhance stability.

Table 5. 2. Average oil droplet diameter $\left(d_{32}\right)$ and surface coverage (C) of the emulsions stabilised with cellulosic particles. Average particle diameter was estimated from Zetasizer measurement. $n=3$.

\begin{tabular}{ccc}
\hline $\begin{array}{c}\text { Particle } \\
\text { concentration }(\% \mathbf{w} / \mathbf{v})\end{array}$ & $\mathbf{d}_{32}(\boldsymbol{\mu m})$ & $\mathbf{C}$ \\
\hline 0.01 & $2.3 \pm 0.29$ & 0.13 \\
0.1 & $5.35 \pm 0.09$ & 2.03 \\
0.5 & $3.56 \pm 0.06$ & 6.78 \\
1.0 & $2.11 \pm 0.01$ & 8.02 \\
\hline
\end{tabular}

Considering the size of the particles $(0.04-10 \mu \mathrm{m})$ and the average size of the emulsion droplets $(2-5 \mu \mathrm{m})$, we expect that the finer particles $(0.04-1.0 \mu \mathrm{m})$ are responsible for the interface stabilisation. A CLSM image of the $0.5 \% \mathrm{w} / \mathrm{v}$ emulsion shows fine solid particles at the interface with larger particles between the oil droplets (Figure 5. 8). Similar results have been reported for cocoa particles, where the stabilization was also ascribed to the finest particles (Gould et al., 2013). The large cellulosic particles contribute to the network formation in the continuous phase and due to their interactions with the adsorbed particles, also contribute to the stabilization against coalescence; however, the network formation also causes the formation of a (stable) cream phase, in which oil droplets are immobilised between the large cellulose particles.

The fine particles stabilising the interface interact mainly through capillary forces, despite their surface charge (Figure 5. 4 A). Capillary attractions overrule electrostatic repulsions and can result in arrangement of particles at the interface, creating an elastic and stable monolayer (Deshmukh et al., 2014; Madivala et al., 2009). At higher particle concentrations, more fine particles can adsorb at the interface and the particle-particle interactions play an important role in reducing lateral movement of the particles and strengthening the interfacial film (Lopetinsky et al., 2006). 


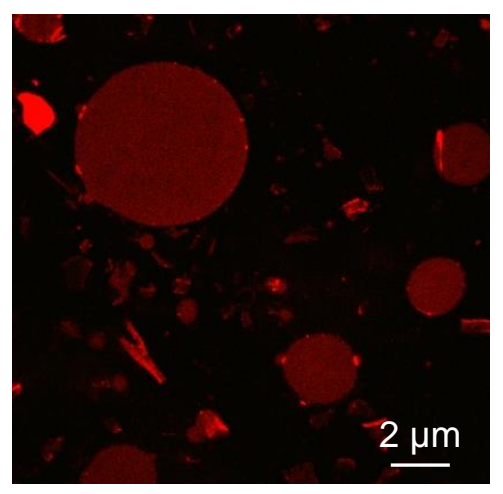

Figure 5. 8. Confocal laser scanning microscopy image of an oil-water emulsion with a particle concentration of $0.5 \% \mathrm{w} / \mathrm{v}$.

The mild processing to obtain cellulosic particles from leaf side streams resulted in solid particles with a rather wide size range, though with a suitable structure to act as Pickering emulsifiers. A Pickering stabiliser obtained from this abundant and currently discarded side stream may be used in food and pharma products, for which food-grade Pickering particles are desired (Berton-Carabin \& Schroën, 2015; Xiao et al., 2016).

\subsection{Conclusions}

Leaf pulp is an abundant, food grade resource that is currently unexploited. Mild fractionation resulted in sheet-like, deformable, rough particles that could stabilise emulsions through Pickering stabilisation. The solid nature of the particles explain the slow adsorption kinetics and interfacial rheology, which is similar to that of Pickering emulsifiers. The finest particles $(0.04-1 \mu \mathrm{m})$ are responsible for the interfacial stability through capillary forces, while larger particles form a network around the oil droplets, which further stabilises them against coalescence but also creates a (stable) concentrated cream phase. The benign, food grade refinement procedure in combination with the stabilisation properties, makes the particles interesting for application in both food and pharmaceutical products. 


\section{Acknowledgments}

The authors thank Thirea Peters for her contribution to the practical work; Jun Qiu for his contribution to the data fitting in MATLAB; and the Technology Foundation STW (The Netherlands) and Royal Cosun (The Netherlands) for their financial and project support.

\section{References}

AACC. (1983a). Method 08-01: Ash - Basic Method. Approved Methods of Analysis, 10th ed. AACC International, St. Paul, MN, U.S.A.

AACC. (1983b). Method 30-25: Crude Fat in Wheat, Corn and Soy Flour, Feeds, and Mixed Feeds. Approved Methods of Analysis, 10th ed. AACC International, St. Paul, MN, U.S.A.

AACC. (1983c). Method 32-05: Total Dietary Fiber. Approved Methods of Analysis, 10th ed. AACC International, St. Paul, MN, U.S.A.

Beck, C. B. (2005). An Introduction to Plant Structure and Development: Cambridge University Press.

Berton-Carabin, C. C., \& Schroën, K. (2015). Pickering emulsions for food applications: Background, trends, and challenges. Annual Review of Food Science and Technology, 6, 263-297. doi: 10.1146/annurev-food-081114-110822

Berton, C., Genot, C., \& Ropers, M. H. (2011). Quantification of unadsorbed protein and surfactant emulsifiers in oil-in-water emulsions. Journal of Colloid and Interface Science, 354(2), 739-748. doi: 10.1016/j.jcis.2010.11.055

Binks, B. P. (2002). Particles as surfactants-similarities and differences. Current Opinion in Colloid \& Interface Science, 7(1-2), 21-41. doi: 10.1016/S1359-0294(02)00008-0

Boker, A., He, J., Emrick, T., \& Russell, T. P. (2007). Self-assembly of nanoparticles at interfaces. Soft Matter, 3(10), 1231-1248. doi: 10.1039/b706609k

Chronakis, I. S., Öste Triantafyllou, A., \& Öste, R. (2004). Solid-state characteristics and redispersible properties of powders formed by spray-drying and freeze-drying cereal dispersions of varying $(1 \rightarrow 3,1 \rightarrow 4)$ - $\beta$-glucan content. Journal of Cereal Science, 40(2), 183-193. doi: 10.1016/j.jcs.2004.03.004

Deshmukh, O. S., Van Den Ende, D., Stuart, M. C., Mugele, F., \& Duits, M. H. G. (2014). Hard and soft colloids at fluid interfaces: Adsorption, interactions, assembly \& rheology. Advances in Colloid and Interface Science, 222, 215-217. doi: 10.1016/j.cis.2014.09.003

Dijkstra, D. S., Linnemann, A. R., \& van Boekel, T. A. (2003). Towards sustainable production of protein-rich foods: appraisal of eight crops for Western Europe. PART 
II: Analysis of the technological aspects of the production chain. Critical Reviews in Food Science and Nutrition, 43(5), 481-506.

Du, K., Glogowski, E., Emrick, T., Russell, T. P., \& Dinsmore, A. D. (2010). Adsorption energy of nano- and microparticles at liquid-liquid interfaces. Langmuir, 26(15), 12518-12522. doi: $10.1021 / \mathrm{la} 100497 \mathrm{~h}$

Engelen, L., \& Van Der Bilt, A. (2008). Oral physiology and texture perception of semisolids. Journal of Texture Studies, 39(1), 83-113. doi: 10.1111/j.1745-4603.2007.00132.x

Eskin, N. A. M., \& Hoehn, E. (2013). Chapter 2 - Fruits and Vegetables Biochemistry of Foods (Third Edition) (pp. 49-126). San Diego: Academic Press.

Galanakis, C. M. (2012). Recovery of high added-value components from food wastes: Conventional, emerging technologies and commercialized applications. Trends in Food Science \& Technology, 26(2), 68-87. doi: 10.1016/j.tifs.2012.03.003

Göksel Saraç, M., \& Dogan, M. (2016). Incorporation of dietary fiber concentrates from fruit and vegetable wastes in butter: effects on physicochemical, textural, and sensory properties. European Food Research and Technology, 242(8), 1331-1342. doi: 10.1007/s00217-016-2637-9

Gould, J., Vieira, J., \& Wolf, B. (2013). Cocoa particles for food emulsion stabilisation. Food \& Function, 4(9), 1369-1375. doi: 10.1039/c3fo30181h

Harris, P. J., \& Smith, B. G. (2006). Plant cell walls and cell-wall polysaccharides: structures, properties and uses in food products. International Journal of Food Science \& Technology, 41(s2), 129-143.

Held, M. A., Jiang, N., Basu, D., Showalter, A. M., \& Faik, A. (2015). Plant cell wall polysaccharides: Structure and biosynthesis Polysaccharides: Bioactivity and Biotechnology (pp. 3-54).

Katepalli, H., John, V. T., Tripathi, A., \& Bose, A. (2017). Microstructure and rheology of particle stabilized emulsions: Effects of particle shape and inter-particle interactions. Journal of Colloid and Interface Science, 485, 11-17. doi: 10.1016/j.jcis.2016.09.015

Kiskini, A., Vissers, A., Vincken, J. P., Gruppen, H., \& Wierenga, P. A. (2016). Effect of plant age on the quantity and quality of proteins extracted from sugar beet (Beta vulgaris L.) leaves. Journal of Agricultural and Food Chemistry, 64(44), 8305-8314. doi: 10.1021/acs.jafc.6b03095

Klein, M., Aserin, A., Ishai, P. B., \& Garti, N. (2010). Interactions between whey protein isolate and gum Arabic. Colloids and Surfaces B: Biointerfaces, 79(2), 377-383. doi: 10.1016/j.colsurfb.2010.04.021

Labavitch, J. M., Powell, A. L. T., Greve, L. C., Blanco-Ulate, B., Cantu, D., \& Vicente, A. R. (2015). Cell wall metabolism: The Yin and Yang of fruit postharvest biology Acta Horticulturae (Vol. 1079, pp. 27-40). 
Li, Z., Harbottle, D., Pensini, E., Ngai, T., Richtering, W., \& Xu, Z. (2015). Fundamental study of emulsions stabilized by soft and rigid particles. Langmuir, 31(23), 62826288. doi: 10.1021/acs.langmuir.5b00039

Liggieri, L., Santini, E., Guzman, E., Maestro, A., \& Ravera, F. (2011). Wide-frequency dilational rheology investigation of mixed silica nanoparticle-CTAB interfacial layers. Soft Matter, 7(17), 7699-7709. doi: 10.1039/c1sm05257h

Liu, F., \& Tang, C.-H. (2016). Soy glycinin as food-grade Pickering stabilizers: Part. I. Structural characteristics, emulsifying properties and adsorption/arrangement at interface. Food Hydrocolloids, 60, 606-619. doi: 10.1016/j.foodhyd.2015.04.025

Lopetinsky, R. J. G., Masliyah, J. H., \& Xu, Z. (2006). Solids-stabilized emulsions: A review Colloidal Particles at Liquid Interfaces (pp. 186-224).

Madivala, B., Vandebril, S., Fransaer, J., \& Vermant, J. (2009). Exploiting particle shape in solid stabilized emulsions. Soft Matter, 5(8), 1717-1727. doi: 10.1039/b816680c

Rayner, M., Marku, D., Eriksson, M., Sjöö, M., Dejmek, P., \& Wahlgren, M. (2014). Biomassbased particles for the formulation of Pickering type emulsions in food and topical applications. Colloids and Surfaces A: Physicochemical and Engineering Aspects, 458(1), 48-62. doi: 10.1016/j.colsurfa.2014.03.053

Serna-Cock, L., García-Gonzales, E., \& Torres-León, C. (2016). Agro-industrial potential of the mango peel based on its nutritional and functional properties. Food Reviews International, 32(4), 364-376. doi: 10.1080/87559129.2015.1094815

Showalter, A. M. (1993). Structure and function of plant cell wall proteins. The Plant Cell, 5(1), 9-23. doi: 10.1105/tpc.5.1.9

Singh, K., Honig, H., Wermke, M., \& Zimmer, E. (1996). Fermentation pattern and changes in cell wall constituents of straw-forage silages, straws and partners during storage. Animal Feed Science and Technology, 61(1-4), 137-153.

Siqueira, G., Bras, J., \& Dufresne, A. (2010). Cellulosic Bionanocomposites: A Review of Preparation, Properties and Applications. Polymers, 2(4), 728-765.

Tamayo Tenorio, A., de Jong, E. W. M., Nikiforidis, C. V., Boom, R., \& van der Goot, A. J. (2016). Interfacial properties and emulsification performance of thylakoid membrane fragments. Soft Matter. doi: 10.1039/c6sm02195f

Tamayo Tenorio, A., Gieteling, J., de Jong, G. A. H., Boom, R. M., \& van der Goot, A. J. (2016). Recovery of protein from green leaves: Overview of crucial steps for utilisation. Food Chemistry, 203, 402-408. doi: 10.1016/j.foodchem.2016.02.092

Tcholakova, S., Denkov, N. D., \& Lips, A. (2008). Comparison of solid particles, globular proteins and surfactants as emulsifiers. Physical Chemistry Chemical Physics, 10(12), 1608-1627. doi: 10.1039/b715933c

Van Hooghten, R., Imperiali, L., Boeckx, V., Sharma, R., \& Vermant, J. (2013). Rough nanoparticles at the oil-water interfaces: Their structure, rheology and applications. Soft Matter, 9(45), 10791-10798. doi: 10.1039/c3sm52089g 
Wallecan, J., McCrae, C., Debon, S. J. J., Dong, J., \& Mazoyer, J. (2015). Emulsifying and stabilizing properties of functionalized orange pulp fibers. Food Hydrocolloids, 47, 115-123. doi: 10.1016/j.foodhyd.2015.01.009

Walstra, P. (2003). Chapter 10: Surface phenomena Physical Chemistry of Foods. USA: Marcel Dekker Inc.

Xiao, J., Li, Y., \& Huang, Q. (2016). Recent advances on food-grade particles stabilized Pickering emulsions: Fabrication, characterization and research trends. Trends in Food Science and Technology, 55, 48-60. doi: 10.1016/j.tifs.2016.05.010 


\section{6 \\ Processing concepts for the use of green leaves as raw materials for the food industry}

\section{Highlight}

- Resource-efficient use of leaves by leaf stabilisation or decentralised processing

- Freezing is feasible to stabilise sugar beet leaf before protein extraction

- Energy requirement for freezing is close to that of plant-based protein production

- Decentralised process reduces leaf perishability and transportation load

- Decentralised process enables recycling of leaf pulp and retention of soil quality

This chapter has been submitted as:

A. Tamayo Tenorio, F.K.G. Schreuders, F.K. Zisopoulos, R.M. Boom and A. J. van der Goot. Processing concepts for the use of green leaves as raw materials for the food industry. 


\section{Abstract}

Large scale processing of leaves for food applications requires quick processing or stabilisation to avoid perishability, due to the high moisture content in this biomass. Leaf perishability is compounded by the seasonal availability of some crops, like sugar beet plants, of which the leaves are regarded as a potential protein source. This study evaluates the resource efficiency of a hypothetical sugar beet leaf processing chain by comparing the use of freezing as stabilisation in a scenario with centralised processing and a scenario with decentralised processing. The study includes an analysis of the effects of centralised/decentralised processing on energy requirements, transportation and soil quality. Energy usage and exergy consumption were used to quantify the thermodynamic performance of the processing options. Freezing has negligible effect on the process-ability of the leaves and the resulting leaf products in terms of protein content and protein yield. Besides, freezing is a more suitable stabilising method than for instance drying the whole leaves. On-farm processing of the leaves (decentralised scenarios) clearly reduces the transportation load due to the large difference in bulk densities of leaves $\left(73 \mathrm{~kg} / \mathrm{m}^{3}\right)$ and leaf juice $\left(1000 \mathrm{~kg} / \mathrm{m}^{3}\right)$. The decentralised scenarios also enable direct returning of the leaf pulp to the soil and thereby improving soil quality (i.e. nutrient retention and fertility). Therefore, the preferred chain configuration would be a decentralised system where the leaves are directly pressed at the farm, the pulp is used to fertilize the soil, and the leaf juice is chilled transported to a centralised factory. The addition of a freezing step to extend the shelf life of the leaves would depend on the capacity of the mechanical pressing. 


\subsection{Introduction}

Green leaves are a potential source of functional food ingredients (Azmir et al., 2013; Lammens et al., 2012; Tamayo Tenorio et al., 2017) and valuable food proteins (Pirie, 1966; Rathore, 2010; Telek and Graham, 1983). Despite our knowledge about leaf as a protein source and the existing extraction methods, the challenges for leaf processing are in the scale-up of the process and in the overall chain feasibility (Bals et al., 2012). Large scale processing of leaves is limited by their high moisture content, which translates into large volumes and heavy weight in relation to the quantity of usable contents (Papendiek et al., 2012). This has implications for transportation, but also for spoilage of the leaves, which are prone to fast enzymatic and microbial decay (Kammes et al., 2011). Therefore, the initial handling (e.g. harvest, storage) and stabilisation of the leaves are as important as the extraction processes to obtain high added value products (e.g. proteins, bioactive compounds).

Sugar beet plants are an important leaf source in Europe, being one of the most produced crops in several countries. Sugar beet leaves (SBL) are already explored for food applications (Jwanny et al., 1993; Merodio and Sabater, 1988; Sheen, 1991; Tamayo Tenorio et al., 2016), but the current practice is to leave them on the land after harvesting the primary product (i.e. sugar beet). With SBL the challenge of dealing with high moisture content is compounded by their seasonal availability, demanding large peak capacities. This is not the case when leaves are the primary product of a crop, like alfalfa or spinach leaves, allowing a different harvesting strategy.

During green leaf processing the first step consists of mechanical pressing to release the intracellular contents. Once the leaves are pressed, the juice is further processed to separate the main leaf components (Tamayo Tenorio et al., 2016). However, leaf stabilisation before mechanical pressing is essential for good extraction yield and net valorisation, due to the seasonality of crops like SBL. In the Netherlands, harvesting all SBL would translate into $\sim 27 \mathrm{kt} /$ day of SBL over 4 months of harvest (Factfish.com, 2014). 
Routes to stabilise fresh leaves include cooling, freezing and drying (van der Goot et al., 2016). Drying is the most energy intensive option (Berghout et al., 2015), given the large volumes of water that need to be removed in case of leaves. The average water content of leaves ranges between $85-90 \%$, whereas that of protein crops (e.g. soybean, lupine beans) ranges between $8-15 \%$ (Kandlakunta et al., 2008; Lee et al., 2016). Besides, drying the leaves damages their nutritive value and hinders the extractability of proteins (Bals et al., 2012). This renders cooling and freezing as most suitable stabilisation methods. For seasonal crops like SBL, the harvesting peaks demand long time storage before all the leaves can be centrally processed. In that case, only freezing is suitable to extent the shelf life of leaves over months, provided that the extraction and properties of final products are not compromised.

The suitability of freezing as a stabilising method, will be assessed on its sustainability (concerning the use of resources), together with the impact on the quality of extracted final products (i.e. protein extract). Exergy use is employed as an indicator for the use of resources, which are important in ensuring sustainability. Exergy is a state variable that is based on the first and second law of thermodynamics and indicates the maximum (i.e. available) work that can be extracted from a stream in relation to an environment of reference (Apaiah et al., 2006). Exergy-based indicators (e.g. exergy efficiency and exergy losses) reflect the environmental impact of a process/product in terms of irreversible destruction of natural resource use (Zisopoulos et al., 2017). Therefore, exergy analysis can be used to objectively identify best processing conditions and practices before the actual implementation of a novel process and to find critical points in the process.

Furthermore, process decentralisation has been suggested as a processing practice to overcome negative environmental impact (i.e. soil nutrient losses) from SBL processing (van Dijk et al., 2013). Instead of processing in a central facility, decentralisation implies the localisation of the first process steps on the farm, allowing easy return of unused side streams to the land to maintain soil quality (Bruins and Sanders, 2012). Process decentralisation brings along other benefits 
like reduction of transportation volumes and decrease of perishability effects by immediate processing (Kolfschoten et al., 2014). Hence, two network configuration scenarios (i.e. centralised versus decentralised) will be analysed together with freezing as stabilisation method.

Currently, residual green leaves from harvested sugar beet plants are not valorised. Therefore, the aim of this paper is to compare the resource efficiency of different processing concepts for the industrial use of leaves. Here, freezing was considered as a stabilisation treatment that enables further extraction of valuable leaf components, such as proteins. The resource efficiency of this stabilising method was assessed in terms of energy requirement and exergy indicators that quantify thermodynamic performance. Finally, we evaluated how the decentralisation of the process would affect the stabilisation treatments and the overall resource efficiency of leaf valorisation.

\subsection{Materials and methods}

\subsubsection{General description of initial leaf processing}

\section{Leaf processing and stabilisation}

Leaf processing implies collection, stabilisation, pressing and further processing into the desired products. For this, we consider two scenarios:

(A) fresh leaves are directly processed without stabilisation; and

(B) leaves are stabilised by freezing after harvesting to extend their shelf life, and consequently extend the time for mechanical pressing.

The sizes and composition of products streams that we propose here for sugar beet leaves (SBL) are based on a lab-scale method described by Tamayo Tenorio et al., (2016) (Figure 6. 1). The equipment capacity and typical energy consumption are based on pilot scale equipment. Initially, the leaves are pressed with a twinscrew press having a capacity of $315 \mathrm{~kg} \mathrm{SBL} / \mathrm{h}$ that uses $42.2 \mathrm{~kJ}$ of electricity/kg SBL (HUBER). The pressing step produces a leaf juice, while the leaf fibres are collected at the farthest end of the screws. 

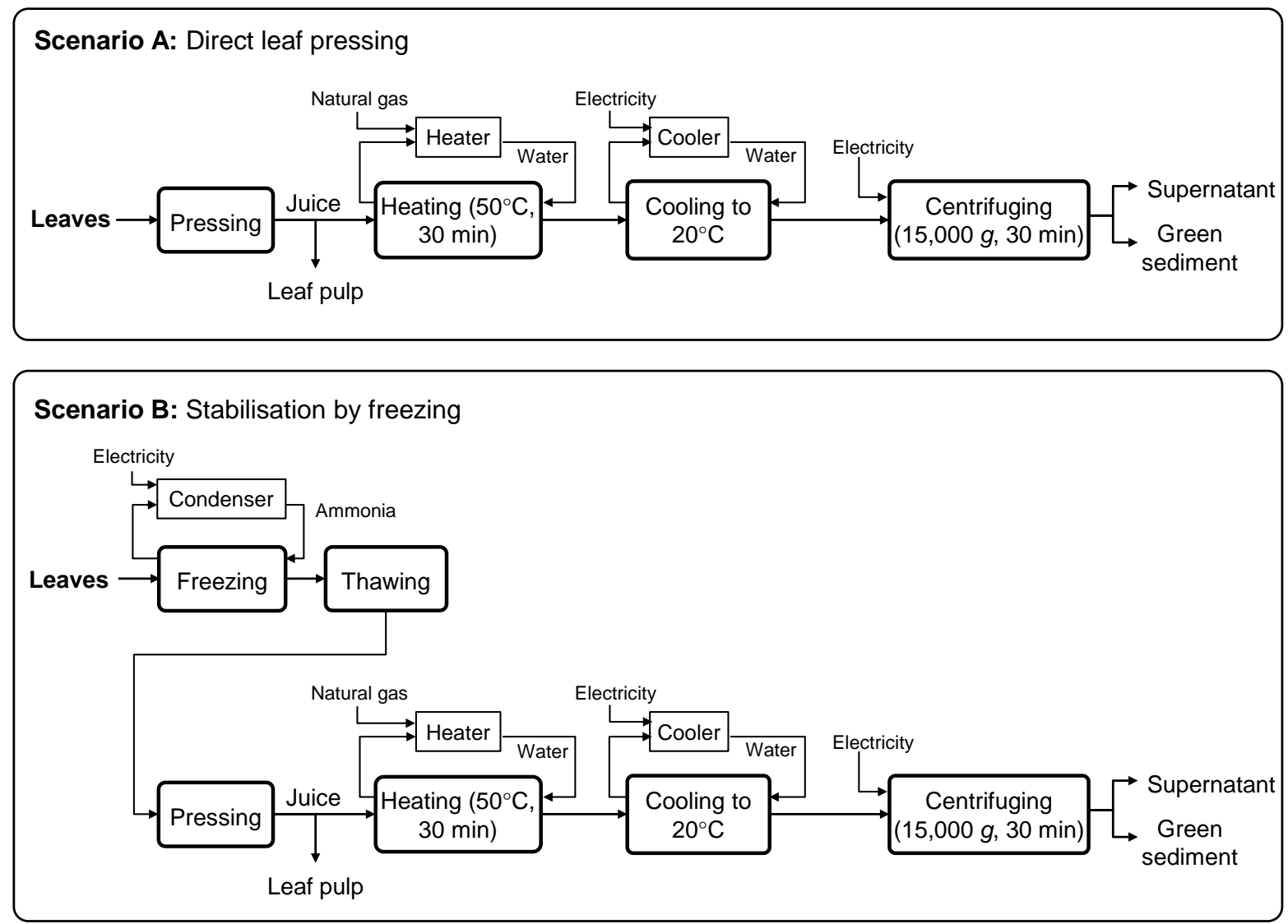

Figure 6. 1. Process scheme for protein extraction from green leaves indicating direct pressing of the leaves (scenario A) and freezing of the whole leaves to extend their shelf life (scenario B). 
After pressing, the fibrous pulp ( $27 \% \mathrm{w} / \mathrm{v}$ of the initial biomass) is discarded. The extracted juice is heated to $50^{\circ} \mathrm{C}$ for $30 \mathrm{~min}$ with hot water at $60^{\circ} \mathrm{C}$ and cooled to room temperature with cold water at $10^{\circ} \mathrm{C}$. For the heating and cooling water we assume that they are readily available on-site. A burner using natural gas is used for heating the water. The juice is centrifuged in a continuous process and the resulting supernatant and sediment are collected. Stabilisation of fresh leaves and leaf juice is done by freezing with a plate-freezer using ammonia as cooling agent, which requires $336.5 \mathrm{~kJ} / \mathrm{kg} \mathrm{SBL}$ (ASHRAE, 2006). The frozen material is stored at $-20^{\circ} \mathrm{C}$ to be processed year round, requiring an average energy input of $0.5 \mathrm{~kJ} / \mathrm{m}^{3}$ (Koelcelvink, 2014). The frozen leaves are thawed before the mechanical pressing, using water at ambient temperature available on-site.

\section{Decentralised scenarios}

Leaves can be frozen and stored until further extraction. This freezing process can be done either at the point of harvesting or in a centralised factory. The network configuration scenarios considered for SBL are depicted in Figure 6. 2 and are adapted from van Dijk et al. (2013). The scenarios A and B described earlier are here considered under centralised (cent) and decentralised (dec) conditions:

\section{Centralised:}

- $\quad\left(\mathbf{A}^{\text {cent }}\right)$ unlimited pressing capacity, which allows continuous pressing of the leaves and makes stabilisation unnecessary; and

- $\quad\left(\mathbf{B}^{\text {cent }}\right)$ pressing capacity is limited and freezing the leaves is necessary to extend their shelf life and allow pressing over a longer time.

Decentralised:

- $\quad\left(\mathbf{A}^{\text {dec }}\right)$ pressing occurs at the farm. Presses are available at every location, which allows for continuous pressing directly after or even during harvesting and makes stabilisation unnecessary; and

- $\quad\left(B^{\text {dec }}\right)$ freezing and pressing occurs at the farm. Presses are not available at every location and freezing is necessary to extend the shelf life of the leaves. 
In both decentralised options only the chilled leaf juice is then transported to the processing factory, analogous to the collection of milk from dairy farms. Moreover, direct leaf pressing at the farm allows direct return of the leaf pulp to the land.

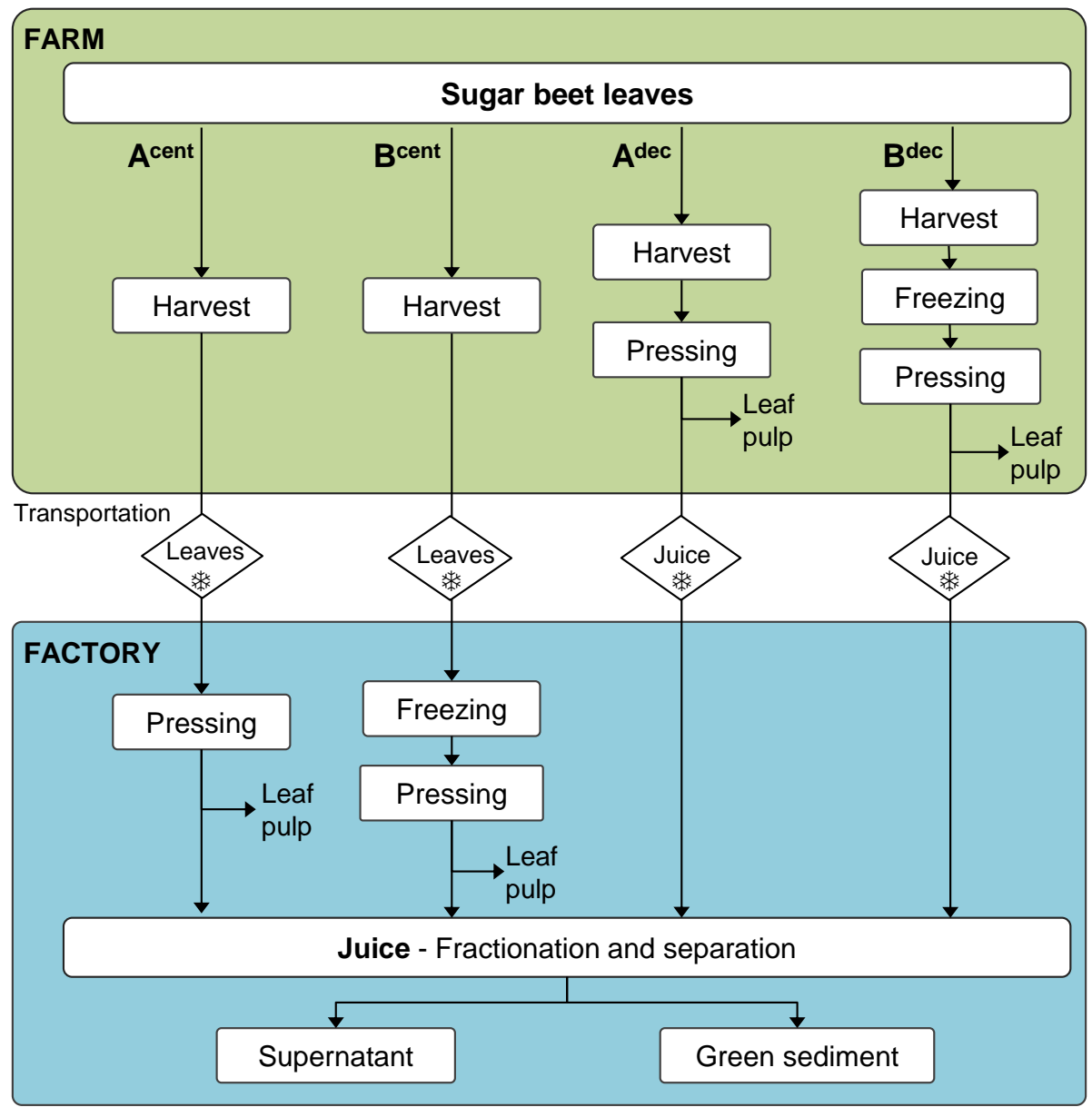

Figure 6. 2. Network configuration scenarios for leaf protein extraction. Centralised processing with $\left(B^{\text {cent }}\right)$ and without $\left(A^{\text {cent }}\right)$ freezing; leaves are transported and all unit operation are at a centralised location. Decentralised processing, allocating unit operations at the farm and factory: $A^{\text {dec }}$, pressing at the farm and $B^{\text {dec }}$, freezing and pressing at the farm; juice is transported to a central factory. denotes cool transportation.

The distance between the farm and the centralised factory is varied between $10 \mathrm{~km}$ and $250 \mathrm{~km}$. Depending on the scenario, transportation involves the transfer of fresh leaves or chilled juice to the central processing facility, and the return of 
empty trucks to the farms. Additional assumptions related to transport are given in Table A 1 in the Appendix.

\subsubsection{Data collection}

The throughput of processed leaves was set to a steady 1 ton/h as base for the calculations. Composition and masses of all fractions were based on experimental work (see below). The compositions of the supernatant and sediment were assumed to be similar for all processing routes. The chemical composition of the processing streams and the main assumptions for the processes are given in Table A 2 and Table A 3 in the Appendix.

\section{Leaf protein extraction (lab-scale)}

Sugar beet leaves (SBL) were harvested from a sandy field $(0.85 \mathrm{ha})$ located in Wageningen, The Netherlands. Fresh and frozen SBL were processed as described by Tamayo Tenorio et al., (2016). Leaves were pressed with a screw press, Angelia juicer II 7500 (Angel Juicers, Queensland, Australia). The extracted juice was heated to $50^{\circ} \mathrm{C}$ for $30 \mathrm{~min}$, cooled to room temperature, followed by centrifugation at $15,000 \mathrm{~g}$ for $30 \mathrm{~min}$. The resulting supernatant and sediment were carefully separated. Leaves and leaf products were oven dried and ground before compositional analysis.

\section{Compositional analysis}

The dry matter content was determined by oven drying at $50^{\circ} \mathrm{C}$ for $48 \mathrm{~h}$ and recording the weight losses. Protein nitrogen was determined by Dumas analysis with a NA 2100 Nitrogen and Protein Analyser (ThermoQuest-CE Instruments, Rodeno, Italy). Methionine was used as standard during the analysis. Duplicate measurements were made for all samples. A conversion factor of 6.25 was used to convert nitrogen values to protein. Protein yield was calculated as gram of protein in the product (e.g. juice, sediment) per gram of protein in the leaves.

\subsubsection{Thermodynamic assessment}

The mass and energy flows were calculated with the following equations: 


$$
\begin{gathered}
\sum \mathrm{m}_{\text {in }}-\sum \mathrm{m}_{\text {out }}=0 \\
\sum(\mathrm{mh})_{\text {out }}-\sum(\mathrm{mh})_{\text {in }}=\mathrm{Q}-\mathrm{W}
\end{gathered}
$$

For exergy calculations (Eq 6. 3), chemical and physical exergy were considered, while mixing exergy was neglected, since the mixing exergy related to macromolecular components is very small at any rate. The chemical exergy (Eq 6 . 4) of a substance is based on the standard chemical exergy, which is the minimum amount of exergy required to produce that substance from a standard environment. The specific exergies of the components studied are given in Table A 4. Physical exergy (Eq 6. 5) can be divided into pressure and thermal exergy (Eq 6.6) related to the deviation from the atmospheric pressure and environmental temperature, respectively. For leaf processing, exergy of fuel and electricity (Eq 6. 7) were also considered. Exergy losses were calculated with (Eq 6. 8) and (Eq 6. 9). Cumulative exergy losses (CEL, kJ/kg SBL) are defined by (Eq 6. 10.

$$
\begin{gathered}
\mathrm{Ex}=\mathrm{Ex}_{\text {chem }}+\mathrm{Ex}_{\text {physical }}+\mathrm{Ex}_{\text {mixing }} \\
\mathrm{Ex}_{\mathrm{chem}}=\mathrm{m} \cdot \sum_{\mathrm{i}=1}^{\mathrm{n}}\left(\mathrm{b}_{0, \mathrm{i}} \cdot \mathrm{x}_{\mathrm{i}}\right) \\
\mathrm{Ex}_{\text {physical }}=\mathrm{Ex}_{\text {thermal }}+\mathrm{Ex}_{\text {pressure }}+\mathrm{Ex}_{\text {electrical }} \\
\mathrm{Ex}_{\text {thermal }}=\mathrm{m} \cdot c_{\mathrm{p}} \cdot\left[\left(\mathrm{T}-\mathrm{T}_{0}\right)-\mathrm{T}_{0} \cdot \ln \left(\frac{\mathrm{T}}{\mathrm{T}_{0}}\right)\right] \\
\mathrm{Ex}_{\mathrm{fuel}}=\mathrm{Q} \cdot f \\
\mathrm{Ex}_{\text {loss }}=\mathrm{Ex}_{\text {in }}-\mathrm{Ex}_{\text {out }} \\
\operatorname{Ex}_{\text {loss }}=\mathrm{Ex}_{\text {waste }}+\mathrm{Ex}_{\text {destruction }} \\
\mathrm{CEL}=\sum \mathrm{Ex}_{\text {loss }}
\end{gathered}
$$

Energy flows were visualized by Sankey diagrams and exergy flows were visualized with Grassmann diagrams, using the software e!Sankey 3.2 (IFU Hamburg GmbH, Hamburg, Germany). 


\subsection{Results and discussion}

\subsubsection{Analysis of the leaf protein extraction (scenarios $A, B$ )}

\section{Effect of freezing on leaf and leaf products}

Figure 6. 3 presents the protein content and protein yield of pressed juice and green sediment from sugar beet leaves, comparing the use of frozen leaves with fresh leaves. Freezing intact leaves resulted in similar protein concentrations in the juice, but a somewhat higher protein concentration in the sediment. However, the higher protein content in the sediment did not exceed the natural variation of the plant material, which is represented with the error bars.

A

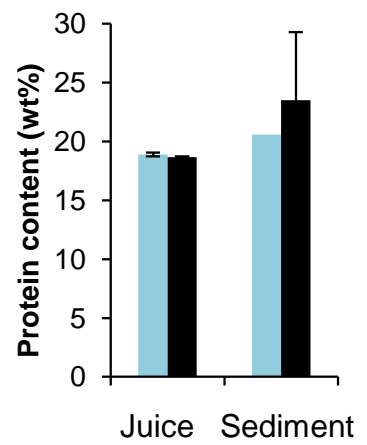

B

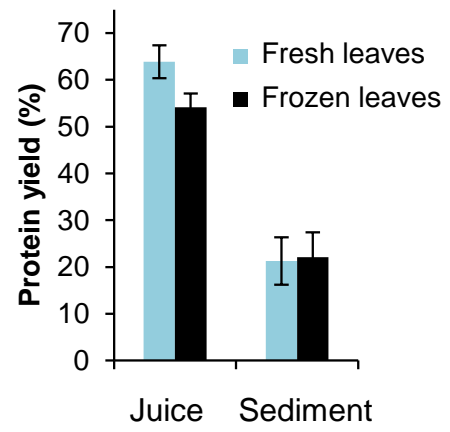

Figure 6. 3. Protein content (a) and protein yield (b) in juice and sediment after processing of fresh and frozen leaves. The confidence interval bars correspond to standard deviations.

Higher protein yield was observed for the juice from fresh leaves than from frozen leaves (Figure 6. $3 \mathrm{~B}$ ), but no effect was observed in the protein yield of the sediment. In frozen leaves, the leaf tissue was disruption due to ice crystals formed during freezing (Silva et al., 2009). The loss of cell integrity together with mechanical pressing determined the division of the material over the juice and the leaf pulp. The variations on protein yield are probably due to batch-to-batch variations of the starting material, explaining the higher protein yield in the control juice. Therefore, we conclude that freezing SBL has negligible effects on the protein content and yield in SBL products, confirming the suitability of freezing as stabilisation treatment. 
When considering other leafy biomass, freezing whole leaves showed improvement on protein extractability from pumpkin and amaranth leaves (Ghaly and Alkoaik, 2010). Moreover, freezing leaf juice from alfalfa leaves was tested as coagulation and concentration method of the soluble protein fraction (Hernández et al., 1997), suggesting a combined effect of freezing to stabilise the biomass and to aid fractionation. However, we did not observe these effects with SBL.

\section{Energy requirements}

The energy flows during leaf processing are visualised in Figure 6. 4. The overall energy requirements for processing the leaves (scenario $A$ ) were estimated to be in total $382 \mathrm{~kJ} / \mathrm{kg}$ SBL (Table 6. 1), with heating and cooling being most energy demanding ( $88 \%$ of the energy). Adding a freezing step to stabilise the leaves (scenario B) would require an additional energy input of $617 \mathrm{~kJ} / \mathrm{kg} \mathrm{SBL}$, of which $337 \mathrm{~kJ} / \mathrm{kg} \mathrm{SBL}$ is needed to freeze the leaves and $280 \mathrm{~kJ} / \mathrm{kg} \mathrm{SBL}$ is needed to store the frozen material over one year. However, the energy cost involved in freezing could be compensated by the increased use of biomass due to an extended shelf life. By freezing the leaves, three times more leaves can be processed when a fixed pressing capacity is assumed. The extension of the leaf shelf life comes at the price of $\sim 28 \%$ more energy, which is needed for the storage at $-20^{\circ} \mathrm{C}$.

Table 6. 1. Energy requirement per processing step.

\begin{tabular}{lc}
\hline & $\mathbf{k J} / \mathbf{k g ~ S B L}$ \\
\hline Leaf pressing (scenario A) & \\
Pressing & 42.2 \\
Heating & 147.2 \\
Cooling & 189.3 \\
Centrifugation & 3.1 \\
\hline Additional freezing (scenario B) & 336.5 \\
$\quad$ Freezing & 280.1 \\
\hline Frozen storage $\left(-20^{\circ} \mathrm{C}\right) /$ year & \\
\hline
\end{tabular}




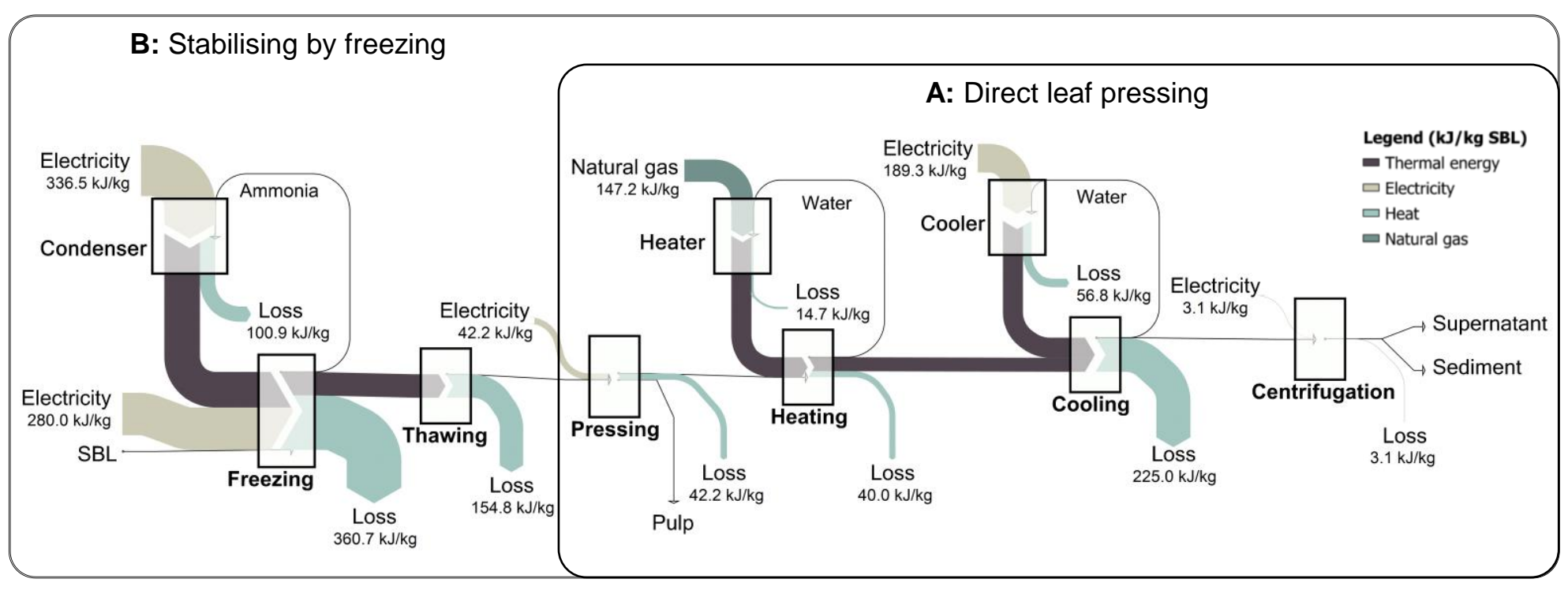

Figure 6. 4. Sankey diagram of the energy flow during leaf processing: direct leaf pressing (scenario A), and leaf stabilisation by freezing (scenario B). 
The energy requirement for freezing and storage is still noticeably lower than for whole leaf drying, considering that drying the leaves constitutes another stabilising method. However, assuming an energy requirement of $6 \mathrm{MJ}$ per $\mathrm{kg}$ water (Berghout et al., 2015), drying the leaves would result in $6,818 \mathrm{~kJ} / \mathrm{kg} \mathrm{SBL}$. Another disadvantage of drying is that dried material is not suitable for protein extraction under mild conditions (i.e. neutral $\mathrm{pH}$, low temperature). Protein extraction from dried alfalfa leaves leads to lower yields and less purity than from fresh leaves (Hojilla-Evangelista et al., 2016). Reaching higher yields would require harsh conditions such as using highly alkaline $\mathrm{pH}(\mathrm{pH} 14)$, as described for dried tea leaves (Zhang et al., 2014).

One may compare the energy required to produce protein from fresh and frozen (or even dried) leaves with the energy required to produce proteins from other sources, either plant or animal-based. Considering that food and nutritional security is one of the 17 sustainable development goals that were agreed on by the United Nations in 2015 (UN, 2015), such a comparison would provide additional incentives to use green leaves for the production of food proteins. The energy cost of producing $1 \mathrm{~kg}$ of protein was estimated and compared to values reported for animal and plant based proteins. For instance, the production of $1 \mathrm{~kg}$ of animalbased protein requires $425 \mathrm{MJ}$ of fossil fuels as compared to $37 \mathrm{MJ}$ required to produce $1 \mathrm{~kg}$ of plant-based proteins (Pimentel and Pimentel, 2003). In the case of $\mathrm{SBL}$, freezing the leaves implies a total use of $35 \mathrm{MJ}$ of energy per kilogram of protein, whereas drying requires up to $380 \mathrm{MJ} / \mathrm{kg}$ protein. Thus, freezing the leaves would result in energy requirements that are still below the energy used for plantbased proteins.

\section{Exergy analysis}

The chemical and physical exergy flows were calculated for the leaf protein extraction process, with and without stabilising by freezing. The pressing step accounts for the largest exergy losses (Figure 6. 5) due to the wastage of the chemical exergy of the fibrous pulp, which accounts for $1.3 \mathrm{MJ} / \mathrm{kg} \mathrm{SBL}$; however this loss is present in both scenarios $(A, B)$. The other processing steps (i.e. 


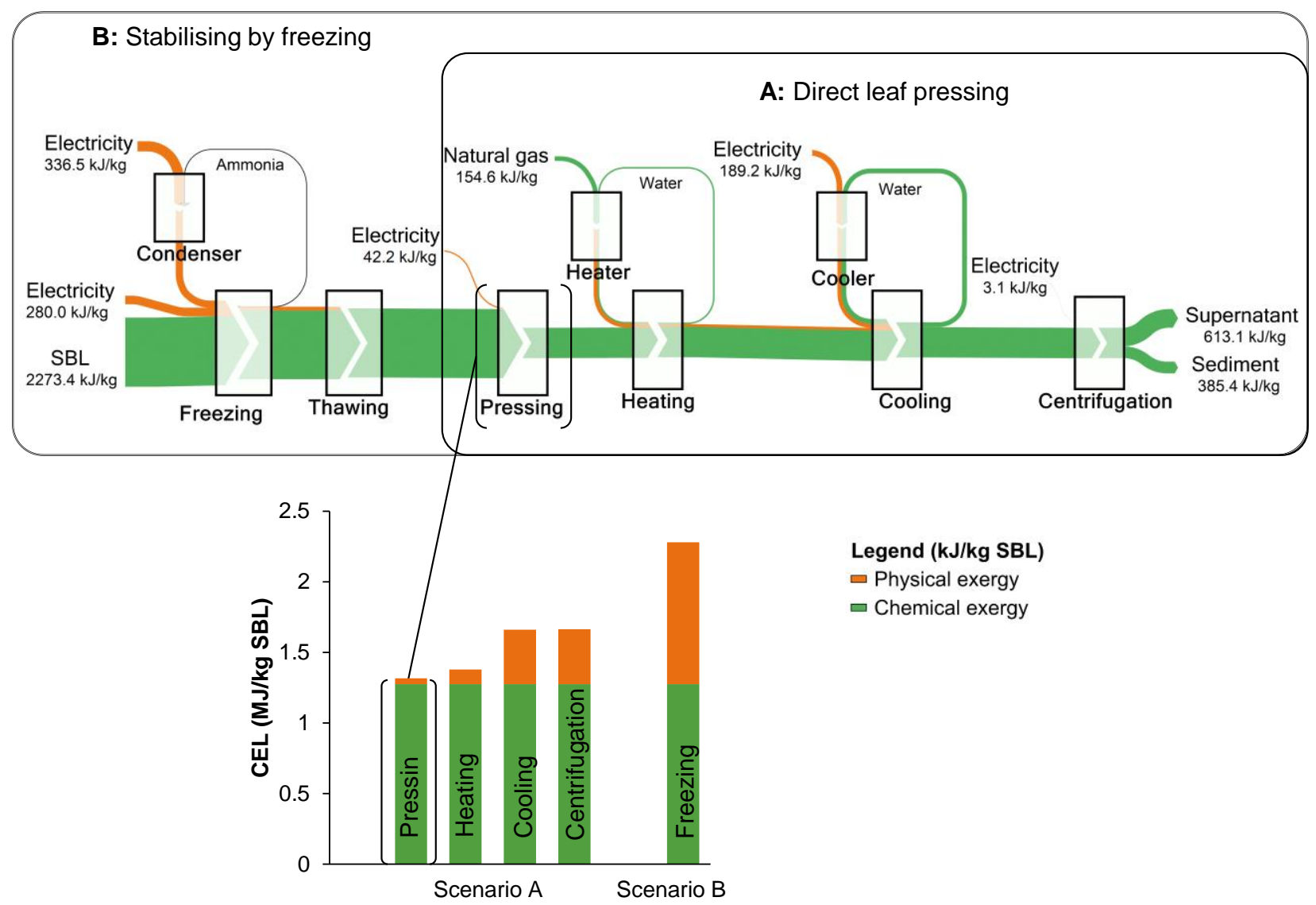

Figure 6. 5. Grassmann diagram of leaf protein extraction (scenario A) and the stabilising step (scenario B), depicting the cumulative exergy losses (CEL). The ammonia used for freezing is recycled and its chemical exergy is not displayed in the diagram to aid visualisation of other/smaller streams. 
pressing, heating, cooling, and centrifugation) result in a physical exergy loss of $0.39 \mathrm{MJ} / \mathrm{kg} \mathrm{SBL}$.

The chemical exergy of process streams is much larger in magnitude than the physical exergy as was shown also for other food processes and food production chains (Berghout et al., 2015; Jankowiak et al., 2014; Vandermeersch et al., 2014). This large difference implies that the generation of waste streams needs to be avoided, either by reusing or recycling (Zisopoulos, 2016). Consequently, valorising the fibrous pulp should be a first priority before any energy optimisation is considered. Possible uses for this stream include feed, soil fertiliser and raw material for the production of functional food ingredients (i.e. cellulose nanoparticles (Liu et al., 2008)).

Nevertheless, both scenarios (A and B) produce the same amount of leaf pulp, and consequently the usage of the pulp is the same. Therefore, when assuming that the pulp is fully utilised the focus should shift towards the reduction of the physical exergy loss due to heating, cooling, freezing etc. The reduction of physical exergy losses can be done by process integration (Paudel et al., 2017), which can identify the most efficient heat exchange network configuration and consequently reducing any additional costs for external heating and cooling utilities.

\subsubsection{Network configuration for leaf processing (Scenarios $A^{\text {cent }}, A^{\text {dec }}$, $B^{\text {cent }}, B^{\text {dec }}$ )}

Based on the analysis described above for scenarios $A$ and $B$, the identification of energy requirements and exergy losses was extended to the centralised and decentralised network configurations described in Figure 6. 2. The analysis also includes the transportation load and potential benefits to the land.

\section{Energy requirements}

Scenarios involving freezing $\left(B^{\text {cent }}, B^{\text {dec }}\right.$ ) would require 2.6 times more energy to process the same amount of leaves compared to scenarios without freezing $\left(A^{\text {cent }}\right.$, $\left.A^{\text {dec }}\right)$. When the pressing capacity was assumed to be unlimited $\left(A^{\text {cent }}\right)$ or presses were present at all farms $\left(A^{\text {dec }}\right)$, pressing accounted only for $11 \%$ of the total 
energy requirement. When freezing was necessary to extend the leaf shelf life (scenarios $B^{\text {cent }}, B^{\text {dec }}$ ), freezing was the most energy demanding process $(62 \%)$, followed by heating (15\%), and cooling (19\%). Thus, having many presses would require less energy than stabilising the leaves by freezing and then pressing. However, the requirements for flexibility in the process and economical optimisation of the total system would determine the preferred scenario, since energy costs can be exceeded by the costs of other operations such as installation, set-up, labour and buildings (Wan et al., 2016).

After pressing the leaves, the leaf juice would be then processed into final products (e.g. protein concentrate) at a centralised facility. The supernatant and sediment obtained after leaf centrifugation also demands quick stabilisation to avoid perishability. The supernatant can be first concentrated through ultrafiltration, which requires hardly any energy (Berghout et al., 2015). Ultrafiltration can increase the dry matter content of the supernatant from $5.6 \%$ to about $30 \%$, and further water removal can be done by drying, requiring $\sim 550 \mathrm{~kJ} / \mathrm{kg} \mathrm{SBL}$ of energy input. The green sediment, which is already a concentrated stream $(30.5 \%$ dry mater content), can be dried with spray drying, requiring $\sim 250 \mathrm{~kJ} / \mathrm{kg} \mathrm{SBL}$. The energy requirement to stabilise both the supernatant and sediment is similar to that of leaf freezing $(617 \mathrm{~kJ} / \mathrm{kg} \mathrm{SBL})$, and therefore close to the energy required to produce plant-based proteins. Nevertheless, the design of the central factory, in terms of capacity and unit operations, will be determined by the products and applications thereof after fractionation. Further investigation is needed to explore the various options for using the supernatant and sediment produced, followed by up-scaling of downstream processes.

\section{Exergy losses}

All scenarios $\left(A^{\text {cent }}, A^{\text {dec }}, B^{\text {cent }}\right.$ and $\left.B^{\text {dec }}\right)$ produce the same amount of leaf pulp, although at different locations. In general, centralised pressing of the leaves would allow the use of the pulp for food or non-food uses, and possibly returning only the unused fractions to the farms; whereas processing at the farms would allow for the direct return of the pulp to the land, but would make exploitation into useful 
products more difficult. Though, returning the pulp to the land fertilises and provides structure to the soil (van Dijk et al., 2013).

The reduction of exergy losses is then focused on the physical exergy losses in the unit operations (heating, cooling, freezing, etc.), which can improve the resource use in the different scenarios. With centralized process configurations ( $A^{\text {cent }}$ and $B^{\text {cent }}$ ), energy can theoretically be re-used by process integration (Paudel et al., 2017). Whereas with decentralised processing, energy integration is much more difficult, although technologies that make use of renewable energy may be used. For example, small-scale hybrid systems to produce electricity, heat and cooling could be used by coupling wind energy with compressed air energy storage systems. Such system can generate $33.67 \mathrm{~kW}$ electricity, $2.56 \mathrm{~kW}$ cooling and 1.82 ton hot water per day (Mohammadi et al., 2017). However, the capital investment for the necessary equipment could be substantial and therefore, they should also be considered.

\section{Transportation load}

In the decentralised scenarios mobile units are used either to press $\left(A^{\text {dec }}\right)$ or to freeze and later press the leaves $\left(B^{\text {dec }}\right)$ on the farm. On-farm pressing of the leaves means that $27 \%$ less material would have to be transported, which is equivalent to the mass percentage of the leaf pulp. Additionally, transportation of the leaf juice requires less than $10 \%$ of the initial transportation volume, due to the difference in bulk density between leaves and juice, estimated as $73 \mathrm{~kg} / \mathrm{m}^{3}$ and $1000 \mathrm{~kg} / \mathrm{m}^{3}$, respectively. For each truckload of leaf juice, about 19 trucks would be required to transport the respective fresh leaves (Table A 5 in the Appendix). Compression of the SBL would induce damage and increase the enzymatic decay and spoilage. Crops with smaller leaves, like spinach, do allow more efficient packing, reaching a density of $118 \mathrm{~kg} / \mathrm{m}^{3}$ (Sharan and Rawale, 2003); hence, the equivalent number of trucks for spinach would be 9 instead of 19 for SBL.

The cumulative exergy losses related to transportation depend on the distances covered (Figure 6. 6 A), either to bring the leaves to a centralised factory (scenarios $A^{\text {cent }}$ and $B^{\text {cent }}$ ), or to only transport the leaf juice produced at the farm 
(scenarios $\mathrm{A}^{\mathrm{dec}}$ and $\mathrm{B}^{\mathrm{dec}}$ ). All scenarios include the transportation of empty trucks back to the farm after delivering either leaves or juice. Whether transportation becomes important in terms of exergy losses or not, depends on the energy intensity of the processing steps. At a hypothetical travelling distance of $100 \mathrm{~km}$ and assuming a total use of the leaf pulp, the CEL of the leaf processing without freezing (scenario $A^{\text {cent }}$ ) was estimated to be $441 \mathrm{~kJ} / \mathrm{kg} \mathrm{SBL}$, of which $12 \%$ would be due to transportation; while with freezing (scenario $B^{\text {cent }}$ ) this value would be $1057 \mathrm{~kJ} / \mathrm{kg} \mathrm{SBL}$ with $5 \%$ due to transportation. Clearly, freezing makes the transportation costs less critical (Figure 6. 6 B). Nevertheless, the suitability of a centralised scenario without freezing the leaves relies on the availability of pressing equipment that can handle all the fresh leaf throughput.

The transportation exergy losses for the decentralised scenarios (on-farm pressing: $A^{\text {dec }}, B^{\text {dec }}$ ) are negligible compared to those for centralised pressing (Figure 6. $6 \mathrm{~A}$ and $B$ ). Moreover, the leaf pulp becomes available for directly returning to the land or for other uses (e.g. silage or bio-gas production), whereas the leaf juice requires cooled transportation, analogous to the collection of raw milk from dairy farms. Ultimately, the small contribution by the transportation of the juice would also mean that on-farm concentration of the leaf juice would not make sense both exergy-wise and economically. The costs of concentrating the juice in many small installations would be far higher than the reduced amount of transportation that would be required.

A

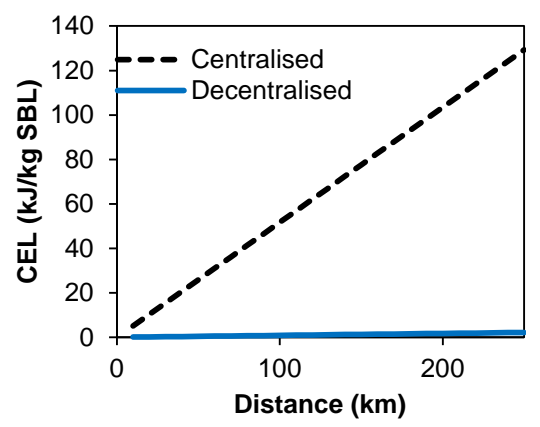

B

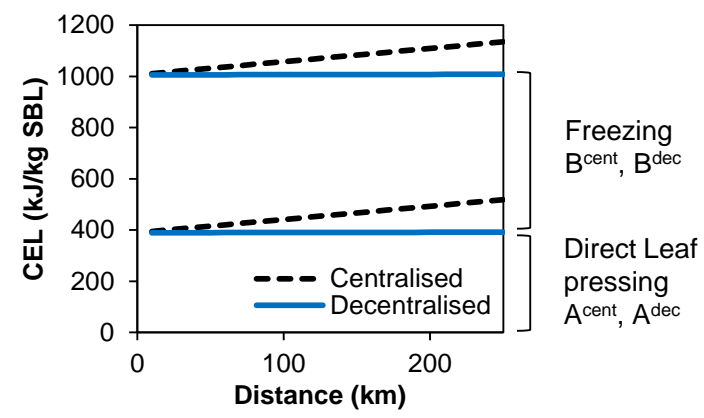

Figure 6. 6. Cumulative exergy losses (CEL): (A) only for transportation; (B) for transportation including leaf processing under the centralised $\left(A^{\text {cent }}, B^{\text {cent }}\right)$ and decentralised $\left(A^{\text {dec }}, B^{\text {dec }}\right)$ scenarios. 


\subsubsection{Benefit to the land}

Decentralised scenarios have already been considered for SBL processing, focusing on the fate of the nutrients in the soil (van Dijk et al., 2013). The use of leaves or biomass that is originally left on the land, like $\mathrm{SBL}$, brings along consequences for the soil like the turnover of soil organic matter, soil erosion, lower crop yields, $\mathrm{N}_{2} \mathrm{O}$ emissions from soils, and release of the substances that leach to ground waters and cause pollution (Cherubini and Ulgiati, 2010; de Ruijter et al., 2010). Van Dijk et al. (2013), showed that decentralisation was considered as the best option in terms of mineral retention and minimising the impact on the land. SBL contain an average of $4,500 \mathrm{~kg}$ of organic matter per hectare that can be converted and become part of the soil. The portion of organic matter that remains after one year is defined as the effective organic substances (EOS) and consists of $20 \%$ for SBL and $25 \%$ for leaf pulp (van Dijk et al., 2013). The EOS can be characterised with their equivalent content of $\mathrm{N}, \mathrm{P}_{2} \mathrm{O}_{5}, \mathrm{~K}_{2} \mathrm{O}, \mathrm{MgO}$ and $\mathrm{CaO}$, and removal of the leaves from the land implies losses of these substances. In such cases, carbon and nutrients are replenished to the land using commercial fertiliser, and other biomass like straw or manure (Papendiek et al., 2012). Compensation of nitrogen and phosphate is possible but only to a certain extent because of standards for application of fertiliser and biomass (CLO, 2014). In contrast, $\mathrm{K}_{2} \mathrm{O}$, $\mathrm{MgO}$ and $\mathrm{CaO}$ have no legal restrictions and they can be totally compensated (CLO, 2014). Nevertheless, the synthesis of commercial fertilisers also requires large inputs of fossil fuels (Brehmer and Sanders, 2007; Pimentel and Pimentel, 2003).

The changes of the nutrient levels in the soil is more complex than nutrient losses and their compensation. In some cases, the removal of biomass from the land is desired to avoid a surplus of specific nutrients or to decrease contaminants, such as nitrogen and phosphorus that can pollute ground waters. Hence, the amount of leaves that can be removed in a sustainable way is determined by a combination of factors such as agricultural practices (e.g. crop rotation, tillage and fertilisation management) (de Ruijter et al., 2010), soil properties and climate (Cherubini and Ulgiati, 2010). For SBL, leaving all the biomass on the land can yield a $N$ surplus 
between $50-107 \mathrm{~kg} / \mathrm{ha}$, but little effect on $\mathrm{N}$ leaching compared to other leaves (i.e. broccoli, leek) (de Ruijter et al., 2010). Based on the $\mathrm{N}$ surplus, only part of the SBL biomass is needed on the soil (3-55\%), leaving material available for other uses. In a decentralised scenario, the soil $\mathrm{N}$ can be replenished with leaf pulp and, in that case, the amount of pulp needed would range between $9-182 \%$ of the total pulp available, depending on the quality of the soil. To reach the upper limit, manure could be used up to $170 \mathrm{~kg} \mathrm{~N} / \mathrm{ha}$ (RVO, 2016), and this option could help to mitigate the current accumulation of manure in some countries (Leenstra et al., 2014). Finally, when only part of the pulp is required on the land (i.e. $9 \%$ ), the excess can be used for animal feed, as an energy source or for high-value products.

The detailed exergetic description of the fate of nutrients on the land along with their cycles is an interesting topic for further studies. Soil effects are very important in sustainability analysis, especially for studies that relate to bio-refinery based systems and circular economy. Unfortunately, fertilisation and structural benefits are not captured yet in exergy analysis, but a good starting point for future research could be an exergy analysis with focus on microbial and plant metabolic processes that occur in the soil. In this way more insights could be gained on the actual impact of applying biomass on the land as chemical ("nutritive") exergy input for microorganisms and plants to produce new biomass driven by solar exergy.

\subsection{Conclusions}

The use of proteins and other valuable components from green leaves for food and non-food purposes is not trivial due to the high water content and the seasonal availability of leaves, in particular for crops like sugar beet. A resource-efficient valorisation of these leaves can be aided either by stabilising the biomass (i.e. freezing) or by decentralising part of the process. The preferred route for large scale leaf processing consists of a decentralised system configuration with on-farm pressing of the leaves, returning the pulp or part of it to the soil, and chilled transportation of the leaf juice for further processing. Excessive stabilisation (e.g. whole leaf freezing) is avoided by pre-processing at the farm, which enables the 
stabilisation of smaller downstream products (i.e. supernatant and sediment). Moreover, decentralised processing contributes to retaining the soil fertility by returning the pulp to the land and reduces the transportation load and -volume by transporting a much smaller and denser stream (juice). Soil fertility is a crucial parameter to consider when assessing the resource efficiency of leaf processing, given the requirements for fertilisers and the long term changes on the soil (e.g. depletion/accumulation of nutrients).

Freezing is a suitable method to stabilise whole leaves when the pressing capacity is limited and this method does not compromise protein extractability. Freezing the leaves constitutes a feasible solution when considering energy requirements for production of other plant or animal proteins.

\section{Acknowledgments}

The authors thank Jochem Jonkman for his contribution to the discussion, Jose M. Jimenez Gutierrez for his contribution to the calculations, and the Technology Foundation STW (The Netherlands) and Royal Cosun (The Netherlands) for their financial and project support.

\section{Nomenclature}

$\begin{array}{ll}\mathrm{m} & \text { mass flow }[\text { ton } / \mathrm{h}] \\ \mathrm{h} & \text { enthalpy }[\mathrm{kJ} / \mathrm{mol}] \\ \mathrm{Q} & \text { thermal energy }[\mathrm{MJ}] \\ \mathrm{W} & \text { work done by the system }[\mathrm{MJ}] \\ \mathrm{Ex} & \text { exergy }[\mathrm{kJ}] \\ \mathrm{b}_{0} & \text { standard chemical exergy }[\mathrm{MJ} / \mathrm{kg}], \text { the } \\ & \text { values can be found in Table A 4 } \\ \mathrm{C}_{\mathrm{p}} & \text { specific heat capacity }[\mathrm{kJ} / \mathrm{kg} \mathrm{K}] \\ \mathrm{T} & \text { temperature }[\mathrm{K}] \\ \mathrm{T}_{0} & \text { reference temperature }[\mathrm{K}] \\ f & \text { exergy quality factor }[-]\end{array}$




\section{Appendix}

Table A 1. Assumptions related to transportation.

\begin{tabular}{lcc}
\hline & & Reference \\
\hline Volume $\left[\mathrm{m}^{3}\right]$ & 18 & \\
Fuel type & Diesel & \\
Lower heating value $[\mathrm{MJ} / \mathrm{kg}]$ & 42.6 & (Koroneos and Nanaki, 2008) \\
Exergy quality factor & 1.07 & (Koroneos and Nanaki, 2008) \\
Fuel efficiency $[\mathrm{L} / \mathrm{km}]$ & 0.33 & (McKinnon, 2012) \\
Fuel use by refrigeration unit $[\mathrm{L} / \mathrm{h}]$ & 3 & (Tassou et al., 2009) \\
Average constant speed $[\mathrm{km} / \mathrm{h}]$ & 60 & Measured as kg of SBL fitting in a \\
Density of SBL $\left[\mathrm{kg} / \mathrm{m}^{3}\right]$ & 73 & crate of $0.03 \mathrm{~m}^{3}$ \\
& & Assumed as water at $4^{\circ} \mathrm{C}$ \\
\hline
\end{tabular}

Table A 2. Chemical composition of processing streams (\% w/w).

\begin{tabular}{lccccc}
\hline & SBL & Juice & Leaf pulp & Sediment & Supernatant \\
\hline Dry matter & 12.0 & 7.6 & 27.0 & 30.5 & 5.6 \\
Protein & 14.8 & 18.3 & 11.5 & 29.3 & 13.2 \\
Fat & 1.8 & 2.6 & 1.1 & 7.5 & 0.3 \\
Total dietary fibre & 35.0 & 12.5 & 56.6 & 29.0 & 4.8 \\
Ash & 21.1 & 31.0 & 11.6 & 20.1 & 36.1 \\
Rest $^{*}$ & 27.3 & 35.6 & 19.2 & 14.1 & 45.6 \\
\hline
\end{tabular}

${ }^{*}$ Calculated by difference 
Table A 3. Main assumptions considered for leaf processing and stabilisation.

\section{General assumptions}

Reference

environment:

$$
\mathrm{T}_{0}=293.15 \mathrm{~K}, \mathrm{P}_{0}=101.325 \mathrm{kPa}, \mathrm{w}_{0}=0.008 \mathrm{~kg} \text { moisture } / \mathrm{kg} \text { dry air }
$$

\begin{tabular}{|c|c|c|}
\hline \multicolumn{3}{|c|}{ Assumptions for direct pressing of the leaves (scenario A) } \\
\hline Pressing & Pressing SBL consumes $42 \mathrm{~kJ} / \mathrm{kg} \mathrm{SBL}$ & (HUBER) \\
\hline \multirow[t]{3}{*}{ Heating } & $\begin{array}{l}\text { The heater has an efficiency of } 70 \% \text { to heat the } \\
\text { juice with hot water }\end{array}$ & Assumed \\
\hline & Efficiency of $90 \%$ of gas combustion to heat water & (Hubbell, 2017) \\
\hline & Natural gas calorific value $54.5 \mathrm{MJ} / \mathrm{kg}$ & Assumed \\
\hline Cooling & $\begin{array}{l}\text { The cooler has an efficiency of } 70 \% \text { to cool the } \\
\text { water with electricity }\end{array}$ & Assumed \\
\hline Centrifugation & Centrifugation consumes $3 \mathrm{~kJ} / \mathrm{kg} \mathrm{SBL}$ & $\begin{array}{c}\text { (Wong Sak Hoi } \\
\text { and De Rosnay, } \\
1996)\end{array}$ \\
\hline
\end{tabular}

\begin{tabular}{|c|c|c|}
\hline \multicolumn{3}{|c|}{ Assumptions for the stabilisation process (scenario B) } \\
\hline Plate-freezer & $\begin{array}{l}\text { Efficiency of cooling ammonia (70\%) with electricity } \\
\text { for the condenser }\end{array}$ & $\begin{array}{l}\text { (ASHRAE, } \\
\text { 2006) }\end{array}$ \\
\hline & $\begin{array}{l}\text { Energy consumption of } 236 \mathrm{~kJ} / \mathrm{kg} \mathrm{SBL} \\
\text { Initial freezing point of }-0.56^{\circ} \mathrm{C} \text { as described for } \\
\text { spinach }\end{array}$ & $\begin{array}{l}\text { (Boonsupthip } \\
\text { and Heldman, } \\
\text { 2007) }\end{array}$ \\
\hline \multirow[t]{2}{*}{$\begin{array}{l}\text { Storage } \\
\text { at }-20^{\circ} \mathrm{C}\end{array}$} & $\begin{array}{l}\text { Leaves are stored over } 1 \text { year. Leaves are removed } \\
\text { from the storage at a rate of } 8.2 \text { ton/day, based on } \\
\text { capacity for mechanical pressing }\end{array}$ & \\
\hline & Freezing camber consumes $0.5 \mathrm{~kJ} / \mathrm{m}^{3}$ & $\begin{array}{c}\text { (Koelcelvink, } \\
\text { 2014) }\end{array}$ \\
\hline \multicolumn{3}{|c|}{ Assumptions for drying (whole leaves, leaf products) } \\
\hline Spray drying & Drying requires $6 \mathrm{MJ} / \mathrm{kg}$ water & $\begin{array}{c}\text { (Berghout et al., } \\
2015)\end{array}$ \\
\hline
\end{tabular}


Table A 4. Standard chemical exergy of the components used for the calculations.

\begin{tabular}{lcc}
\hline Component & (MJ/kg) & Reference \\
\hline Protein & 22.61 & (Szargut, 1989) \\
Lipid & 43.09 & (Berghout et al., 2015) \\
Total dietary fibre & 24.00 & (Sorgüven and Özilgen, 2012) \\
Ash $^{\mathrm{a}}$ & 7.10 & (Szargut, 1989) \\
Rest of dry matter $^{\mathrm{b}}$ & 16.70 & (Szargut, 1989) \\
Water (liquid) & 0.05 & (Szargut, 1989) \\
Water (solid) & 0.03 & (Szargut, 1989) \\
Ammonia & 19.87 & Adapted from (Ayres et al., 1996) \\
Exergy quality factor for electricity & 1 & (Nielsen and Jørgensen, 2015) \\
Exergy quality factor for natural gas & 1.05 & (Jørgensen and Nielsen, 2012) \\
\hline a (Romney et al., 1982) & & \\
b regarded as simple carbohydrates: sucrose, glucose and fructose
\end{tabular}

Table A 5. Transportation load for sugar beet leaves and leaf juice.

\begin{tabular}{cccccc|c}
\hline & Biomass $(\mathbf{k g})$ & Density $\left(\mathbf{k g} / \mathbf{m}^{\mathbf{3}}\right)$ & Truck capacity $\left(\mathbf{m}^{\mathbf{3}}\right)$ & \multicolumn{2}{c}{ Number of trucks } \\
\hline SBL & 1000 & 73 & 18 & 0.76 & Ratio \\
Juice & 730 & 1000 & 18 & 0.04 & $19: 1$ \\
\hline
\end{tabular}

\section{References}

Apaiah, R. K., Linnemann, A. R., \& Van Der Kooi, H. J. (2006). Exergy analysis: A tool to study the sustainability of food supply chains. Food Research International, 39(1), 1-11. doi: 10.1016/j.foodres.2005.04.006

ASHRAE. (2006). Chapter 9 Thermal properties of foods 2006 ASHRAE Handbook: Refrigeration: American Society of Heating, Refrigeration and Air-Conditioning Engineers.

Ayres, R. U., Ayres, L. W., \& Martinas, K. (1996). Eco-thermodynamics: exergy and life cycle analysis. Fontainebleau, France: Centre for the Management of Environmental Resources.

Azmir, J., Zaidul, I. S. M., Rahman, M. M., Sharif, K. M., Mohamed, A., Sahena, F., . . . Omar, A. K. M. (2013). Techniques for extraction of bioactive compounds from plant materials: A review. Journal of Food Engineering, 117(4), 426-436. doi: 10.1016/j.jfoodeng.2013.01.014 
Bals, B., Dale, B. E., Balan, V., Bergeron, C., Carrier, D. J., \& Ramaswamy, S. (2012). Recovery of leaf protein for animal feed and high-value uses Biorefinery CoProducts (pp. 179-197): John Wiley \& Sons, Ltd.

Berghout, J. A. M., Pelgrom, P. J. M., Schutyser, M. A. I., Boom, R. M., \& van der Goot, A. J. (2015). Sustainability assessment of oilseed fractionation processes: A case study on lupin seeds. Journal of Food Engineering, 150, 117-124. doi: 10.1016/j.jfoodeng.2014.11.005

Boonsupthip, W., \& Heldman, D. R. (2007). Prediction of frozen food properties during freezing using product composition. Journal of Food Science, 72(5), E254-263. doi: 10.1111/j.1750-3841.2007.00364.x

Brehmer, B., \& Sanders, J. (2007). Energetic and exergetic life cycle analysis to explain the hidden costs and effects of current sulphur utilisation. International Journal of Exergy, 4(2), 117-133. doi: 10.1504/ijex.2007.012061

Bruins, M. E., \& Sanders, J. P. (2012). Small-scale processing of biomass for biorefinery. Biofuels, bioproducts and biorefining, 6(2), 135-145. doi: 10.1002/bbb.1319

Cherubini, F., \& Ulgiati, S. (2010). Crop residues as raw materials for biorefinery systems - A LCA case study. Applied Energy, 87(1), 47-57. doi: 10.1016/j.apenergy.2009.08.024

CLO. (2014, May 14, 2014). Landbouw en milieu. Wettelijke normen voor het gebruik van meststoffen. Retrieved November 22, 2016, from http://www.clo.nl/indicatoren/nl0400-wettelijke-normen-meststoffen

de Ruijter, F. J., ten Berge, H. F. M., \& Smit, A. L. (2010). The fate of nitrogen from crop residues of broccoli, leek and sugar beet. Paper presented at the Acta Horticulturae.

Factfish.com. (2014). Netherlands: Sugar beet, production quantity (tons) Retrieved August 18, 2016, from http://www.factfish.com/statisticcountry/netherlands/sugar\%20beet,\%20production\%20quantity

Ghaly, A. E., \& Alkoaik, F. N. (2010). Extraction of protein from common plant leaves for use as human food. American Journal of Applied Sciences, 7(3), 331-342.

Hernández, T., Martínez, C., Hernández, A., \& Urbano, G. (1997). Protein quality of alfalfa protein concentrates obtained by freezing. Journal of Agricultural and Food Chemistry, 45(3), 797-802.

Hojilla-Evangelista, M. P., Selling, G. W., Hatfield, R., \& Digman, M. (2016). Extraction, composition, and functional properties of dried alfalfa (Medicago sativa L.) leaf protein. Journal of the Science of Food and Agriculture, 97(3), 882-888. doi: $10.1002 /$ jsfa. 7810

Hubbell. (2017). Hubbell Water Heaters. Retrieved January 21, 2017, from http://www.hubbellheaters.com/model/dgx/\#specs 
HUBER. HUBER Screw Press Q-PRESS. Retrieved November 4th, 2016, from http://www.huber.de/fileadmin/01_products/04_sludge/03_entwaessern/02_ros3q/p ro_qpress_en.pdf

Jankowiak, L., Jonkman, J., Rossier-Miranda, F. J., van der Goot, A. J., \& Boom, R. M. (2014). Exergy driven process synthesis for isoflavone recovery from okara. Energy, 74(C), 471-483. doi: 10.1016/j.energy.2014.07.013

Jørgensen, S. E., \& Nielsen, S. N. (2012). Assessment of sustainability for the danish island of samsø by application of a work energy (exergy) balance Sustainable Energy Landscapes (pp. 373-384): CRC Press.

Jwanny, E. W., Montanari, L., \& Fantozzi, P. (1993). Protein production for human use from sugarbeet: byproducts. Bioresource Technology, 43, 67-70.

Kammes, K. L., Bals, B. D., Dale, B. E., \& Allen, M. S. (2011). Grass leaf protein, a coproduct of cellulosic ethanol production, as a source of protein for livestock. Animal Feed Science and Technology, 164(1-2), 79-88. doi: 10.1016/j.anifeedsci.2010.12.006

Kandlakunta, B., Rajendran, A., \& Thingnganing, L. (2008). Carotene content of some common (cereals, pulses, vegetables, spices and condiments) and unconventional sources of plant origin. Food Chemistry, 106(1), 85-89. doi: 10.1016/j.foodchem.2007.05.071

Koelcelvink. (2014). Energiekosten koelcel. Retrieved November 4th, 2016, from http://koelcelvink.nl/kosten-van-een-koelcel/

Kolfschoten, R. C., Bruins, M. E., \& Sanders, J. P. M. (2014). Opportunities for small-scale biorefinery for production of sugar and ethanol in the Netherlands. Biofuels, bioproducts and biorefining, 8(4), 475-486. doi: 10.1002/bbb.1487

Koroneos, C. J., \& Nanaki, E. A. (2008). Energy and exergy utilization assessment of the Greek transport sector. Resources, Conservation and Recycling, 52(5), 700-706. doi: 10.1016/j.resconrec.2007.09.006

Lammens, T. M., Franssen, M. C. R., Scott, E. L., \& Sanders, J. P. M. (2012). Availability of protein-derived amino acids as feedstock for the production of bio-based chemicals. Biomass \& Bioenergy, 44, 168-181. doi: 10.1016/j.biombioe.2012.04.021

Lee, J., Nam, D. S., \& Kong, C. (2016). Variability in nutrient composition of cereal grains from different origins. SpringerPlus, 5(1), 419. doi: 10.1186/s40064-016-2046-3

Leenstra, F., Vellinga, T., Neijenhuis, F., \& de Buisonjé, F. (2014). Manure - A valuable resource. The Netherlands: Wageningen UR Livestock Research Retrieved from http://edepot.wur.nl/294017.

Liu, Z., Jiao, Y., Wang, Y., Zhou, C., \& Zhang, Z. (2008). Polysaccharides-based nanoparticles as drug delivery systems. Advanced Drug Delivery Reviews, 60(15), 1650-1662. doi: 10.1016/j.addr.2008.09.001 
McKinnon, A. (2012). The Role of Road Transport in a Green Transport System. Paper presented at the 2nd IRU / EU Road Transport Conference, Brussels. file://wurnet.nl/homes/tamay004/My\%20Documents/PhD/Biorefinery/McKinnon\%20 2012\%20transport.pdf

Merodio, C., \& Sabater, B. (1988). Preparation and properties of a white protein fraction in high yield from sugar beet (Beta vulgaris $L$ ) leaves. Journal of the Science of Food and Agriculture, 44, 237-243.

Mohammadi, A., Ahmadi, M. H., Bidi, M., Joda, F., Valero, A., \& Uson, S. (2017). Exergy analysis of a combined cooling, heating and power system integrated with wind turbine and compressed air energy storage system. Energy Conversion and Management, 131, 69-78. doi: 10.1016/j.enconman.2016.11.003

Nielsen, S. N., \& Jørgensen, S. E. (2015). Sustainability analysis of a society based on exergy studies - a case study of the island of Samsø (Denmark). Journal of Cleaner Production, 96, 12-29. doi: 10.1016/j.jclepro.2014.08.035

Papendiek, F., Ende, H.-P., Steinhardt, U., \& Wiggering, H. (2012). Biorefineries: relocating biomass refineries to the rural area. Landscape Online, 27(9).

Paudel, E., Van der Sman, R. G. M., Westerik, N., Ashutosh, A., Dewi, B. P. C., \& Boom, R. M. (2017). More efficient mushroom canning through pinch and exergy analysis. Journal of Food Engineering, 195, 105-113. doi: 10.1016/j.jfoodeng.2016.09.021

Pimentel, D., \& Pimentel, M. (2003). Sustainability of meat-based and plant-based diets and the environment. American Journal of Clinical Nutrition, 78(3 SUPPL.), 660S-663S.

Pirie, N. W. (1966). Leaf protein as a human food. Science, 152(3730), 1701-1705. doi: $10.2307 / 1718350$

Rathore, M. (2010). Leaf protein concentrate as food supplement from arid zone plants. Journal of Dietary Supplements, 7(2), 97-103. doi: 10.3109/19390211003766777

RVO. (2016). Dierlijke mest gebruiksnorm en gebruiksruimte. Retrieved December 12, 2016, from http://www.rvo.nl/onderwerpen/agrarisch-ondernemen/mest-engrond/mest/gebruiksnormen/dierlijke-mest

Sharan, G., \& Rawale, K. (2003). Physical characteristics of some vegetables grown in ahmedabad region: Indian Institute of Management Ahmedabad, Research and Publication Department.

Sheen, S. J. (1991). Comparison of chemical and functional properties of soluble leaf proteins from four plant species. Journal of Agricultural and Food Chemistry, 39, 681-685.

Silva, C. L. M., Gonçalves, E. M., \& Brandão, T. R. S. (2009). Freezing of fruits and vegetables Frozen Food Science and Technology (pp. 165-183).

Sorgüven, E., \& Özilgen, M. (2012). Energy utilization, carbon dioxide emission, and exergy loss in flavored yogurt production process. Energy, 40(1), 214-225. doi: 10.1016/j.energy.2012.02.003 
Szargut, J. (1989). Chemical exergies of the elements. Applied Energy, 32(4), 269-286. doi: 10.1016/0306-2619(89)90016-0

Tamayo Tenorio, A., de Jong, E. W. M., Nikiforidis, C. V., Boom, R. M., \& van der Goot, A. J. (2017). Interfacial properties and emulsification performance of thylakoid membrane fragments. Soft Matter, 13, 608 - 618. doi: 10.1039/c6sm02195f

Tamayo Tenorio, A., Gieteling, J., de Jong, G. A. H., Boom, R. M., \& van der Goot, A. J. (2016). Recovery of protein from green leaves: Overview of crucial steps for utilisation. Food Chemistry, 203, 402-408. doi: 10.1016/j.foodchem.2016.02.092

Tassou, S. A., De-Lille, G., \& Ge, Y. T. (2009). Food transport refrigeration - Approaches to reduce energy consumption and environmental impacts of road transport. Applied Thermal Engineering, 29(8-9), 1467-1477. doi: 10.1016/j.applthermaleng.2008.06.027

Telek, L., \& Graham, H. D. (1983). Leaf protein concentrates: AVI Pub. Co.

UN. (2015). Sustainable development Goals. Retrieved December 19, 2016, from https://sustainabledevelopment.un.org/?menu=1300

van der Goot, A. J., Pelgrom, P. J. M., Berghout, J. A. M., Geerts, M. E. J., Jankowiak, L., Hardt, N. A., . . Boom, R. M. (2016). Concepts for further sustainable production of foods. Journal of Food Engineering, 168, 42-51. doi: 10.1016/j.jfoodeng.2015.07.010

van Dijk, W., van Geel, W., \& van der Voort, M. (2013). Effect van verschillende varianten van raffinage van bietenblad op bodemvruchtbaarheid en stikstofverliezen. Wageningen, The Netherlands: Application centre for renewable resources (ACRRES).

Vandermeersch, T., Alvarenga, R. A. F., Ragaert, P., \& Dewulf, J. (2014). Environmental sustainability assessment of food waste valorization options. Resources, Conservation and Recycling, 87, 57-64. doi: 10.1016/j.resconrec.2014.03.008

Wan, Y. K., Sadhukhan, J., \& Ng, D. K. S. (2016). Techno-economic evaluations for feasibility of sago-based biorefinery, Part 2: Integrated bioethanol production and energy systems. Chemical Engineering Research and Design, 107, 102-116. doi: 10.1016/j.cherd.2015.09.017

Wong Sak Hoi, I., \& De Rosnay, P. (1996). Evaluation of a high grade continuous centrifugal. Paper presented at the Annual Congress of the South African Sugar Technologists' Association.

Zhang, C., Sanders, J. P. M., \& Bruins, M. E. (2014). Critical parameters in cost-effective alkaline extraction for high protein yield from leaves. Biomass and Bioenergy, 67, 466-472. doi: 10.1016/j.biombioe.2014.05.020

Zisopoulos, F. K. (2016). Exergy analysis in industrial food processing. (Doctor), Wageningen University, Wageningen, The Netherlands. 
Zisopoulos, F. K., Rossier-Miranda, F. J., van der Goot, A. J., \& Boom, R. M. (2017). The use of exergetic indicators in the food industry - A review. Critical Reviews in Food Science and Nutrition, 57(1), 197-211. doi: 10.1080/10408398.2014.975335 


\section{General Discussion}




\subsection{Outline}

Leaves have potential to become a source of protein and other valuable components. While isolated and purified soluble proteins (i.e. rubisco) are already considered for food production, there is added potential in leaf proteins that are currently discarded during rubisco isolation. Therefore, the aim of the work described in this thesis was to obtain understanding on the use of green leaves for foods. This chapter summarises the main findings of the preceding chapters, and from these then compiles a processing approach aiming at enriched-functional fractions, rather than pure components. The chapter concludes with the implications for value creation out of green leaves and outlook for future research on leaf processing.

\subsection{Main findings and conclusions}

Extraction processes of leaf proteins typically include a mechanical pressing step and subsequent thermal fractionation of the proteins. The heat treatment is thought to precipitate the insoluble proteins together with fibres, chlorophyll and other components, resulting in a green curd that is discarded. In Chapter 2, we showed that both soluble and insoluble protein distribute almost evenly over the leaf fractions: juice, pulp, supernatant and final pellet. The even distribution of the proteins is attributed to the anatomy of leaves and their biological function, which is predominantly the enzymatic activity related to photosynthesis. This is in contrast to the traditional plant storage tissues used for protein extraction, in which components are stored in clear entities (e.g. protein bodies and oil bodies in seeds, or starch granules in roots). After the heat fractionation, the soluble protein found in the green pellet cannot be re-dissolved either by consecutive washes or by the addition of surfactants. We hypothesized that this is due to irreversible association (complexation) of the proteins with insoluble material (e.g. cell debris, insoluble proteins). The conclusion of this chapter is that striving for high purity severely compromises the yield, and consequently results in inefficient use of the leave proteins. 
Before studying total protein extraction, we investigated how to extract the insoluble fraction (membrane proteins), by learning from the analytical sciences, in this case proteomics. In Chapter $\mathbf{3}$ we described the use of proteomic extraction protocols on green leaves to gain understanding of the extraction conditions needed for membrane protein isolation. Harsh and/or non-food grade conditions were required to isolate the leaf membrane proteins with high purity, as was envisaged in Chapter 2. Membrane proteins are heterogeneous w.r.t. charge, hydrophobicity, post-translational modification and complexation, leading to nonselective behaviour when regarded as a single pool of proteins. This heterogeneity impedes a simple total membrane protein extraction by a unique method or even combinations of processing steps. With the protocols used, four fundamental extraction steps were identified: (1) tissue disruption, (2) enzymatic inhibition, (3) removal of interfering compounds, and (4) protein fractionation and purification. Part of these extraction steps can be translated into food-grade alternatives. Nevertheless, the final protein yield achieved with leaves is much lower than for other plant sources that are already used at industrial scale (e.g. soy and lupine beans), suggesting the need for fractionation of the whole leaf, rather than fractionation of the leaf proteins (i.e. soluble and insoluble proteins).

Given the large challenges in producing high purity proteins, we studied another approach in which green leaves were considered as a source of natural structural elements that have techno-functional properties for food products, like the chloroplastic membranes (i.e. thylakoid membranes) and cellulose-rich fibres. In Chapter 4, we investigated the interfacial behaviour of thylakoid membranes as stabilisers of emulsions. Intact thylakoid membranes isolated from green leaves were disrupted into smaller membrane fragments using high-pressure homogenisation. The resulting fragments consisted of membrane domains and protein clusters surrounded by lipids. The thylakoid membrane fragments $(0.5$ $2.8 \mu \mathrm{m}$ ) showed surface active properties; their adsorption kinetics was typical for large molecules or soft particles. Once adsorbed at an interface, an elastic network is formed due to non-covalent interactions between adjacent fragments along the interface. The thylakoid fragments adsorbed at the oil/water interface and 
effectively stabilised emulsion droplets, even though aggregation was observed already during emulsion preparation and increased with increased thylakoid concentration. We suggest that the droplet aggregates are formed through bridging in a similar manner as the native membranes arrange themselves in their $3 \mathrm{D}$ conformation (i.e. stacking).

In Chapter $\mathbf{5}$ we described the production and application of cellulosic particles obtained from the leaf fibrous pulp. This leaf side-product mostly consists of cell wall components such as cellulose, hemicellulose, pectin, lignin and structural proteins. Aqueous purification of the leaf pulp removed soluble material and resulted in particles that are rich in dietary fibres $(\sim 78 \mathrm{wt} \%)$ and still contained some residual protein $(\sim 6 \mathrm{wt} \%)$. These so-called cellulosic particles showed spontaneous adsorption to the oil-water interface that was attributed to deformability of the particles, probably due to swelling after suspending in water. After adsorption, the particles showed interfacial behaviour similar to that of solid particles, characterised by a small decrease on the interfacial tension. Subsequent dilatational rheology analyses showed the formation of an interfacial film with elastic properties. Attractive capillary interactions are responsible for interactions between adsorbed particles. The emulsions stabilised by cellulosic particles showed two emulsion phases, a droplet rich and a droplet poor phase, and were stable against droplet coalescence above a fibre concentration of $0.1 \% \mathrm{w} / \mathrm{v}$. Mostly particle fines $(0.04-1.0 \mu \mathrm{m})$ stabilised the droplet interface, whereas larger particles $(>10 \mu \mathrm{m})$ created a network in the continuous phase and formed a (stable) concentrated cream phase.

Chapter 6 considered the results in an industrial perspective. Various options for processing sugar beet leaves were evaluated on their resource use efficiency. This included stabilising routes to prevent spoilage, and decentralised processing to improve both resource use and possible effects on the land. The use of resources was assessed in terms of energy requirement and exergy indicators. In a first option, freezing was chosen as stabilising method since its energy requirements are moderate compared to other options (e.g. drying), and freezing was shown to 
have minor effects on the quality of the leaves and leaf products. Similar protein content and protein yields were obtained from frozen leaves and/or frozen leaf juice. Even though freezing implies additional energy requirements, the overall resource efficiency of the process was dominated by the amount of leaf material effectively used, which stresses the importance of full use of all (side-)streams. A second option, decentralised processing, allocates the pressing of the leaves towards the farms. The juice is then chilled to preserve its quality until it can be transported to a central processing facility. This approach constitutes a good option compared to freezing, since solid side streams can be directly returned the land, returning nutrients to the soil, and reducing transportation loads. With a decentralised process, freezing of the leaves becomes unnecessary; the leaf juice is transported while chilled, resembling the transportation of fresh milk that is also chill-transported from the farm to a central factory.

\subsection{Processing towards enriched fractions}

Purification of some of the leaf components is technically feasible, like the isolation of rubisco protein (Edwards et al., 1975; Knuckles et al., 1980), but is currently rather unfavourable because of the higher protein yields obtained with protein crops that are already available. Purification processes come with the cost of low yield and large side streams. Higher value and/or better economics of leaf processing can be obtained through mild fractionation, which produces enriched but functional fractions instead of pure components. This approach was motivated by the high moisture content of leaves and their sophisticated architecture, which offers valuable structures that can be useful in food products. Therefore, we considered process adaptations to obtain these enriched and functional fractions.

\subsubsection{Routes for process optimisation}

Leaf juice is a dispersion of sub-cellular components that interact in the leaf and during processing (Figure 7. 1). Processing green leaves with traditional processing conditions (pressing, heating, centrifugation) results in irreversible complexation of soluble components and subsequent inefficient fractionation of leaf 
proteins. We think that the complexation of leaf components occurs during processing, because both centrifugation and heating lead to protein aggregation. This was concluded in Chapter 2, and this outcome was used to propose a process aiming for total protein use. However, this implies that other leaf components are co-extracted with the proteins, and in fact distribute almost evenly among the resulting leaf fractions. Therefore, we proposed a new process based on the fractionation of main leaf components that yields enriched fractions instead of pure single components.

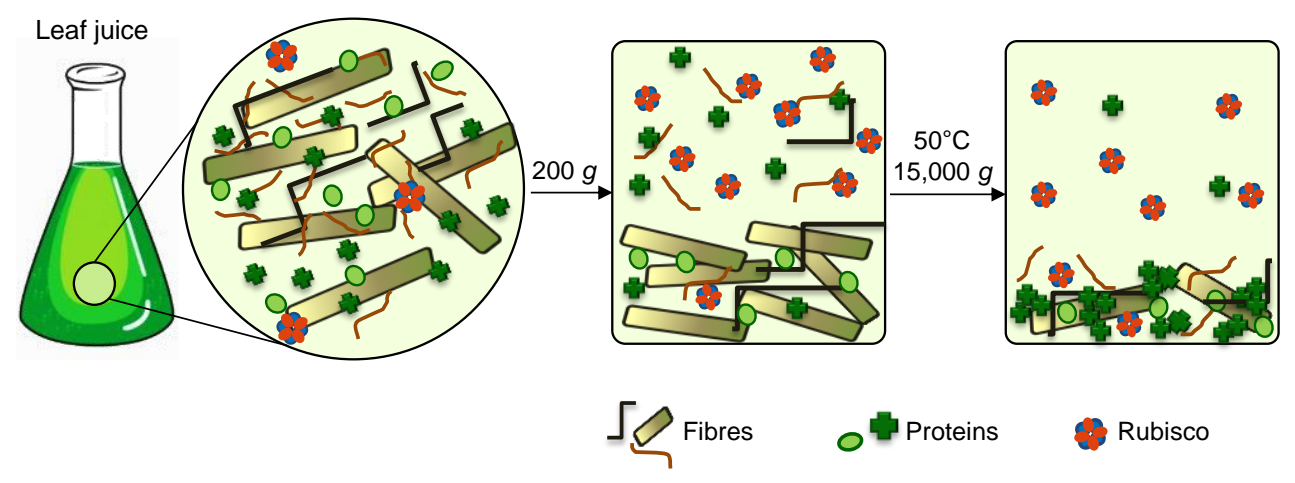

Figure 7. 1. Highly schematic representation of leaf juice and the behaviour of leaf main components (proteins, fibres) during a two-step centrifugation process. A low-speed centrifugation mainly enables the precipitation of fibres, containing proteins that are part of the cell wall or that are physically entrapped in the within the fibres. The heating step produces protein aggregates, which are recovered through a second centrifugation at higher speed while rubisco remains in solution.

The adjusted process consisted of a two-step centrifugation combined with heating (Figure 7. 2). After leaf pressing, the juice is centrifuged at low speed (200 g) and the resulting supernatant was heated at $50^{\circ} \mathrm{C}$, followed by a second centrifugation step at higher speed $(15,000 \mathrm{~g})$. Figure 7.1 depicts the behaviour of the different leaf components during the two-step centrifugation process. The first centrifugation induces the precipitation of mainly fibres (48 wt\% dietary fibre in dry basis), but avoids significant separation of proteins or protein aggregates. The fibres found in the juice are rod-like fragments, which are much larger than chloroplastic membranes or other leaf structures. Therefore, the first precipitate was denoted as the 'fibre-rich fraction'. These fibres have a high water binding capacity, which 
causes trapping of other leaf components within the fibres, like proteins (28 wt\% protein on dry basis).

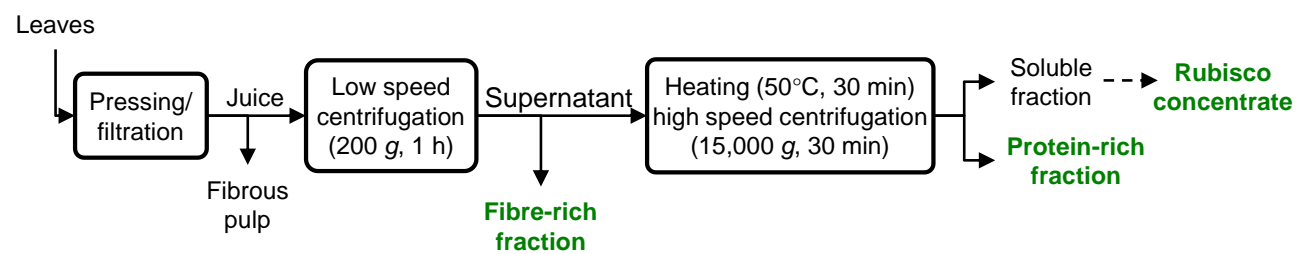

Figure 7. 2. Leaf processing by a two-step centrifugation method. Leaves were pressed as described in Chapter 2.

The subsequent heating step at $50^{\circ} \mathrm{C}$ causes the aggregation of the insoluble proteins (Nagy et al., 1978). The protein aggregates are then recovered by a second centrifugation step at higher speed. This fraction has about twice the protein content (44 wt\%, dry basis) compared to the first precipitate, as well as half of the dietary fibre (22 wt\%, dry basis). This second precipitate was denoted as the 'protein-rich fraction'. Through this adjusted process, more leaf proteins were extracted compared to the traditional process described in Chapter 2. The combined protein yield of both precipitates is $35.4 \%$, which is $~ 24 \%$ more than with a single heating/centrifugation step (28.5\%). The enriched fractions are suitable for different applications based on their nutritional profile and technofunctionality. The final juice contains almost exclusively soluble proteins, mostly rubisco, which can be concentrated and dehydrated as is currently done.

To improve the extraction process, enzyme assisted extraction has been proposed for several crops (Sari et al., 2015). The addition of enzymes leads to higher yields, but this gain in yield should be balanced against the use of energy and other resources during enzyme production (van Donkelaar et al., 2016). Moreover, adding enzymes could destroy or alter the structural functionality explored in this thesis.

A final aspect to consider is the portion of the leaf used for extraction, in particular for large leaves like those from the sugar beet plant. Sugar beet leaves consist of 
blades and stems, both accounting for roughly half of the leaf mass. Separation of the leaf sections can improve protein extraction given the higher protein content in the blades (21.6 wt\%, dry basis) compared to the stems (10.4 wt\%, dry basis). Processing only leaf blades resulted in higher content of soluble proteins, which was observed as higher dry matter and higher protein content in the supernatant obtained through the standard process. However, the stem removal compromised the efficiency of the pressing step, since less juice was produced when only the blades were processed. The stems facilitate pressing and filtration of the leaves in a screw-press by forming a layer of fibres around the screws that act as filter aid. In addition, separation of stems from leave blades cannot yet be done mechanically, as the equipment for it has not yet been developed.

\subsubsection{Integrated process}

The two-step centrifugation process described above can be coupled to the production of the functional fractions discussed in Chapter $\mathbf{4}$ and 5, namely thylakoid membranes and cellulose particles. The integrated process is depicted in Figure 7. 3. Starting from the pressing step, the fibrous pulp is processed as described in Chapter 4. Regarding the thylakoid membranes, the isolation process might require adjustments (e.g. buffer composition and buffer recycling) to enable the direct use of (chilled or frozen) leaf juice instead of fresh leaves. The soluble fraction after the second centrifugation contains $34 \%$ soluble proteins that can be recovered as a 'rubisco concentrate'. For this purpose, $\mathrm{pH}$ precipitation at $\mathrm{pH} 3.5$ is suggested. The resulting precipitate can yield a fraction with $64 \mathrm{wt} \%$ protein that accounts for $11 \%$ of the total leaf proteins. Additional considerations may be the recycling of the discarded liquid streams (i.e. washing liquid). Through filtration and recirculation, these streams can be further used for aqueous extractions, while the retentate can be used for cattle feed. Similarly, the 'protein-rich fraction' could replace soybean meal for animal feed due to its comparable protein content. This application requires supplementation with lysine and methionine (Bals et al., 2012) or mixture with other products (e.g. maize and wheat grain distillers) to comply with nutritional requirements as suggested for leaf protein concentrate from alfalfa (Désialis, 2012). 


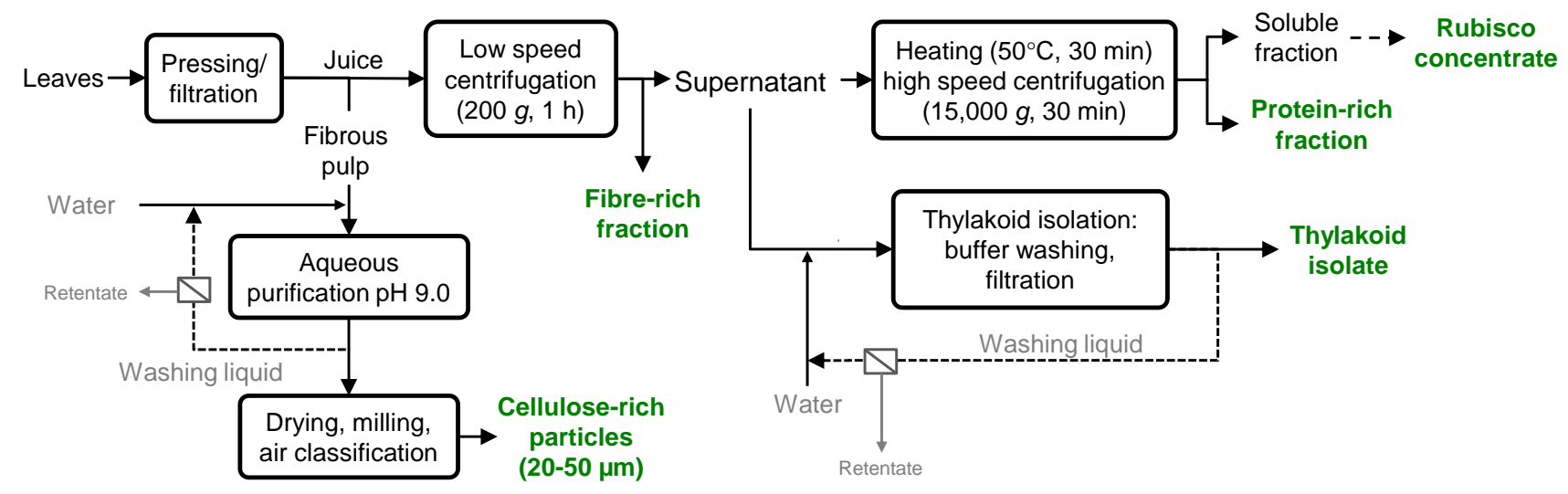

Figure 7. 3. Coupling of processing options of green leaves to obtain enriched and functional fractions. 


\subsection{Understanding the challenges in leaf fractionation}

\subsubsection{A matter of physiology}

The fractionation of sugar beet leaves is characterised by two major features: their high moisture content and the anatomy of the leaves. The high moisture content implies that during the whole refining process the streams are dilute; the leaf's primary photosynthetic role yields a raw material with components that are quite evenly distributed over the whole leaves. More than a matter of small scale of size, the photosynthetic arrangements translate into intricate and highly interconnected components. Figure 7. 4 presents plant cell structures to identify different levels of organisation, from tissue in cereals/legumes and 3D nano-structure of thylakoids in the chloroplast, to the molecular arrangement of leaf membrane protein in the thylakoid membrane. The high level of organisation at small length scales implies that the number of bonds or interactions that need to be severed is much higher in the case of leaf proteins than with traditional storage crops. Thus, larger driving forces and energy inputs are needed for separation, which is reflected in more intensive processing conditions. The use of intensive processing or harsh conditions may result in low-value or even toxic side streams that can compromise the overall sustainability of the process.
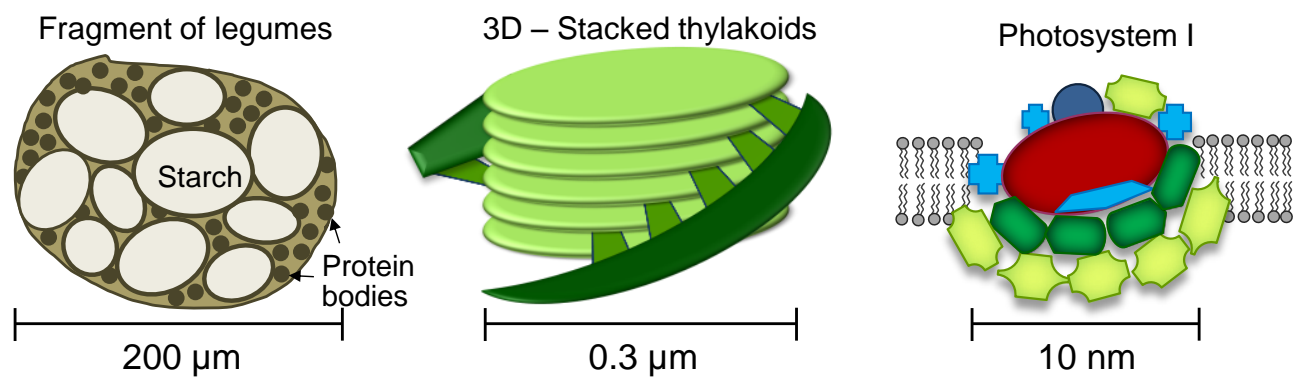

$0.3 \mu \mathrm{m}$

$10 \mathrm{~nm}$

Figure 7. 4. Plant cell tissue (fragment of legumes), supramolecular structure (3D stacked thylakoids, based on Ruban \& Johnson (2015)) and membrane protein domain (Photosystem I, based on Dekker \& Boekema (2005)).

The metabolic role of green leaves is also reflected in the relative stability of the protein content in the leaves over time. The total protein content in sugar beet 
leaves is rather stable during the root harvesting campaign and between different harvests. Figure 7. 5a presents the protein content in the green pellet over 11 weeks of harvest between September and November, 2013. The leaves did present physical differences as a result of climate conditions, but their composition showed only slight variations over time. Comparable results have been reported by Kiskini et al., (2016), who indicated that the age of sugar beet leaves does not affect the protein content in the whole foliage. Similarly, the protein content and protein yield in the green pellet showed only slight variations between the harvests (Figure 7. 5b). The photosynthetic metabolism is active and constant, being a complex system of diverse photosynthetic enzymes that are active during both day and night. At the same time, the generated storage carbohydrates (e.g. starch) are mobilised from the leaf to the storage organs (roots, seeds), and the starch concentration in the leaves changes even during the day (Fondy \& Geiger, 1982).

A

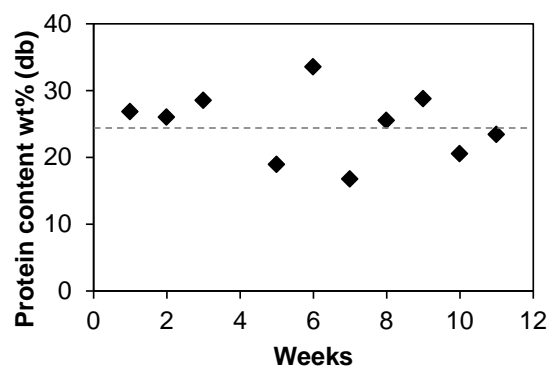

B

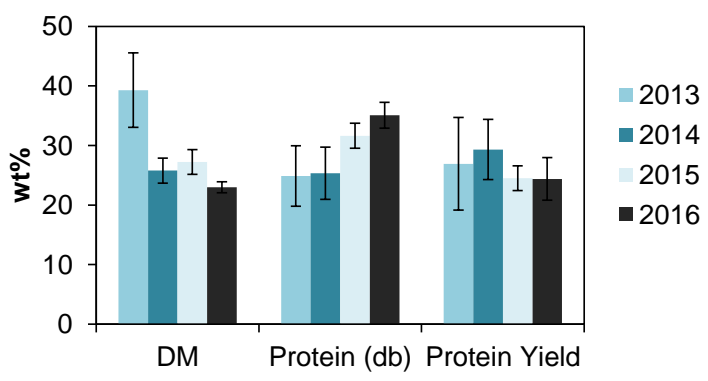

Figure 7. 5. Composition of green pellet produced from SBL with standard extraction process. (A) protein content over 11 weeks of sugar beet's harvesting campaign. (B) Average composition (dry matter and protein) and protein yield of four harvesting seasons.

The relative constant protein content is beneficial for our use of the leaves, because the quality also remains constant and enables the use of not just the proteins, but the overall supramolecular structures (i.e. thylakoids). Therefore, when using leaves for food ingredients, this constant composition can ensure a homogeneous supply of material, which can be translated as an advantage for processing. 


\subsubsection{Comparing to storage crops}

When leaves are considered as a protein source, it is interesting to compare protein extraction yields with those of other plant protein sources, such as cereals and legumes. For this comparison, we have compiled information on the purities of extracted proteins as a function of their extraction yields (Figure 7. 6) for several crops. Soy is considered as state of the art for protein extraction, given massive scales of its production and application. Lupine, rapeseed and some pulses are relatively novel protein sources with similar or potentially similar performance as soy. These protein crops follow a similar trend and establish processing goals of $50-60 \%$ yield with a protein purity of $\sim 90 \%$. A different trend is found when considering protein yield and purity for leaves. Remarkably, the trend found for leaves also holds for other photosynthetic active tissues like algae and duckweed, only at much lower yields. For these non-protein crops, a high-protein extract (60 $80 \mathrm{wt} \%$ protein) is only achieved at less than $10 \%$ protein yield. We hypothesize that the low yields are due to the lack of protein storage anatomy in these crops, even when the initial protein content in the dry matter (e.g. $40-50 \%$ in algae) is comparable to that of soy. Closing the gap between storage crops and photosynthetic crops demands a major technological breakthrough that guarantees high yields with a feasible/sustainable process. Attempts to such technologies include crystallisation, aqueous two phase systems, pulse electric fields, among others, which still require further development for feasible implementation or are suitable for biomolecules different from proteins (Azmir et al., 2013; Baiano, 2014). In the meantime, we propose to rethink the process and to apply a different approach that can avoid non-favourable compromises and exploit the functionality of the anatomic structures where the proteins reside.

Figure 7. 6 presents the protein purity values in dry basis. Converting the plot to wet basis would point out an even larger gap between protein crops and photosynthetic crops, which have a dry matter content ranging between 85 - 90\% and $5-15 \%$, respectively. More importantly, a wet basis comparison would highlight the additional requirements involved in drying of the final products, which could easily exceed the energy requirements for the extraction process. For 
instance, the protein extraction from algae has been optimised with bead milling technology, reaching an energy requirement of $17.3 \mathrm{~kJ} / \mathrm{g}$ protein (Postma et al., 2015). The energy needed for spray drying of the final products can go up to $240 \mathrm{~kJ} / \mathrm{g}$ protein, assuming that the final products has $2-3 \mathrm{wt} \%$ dry matter (Postma et al.) and drying requires about $6 \mathrm{MJ} / \mathrm{kg}$ water (Berghout et al., 2015). Clearly, combining extraction with the final application could avoid unnecessary drying, since dry protein extracts are generally used in products that contain water.

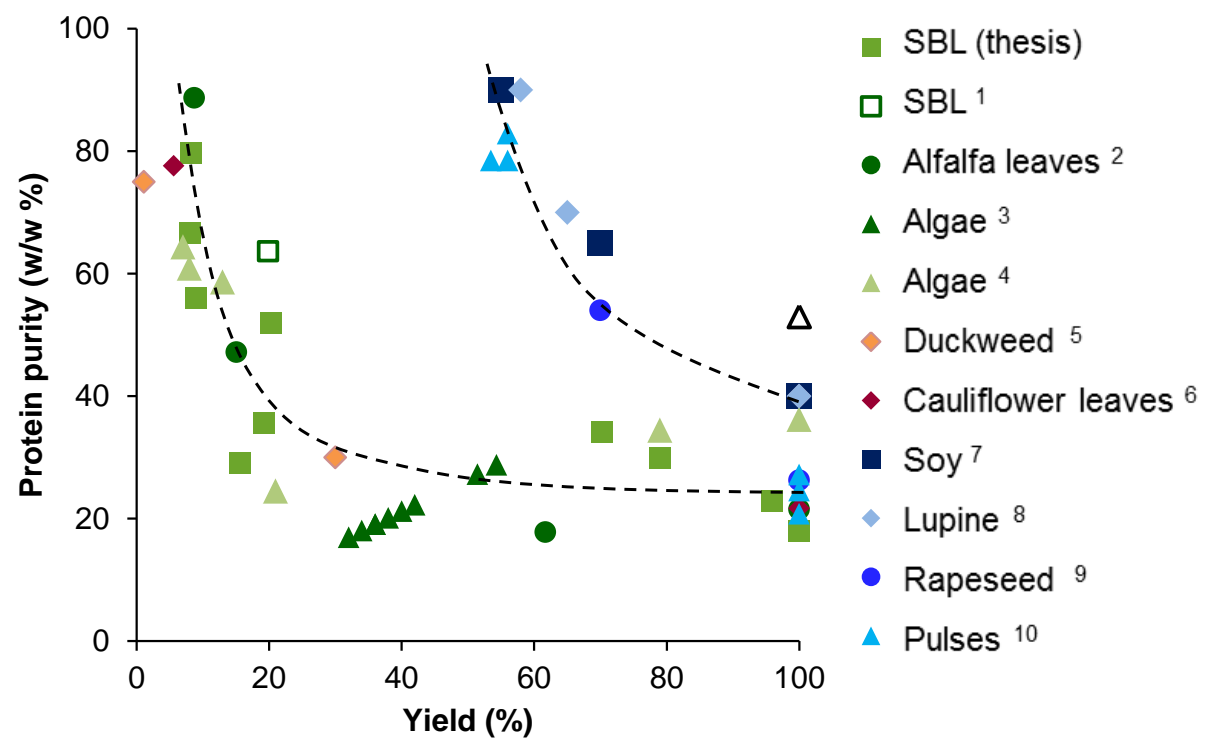

Figure 7. 6. Yield of extracted protein as a function of the protein purity (\% w/w, dry basis) ( $g$ protein in product per gram of protein in raw material). ${ }^{1}$ (Kiskini et al., 2016), ${ }^{2}$ (Edwards et al., 1975), ${ }^{3}$ (Postma et al.), ${ }^{4}$ (Schwenzfeier et al., 2011), ${ }^{5}$ (van Krimpen et al., 2013), ${ }^{6}$ (Xu et al.), ${ }^{7}$ (Cambell, 2010; Day, 2013), ${ }^{8}$ (Berghout et al., 2015), ${ }^{9}$ (Dijkstra et al., 2003), ${ }^{10}$ (Boye et al., 2010). The point $(\triangle)$ highlights the high protein content of microalgae, known as an unconventional protein source (Spolaore et al., 2006).

\subsection{Future research on green leaves}

Biomass processing requires highly integrated supply chains to manage the seasonal nature of harvesting (WEF, 2010) and to create maximum value from agro-materials (Jonkman et al., 2017). While leaves have potential for the production of valuable components for foods, the production of pure proteins is probably not economically attractive. However, the total use of leaves may well become attractive by producing functional fractions for high-value uses in food, and 
by using residual fractions for other, lower-value applications. The integrated approach proposed in this thesis deviates from the traditional production of a single primary product but it is expected to maximise the valorisation of leaves (Kolfschoten et al., 2014) and avoid inefficient supply chains (Jonkman et al., 2017). The latter is achieved by identifying potential uses of the different fractions before the complete design of a process.

\subsubsection{Rethinking functionality}

Changing the approach to processing leaves also implies changing the approach on how functionality is defined. It is known that for biorefinery the main challenges are to define the application of the novel products and to address their advantages compared to conventional ingredients (Scholey et al., 2016; WEF, 2010). However, novel materials bring along novel functionalities that we initially might not be even aware of. Discovering these new functions/applications requires cooperative work with other disciplines, especially those that are not related to food and that can broaden our existing limited view on functionality (e.g. foams, gels, emulsions, water holding).

Thylakoids can be used to exemplify the vision. As Pickering emulsifiers, thylakoid fragments at oil-water interfaces are stable against coalescence. In addition, thylakoid fragments possess extra traits such as antioxidant potential and satiation effects. By nature, thylakoid membranes have antioxidants to protect the cell from high oxidative stress during photosynthesis. Its mechanism consists of single, small molecules (e.g. tocopherol, carotenoids) and antioxidant enzymatic systems (e.g. ascorbate-glutathione cycle) (B. Thomas, Murray, et al., 2016). Extracted thylakoids and the resulting fragments retain part of these antioxidant compounds and supplement the bio-functionality of this material. The antioxidant activity plus the emulsion stabilisation are a perfect combination for the encapsulation of labile components. The satiation effect attributed to thylakoid membranes is also a combination of functional properties. Thylakoids may inhibit digestive enzymes (i.e. lipase/colipase) and reduce food ingestion by triggering the releasing satiation hormones. This unique functionality is a result of its composition and physical 
properties (Albertsson et al., 2007). Compared to other biological membranes or drugs that supress fat digestion, only thylakoid membranes have the combined effect of reduced fat digestion, hormone release and suppression of food intake (Erlanson-Albertsson \& Albertsson, 2015).

Besides functional fractions (i.e. thylakoids and cellulosic particles), the integrated process for sugar beet leaves produces other less refined streams such as proteinrich and fibre-rich fractions, which can be considered as bulk products. The proposed applications for these fractions rely on their nutritional profile and could for instance replace soy in animal feed. With the current meat production in Europe, tons of soybeans are daily imported to fulfil the demand for animal feed (De Visser et al., 2014). The relocation of this biomass, e.g. from Brazil to Europe, translates into long term changes on carbon and nutrient cycles and underlines land-use management and soil fertility as future research priorities (Leopoldina, 2012; N. Thomas, Solène, et al., 2016). Thus, local solutions for animal feed are as relevant as securing food proteins within a global sustainability perspective.

\subsubsection{Leaves as raw material for non-food applications}

Coproduction of leaf protein, fuels and chemicals has been studied in several biorefinery scenarios. Researchers have analysed the recovery of leaf protein as leaf protein concentrate (LPC) from fresh green plant material, while the fibrous pulp obtained after leaf pressing is used for bio-fuel production through fermentation (Dale et al., 2009; Dale \& Matsuoka, 1981; Kammes et al., 2011). The use of fermentable streams to bio-fuel production (bio-gas or bio-ethanol) is a low-value application and uncertain, since the future of biofuels depends on fluctuating oil prices and on regulations and subsidies that define concrete industrial implementations (WEF, 2010). The enriched leaf fractions proposed in this thesis represent a potential alternative for leaf biorefining, offering higher yields and potential uses for different types of feed (e.g. for ruminant and monogastric animals). However, the leaf fractions would still face the challenge of competing with other feed sources, as it occurs with leaf protein concentrates (Dale et al., 2009). 
Finally, any leaf biorefining route should compensate the nutrient losses caused by the total removal of the leaves, for example by returning to the land some of the residual streams from the process. Chapter 6 discussed the best practices for leaf processing that can benefit both the land and the sustainability of the process. Even unused leaves are important for maintaining the quality of the soil. Those aspects could be combined in an overall supply chain design that will connect sustainable production with full use of the value in the leaves.

\subsection{Conclusion}

Using fresh biomass like green leaves is complicated by its large volume relative to the quantity of usable contents. Besides, the sophisticated subcellular architecture causes additional challenges, often evidenced by low extraction yields of single components. Leaf valorisation therefore requires non-conventional approaches that go beyond higher extraction yields but that do consider a complete use of the biomass.

By making use of the supramolecular structure in the leaves instead of regarding it as an impediment, one can create fractions that have complex composition, but that exhibit good nutritional and technical functionality. These supramolecular structures can be isolated at higher yields and with potential high value, rendering the use of leaves as food source a realistic option for the future.

\section{References}

Albertsson, P.-A., Köhnke, R., Emek, S. C., Mei, J., Rehfeld, J. F., \& Akerlund, H.-E. (2007). Chloroplast membranes retard fat digestion and induce satiety: effect of biological membranes on pancreatic lipase/co-lipase. Biochemical Journal, 401, 727-733.

Azmir, J., Zaidul, I. S. M., Rahman, M. M., Sharif, K. M., Mohamed, A., Sahena, F., . . . Omar, A. K. M. (2013). Techniques for extraction of bioactive compounds from plant materials: A review. Journal of Food Engineering, 117(4), 426-436. doi: 10.1016/j.jfoodeng.2013.01.014

Baiano, A. (2014). Recovery of Biomolecules from Food Wastes - A Review. Molecules, 19(9), 14821. 
Bals, B., Dale, B. E., Balan, V., Bergeron, C., Carrier, D. J., \& Ramaswamy, S. (2012). Recovery of leaf protein for animal feed and high-value uses Biorefinery CoProducts (pp. 179-197): John Wiley \& Sons, Ltd.

Berghout, J. A. M., Pelgrom, P. J. M., Schutyser, M. A. I., Boom, R. M., \& van der Goot, A. J. (2015). Sustainability assessment of oilseed fractionation processes: A case study on lupin seeds. Journal of Food Engineering, 150, 117-124. doi: 10.1016/j.jfoodeng.2014.11.005

Boye, J. I., Aksay, S., Roufik, S., Ribéreau, S., Mondor, M., Farnworth, E., \& Rajamohamed, S. H. (2010). Comparison of the functional properties of pea, chickpea and lentil protein concentrates processed using ultrafiltration and isoelectric precipitation techniques. Food Research International, 43(2), 537-546. doi: 10.1016/j.foodres.2009.07.021

Cambell, K. A. (2010). Protein and oil recoveries from enzyme-assisted aqueous extraction of soybeans and sunflower seed. (Doctor of Philosophy Graduate Theses and Dissertations), lowa State University, Ames, lowa. Retrieved from http://lib.dr.iastate.edu/cgi/viewcontent.cgi?article=2121\&context=etd (11172)

Dale, B. E., Allen, M. S., Laser, M., \& Lynd, L. R. (2009). Protein feeds coproduction in biomass conversion to fuels and chemicals. Biofuels, bioproducts and biorefining, 3(2), 219-230.

Dale, B. E., \& Matsuoka, M. (1981). Protein recovery from leafy crop residues during biomass refining. Biotechnology and bioengineering, 23(6), 1417-1420.

Day, L. (2013). Proteins from land plants - Potential resources for human nutrition and food security. Trends in Food Science \& Technology, 32(1), 25-42. doi: 10.1016/j.tifs.2013.05.005

De Visser, C. L. M., Schreuder, R., \& Stoddard, F. (2014). The EU's dependency on soya bean import for the animal feed industry and potential for EU produced alternatives. OCL - Oilseeds and fats, 21(4). doi: 10.1051/ocl/2014021

Dekker, J. P., \& Boekema, E. J. (2005). Supramolecular organization of thylakoid membrane proteins in green plants. Biochimica et Biophysica Acta (BBA) - Bioenergetics, 1706(1-2), 12-39. doi: 10.1016/j.bbabio.2004.09.009

Désialis. (2012). Désialis prodcuts. Retrieved June 29, 2015, from http://www.desialis.com/en/our-products

Dijkstra, D. S., Linnemann, A. R., \& van Boekel, T. A. (2003). Towards sustainable production of protein-rich foods: appraisal of eight crops for Western Europe. PART II: Analysis of the technological aspects of the production chain. Critical Reviews in Food Science and Nutrition, 43(5), 481-506.

Edwards, R. H., Miller, R. E., Fremery, D. d., Knuckles, B. E., Bickoff, E. M., \& Kohler, G. O. (1975). Pilot Plant Production of an Edible White Fraction Leaf Protein Concentrate from Alfalfa. Journal of Agricultural and Food Chemistry, 23(4). 
Erlanson-Albertsson, C., \& Albertsson, P. A. (2015). The use of green leaf membranes to promote appetite control, suppress hedonic hunger and loose body weight. Plant Foods for Human Nutrition, 70(3), 281-290. doi: 10.1007/s11130-015-0491-8

Fondy, B. R., \& Geiger, D. R. (1982). Diurnal Pattern of Translocation and Carbohydrate Metabolism in Source Leaves of Beta vulgaris L. Plant Physiology, 70(3), 671-676.

Jonkman, J., Bloemhof, J. M., van der Vorst, J. G. A. J., \& van der Padt, A. (2017). Selecting food process designs from a supply chain perspective. Journal of Food Engineering, 195, 52-60. doi: 10.1016/j.jfoodeng.2016.09.015

Kammes, K. L., Bals, B. D., Dale, B. E., \& Allen, M. S. (2011). Grass leaf protein, a coproduct of cellulosic ethanol production, as a source of protein for livestock. Animal Feed Science and Technology, 164(1-2), 79-88. doi: 10.1016/j.anifeedsci.2010.12.006

Kiskini, A., Vissers, A., Vincken, J. P., Gruppen, H., \& Wierenga, P. A. (2016). Effect of Plant Age on the Quantity and Quality of Proteins Extracted from Sugar Beet (Beta vulgaris L.) Leaves. Journal of Agricultural and Food Chemistry, 64(44), 83058314. doi: $10.1021 /$ acs.jafc.6b03095

Knuckles, B. E., Edwards, R. H., Kohler, G. O., \& Whitney, L. F. (1980). Flocculants in the separation of green and soluble white protein fractions from alfalfa. Journal of Agricultural and Food Chemistry, 28(1), 32-36.

Kolfschoten, R. C., Bruins, M. E., \& Sanders, J. P. M. (2014). Opportunities for small-scale biorefinery for production of sugar and ethanol in the Netherlands. Biofuels, bioproducts and biorefining, 8(4), 475-486. doi: 10.1002/bbb.1487

Leopoldina. (2012). Biorefineries - changes and limits. In C. Anton (Ed.): German National Academy of Sciences.

Nagy, S., Telek, L., Hall, N. T., \& Berry, R. E. (1978). Potential Food Uses for Protein from Tropical and Subtropical Plant Leaves. Journal of Agricultural and Food Chemistry, 26(5).

Postma, P. R., Miron, T. L., Olivieri, G., Barbosa, M. J., Wijffels, R. H., \& Eppink, M. H. (2015). Mild disintegration of the green microalgae Chlorella vulgaris using bead milling. Bioresource Technology, 184, 297-304. doi: 10.1016/j.biortech.2014.09.033

Postma, P. R., Suarez-Garcia, E., Safi, C., Yonathan, K., Olivieri, G., Barbosa, M. J., . . . Eppink, M. H. M. (2016). Energy efficient bead milling of microalgae: Effect of bead size on disintegration and release of proteins and carbohydrates. Bioresource Technology, 224, 670-679. doi: 10.1016/j.biortech.2016.11.071

Ruban, A. V., \& Johnson, M. P. (2015). Visualizing the dynamic structure of the plant photosynthetic membrane. Nature Plants, 1. doi: 10.1038/nplants.2015.161

Sari, Y. W., Mulder, W. J., Sanders, J. P. M., \& Bruins, M. E. (2015). Towards plant protein refinery: Review on protein extraction using alkali and potential enzymatic assistance. Biotechnology Journal, 10(8), 1138-1157. doi: 10.1002/biot.201400569 
Scholey, D. V., Burton, E. J., \& Williams, P. E. V. (2016). The bio refinery; producing feed and fuel from grain. Food Chemistry, 197, Part A, 937-942. doi: 10.1016/j.foodchem.2015.11.063

Schwenzfeier, A., Wierenga, P. A., \& Gruppen, H. (2011). Isolation and characterization of soluble protein from the green microalgae Tetraselmis sp. Bioresource Technology, 102(19), 9121-9127. doi: 10.1016/j.biortech.2011.07.046

Spolaore, P., Joannis-Cassan, C., Duran, E., \& Isambert, A. (2006). Commercial applications of microalgae. Journal of Bioscience and Bioengineering, 101(2), 8796. doi: $10.1263 / \mathrm{jbb} .101 .87$

Thomas, B., Murray, B. G., \& Murphy, D. J. (2016). Encyclopedia of applied plat sciences (Second ed. Vol. 1): Elsevier.

Thomas, N., Solène, R., Geneviève, S. M., \& Elena, M. B. (2016). The surprisingly small but increasing role of international agricultural trade on the European Union's dependence on mineral phosphorus fertiliser. Environmental Research Letters, 11(2), 025003.

van Donkelaar, L. H. G., Mostert, J., Zisopoulos, F. K., Boom, R. M., \& van der Goot, A.-J. (2016). The use of enzymes for beer brewing: Thermodynamic comparison on resource use. Energy, 115, Part 1, 519-527. doi: 10.1016/j.energy.2016.09.011

van Krimpen, M. M., Bikker, P., van der Meer, I. M., van der Peet-Schwering, C. M. C., \& Vereijken, J. M. (2013). Cultivation, processing and nutritional aspects for pigs and poultry of European protein sources as alternatives for imported soybean products. Wageningen, The Netherlands: Wageningen UR Livestock Research.

WEF. (2010). The future of industrial biorefineries: World Economic Forum.

Xu, Y., Li, Y., Bao, T., Zheng, X., Chen, W., \& Wang, J. (2016). A recyclable protein resource derived from cauliflower by-products: potential biological activities of protein hydrolysates. Food Chemistry, 221, 114-122. doi: 10.1016/j.foodchem.2016.10.053 


\section{Summary}

Plant leaves are recognised as a potential source for food applications based on their nutritional profile and interesting technological properties of leaf components, and based on the large availability of plant leaves in agricultural waste streams. Several attempts have been made to find high-value uses through biorefining, including protein extraction for feed and human food. While isolated and purified soluble proteins (i.e. rubisco) are already considered for food production, there is added potential in leaf fractions that are currently discarded after rubisco isolation, including leaf membrane proteins. Besides proteins, leaves have a rich nutritional profile (e.g. dietary fibres, minerals and secondary metabolites) and consist of complex biological structures (e.g. chloroplastic membranes) that can be explored as novel fractions that ultimately broaden the use of leaves.

The overall aim of this thesis is to explore green leaves as a food source, with emphasis on neglected leaf fractions. This thesis describes a processing approach that aims at separating/generating enriched-functional fractions rather than pure components, and highlights the implications for value creation out of green leaves. The extraction of leaf membrane proteins is investigated using a proteomics extraction method, while the properties of other valuable leaf components (complexes and fibres) are analysed for techno-functional applications. Furthermore, the feasibility of leaves as a food source is studied at an industrial scale, considering large scale processing and options for leaf stabilisation.

The extraction of proteins from sugar beet leaves is evaluated in Chapter 2 by using a traditional heat coagulation method. The heat treatment is thought to precipitate the insoluble proteins together with fibres, chlorophyll and other components, resulting in a green curd. Therefore, the distribution of soluble and insoluble proteins was followed along the extraction process to discern the effect of the heating step on protein fractionation. This study showed that both soluble and insoluble protein distribute almost evenly over the leaf fractions juice, pulp, supernatant and final pellet. The even distribution of the proteins was attributed to the anatomy of leaves and their biological function, which is predominantly the enzymatic activity related to photosynthesis instead of protein storage, which 
occurs in other plant tissues. This even protein distribution was also reflected in low protein yields in the final green pellet. Most likely, harsh conditions might be required to obtain higher protein yields, which can impair the protein quality. Further processing of the green pellet, containing leaf membrane proteins, is proposed through multiple washings and the addition of surfactants. However, the washing steps were not able to re-dissolve the soluble protein found in this fraction. We hypothesized that this is due to irreversible association (complexation) of the proteins with insoluble material (e.g. cell debris, insoluble proteins). The conclusion of this chapter is that striving for high purity severely compromises the yield, and consequently results in inefficient use of the leave proteins.

Chapter 3 describes the application of proteomic analytical extraction protocols to analyse the fractionation behaviour of leaf proteins. This analysis leads to a deeper understanding of the feasibility of extraction of leaf insoluble proteins. First, a solvent extraction protocol was examined, followed by an analysis of the effect of each extraction step on the extracted proteins and other leaf components (e.g. secondary metabolites), as well as on the protein yield. Second, a milder proteomics protocol was considered (i.e. phase-partitioning with surfactant) to have a broader view on membrane protein extraction options. This knowledge was then translated into food-grade processes based on four fundamental extraction steps: (1) tissue disruption, (2) enzymatic inhibition, (3) removal of interfering compounds, and (4) protein fractionation and purification. Part of these extraction steps can be translated into food-grade alternatives, while the processing conditions determine the potential properties for food of the final products. Nevertheless, it was concluded that harsh and/or non-food grade conditions were required to isolate the leaf membrane proteins with high purity. Those results were explained by the fact that membrane proteins are heterogeneous w.r.t. charge, hydrophobicity, posttranslational modification and complexation, leading to non-selective behaviour when compared with a single pool of proteins. It is suspected that the final protein yield achieved with leaves will remain much lower than for other plant sources that are already used at industrial scale (e.g. soy and lupine beans), suggesting the need for an alternative approach to fractionate the whole leaf into fractions with 
richer composition, rather than fractionation of the leaf proteins (i.e. soluble and insoluble proteins).

Given the large challenges in isolating membrane proteins from leaves, we studied another approach in which green leaves are considered as a source of naturally structured elements that have relevant techno-functional properties for food products, like the chloroplastic membranes (i.e. thylakoid membranes) and cellulose-rich fibres. Chapter $\mathbf{4}$ describes the properties of thylakoid membranes and their emulsifying mechanism. Thylakoid membranes are regarded as protein/lipid complexes that are characterised by a sophisticated and dynamic structure. These membranes were extracted from sugar beet leaves through a sequence of buffer washing and filtration steps, followed by high-pressure homogenisation that disrupts the membranes into smaller fragments. The thylakoid fragments (typical size $0.5-2.8 \mu \mathrm{m}$ ) consisted of membrane domains and protein clusters surrounded by lipids. These fragments showed surface active properties and their adsorption kinetics were typical for large molecules or soft particles. After adsorption, the interfacial rheology analysis showed that the adsorbed fragments form an elastic network due to non-covalent interactions between adjacent fragments along the interface. The thylakoid fragments can effectively stabilise emulsion droplets, even though aggregation was observed already during emulsion preparation and increased with increased thylakoid concentration. We hypothesized that droplet aggregates were formed through bridging in a similar manner as the native membranes arrange themselves in their 3D conformation (i.e. stacking). Both composition and structure make thylakoid membranes suitable as a biobased material for food and pharma applications.

To continue exploring valuable fractions from leaves, Chapter 5 reports on the interfacial behaviour of cellulose-rich particles obtained from leaf pulp. The pulp obtained after leaf pressing is rich in dietary fibre and represents a large side stream during leaf processing. To determine potential applications for this pulp, aqueous purification was applied, followed by drying and milling. The resulting particles were rich in dietary fibres $(\sim 78 \mathrm{wt} \%)$ and still contained some residual protein $(\sim 6 \mathrm{wt} \%)$. These so-called cellulosic particles showed spontaneous 
adsorption onto the oil-water interface. After adsorption, the particles showed interfacial behaviour similar to that of solid particles, characterised by a small decrease on the interfacial tension and slow adsorption kinetics. Their interfacial behaviour suggested deformability of the particles, probably due to swelling after suspending in water. This behaviour was confirmed by subsequent dilatational rheology analyses that showed the formation of an interfacial film with elastic properties. This film is likely formed by attractive capillary interactions between the adsorbed particles. Addition of cellulosic particles to oil-in-water emulsions resulted in stable emulsions above a particle concentration of $0.1 \% \mathrm{w} / \mathrm{v}$, although phase separation was observed. The particle fines $(0.04-1.0 \mu \mathrm{m})$ stabilised the droplet interface, while large particles formed a network in the continuous phase and rendered a top (green) phase in the emulsions. Oil droplet coalescence and free oil were observed after one day of storage at particle concentrations below $0.1 \% \mathrm{w} / \mathrm{v}$, due to insufficient material to cover the emulsion interface. Finding applications for leaf side streams, like leaf pulp, broadens the options for total leaf processing and contributes to resource use optimisation.

A sustainability assessment of leaf processing is discussed in Chapter 6, considering the challenges that may appear at industrial scale. Sugar beet plants, as potential leaf sources, are seasonal crops and the beet root determines the optimum harvest time. The seasonal availability of leaves implies the need of processing large amounts of biomass within a short time due to their high moisture content (85-90\%) and their sensitivity to spoilage. Various options for processing sugar beet leaves were evaluated on their resource use efficiency in terms of energy requirement and exergy indicators. Cumulative exergy losses were used as indicators to visualise the effect of different scenarios during leaf processing. In a first option, freezing was chosen as stabilising method since its energy requirements are moderate compared to other options (e.g. drying), and freezing was shown to have minor effects on the quality of the leaves and leaf products. Similar protein content and protein yields were obtained from frozen leaves and/or frozen leaf juice. Even though freezing implies additional energy requirements, the overall resource efficiency of the process is dominated by the amount of leaf 
material effectively used, which stresses the importance of full use of all (side-) streams. A second option, decentralised processing, allocates the pressing of the leaves towards the farms. The juice is then chilled to preserve its quality until it can be transported to a central processing facility. The feasibility of this approach was extended with reported information on soil quality and fertility associated to sugar beet leaves. A decentralised process constitutes a good option compared to freezing, since solid side streams can be directly returned the land, leaving nutrients to the soil, and reducing transportation loads. With a decentralised process, freezing of the leaves becomes unnecessary; the leaf juice is transported while chilled, resembling the transportation of fresh milk that is also chilltransported from the farm to a central factory.

Chapter 7 concludes this thesis with a general discussion of the main findings. It starts with a summary of the main results and conclusions, followed by the implications for processing options that aim at total leaf biorefining. An integrated process for leaf valorisation is described, which combines the production of functional fractions with the production of bulk products such as protein-rich and fibre-rich fractions. The latter are obtained through a two-step centrifugation process, whereas the functional fractions are obtained though the processes described in Chapters 4 and 5. The chapter continues with a compilation of available data on protein yield and protein purity of fractions obtained from protein crops (e.g. soy, lupine beans, pulses) and from photosynthetic active tissues (e.g., leaves, algae, duckweed). Protein crops reach 50 - 60\% protein yield with a protein purity of $\sim 90 \%$, whereas leaves and other photosynthetic active tissues reach similar protein purity $(60-80 \mathrm{wt} \%$ protein) but at much lower yields $(10 \%)$. We hypothesize that the low yields are due to the small length scale in which protein is structured inside the leaves and the lack of protein storage anatomy in these tissues. Therefore, we conclude that leaf valorisation requires non-conventional approaches that go beyond higher extraction yields but that consider a complete use of the biomass. The chapter ends with an overview on potential applications, which requires cooperation with other disciplines to discover more/better uses for the final products. 


\section{Acknowledgements}

Now it is time to thank you all. This thesis was actually a team work and I was very fortunate to have amazing team players around me, either people that were involved directly in my daily work, or that kept me motivated and cheered me up, or that from far away made sure I was doing fine.

I would like to thank my daily supervisor, Atze Jan van der Goot for his committed guidance, for helping me making choices on the many research topics that this thesis covered, for the quick response to all my emails and questions, and for guiding me through these 4 years of continuous learning. Thank you to Remko Boom, my promoter, for the inspiring and motivating discussions with many insightful ideas. Our meetings were very helpful to organize in 1 hour the many results of several months, and to keep the bigger picture of my research project. I am also very grateful for his "smileys" in emails, it made me feel part of the FPE family.

Thank you very much to my project partners, Aard de Jong, Paul Bussmann, Mike Litjens, Edwin Hamoen, Henry van der Valk and René Floris, for the insightful discussions and contributions to the development of this project. I'm very grateful for all your ideas, questions and friendly support.

Costas, I cannot explain here how thankful I am for all your help and supervision. Thanks a lot for the great discussions and many skype meetings, and for keeping me motivated. Also, thank you and Maria for the delicious dinners.

To my dear paranymphs, Jue Wang and Jacqueline Berghout, I'm very happy to have the most experience paranymphs in FPE. Thank you for your advice and support, for the useful Do's and Don'ts while starting my PhD, it was great to start this journey around you girls. Thank you also for our friendship and memorable moments. Also thanks to Ekaraj, Sami and Marta, l've learn a lot from all of you and I keep many nice memories with you guys. Thank you to my officemates Rupali, Jorien, Laura, Nicolas, Evelien and Anja for the nice atmosphere and 
nice conversations. Thank you Anja for all your "food-physics" help and Evelien for making sure I was doing fine.

Dimitri, thanks a lot for being there when my "filter" was broken, for the "Lecce" bell and our coffee breaks. Thanks for being so relax, it helps people around you to be relax as well. My dear Fiona, Patty, Juliana and Birgit, thank you girls for being such great colleagues and friends. Fiona, thank you for your positive energy and glowing smile. Thank you Mauricio for sharing your meat love and your unbelievable stories.

Filippos, thanks a lot for all you help, specially towards the end of my PhD. Thank you for the nice discussion, for your exergy wisdom and for your contagious laugh. Jun, thank you again for your help with Matlab, it probably saved me many hours of struggle. Jochem, thank you very much for all you help and contribution to my work and for your cheerful personality. Lord Dijkshoorn, thanks a lot for passing by and sharing smiles and nice stories. Claire, thank you very much for the short conversations while heating-up our lunch. I always appreciated that you care about my progress and my work. Marjan, thank you for being so attentive and always whiling to help; you are a valuable team member in FPE. Maurice, thank you for the nice coffee and lunch breaks, for the game nights and for the AMMEs, those emails always made me smile. Thank you for assisting me with reaching things on high shelves and for helping me anytime I had lab requests. Jos, thank you for your endless energy to help and fix things for me and my students, and for always finding a solution to any question. Thanks to Jarno for all his work on my project and contributions to my thesis, and for organising nice group activities (WeDay, FPE day). Martin, thank you very much for your help every time I had questions, and for following Colombian bikers during many European tours.

And thanks to all my colleagues for making FPE a great and enjoyable working place: Ali, Victor R and Victor F, Zulhaj, Anton, Ties, Meinou, Qinhui, Pina, Kevin, Kelly, Ivon, Jan-Eise, Marlies, Eline, Maarten, Anja J, Carla and Karin. Also thanks to our special guest and dear friends Davide, Kacie, Alime, Peio and Yamira. I would also like to thank my students, Marius, Kris, Martijn, Charl, 
Adam, Chema, Laura, Qianyu, Gijs and Floor. Thank you all for your help and nice discussions. I've learnt a lot from each of you and I'm very grateful for your contribution to my work. Laura and Floor, thank you again for all your help and support during the last stretch of my project.

Thanks a lot to my friends and housemates Anika, Lisette and Uta, for nice dinners, friendly atmosphere and funny moments. Thank you Anika for all your support and unconditional help. To my dear friend Jinfeng, thank you for all your support, motivation, and fruitful lunch breaks, for keeping me motivated and for sharing many nice moments and stories with me.

Thanks to my friends back in Medellin, Isabel, Diana, Carolina and Monica. Your support meant a lot to me. Thanks for cheering me up and for our long-lasting friendship. Benja, thank you for introducing me to the food science world, for sharing your passion for research, for your valuable friendship and for the alwaysfunny conversations. Juan Diego, I don't have enough words to thank you for your unconditional support, for making sure I was doing fine and for being an amazing friend.

A mi familia, Adriana, Alberto, Alexandra, Lucho y Susi, muchas gracias por todo el apoyo, por estar pendiente de mi bienestar, por alegrarse de mis logros, por siempre tener tiempo y consejos para compartir conmigo. Gracias también a todos mis familiares y amigos que desde lejos me mostraron su apoyo. Muchas gracias a Any y a Ton por todo el apoyo y cálida acogida.

And to my patient and supportive husband, Daniel, infinite thanks. You were also an important team player in this work, I would not have made it without you. Thank you for believing in my, for giving me strength and for sharing these 4 years of continuous learning with me. 


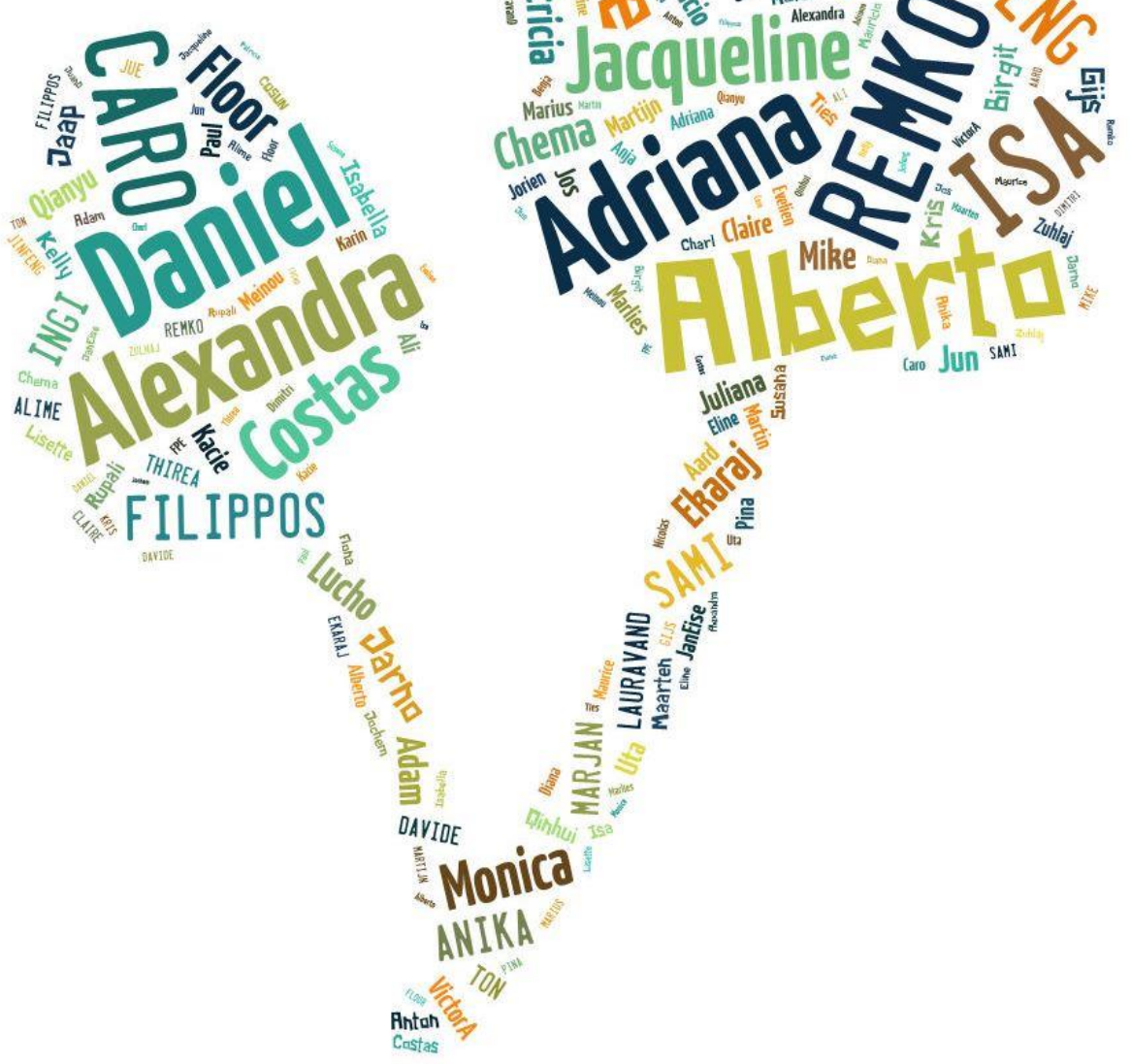




\section{About the author}

Angelica Tamayo Tenorio was born in Tuluá, Colombia, on October 30th 1987. She went to Universidad Nacional de Colombia - Sede Medellin, where she obtained her bachelor degree in 2009 in Biological Engineering. After her bachelor, she was part of the Food Science and Technology research group in Universidad Nacional de Colombia, working on analysis of antioxidant activity of natural products.

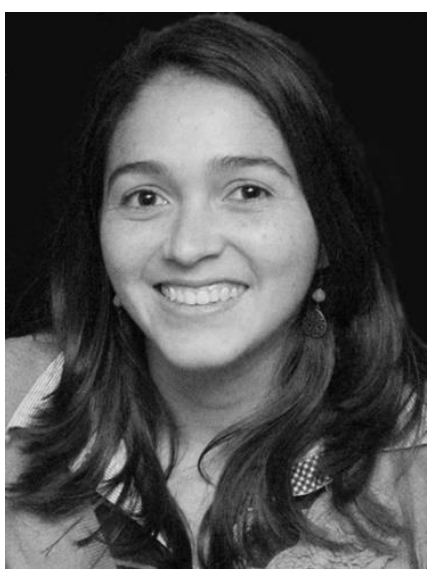

In 2010, she started the European Master Degree in Food Studies at Wageningen University. During this academic program, she was part of a team of 11 people that worked on a Product \& Process development project to produce an insect-based product. This project involved marketing, technical development and project management, aiming at an innovative food product. During her master thesis and internship at Heineken, Angelica worked on sustainable development of beer making, exploring mild processing options for malt and barley to improve up-stream steps of the brewing process. This project was in cooperation with the Food Process Engineering Group at Wageningen University.

After completing her MSc studies, she joined the Food Process Engineering Group at Wageningen University in 2013 , working as a $\mathrm{PhD}$ on the GreenProteins project.

Angelica can be contacted at: atamayotenorio@gmail.com 


\section{List of publications}

Tamayo Tenorio, A., Boom, R. M., \& van der Goot, A. J. (2017). Understanding leaf membrane protein extraction to develop a food-grade process. Food Chemistry, 217, 234-243.

Tamayo Tenorio, A., de Jong, E. W. M., Nikiforidis, C. V., Boom, R. M., \& van der Goot, A. J. (2017). Interfacial properties and emulsification performance of thylakoid membrane fragments. Soft Matter, 13, 608-618

Tamayo Tenorio, A., Gieteling, J., de Jong, G. A. H., Boom, R. M., \& van der Goot, A. J. (2016). Recovery of protein from green leaves: Overview of crucial steps for utilisation. Food Chemistry, 203, 402-408

Tamayo Tenorio, A., Gieteling, J., Nikiforidis, C.V., Boom, R.M., \& A. J. van der Goot. Submitted as: Interfacial properties of green leaf cellulosic particles.

Tamayo Tenorio, A., Schreuders, F.K.G., Zisopoulos, F.K., Boom, R.M., \& A. J. van der Goot. Submitted as: Processing concepts for the use of green leaves as raw materials for the food industry. 


\section{Overview of completed training activities}

\section{Discipline specific activities}

Conferences and meetings

NPS Conference ${ }^{\mathrm{P}}$, Utrecht (NL), 2014

EFFoST International Conference ${ }^{\mathrm{P}}$, Uppsala (SE), 2014

EFFoST International Conference ${ }^{\circ}$, Athens (GR), 2015

EFFoST International Conference ${ }^{\circ}$, Vienna (AT), 2016

\section{Courses}

Sustainability analysis in food and biobased production (VLAG), Wageningen (NL), 2013

Industrial Food Proteins (VLAG), Wageningen (NL), 2013

Microscopy (WUR), Wageningen (NL), 2013

Macroscopical Physical Chemistry, Han-sur-lesse (BE), 2014

Biorefinery for biomolecules, (VLAG), Wageningen (NL), 2015

Process economics and cost engineering (OSPT), Eindhoven (NL), 2016

\section{General courses}

Ph.D. introduction week (VLAG), Barlo (NL), 2014

Ph.D. competence assessment (WGS), Wageningen (NL), 2013

Scientific writing (WGS), Wageningen (NL), 2013

Information literacy including EndNote (WGS), Wageningen (NL), 2014

Effective behaviour in your professional surroundings (WGS), Wageningen (NL), 2013

Scientific Publishing (WGS), Wageningen (NL), 2014

High Impact Writing (WIAS), Wageningen (NL), 2015

Career perspectives (WGS), Wageningen (NL), 2016

\section{Optional}

Scientific Ph.D. excursion to Chile and Brazil ${ }^{\circ}$, WUR (FPE), 2014

Scientific Ph.D. excursion to Germany and Switzerland ${ }^{\text {PO }}$, WUR (FPE), 2016

Organization Scientific Ph.D. excursion to Germany and Switzerland

${ }^{\mathrm{P}}$ Poster presentation

O Oral presentation 
Used abbreviations:

VLAG: Graduate School for Nutrition, Food Technology, Agrobiotechnology and Health Science

WGS: Wageningen Graduates School

WIAS: Wageningen Institute of Animal Sciences

WUR: Wageningen University

FPE: Laboratory of Food Process Engineering 

The work presented in this thesis is executed within a project of the Protein Innovation Program of the Dutch Technology Foundation STW, which is part of NWO, the Dutch national science foundation. The program is also partly funded by the Dutch Ministry of Economic Affairs. The project is entitled "Green Proteins Isolation of hydrophobic proteins from green plant materials", project number STW 12627. As from January 2017 STW continues its activities as NWO Applied and Engineering Sciences, NWO domain TTW.

Printed by Gildeprint. 
